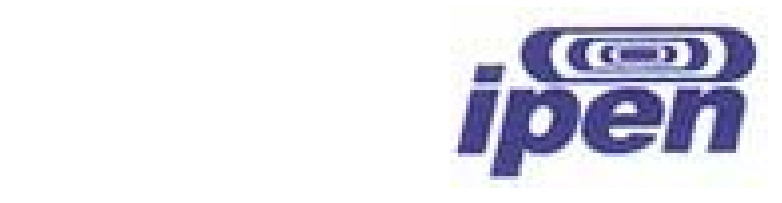

INSTITUTO DE PESQUISAS ENERGÉTICAS E NUCLEARES

Autarquia associada à Universidade de São Paulo

MODELAGEM ANALÍTICA DA PROPAGAÇÃO DE ONDAS DE TENSÃO EM TUBOS DE PAREDE FINA VISANDO A LOCALIZAÇÃO DE UMA FONTE PONTUAL HARMÔNICA EM SUA SUPERFÍCIE

MARIO FRANCISCO GUERRA BOARATTI

Tese apresentada como parte dos requisitos para obtenção do Grau de Doutor em Ciências na Área de Tecnologia Nuclear - Reatores

Orientador:

Dr. Daniel Kao Sun Ting 
INSTITUTO DE PESQUISAS ENERGÉTICAS E NUCLEARES

Autarquia associada à Universidade de São Paulo

MODELAGEM ANALÍTICA DA PROPAGAÇÃO DE ONDAS DE TENSÃO EM TUBOS DE PAREDE FINA VISANDO A LOCALIZAÇÃO DE UMA FONTE PONTUAL HARMÔNICA EM SUA SUPERFÍCIE

MARIO FRANCISCO GUERRA BOARATTI

Tese apresentada como parte dos requisitos para obtenção do Grau de Doutor em Ciências na Área de Tecnologia Nuclear - Reatores

Orientador:

Dr. Daniel Kao Sun Ting

SÃO PAULO

2006 


\section{DEDICATÓRIA}

Dedico este trabalho aos meus pais Pedro e Thereza que me deram a vida e a base familiar necessária para chegar até aqui. À minha esposa Nanci, companheira e amiga que tanto me incentiva. Aos meus filhos André e Aline os quais amo muito. 


\section{AGRADECIMENTOS}

Um trabalho de doutoramento não é um trabalho solitário, ele envolve a participação de inúmeras pessoas, que de algum modo contribuem para a sua execução. Eu quero agradecer a todos que contribuíram e me apoiaram, em particular:

$>$ Professor Daniel Ting, meu orientador, pela dedicação, empenho e espírito pesquisador.

$>$ Minha esposa Nanci pelo carinho e incentivo nos momentos mais difíceis, gerando um ambiente favorável à superação das dificuldades. Por entender as ausências e privações necessárias ao desenvolvimento deste trabalho.

Aos colegas do IPEN que colaboraram com informações técnicas, instrumentações, confecções de dispositivos e incentivos nos momentos de dificuldades.

Aos professores do IPEN e da Escola Politécnica que dividiram seus conhecimentos durante a realização deste trabalho.

> Minha família que forneceu a base necessária para o desenvolvimento deste trabalho.

Aos amigos que colaboraram e incentivaram ao menos com uma palavra de coragem.

$>$ A Deus pela sua proteção e sabedoria. 
Fazer ciência só tem sentido se for para o bem estar da humanidade e da natureza. 


\title{
MODELAGEM ANALÍTICA DA PROPAGAÇÃO DE ONDAS DE TENSÃO EM TUBOS DE PAREDE FINA VISANDO A LOCALIZAÇÃO DE UMA FONTE PONTUAL HARMÔNICA EM SUA SUPERFÍCIE
}

\author{
Mario Francisco Guerra Boaratti
}

\begin{abstract}
RESUMO
Vazamentos em tubos pressurizados geram ondas acústicas que se propagam através das paredes destes tubos, as quais podem ser captadas por acelerômetros ou por sensores de emissão acústica. O conhecimento de como estas paredes podem vibrar, ou de outro modo como as ondas acústicas se propagam neste meio, é fundamental em um processo de detecção e localização da fonte de vazamento. Neste trabalho, foi implementado um modelo analítico, através das equações de movimento da casca cilíndrica, com o objetivo de entender o comportamento da superfície do tubo em função de uma excitação pontual. Como a superfície cilíndrica é um meio fechado na direção circunferencial, ondas que iniciaram sua jornada, a partir de uma fonte pontual sobre a superfície, se encontrarão com outras que já completaram a volta na casca cilíndrica, tanto no sentido horário como no anti-horário, gerando interferências construtivas e destrutivas. Após um tempo suficiente, uma estacionariedade é atingida, criando pontos de picos e vales na superfície da casca, os quais podem ser visualizadas através de uma representação gráfica do modelo analítico criado. Os resultados teóricos foram comprovados através de medidas realizadas em uma bancada de testes composta de um tubo de aço terminado em caixa de areia, simulando a condição de tubo infinito. Para proceder à localização da fonte pontual sobre a superfície, adotou-se o processo de solução inversa, ou seja, conhecidos os sinais dos sensores dispostos na superfície do tubo, determina-se através do modelo teórico onde a fonte que gerou estes sinais pode estar.
\end{abstract}




\title{
ANALYTIC MODEL OF THE STRESS WAVES PROPAGATION IN THIN WALL TUBES, SEEKING THE LOCATION OF A HARMONIC POINT SOURCE IN ITS SURFACE
}

\author{
Mario Francisco Guerra Boaratti
}

\begin{abstract}
Leaks in pressurized tubes generate acoustic waves that propagate through the walls of these tubes, which can be captured by accelerometers or by acoustic emission sensors. The knowledge of how these walls can vibrate, or in another way, how these acoustic waves propagate in this material is fundamental in the detection and localization process of the leak source. In this work an analytic model was implemented, through the motion equations of a cylindrical shell, with the objective to understand the behavior of the tube surface excited by a point source. Since the cylindrical surface has a closed pattern in the circumferential direction, waves that are beginning their trajectory will meet with another that has already completed the turn over the cylindrical shell, in the clockwise direction as well as in the counter clockwise direction, generating constructive and destructive interferences. After enough time of propagation, peaks and valleys in the shell surface are formed, which can be visualized through a graphic representation of the analytic solution created. The theoretical results were proven through measures accomplished in an experimental setup composed of a steel tube finished in sand box, simulating the condition of infinite tube. To determine the location of the point source on the surface, the process of inverse solution was adopted, that is to say, known the signals of the sensor disposed in the tube surface, it is determined through the theoretical model where the source that generated these signals can be.
\end{abstract}




\section{SUMÁRIO}

Página

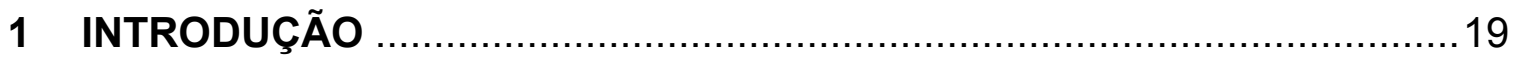

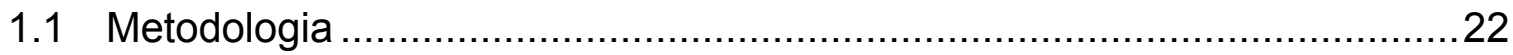

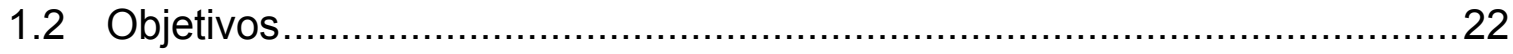

2 REVISÃO DA LITERATURA

3 PROPAGAÇÕES DE ONDAS DE TENSÃO EM MEIOS SÓLIDOS

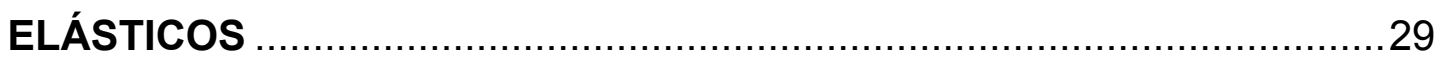

3.1 Componentes de tensão e deformação em meio sólido ……………….......29

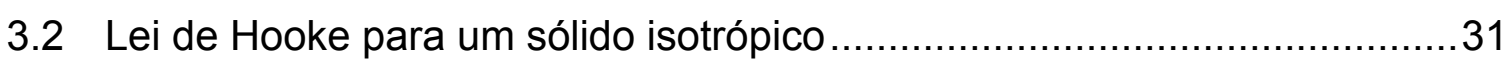

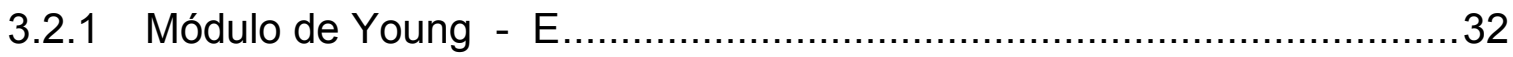

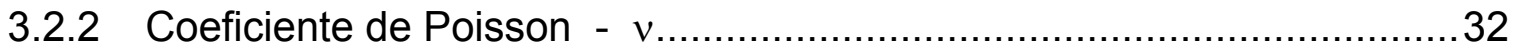

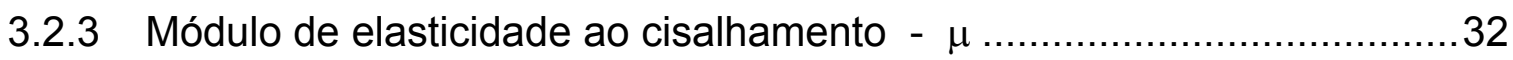

3.3 Equações do equilíbrio e do movimento em um meio sólido .......................33

3.4 Equação do movimento em função dos deslocamentos..............................34

3.5 Velocidades de propagações das ondas em um corpo sólido ......................35

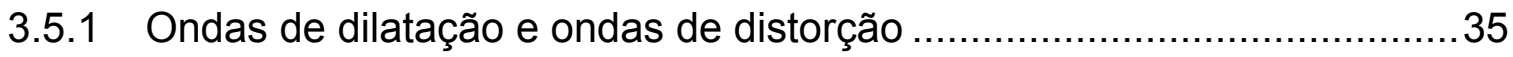

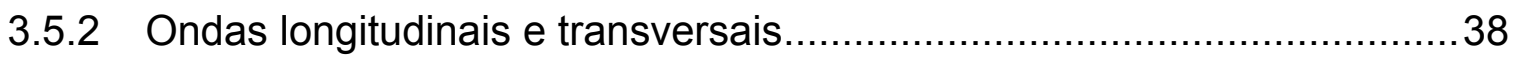

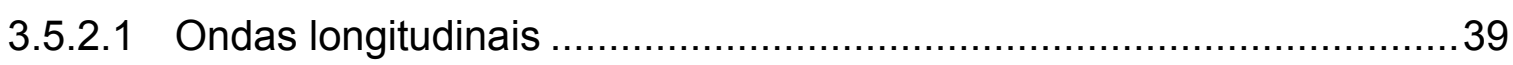

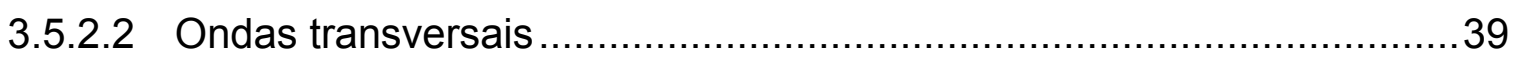

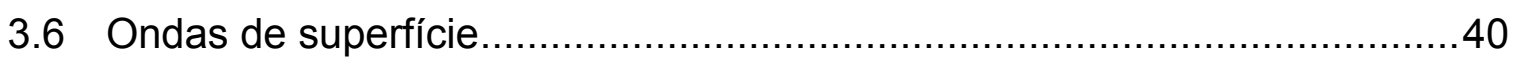

4 EQUAÇÃO DE ONDA EM UMA CASCA CILÍNDRICA FINA ......................45

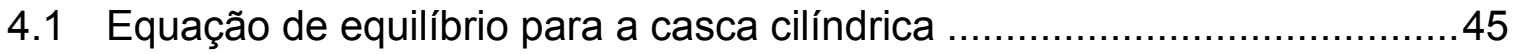

4.2 Equação de movimento para a casca cilíndrica .....................................49

4.3 Considerações sobre vibrações acústicas provocadas por jatos ...............51

5 SOLUÇÃO ANALÍtICA DA EQUAÇÃO DE MOVIMENTO EM

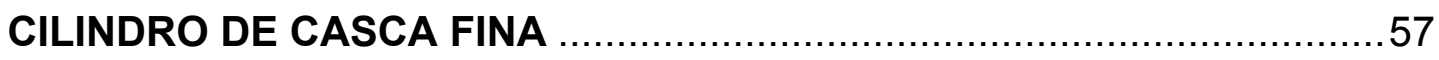

5.1 Solução analítica para a obtenção do modelo matemático .........................57

5.2 Descrição do fenômeno de interferência de ondas ...................................64 
5.3 Implementação numérica do modelo matemático

5.4 Análise dos modos circunferenciais na implementação numérica do modelo matemático

5.5 Análise dos números de onda axiais na implementação numérica do modelo matemático

5.6 Solução não senoidal da equação do movimento .80

6 MEDIDAS DAS VELOCIDADES DE PROPAGAÇÃO LONGITUDINAL E TRANSVERSAL 83

6.1 Resultados para o tubo de $3 \mathrm{~m}$ de comprimento e diâmetro de $6 \mathrm{~cm}$. .84

6.2 Resultados para o tubo de $6 \mathrm{~m}$ de comprimento e diâmetro de $20 \mathrm{~cm}$........88

7 VALIDAÇÃO DO MODELO VIA MEDIDAS EXPERIMENTAIS .................. 91

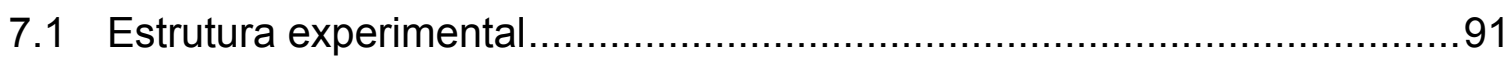

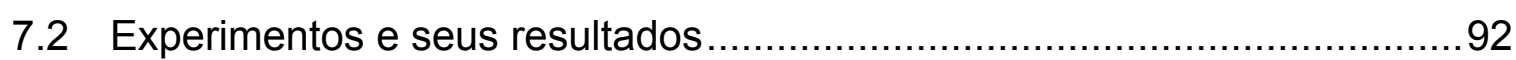

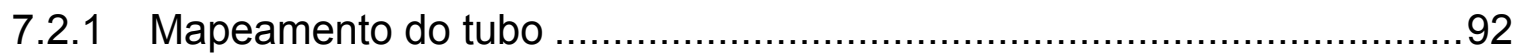

7.2.1.1 Mapeamento sobre o ângulo zero ............................................92

7.2.1.2 Mapeamento nas direções axial e circunferencial ..............................98

7.2.1.3 Determinação da relação entre as amplitudes medidas nos acelerômetros e a amplitude da força $F 0$ da solução teórica. 101

7.2.1.4 Determinação das freqüências de ressonância por meio do modelo teórico e das medidas no sistema real............................... 104

8 ANÁLISE PARAMÉTRICA DO MODELO TEÓRICO ............................... 107

8.1 Influência da espessura.............................................................. 107

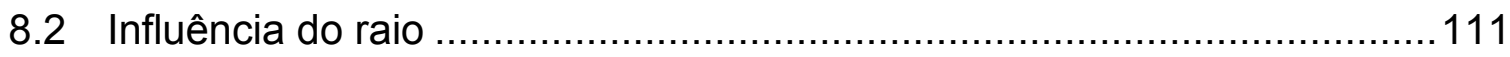

8.3 Influência dos parâmetros do material.............................................. 114

8.4 Influência dos parâmetros para alguns materiais reais..........................118

9 DETECÇÃO E LOCALIZAÇÃO DA FONTE PONTUAL ......................... 120

9.1 Detecção de uma falha ............................................................. 120

9.2 Localização de uma falha .......................................................... 121

9.3 Metodologia de localização proposta.............................................. 122

9.4 Posicionamento dos sensores ..................................................... 124

9.5 Resultados da localização ......................................................... 125

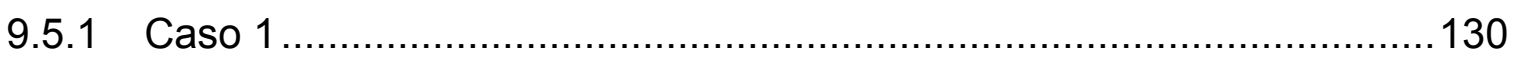

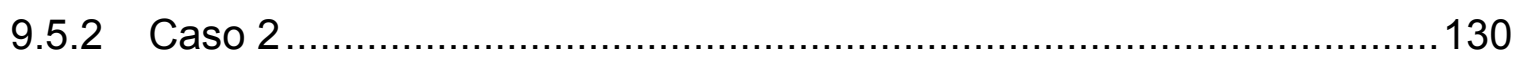

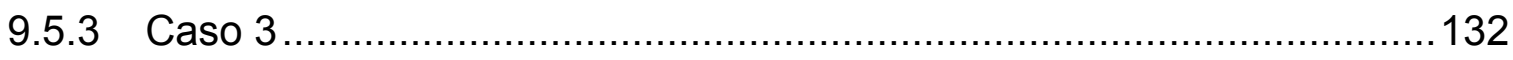




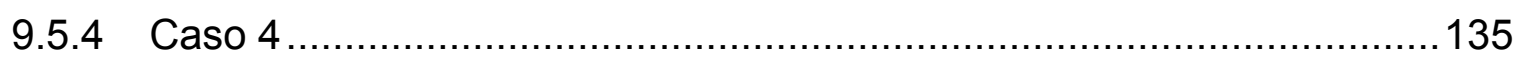

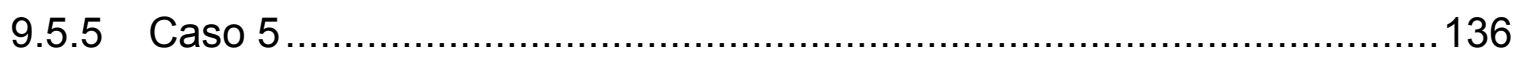

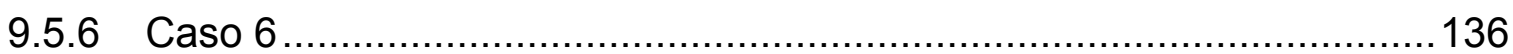

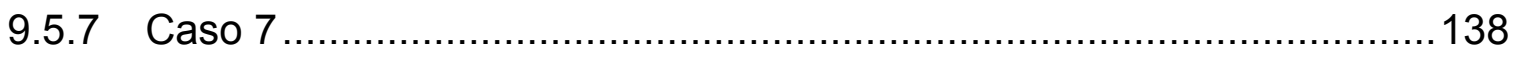

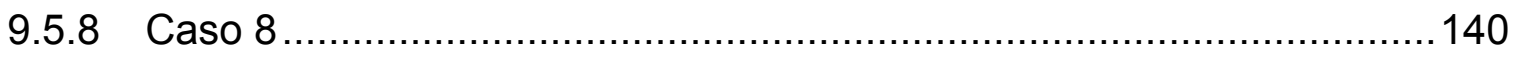

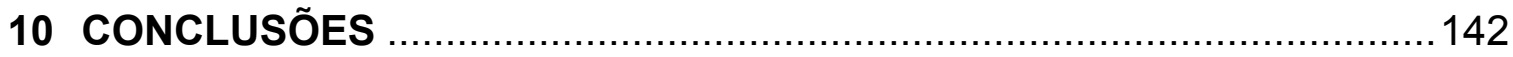

APÊNDICES

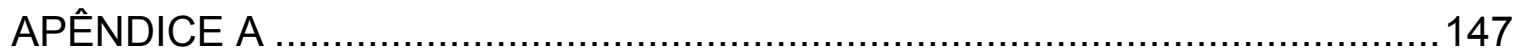

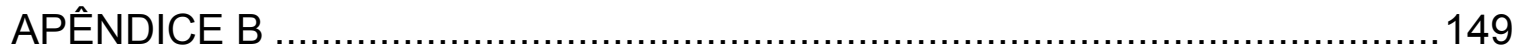

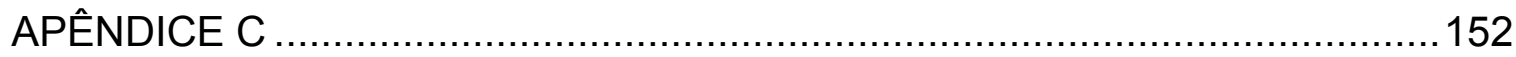

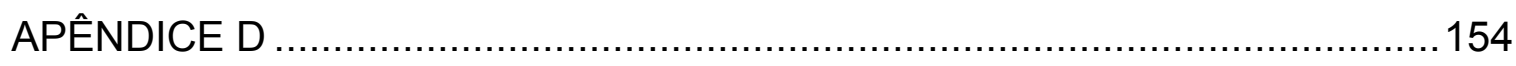

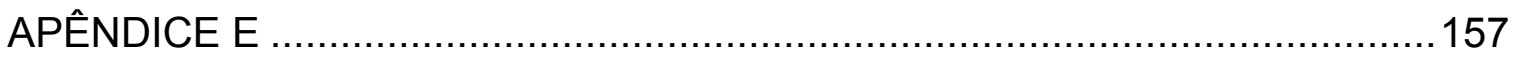

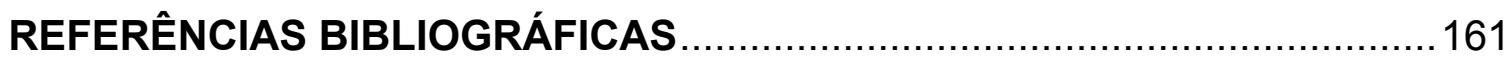




\section{LISTA DE TABELAS}

Página

TABELA 5.1 - Comprimentos de onda e velocidades de propagação. .74

TABELA 5.2 - Análise de desvio da solução em função do máximo valor do modo $n$ utilizado no cálculo teórico

TABELA 7.1 - Atrasos e velocidades para a freqüência de $1 \mathrm{KHz}$ 97

TABELA 7.2 - Atrasos e velocidades para a freqüência de $2 \mathrm{KHz}$................97

TABELA 7.3 - Atrasos e velocidades para a freqüência de $3 \mathrm{KHz}$.................97

TABELA 7.4 - Freqüências de ressonância..............................................105

TABELA 8.1 - Comportamento do comprimento de onda com as

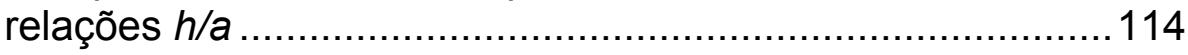

TABELA 8.2 - Exemplo do comportamento de alguns materiais .................118

TABELA 9.1 - Combinações entre os sensores .......................................128

TABELA 9.2 - Resultados encontrados para a fonte em $-0,3 \mathrm{~m}$ e $0^{\circ}$ com freqüência de $1 \mathrm{KHz}$

TABELA 9.3 - Resultados encontrados para a fonte em $-2,5 \mathrm{~m}$ e $0^{\circ}$ com freqüência de $2 \mathrm{KHz}$

TABELA 9.4 - Resultados encontrados para a fonte em $-2,4 \mathrm{~m}$ e $0^{\circ}$ com freqüência de $2 \mathrm{KHz}$

TABELA 9.5 - Atrasos para o sensor B em relação ao sensor A, obtidos através de correlação cruzada entre eles.

TABELA 9.6 - Resultados encontrados para a fonte em $+0,3 \mathrm{~m} \mathrm{e} 0^{\circ} \mathrm{com}$ freqüência de $3 \mathrm{KHz}$

TABELA 9.7 - Resultados encontrados para a fonte em $+1,0 \mathrm{~m}$ e $0^{\circ} \mathrm{com}$ freqüência de $3 \mathrm{KHz}$

TABELA 9.8 - Resultados encontrados para a fonte em $-2,5 \mathrm{~m} \mathrm{e} 30^{\circ} \mathrm{com}$ freqüência de $2 \mathrm{KHz}$

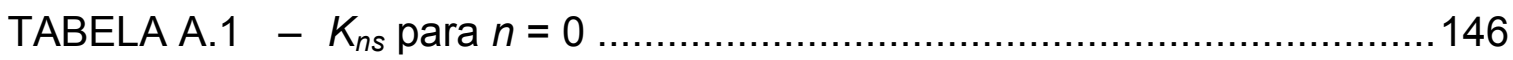

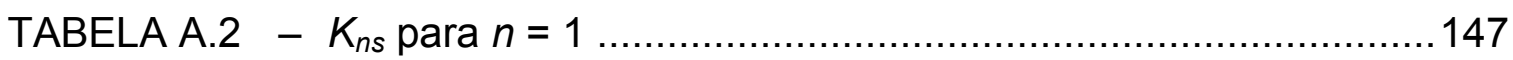

TABELA B.1 - Características dos acelerômetros (usados no capítulo 8) ....149

TABELA B.2 - Características dos acelerômetros .......................................150 


\section{LISTA DE FIGURAS}

Página

FIGURA 3.1 - Componentes de tensão atuando em um elemento cúbico infinitesimal.

FIGURA 3.2 - Variações das componentes de tensão atuando em um elemento cúbico infinitesimal.

FIGURA 3.3 - Onda acústica se propagando na superfície livre de um corpo sólido com velocidade $c_{R}$

FIGURA 3.4 - Fator $\alpha$ em função do coeficiente de Poisson.

FIGURA 3.5 - Efeito da profundidade nos deslocamentos $u$ e $w$ para coeficiente de Poisson $v=0,28$.

FIGURA 3.6 - Movimento das partículas na onda de Rayleigh..................44

FIGURA 4.1 - Superfície cilíndrica. ...............................................46

FIGURA 4.2 - Detalhe do elemento de área retirado da superfície cilíndrica.

FIGURA 4.3 - Fotografia Schlieren de jato blocado e propagação das ondas de som, Blake (1986).

FIGURA 4.4 - Freqüência em função do diâmetro para várias pressões.

FIGURA 4.5 - Freqüência em função do diâmetro para diferentes gases em diferentes pressões e temperaturas.

FIGURA 4.6 - Esboço de bordas: a) retangular; b) afiada, tipo faca. 55

FIGURA 4.7 - Variação da freqüência com a viscosidade para jato não blocado.

FIGURA 5.1 - Sistema de coordenadas na casca cilíndrica. ....................58

FIGURA 5.2 - Padrões modais circunferenciais da casca cilíndrica. .........59

FIGURA 5.3 - Ondas esféricas propagando-se radialmente em todas as direções, a partir de uma fonte puntiforme na superfície plana.

FIGURA 5.4 - Esboço das ondas propagando-se em todas as direções na superfície da casca cilíndrica, planificada de $-\pi$ até $\pi$.

FIGURA 5.5 - Alguns raios de ondas propagando-se helicoidalmente na superfície da casca cilíndrica. 
FIGURA 5.6 - Caminhos percorridos por algumas ondas propagando-se helicoidalmente na superfície da casca cilíndrica.

FIGURA 5.7 - Vista das ondas propagando-se em todas as direções na superfície da casca cilíndrica, planificada de $-\pi a$ até $\pi a$.

FIGURA 5.8 - Vista superior das ondas propagando-se em todas as direções na superfície da casca cilíndrica, planificada de $-\pi a$ até $\pi a$.

FIGURA 5.9 - Vista em corte da FIG 5.8 sobre a linha de ângulo zero......70

FIGURA 5.10 - Espectro da propagação sobre o ângulo zero. .71

FIGURA 5.11 - Autocorrelação normalizada da propagação sobre o ângulo zero, indicando um comprimento de onda de $0,55 \mathrm{~m}$.

FIGURA 5.12 - Vista em corte sobre o arco na posição $x=0 \mathrm{~m}$ na superfície da casca cilíndrica na direção circunferencial.....72

FIGURA 5.13 - Espectro da propagação sobre o arco em $x=0 \mathrm{~m}$.

FIGURA 5.14 - Autocorrelação normalizada da propagação sobre o arco em $x=0 \mathrm{~m}$, indicando um comprimento de onda de $0,15 \mathrm{~m}$.

FIGURA 5.15 - Cristas de fase constante em função do ângulo de propagação.

FIGURA 5.16 - Vista superior das ondas propagando-se em todas as direções na superfície da casca cilíndrica, planificada de $-\pi a$ até $\pi$ a, para fonte em $x_{0}=1 \mathrm{me} \theta_{0}=50^{\circ}$

FIGURA 5.17 - Variação da forma de onda em função da somatória dos modos de vibração circunferencial para $1 \mathrm{KHz} \ldots \ldots \ldots \ldots . . .77$

FIGURA 5.18 - Variação da forma de onda em função da somatória dos modos de vibração circunferencial para $2 \mathrm{KHz}$..............77

FIGURA 5.19 - Variação da forma de onda em função da somatória dos modos de vibração circunferencial para $3 \mathrm{KHz}$.............78

FIGURA 5.20 - Região dos pólos utilizados na solução...............................80

FIGURA 5.21 - Propagação da excitação da onda quadrada de $1 \mathrm{KHz}$ até a $99^{a}$ harmônica. $O$ eixo que indica a aceleração está direcionado saindo do papel.

FIGURA 5.22 - Resposta para a onda quadrada de $1 \mathrm{KHz}$ até a $99^{\mathrm{a}}$ harmônica.

FIGURA 6.1 - Propagação das ondas de impacto. Condições: distância entre os dois acelerômetros de $0,75 \mathrm{~m}$, $1 \mathrm{M}$ amostras $/ \mathrm{s}$ e ganho do amplificador de $10 \mathrm{mV} / \mathrm{ms}^{-2}$ 
FIGURA 6.2 - Propagação das ondas de impacto. Condições: distância entre os dois acelerômetros de $0,75 \mathrm{~m}$, $1 \mathrm{M}$ amostras/s e ganho do amplificador de $316 \mathrm{mV} / \mathrm{ms}^{-2}$.

FIGURA 6.3 - Propagação das ondas de impacto. Condições: distância entre os dois acelerômetros de $1,5 \mathrm{~m}$, $1 \mathrm{M}$ amostras/s e ganho do amplificador: a) $10 \mathrm{mV} / \mathrm{ms}^{-2}$; b) $316 \mathrm{mV} / \mathrm{ms}^{-2}$.

FIGURA 6.4 - Visualização da propagação da onda de impacto para amplificador com ganho 10 .

FIGURA 6.5 - Visualização da propagação da onda de impacto para amplificador com ganho 100.

FIGURA 7.1 - Bancada de testes e detalhe do apoio em caixa de areia.

FIGURA 7.2 - Esboço da distribuição da fonte e dos acelerômetros na superfície do tubo.

FIGURA 7.3 - Vista da distribuição dos acelerômetros na superfície do tubo e a fonte de excitação para uma seqüência de medidas

FIGURA 7.4 - Mapa da propagação da onda medida sobre a linha $0^{\circ}$ na direção axial na superfície do tubo.

FIGURA 7.5 - Mapa da propagação da onda simulada sobre a linha $0^{\circ}$ na direção axial na superfície do tubo.

FIGURA 7.6 - Mapas das propagações das ondas medidas (a) e simuladas (b), para $1 \mathrm{KHz}$.

FIGURA 7.7 - Mapas das propagações das ondas medidas (a) e simuladas (b), para $3 \mathrm{KHz}$.

FIGURA 7.8 - Comparação no tempo entre propagação medida (a) e simulada (b), para $1 \mathrm{KHz}$.

FIGURA 7.9 - Comparação no tempo entre propagação medida (a) e simulada (b), para $2 \mathrm{KHz}$

FIGURA 7.10 - Comparação no tempo entre propagação medida (a) e simulada (b), para $3 \mathrm{KHz}$

FIGURA 7.11 - a) Disposições dos sensores para o mapeamento da superfície do tubo.

b) Detalhe dos sensores junto com a régua de posicionamento.

FIGURA 7.12 - a) Mapeamento da superfície do tubo na freqüência de $1 \mathrm{KHz}$.

b) Solução teórica do mapeamento para $1 \mathrm{KHz}$ e $n=10$. 
FIGURA 7.13 - a) Mapeamento da superfície do tubo na freqüência de $2 \mathrm{KHz}$.

b) Solução teórica do mapeamento para $2 \mathrm{KHz}$ e $n=10$.

FIGURA 7.14 - a) Mapeamento da superfície do tubo na freqüência de $3 \mathrm{KHz}$.

b) Solução teórica do mapeamento para $3 \mathrm{KHz}$ e $n=10$.

FIGURA 7.15 - Determinação da força de excitação nas freqüências:
a) $1 \mathrm{KHz}$;
b) $2 \mathrm{KHz}$;
c) $3 \mathrm{KHz}$

FIGURA 7.16 - Comparação entre solução teórica e medida em $1 \mathrm{KHz}$ para três ângulos ao longo da direção axial, no instante zero segundo

FIGURA 7.17 - Comparação entre solução teórica e medida em $2 \mathrm{KHz}$ para três ângulos ao longo da direção axial, no instante zero segundo.

FIGURA 7.18 - Comparação entre solução teórica e medida em $3 \mathrm{KHz}$ para três ângulos ao longo da direção axial, no instante zero segundo.

FIGURA 7.19 - Resposta em freqüência teórica.

FIGURA 7.20 - Resposta em freqüência medida:

A é o sensor junto à fonte de excitação,

B é o sensor a $5 \mathrm{~cm}$ da fonte de excitação.

FIGURA 8.1 - Mapas de um pedaço da superfície do tubo, relacionando distância com o tempo de propagação para espessura variando.

FIGURA 8.2 - Espectro no espaço para o instante zero segundo, $h$ variando

FIGURA 8.3 - Propagação da onda no espaço para o instante zero segundo.

FIGURA 8.4 - Variação do comprimento de onda com a espessura.

FIGURA 8.5 - Mapas de um pedaço da superfície do tubo, relacionando distância com o tempo de propagação, para raio variando.

FIGURA 8.6 - Espectro no espaço para o instante zero segundo, para raio variando.

FIGURA 8.7 - Comportamento da velocidade $c_{p}$ com $E, \rho$ e $v$.................115

FIGURA 8.8 - Comportamento da freqüência de ring com $E, \rho$ e $v$........116

FIGURA 8.9 - Comportamento do comprimento de onda com $E$, $\rho$ e v...117

FIGURA 9.1 - Exemplo de sinais de fundo e de falha............................121 
FIGURA 9.2 - Esboço da disposição dos sensores na superfície do tubo.

FIGURA 9.3 - Disposição dos sensores na superfície do tubo................125

FIGURA 9.4 - Visualização da tela de resultados para fonte na posição $+0,3 \mathrm{~m} \mathrm{e} 30^{\circ} \mathrm{com}$ freqüência de $1 \mathrm{KHz}$.

FIGURA 9.5 - Visualização da tela de resultados para fonte na posição $-1,3 \mathrm{~m}$ e $0^{\circ}$ com freqüência de $2 \mathrm{KHz}$.

FIGURA 9.6 - Espectro do sinal do sensor B para fonte na posição $-2,4 \mathrm{~m}$ e $0^{\circ}$ com freqüência de $2 \mathrm{KHz}$, antes e depois da filtragem.

FIGURA 9.7 - Visualização dos sinais medidos para a excitação em $-2,4 \mathrm{~m}$ e $30^{\circ}$ com freqüência de $1 \mathrm{KHz}$.

FIGURA 9.8 - Visualização dos sinais medidos para a excitação em $+2,4 \mathrm{~m} \mathrm{e} 30^{\circ}$ com freqüência de $1 \mathrm{KHz}$.

FIGURA 9.9 - Recortes das telas de resposta do programa de localização, sendo a excitação em $+2,0 \mathrm{~m}$ e $45^{\circ} \mathrm{com}$ freqüência de $1 \mathrm{KHz}$.

FIGURA C.1 - Foto do braço articulado...............................................152

FIGURA C.2 - Fotos do excitador................................................152

FIGURA C.3 - Esquema elétrico do desacoplador de nível DC................153

FIGURA D.1 - Espectros das respostas em freqüência para fixação com base magnética e com cera de abelha......................155

FIGURA D.2 - Fotos do acelerômetro com cera de abelha. .....................156 


\section{LISTA DE SÍMBOLOS E SIGLAS}

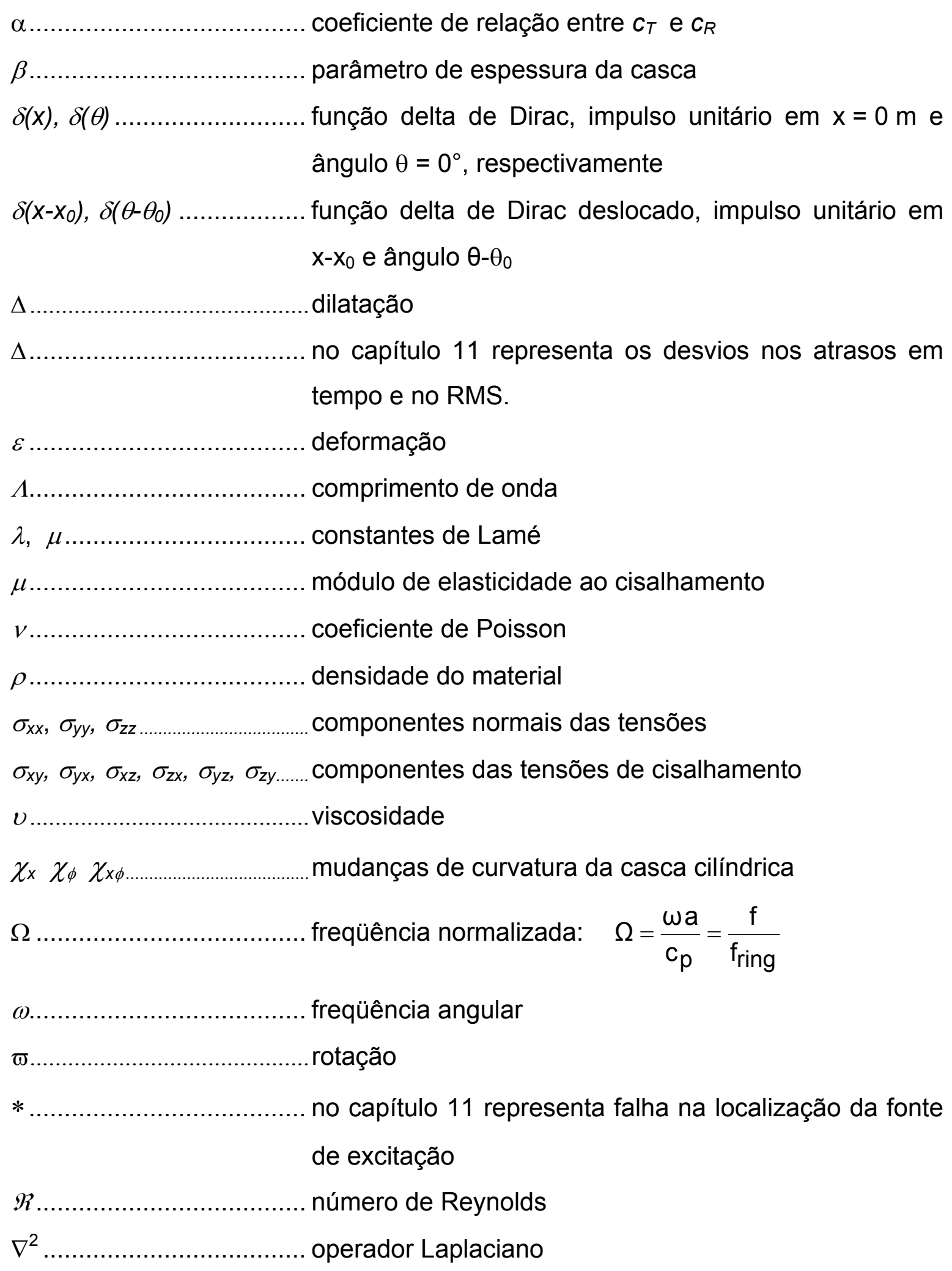




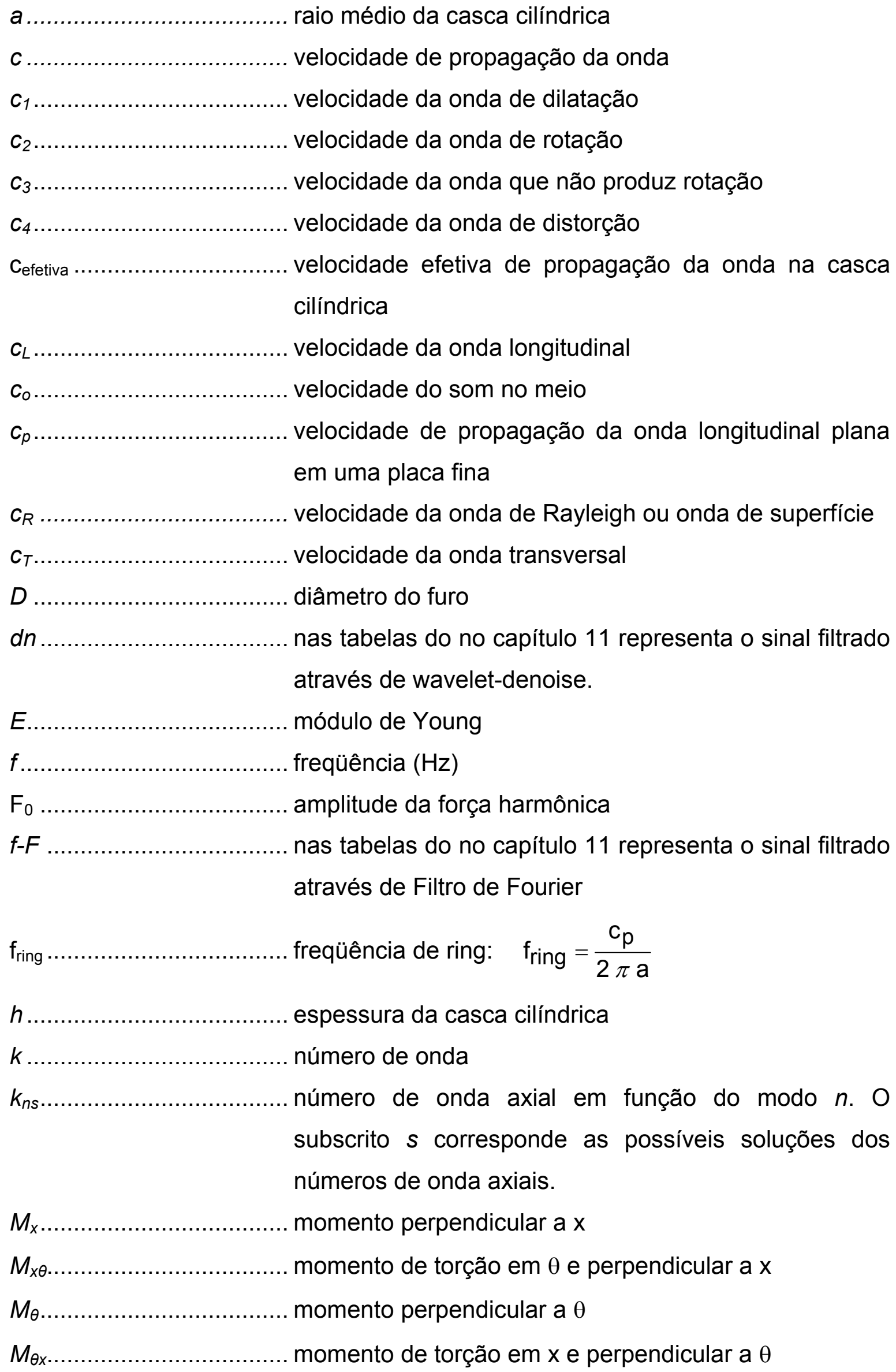




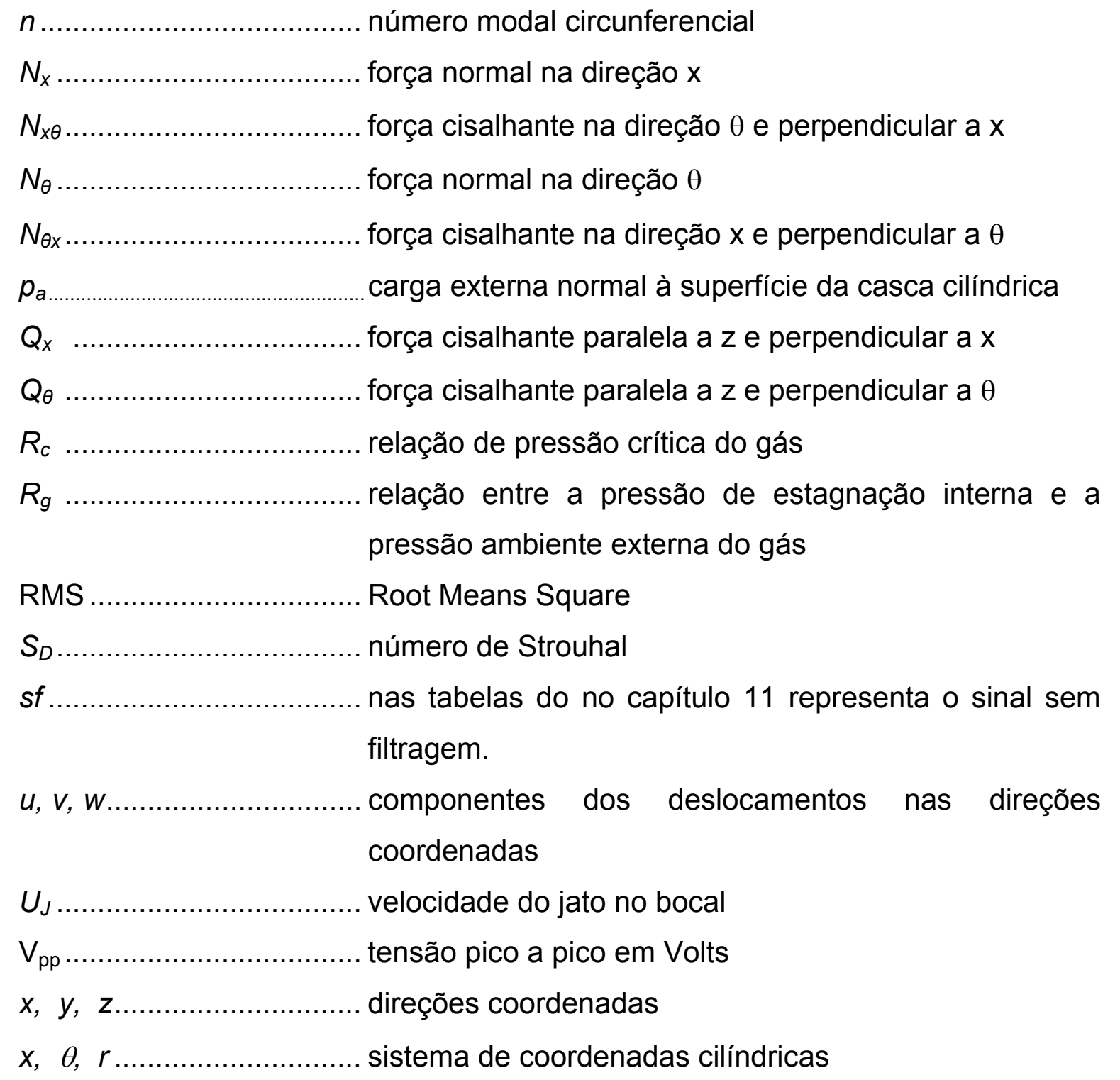




\section{INTRODUÇÃO}

A garantia da integridade de tubos pressurizados em processos industriais é um fator de fundamental importância na manutenção destes processos. Tais situações podem ser encontradas em plantas de geração elétrica, siderúrgica, química, petroquímica e outras, onde o transporte de fluídos e gases pressurizados é comum. Em todos estes casos, vazamentos geram situações de riscos e de prejuízos; se não detectados a tempo podem causar acidentes graves, com conseqüências ambientais severas.

Como exemplo, é citado um sistema de tubulação de vapor de um reator nuclear que apresente um pequeno furo. Este furo liberará vapor contaminado o qual só será detectado pelo aumento da radioatividade do meio. Isto ocasionará a parada do reator, um trabalho de detecção e localização do tubo furado e o devido reparo. Esta detecção, utilizando técnicas existentes, por exemplo Eddy-Current (Lopes e Ting, 2000; Cizelj et al., 1998; Rodriguez e Raj, 1997), pode mostrar-se um trabalho demorado e custoso. Outro fator a ser considerado é que a deteç̧ão só se dará após a contaminação do meio externo. Sendo assim, um sistema capaz de detectar um vazamento em um tubo pressurizado tão logo este se inicie é de vital importância para garantir a segurança, a disponibilidade e a confiabilidade da instalação. Além disso, se este sistema for capaz de localizar a origem da falha ou suas imediações de modo que o tempo de parada para manutenção seja reduzido, com certeza implicará na redução dos custos da parada.

Segundo Blake (1986) e Loth (2004), a passagem de um jato de gás em alta pressão através de uma fratura na parede de um tubo gera vibrações na parede deste tubo com uma larga faixa de freqüências. Quando a velocidade do gás no bocal fica sônica, ou seja, na pressão crítica ou além, é superimposto ao som de faixa larga um tom acústico que é associado com a existência de um padrão estável com zonas de expansão e compressão ao longo do eixo do jato, Blake (1986). Pode-se dizer, então, que vazamentos em tubos pressurizados geram ondas de tensão que se propagam através das paredes destes tubos, as quais podem ser captadas por sensores de vibração ou de emissão acústica. 
Acústica é o ramo da física que trata da geração, transmissão e recepção de energia na forma de ondas de vibração na matéria. Quando os átomos ou moléculas de um fluído ou sólido são deslocados de sua configuração inicial, uma força de restauração elástica interna aparece. Esta força de restauração unida com a inércia do sistema, é que capacita a matéria de participar em uma vibração oscilatória e portanto gerar e transmitir ondas acústicas (Kinsler e Frey, 1982). Sendo assim, todo material tem a capacidade de propagar ondas de vibração, alguns com mais outros com menos facilidade. A propagação da onda de vibração se caracteriza pela velocidade de deslocamento no meio e pela sua freqüência, as quais são funções das características do material tais como, a densidade, o módulo de elasticidade, o coeficiente de Poisson e também da geometria do material.

Com base no exposto acima e na necessidade que as tubulações modernas possuem de garantia da sua integridade quanto à monitoração de vazamentos, surgiu à motivação do estudo e desenvolvimento de uma metodologia capaz de localizar uma fonte pontual de vazamento em um tubo, utilizando técnicas não invasivas, através de sensores piezelétricos posicionados na superfície externa deste tubo. Tal método de localização, poderia ser estendido a qualquer planta industrial, que apresente um ruído causado por uma falha em um certo local e que precise ser monitorado para a determinação de sua origem. Por exemplo, uma tubulação de petróleo ou gás natural com vários quilômetros poderia ser monitorada através da instalação de matrizes de sensores em pontos estratégicos da tubulação, os quais teriam seus sinais constantemente analisados, indicando a integridade desta tubulação. Tão logo um pequeno vazamento se inicie, uma central detectaria o evento e enviaria uma equipe para o local onde o vazamento se apresenta. Tal estratégia evitaria um acidente ecológico de maiores proporções.

O trabalho foi estruturado de forma a gerar uma seqüência, a mais didática possível, para o entendimento do fenômeno de propagação de onda na parede de uma casca cilíndrica e da técnica adotada para a localização da fonte pontual. No capítulo 3, são tratadas as propagações das ondas de tensão em meio sólido, onde são definidas as componentes de tensão e deformação neste meio, a Lei de Hooke, as equações do equilíbrio e do movimento, as velocidades das propagações das ondas de dilatação, de distorção, longitudinais, transversais 
e de superfície. O capítulo 4 apresenta a equação de onda em uma casca cilíndrica fina com base nas equações de equilíbrio e movimento descritas por Donnell. No capítulo 4, também são tecidas considerações sobre vibrações acústicas provocadas por jatos. No capítulo 5 , é desenvolvida a solução analítica das equações de movimento para a casca cilíndrica e obtenção do modelo matemático, bem como, o estudo do fenômeno de interferência de ondas e implementação numérica do modelo teórico e sua análise. No capítulo 6 , são apresentadas as medidas das velocidades das propagações longitudinal e transversal com base no tempo de atraso de chegada das ondas geradas por um impacto pontual na superfície do tubo, bem como, a influência do ruído, de sua filtragem via transformada de wavelet e do ganho do sinal medido. No capítulo 7 , é relatada a validação do modelo através de medidas experimentais, tendo como objetivo verificar o comportamento das propagações das ondas na superfície da casca cilíndrica tanto na direção axial como circunferencial, com base no mapeamento da superfície do tubo de aço. Inicialmente é descrito com detalhes a estrutura da bancada de testes e os cuidados com relação à fonte de excitação e a fixação dos sensores por meio de cera de abelha, entre outros, necessários às realizações dos experimentos. As análises descritas tratam do mapeamento da superfície do tubo nas direções axial e circunferencial, dos atrasos de propagações das ondas e suas velocidades, da relação entre as amplitudes medidas nos acelerômetros e a amplitude da força $F_{0}$ da solução teórica e das freqüências de ressonância via modelo teórico e via medidas no sistema real. 0 capítulo 8 trata da análise paramétrica do modelo teórico, com relação à variação da espessura da parede, do raio do tubo e da Influência dos parâmetros do material no comportamento da superfície da casca cilíndrica. O capítulo 9 encerra com a metodologia proposta para a localização da fonte pontual, apresentando o método de localização de uma fonte pontual com base no mapeamento teórico da superfície e de sinais obtidos de acelerômetros posicionados na parede externa do tubo. São apresentados também, os resultados obtidos das localizações e as análises de casos, onde são aplicadas duas técnicas de filtragem dos sinais gerados pelos sensores. Uma técnica de filtragem é wavelet-denoise e a outra é Filtro de Fourier. A filtragem tem por objetivo a retirada de ruídos ou componentes indesejadas do sinal medido, que atrapalham o processo de localização da fonte de excitação. 
O estudo apresentado teve como premissa entender o fenômeno de propagação da onda de vibração na parede de uma casca cilíndrica através da modelagem analítica desta geometria. Para isto, adotou-se uma casca cilíndrica fina, infinita, envolvida por vácuo, constituída de material elástico, homogêneo e isotrópico, não contemplando os efeitos da reflexão e da atenuação. Após a obtenção do modelo analítico e de sua validação através de ensaios, buscou-se um modo de localizar uma fonte pontual na superfície desta casca fina com base no modelo idealizado das ondas de vibração que se propagam na parede da casca cilíndrica.

\subsection{Metodologia}

Este estudo foi desenvolvido dentro de uma base teórico - experimental. Para alcançar os objetivos desejados as seguintes etapas foram realizadas, as quais em vários momentos aconteceram em paralelo: estudo do fenômeno de propagação de onda em materiais elásticos; obtenção de um modelo analítico de propagação de ondas em uma casca cilíndrica; montagem de um circuito experimental e de acessórios de apoio necessários; ensaios para verificação e validação do modelo analítico; estudo de ferramentas estatísticas de análise; estudo de técnicas de filtragem e redução de ruídos; obtenção de uma metodologia para localização de uma fonte na superfície do tubo.

Os equipamentos, a bancada de testes e os dispositivos criados são descritos nos capítulos associados às suas utilizações, bem como os programas e métodos empregados no desenvolvimento dos ensaios e análises.

\subsection{Objetivos}

Entender o comportamento da superfície de uma casca cilíndrica fina quando excitada por uma fonte pontual harmônica, modelar este comportamento e validar o modelo obtido através de ensaios em uma bancada de testes. Com base neste modelo, apresentar uma metodologia de localização de uma fonte harmônica e pontual, posicionada na superfície de um tubo, utilizando-se de um conjunto de sensores piezelétricos, combinado com técnicas de deteç̧ão do atraso de propagação da onda. 
A originalidade do trabalho está na obtenção da solução analítica da equação de casca fina para uma excitação pontual e harmônica sobre a superfície da casca e na proposta de uma metodologia de localização da fonte de excitação, com base nesta solução analítica, através da solução do problema inverso, dos atrasos das propagações das ondas combinados com o RMS dos sinais obtidos dos sensores posicionados sobre a superfície da casca cilíndrica. 


\section{REVISÃO DA LITERATURA}

O problema da monitoração de falhas em tubulações e vasos pressurizados é uma preocupação atual, como pode ser observado pelo número elevado de trabalhos publicados e técnicas propostas. A seguir, são apresentadas algumas técnicas que estão sendo estudadas ou aplicadas com o objetivo de monitorar falhas ou vazamentos em tubulações e vasos pressurizados.

A técnica ultra-sônica é uma das mais utilizadas na avaliação de integridade de materiais sujeitos a condições severas de serviço, com solicitações mecânicas associadas ou não a ambientes agressivos. Esta técnica permite a detecção e o dimensionamento de descontinuidades no interior do material analisado. Rodriguez e Raj (1997) relatam o uso de ultra-som para a caracterização de microestruturas e inspeção das juntas dos bocais de água no reator de água fervente (BWR). Uma segunda técnica aplicada em tubos de aço, é a da análise da deformação das linhas de campo magnético causadas por trincas ou falhas internas aos tubos, tais como bolhas ou fissuras. Nesta técnica, induz-se no tubo de ferro ou aço um campo magnético, através da circulação, em uma sonda, de uma corrente elétrica elevada, e observam-se as deformações deste campo ao longo da superfície do tubo. Ocorrendo a deformação aí existe uma falha. Uma terceira técnica é a conhecida como Eddy-Current (Lopes e Ting, 2000; Cizelj et al., 1998; Rodriguez e Raj, 1997). Esta técnica, empregada na inspeção dos tubos dos geradores de vapor de centrais nucleares, utiliza o princípio eletromagnético das correntes parasitas ou correntes de Foucault para a inspeção e deteç̧ão de falhas nos tubos, bem como os principais tipos de defeitos. As correntes parasitas são geradas no material ensaiado por meio de um campo magnético alternado com freqüência e intensidade definidas, através de uma bobina indutora. A formação de correntes parasitas no tubo depende da geometria e, principalmente, das características eletromagnéticas, como condutividade e permeabilidade magnética. Defeitos como trincas ocasionam um decréscimo na condutividade e, se a bobina passa pelo defeito, isto pode ser detectado pela variação da fase e da amplitude do sinal resultante. Contudo, vemos que tais técnicas têm sua principal aplicação na verificação da qualidade 
do material antes da instalação do tubo em campo e colocação em operação normal ou requer o desligamento da instalação para a execução da verificação.

Um sistema comercial para detecção e localização de vazamentos de vapor e de água em tubulações, tanques e vasos, com aplicações em plantas nucleares de potência desenvolvido pela Siemens, chamado FLÜS, trabalha com o fato que vazamentos de fluidos resultam em um aumento pronunciado da umidade do ar dentro do isolante térmico na redondeza da falha. Monitorando esta umidade, o sistema determina a localização do vazamento (Siemens,1993).

Fukushima et al. (2000) propõem um método que é uma extensão do método de balanço volume-massa. Em um primeiro passo, um balanço de pressão da linha de tubo de gás é simulado baseado em um modelo. No segundo passo, as diferenças entre o balanço de pressão simulado e o real são avaliadas para determinar um possível vazamento. As medidas da pressão e temperatura são realizadas nas estações de válvulas as quais são espaçadas umas das outras de uma distância conhecida. Segundo os autores, o método é capaz de estimar o ponto do vazamento.

Outra técnica de identificação de vazamento em linha de tubo é apresentada por Souza et al. (2000). A técnica apresentada baseia-se em análise espectral de sinais transientes de pressão medidos, através de transdutores de pressão instalados em seções da linha de tubo, durante a partida e a parada de bombas. Estes sinais são tratados por um filtro de diferença inversa e transformados para o domínio da freqüência através da transformada rápida de Fourier (FFT).

$\mathrm{Na}$ seqüência são apresentados alguns estudos de detecção de vazamento com a utilização de técnicas acústicas ou acelerometria.

Conforme relatado por Rodriguez e Raj (1997), técnicas de emissão acústica têm sido aplicadas com sucesso para a detecção da presença de vazamentos em um lado inacessível da blindagem final de uma unidade da Rajasthan Atomic Power Station. Esta tecnologia foi baseada no fato que sinais de emissão acústica de vazamento de ar e água tem diferentes traços característicos. As análises restringiram-se na monitoração do vazamento através das tensões RMS e do espectro das freqüências oriundas dos sensores de emissão acústica. 
Hessel et al. (1999) mostram a combinação de rede neural com métodos acústicos para tornar possível a localização de vazamento e estimação da taxa de vazamento em uma estrutura geodésica complexa. Esta técnica combinada é aplicada no reator Russo VVER ${ }^{1}$ na região de "standpipe" do vaso. A rede neural foi treinada usando uma fonte móvel de som que simulava um vazamento junto a todas posições de risco. Os padrões de som são monitorados por uma matriz de 12 sensores de emissão acústica e três microfones. Valores RMS, componentes do espectro de potência e valores de coerência são usados para extrair vetores de características adequadas como entrada para a rede neural. Conforme relatam os autores, a eficiência da rede de percepção de multicamada para monitoração acústica no vaso pressurizado do VVER-440 é experimentalmente comprovada.

A perda de água nas tubulações das companhias de distribuição é um fator de grande prejuízo. Para reduzir esta perda, as companhias conduzem sistematicamente programas para localizar e reparar vazamentos. Técnicas usando varinhas de escuta, aquafones e microfones de terra são usados para detectar o som induzido pelos vazamentos de água. A efetividade dos métodos existentes foi demonstrada no passado em tubos metálicos, para o plástico a efetividade destes métodos contudo não é bem estabelecida. Neste sentido, características acústicas de sinais de vazamentos em tubos plásticos foram investigadas por Hunaidi e Chu (1999), para vários tipos de vazamentos simulados sobre condições controladas em um terreno experimental. Para as medidas das vibrações foram usados acelerômetros piezelétricos e para as medidas dos sons hidrofones colocados nas conexões de serviços e nos hidrantes. $O$ tratamento matemático se deu através de análise espectral via FFT e função de correlação cruzada, para um sinal limitado em banda de $15 \mathrm{~Hz}$ até $100 \mathrm{~Hz}$.

A Siemens possui um sistema de monitoração acústica de vazamento denominado ALUES, o qual é relatado por Kunze (1999) e usado nas linhas de resfriamento de plantas nucleares de potência equipada com reatores VVER440 com o objetivo de aumentar a segurança nestas plantas. A tarefa do ALUES consiste de continuamente monitorar o ruído de operação, sendo o objetivo

\footnotetext{
${ }^{1}$ Vodo-Vodyannoy Energeticheskiy Reactor (Water-Cooled, Water-Moderated, Energy Reactor).
} 
detectar e localizar vazamentos nos limites do refrigerador pressurizado do reator. O sistema usa o fato de que escape nos componentes de retenção de pressão causam ondas de som de alta freqüência, as quais propagam-se através da estrutura de pressão na forma de som. ALUES detecta e localiza o vazamento registrando diferenças na intensidade de som medida em diferentes lugares. $O$ sistema é composto de Fonocaptores ultra-sônicos na faixa de $100-400 \mathrm{KHz}$, sistema de aquisição e processamento de sinal. Os parâmetros de avaliação são os valores RMS de vários canais, os quais são continuamente comparados com limiares móveis e fixos individualmente pré-ajustados, e que inicia um alarme de vazamento se o limiar é excedido. Para localizar um vazamento, os ruídos registrados por dois sensores relacionados são usados para apontar um vazamento. Contudo o nível de ruído gerado pelo vazamento deve ser suficiente para que o ruído amortecido na tubulação alcance adequadamente e exceda a magnitude do ruído de fundo junto aos sensores.

Srinivasan et al (2000) descrevem uma técnica estatística baseada em matriz de covariância para detectar vazamentos, identificar fontes de ruído e caracterizar transmissão de ruído em dados vindos de unidades geradoras de vapor PFR (UK Prototype Fast Reactor). Segundo os autores, o método promete detectar vazamentos em unidades geradoras de vapor reais a partir de dados ruidosos de baixíssima relação sinal-ruído. Os estudos de ruído de vazamento foram executados em dados sintetizados obtidos por injeção de vapor/água em sódio em "loops" de teste e não no SGU real. Para detectar o sinal da injeção, aspectos estatísticos como variância, PSD-SUM ${ }^{2}$, determinante e traço $^{3}$ da matriz de covariância, foram avaliados para todas as quatro guias de onda com acelerômetros instalados.

Segundo Hsiung e Himmelblau (1996), o uso de ruído acústico passivo para detectar falha tem muitas características atrativas. Primeiro, é fácil coletar formas de ondas acústicas em lugares inacessíveis em equipamentos. Segundo, o ruído acústico fornece muito mais informações do que é obtida com outros processos como temperatura e pressão. Terceiro, ondas acústicas têm a

\footnotetext{
${ }^{2}$ Nesta análise, é definido como a soma das potências nas 30 primeiras linhas de freqüências no PSD, as quais cobrem uma faixa de freqüência de aproximadamente $5 \mathrm{KHz}$.

${ }^{3}$ Determinante e características de traço são formadas dos componentes APSD (Auto Power Spectral Density) do sinal de ruído.
} 
propriedade da superposição encontrada em sistemas lineares. Isto significa que pode existir mais que um defeito ocorrendo simultaneamente, pois a presença de uma fonte de sinal não afeta a média ou perturba a outra fonte de sinal. Por causa desta propriedade, uma falha detectada individualmente também pode ser detectada quando ocorre simultaneamente com outras. Contudo, a forma de onda é facilmente distorcida quando passa por diferentes meios ou reflexões na estrutura do equipamento. Estes ruídos estranhos corrompem a informação que é de interesse, tornando o procedimento de extração da informação difícil. Portanto, o tratamento ou redução destes ruídos estranhos torna-se o maior problema quando é usado ruído acústico para detecção de falha.

Tubos pressurizados, tais como linhas de tubos de gás e tubulação de transporte de calor em estação de potência, são geralmente desenhados para satisfazer um conceito de vazar antes de quebrar. Contudo, este conceito é viável somente se um vazamento é detectado em um estágio precoce. Sendo assim, monitoração de emissão acústica é uma técnica potencial para vigilância de vazamentos (Boaratti et al., 2001).

Na seqüência são mencionados alguns trabalhos correlacionados com estudos de cascas cilíndricas, os quais, tratam das propriedades acústicas, do fluxo de energia, da mobilidade da parede, da propagação de onda e da vibração livre da casca cilíndrica. Os trabalhos são assinados por Fuller (1982 e 1983), Feng (1996), Amabili (1996), Xu \& Zhang (1998, 1999 e 2000) e Ming (2000). Estes artigos serviram de referência para o estudo aqui apresentado e são citados ao longo do texto, principalmente, nos capítulos que tratam da equação de onda da casca cilíndrica. 


\section{PROPAGAÇÕES DE ONDAS DE TENSÃO EM MEIOS SÓlidOS ELÁSTICOS}

Quando um corpo sólido é carregado por um impacto ou por deslocamentos súbitos tem-se essencialmente um problema dinâmico, o qual é modelado pelas equações de movimento correspondentes. Neste sentido, quando um sólido é submetido a uma força, que varia rapidamente, observa-se que sua ação não é transmitida instantaneamente a todas as partes do sólido. Ondas de tensão e de deformação aparecerão e serão irradiadas em todas as direções no interior deste sólido com velocidades finitas. Deste modo, um ponto situado a uma certa distância do ponto onde o esforço foi aplicado só sentirá seu efeito transcorrido algum tempo.

No interior de um sólido infinito, somente dois tipos de ondas podem se propagar. Estes dois tipos de ondas são chamados de onda de dilatação e onda de distorção e possuem velocidades de propagação distintas (Kolsky, 1963). Contudo, quando neste sólido existirem superfícies livres ou interfaces entre dois meios, aparecerão ondas conhecidas como ondas de superfície as quais possuem velocidades de propagação diferentes das duas primeiras. Lorde Rayleigh foi quem primeiro chamou a atenção para a existência dessas ondas (Timoshenko \& Goodier, 1980, p. 498).

\subsection{Componentes de tensão e deformação em meio sólido}

Tomando-se no interior de um corpo sólido elástico, homogêneo e isotrópico, um cubo infinitesimal em um ponto $P$, o qual é referenciado por três eixos mutuamente perpendiculares $x, y$ e $z$, como indicado na FIG.3.1, e considerando-se tensões agindo neste corpo sobre os três planos $X, Y$ e $Z$, observa-se a existência de nove componentes de tensão, as quais são indicadas por $\sigma_{a b}$. A primeira letra indica a direção da tensão e a segunda o plano onde ela atua.

As componentes normais das tensões são: $\sigma_{x x} ; \sigma_{y y}$ e $\sigma_{z z}$. As componentes das tensões de cisalhamento são: $\sigma_{x y} ; \sigma_{y x} ; \sigma_{x z} ; \sigma_{z x} ; \sigma_{y z}$ e $\sigma_{z y}$. No equilíbrio, $\sigma_{x y}=\sigma_{y x}, \sigma_{x z}=\sigma_{z x}$ e $\sigma_{y z}=\sigma_{z y}$. Deste modo, as nove componentes de 
tensão se reduzem a seis componentes independentes em um ponto no interior de um corpo sólido. (Kolsky, 1963; Timoshenko \& Goodier, 1980).

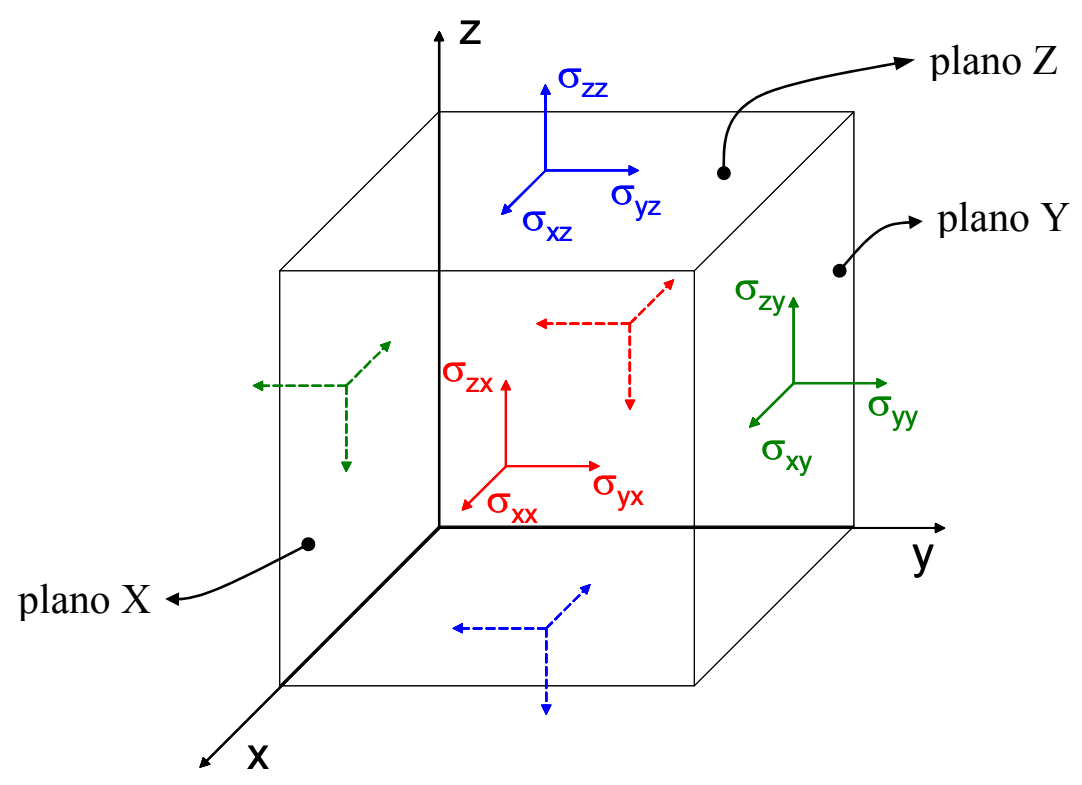

FIGURA 3.1 - Componentes de tensão atuando em um elemento cúbico infinitesimal.

Considere um elemento infinitesimal $d x, d y$ e $d z$ do corpo sólido. Se este corpo sofrer uma pequena deformação, os pequenos deslocamentos das partículas deste corpo deformado poderão ser decompostos nas componentes $u$, $v$ e $w$ paralelos às direções $x, y$ e $z$, respectivamente. É demonstrado em Kolsky (1963), Timoshenko \& Goodier (1980) e Love (1927), que nove quantidades surgirão, as quais são descritas como segue:

a) Expansão e contração infinitesimal ou deformação normal:

$$
\varepsilon_{x x}=\frac{\partial u}{\partial x}, \quad \varepsilon_{y y}=\frac{\partial v}{\partial y}, \quad \varepsilon_{z z}=\frac{\partial w}{\partial z} .
$$

b) Deformação por cisalhamento ou distorção:

$$
\varepsilon_{y z}=\frac{\partial w}{\partial y}+\frac{\partial v}{\partial z}, \quad \varepsilon_{z x}=\frac{\partial u}{\partial z}+\frac{\partial w}{\partial x}, \quad \varepsilon_{x y}=\frac{\partial v}{\partial x}+\frac{\partial u}{\partial y}
$$


c) Rotação do elemento:

$$
\varpi_{x}=\frac{1}{2}\left(\frac{\partial w}{\partial y}-\frac{\partial v}{\partial z}\right), \quad \varpi_{y}=\frac{1}{2}\left(\frac{\partial u}{\partial z}-\frac{\partial w}{\partial x}\right), \quad \varpi_{z}=\frac{1}{2}\left(\frac{\partial v}{\partial x}-\frac{\partial u}{\partial y}\right)
$$

As seis primeiras quantidades descritas nas equações (3.1) e (3.2) são chamadas de componentes de deformação.

\subsection{Lei de Hooke para um sólido isotrópico}

A maioria dos sólidos possui deformação linearmente proporcional à carga aplicada, contanto que a carga não exceda um dado valor conhecido como limite elástico. Estas relações lineares entre as componentes de tensão e de deformação são conhecidas como lei de Hooke generalizada, a qual é definida por 36 coeficientes independentes, (Kolsky, 1963).

Devido à simetria, em um sólido isotrópico, os valores dos coeficientes são funções de duas constantes independentes. Estas duas constantes elásticas $\lambda$ e $\mu$, as quais definem completamente o comportamento elástico de um sólido isotrópico, são conhecidas como constantes de Lamé, (Kolsky, 1963; Timoshenko \& Goodier, 1980; Kino, 1987). A lei de Hooke para sólidos isotrópicos é portanto escrita como:

$$
\left[\begin{array}{c}
\sigma_{x x} \\
\sigma_{y y} \\
\sigma_{z z} \\
\sigma_{y z} \\
\sigma_{z x} \\
\sigma_{x y}
\end{array}\right]=\left[\begin{array}{cccccc}
c_{11} & c_{12} & c_{13} & 0 & 0 & 0 \\
c_{21} & c_{22} & c_{23} & 0 & 0 & 0 \\
c_{31} & c_{32} & c_{33} & 0 & 0 & 0 \\
0 & 0 & 0 & c_{44} & 0 & 0 \\
0 & 0 & 0 & 0 & c_{55} & 0 \\
0 & 0 & 0 & 0 & 0 & c_{66}
\end{array}\right]\left[\begin{array}{l}
\varepsilon_{x x} \\
\varepsilon_{y y} \\
\varepsilon_{z z} \\
\varepsilon_{y z} \\
\varepsilon_{z x} \\
\varepsilon_{x y}
\end{array}\right]
$$

sendo: $\quad\left\{\begin{array}{l}c_{11}=c_{22}=c_{33}=\lambda+2 \mu, \\ c_{12}=c_{13}=c_{21}=c_{23}=c_{31}=c_{32}=\lambda, \\ c_{44}=c_{55}=c_{66}=\mu .\end{array}\right.$ 
Desenvolvendo o produto das matrizes, a equação (3.4) pode ser escrita da seguinte forma:

$$
\begin{aligned}
\sigma_{x x} & =\lambda \Delta+2 \mu \varepsilon_{x x} \\
\sigma_{y y} & =\lambda \Delta+2 \mu \varepsilon_{y y} \\
\sigma_{z z} & =\lambda \Delta+2 \mu \varepsilon_{z z} \\
\sigma_{y z} & =\mu \varepsilon_{y z} \\
\sigma_{z x} & =\mu \varepsilon_{z x} \\
\sigma_{x y} & =\mu \varepsilon_{x y}
\end{aligned}
$$

$\Delta=\varepsilon_{x x}+\varepsilon_{y y}+\varepsilon_{z z}$ é chamado de dilatação, e representa a variação de volume do cubo infinitesimal ( $d x d y d z)$.

É conveniente definir três outras constantes que são normalmente utilizadas na literatura, as quais são derivadas das constantes de Lamé:

\subsubsection{Módulo de Young - $E$}

O parâmetro $E$ é uma constante obtida quando uma barra é esticada em uma máquina de teste de tração. É definido como a relação entre a tensão aplicada e a deformação normal resultante quando um corpo de prova é submetido a uma tensão constante em suas extremidades e as superfícies laterais são livres de restrição (Kolsky, 1963; Kino, 1987; Love, 1927).

$$
E=\frac{\mu(3 \lambda+2 \mu)}{\lambda+\mu}
$$

\subsubsection{Coeficiente de Poisson - $v$}

O parâmetro $v$ é definido como a relação entre a deformação transversal e a deformação longitudinal quando um corpo de prova é submetido a uma tensão axial (Kolsky, 1963; Kino, 1987; Love, 1927).

$$
v=\frac{\lambda}{2(\lambda+\mu)}
$$

\subsubsection{Módulo de elasticidade ao cisalhamento - $\mu$}

O parâmetro $\mu$ também é chamado de módulo de rigidez ou módulo de elasticidade transversal ou simplesmente módulo de cisalhamento, e corresponde à relação entre a tensão de cisalhamento e a deformação de cisalhamento 
conforme a equação (3.5). O parâmetro $\mu$ é reescrito na equação (3.8a), (Kolsky, 1963; Timoshenko \& Goodier, 1980).

$$
\mu=\frac{\sigma_{y z}}{\varepsilon_{y z}}=\frac{\sigma_{z x}}{\varepsilon_{z x}}=\frac{\sigma_{x y}}{\varepsilon_{x y}}
$$

O mesmo parâmetro $\mu$ também pode ser apresentado em função da constante $\lambda$ ou do módulo de Young e do coeficiente de Poisson como segue:

$$
\begin{aligned}
& \mu=\frac{\lambda}{2 v}-\lambda, \\
& \mu=\frac{E}{2(1+v)} .
\end{aligned}
$$

\subsection{Equações do equilíbrio e do movimento em um meio sólido}

O objetivo aqui é apresentar as equações de movimento para um meio sólido elástico e as velocidades das ondas que podem propagar neste meio. Neste sentido, as condições de equilíbrio de um pequeno cubo infinitesimal de arestas $d x, d y$ e $d z$ devem ser consideradas. As componentes de tensão atuando nas faces deste cubo e suas variações infinitesimais através das faces são mostradas na FIG. 3.2.

Multiplicando-se o valor da tensão no centro de cada face pela área da respectiva face, obtém-se a força atuando em cada face do cubo. Considerando agora a somatória das forças que agem neste elemento na direção $x$, desprezando as deformações causadas pelas forças gravitacionais, obtém-se a equação do equilíbrio nesta direção. Repetindo o procedimento nas outras direções, obtêm-se as equações do equilíbrio nas três direções:

$$
\begin{aligned}
& \left(\frac{\partial \sigma_{x x}}{\partial x}+\frac{\partial \sigma_{x y}}{\partial y}+\frac{\partial \sigma_{x z}}{\partial z}\right)=0 \\
& \left(\frac{\partial \sigma_{y x}}{\partial x}+\frac{\partial \sigma_{y y}}{\partial y}+\frac{\partial \sigma_{y z}}{\partial z}\right)=0 \\
& \left(\frac{\partial \sigma_{z x}}{\partial x}+\frac{\partial \sigma_{z y}}{\partial y}+\frac{\partial \sigma_{z z}}{\partial z}\right)=0 .
\end{aligned}
$$




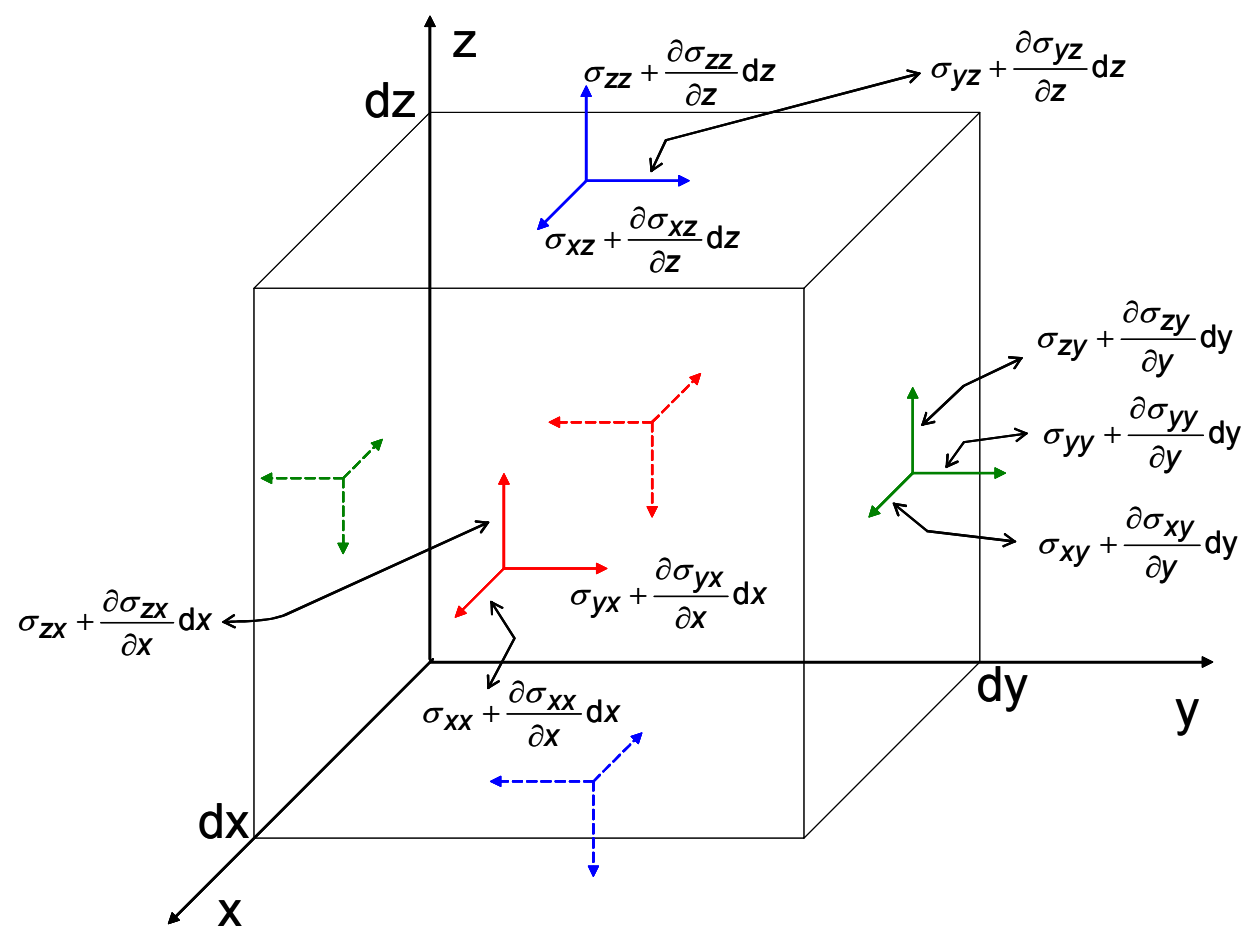

FIGURA 3.2 - Variações das componentes de tensão atuando em um elemento cúbico infinitesimal.

Adicionando-se a força de inércia nas equações do equilíbrio, pela segunda lei de Newton, sendo $\rho$ a densidade do material, obtêm-se as equações para o movimento nas três direções:

$$
\begin{gathered}
\frac{\partial \sigma_{x x}}{\partial x}+\frac{\partial \sigma_{x y}}{\partial y}+\frac{\partial \sigma_{x z}}{\partial z}=\rho \frac{\partial^{2} u}{\partial t^{2}} \\
\frac{\partial \sigma_{y x}}{\partial x}+\frac{\partial \sigma_{y y}}{\partial y}+\frac{\partial \sigma_{y z}}{\partial z}=\rho \frac{\partial^{2} v}{\partial t^{2}} \\
\frac{\partial \sigma_{z x}}{\partial x}+\frac{\partial \sigma_{z y}}{\partial y}+\frac{\partial \sigma_{z z}}{\partial z}=\rho \frac{\partial^{2} w}{\partial t^{2}}
\end{gathered}
$$

\subsection{Equação do movimento em função dos deslocamentos}

As equações do movimento podem ser reescritas em função dos deslocamentos $u, v$ e $w$. Sendo assim, para eliminar as componentes de tensão nas equações (3.10), aplica-se a lei de Hooke para um meio isotrópico, equação (3.5): 


$$
\begin{aligned}
& \frac{\partial\left(\lambda \Delta+2 \mu \varepsilon_{x x}\right)}{\partial x}+\frac{\partial \mu \varepsilon_{x y}}{\partial y}+\frac{\partial \mu \varepsilon_{x z}}{\partial z}=\rho \frac{\partial^{2} u}{\partial \mathrm{t}^{2}} \\
& \frac{\partial\left(\mu \varepsilon_{y x}\right)}{\partial x}+\frac{\partial\left(\lambda \Delta+2 \mu \varepsilon_{y y}\right)}{\partial y}+\frac{\partial \mu \varepsilon_{y z}}{\partial z}=\rho \frac{\partial^{2} v}{\partial \mathrm{t}^{2}} \\
& \frac{\partial \mu \varepsilon_{z x}}{\partial x}+\frac{\partial \mu \varepsilon_{z y}}{\partial y}+\frac{\partial\left(\lambda \Delta+2 \mu \varepsilon_{z z}\right)}{\partial z}=\rho \frac{\partial^{2} w}{\partial \mathrm{t}^{2}} .
\end{aligned}
$$

Nas expressões acima, representando as componentes de deformação $\varepsilon$ em termos dos deslocamentos através das equações (3.1) e (3.2) e após um tratamento algébrico destas equações, chega-se às equações gerais de movimento de um corpo sólido isotrópico e elástico, igualmente descrito por Love (1927), Kolsky (1963), Timoshenko \& Goodier (1980) e Kino (1987):

$$
\begin{aligned}
& (\lambda+\mu) \frac{\partial \Delta}{\partial x}+\mu \nabla^{2} u=\rho \frac{\partial^{2} u}{\partial \mathrm{t}^{2}} \\
& (\lambda+\mu) \frac{\partial \Delta}{\partial y}+\mu \nabla^{2} v=\rho \frac{\partial^{2} v}{\partial \mathrm{t}^{2}} \\
& (\lambda+\mu) \frac{\partial \Delta}{\partial z}+\mu \nabla^{2} w=\rho \frac{\partial^{2} w}{\partial \mathrm{t}^{2}}
\end{aligned}
$$

Sendo o operador $\nabla^{2}=\frac{\partial^{2}}{\partial x^{2}}+\frac{\partial^{2}}{\partial y^{2}}+\frac{\partial^{2}}{\partial z^{2}}$ e $\Delta$ a dilatação.

\subsection{Velocidades de propagações das ondas em um corpo sólido}

\subsubsection{Ondas de dilatação e ondas de distorção}

Como já mencionado, no interior de um corpo sólido, as ondas podem se propagar com apenas duas velocidades distintas. Para qualquer tipo de onda, pode-se mostrar que as equações de movimento têm a seguinte forma comum, descrita pela equação de onda, sendo que $\psi$ é uma função do tempo e das coordenadas e c é a velocidade de propagação, (Love,1927; Timoshenko \& Goodier, 1980).

$$
\frac{\partial^{2} \psi}{\partial \mathrm{t}^{2}}=c^{2} \nabla^{2} \psi
$$


Tomando-se as equações (3.12a, b, c) e diferenciando os dois lados destas equações com referência a $x, y$ e $z$ respectivamente e somando os três resultados, obtém-se a equação (3.14), a qual tem a mesma forma da equação característica de uma onda (3.13), Love (1927). Deste modo, por comparação, verifica-se que a onda de dilatação $\Delta$ se propaga com a velocidade indicada pela equação (3.15).

$$
\begin{aligned}
\rho \frac{\partial^{2} \Delta}{\partial \mathrm{t}^{2}} & =(\lambda+2 \mu) \nabla^{2} \Delta, \\
c_{1} & =\sqrt{\frac{\lambda+2 \mu}{\rho}} .
\end{aligned}
$$

Tomando-se agora a equação (3.12b) e diferenciando os dois lados com referência a $z$, e de modo idêntico para a equação (3.12c) com referência a $y$ e subtraindo os resultados, obtém-se a equação (3.16a). Seguindo-se o mesmo raciocínio para as equações $(3.12 a)$ e $(3.12 c)$ e para as equações (3.12a) e (3.12b), obtêm-se as equações (3.16 b) e (3.16c) respectivamente:

$$
\begin{gathered}
\rho \frac{\partial^{2}\left(\frac{\partial w}{\partial y}-\frac{\partial v}{\partial z}\right)}{\partial \mathrm{t}^{2}}=\mu \nabla^{2}\left(\frac{\partial w}{\partial y}-\frac{\partial v}{\partial z}\right) \\
\rho \frac{\partial^{2}\left(\frac{\partial u}{\partial z}-\frac{\partial w}{\partial x}\right)}{\partial \mathrm{t}^{2}}=\mu \nabla^{2}\left(\frac{\partial u}{\partial z}-\frac{\partial w}{\partial x}\right) \\
\rho \frac{\partial^{2}\left(\frac{\partial v}{\partial x}-\frac{\partial u}{\partial y}\right)}{\partial \mathrm{t}^{2}}=\mu \nabla^{2}\left(\frac{\partial v}{\partial x}-\frac{\partial u}{\partial y}\right)
\end{gathered}
$$

As equações acima podem ser reescritas em função de $\varpi_{x}, \varpi_{y}$ e $\varpi_{z}$ que são as rotações do elemento em relação aos eixos $x$, y e z como mostrado na equação (3.3), resultando assim nas equações (3.17): 


$$
\begin{aligned}
& \rho \frac{\partial^{2} \varpi_{x}}{\partial \mathrm{t}^{2}}=\mu \nabla^{2} \varpi_{x}, \\
& \rho \frac{\partial^{2} \varpi_{y}}{\partial \mathrm{t}^{2}}=\mu \nabla^{2} \varpi_{y}, \\
& \rho \frac{\partial^{2} \varpi_{z}}{\partial \mathrm{t}^{2}}=\mu \nabla^{2} \varpi_{z} .
\end{aligned}
$$

Observa-se que a equação (3.17) tem a mesma forma da equação de onda (3.13). Deste modo, pode-se dizer que a onda de rotação se propaga com a velocidade:

$$
c_{2}=\sqrt{\frac{\mu}{\rho}} .
$$

Em outra condição particular na qual as deformações produzidas pelas ondas não causam rotação, ou seja, na equação (3.3) as rotações $\varpi_{x}, \varpi_{y}$ e $\varpi_{z}$ são assumidas como sendo zero, a condição irrotacional é satisfeita se $u=\frac{\partial \phi}{\partial x}, \quad v=\frac{\partial \phi}{\partial y}, \quad w=\frac{\partial \phi}{\partial z}$ onde $\phi$ é uma função potencial tal que: $\Delta=\nabla^{2} \phi \quad \mathrm{e}$ $\frac{\partial \Delta}{\partial x}=\frac{\nabla^{2} \phi}{\partial x}=\nabla^{2} u$. Substituindo na equação (3.12a), encontra-se a equação (3.19), conforme demonstrado em Love (1927), Kolsky (1963) e Timoshenko \& Goodier (1980):

$$
\rho \frac{\partial^{2} \Delta}{\partial \mathrm{t}^{2}}=(\lambda+2 \mu) \nabla^{2} \Delta .
$$

Novamente observa-se que a equação resultante tem a mesma forma da equação de onda (3.13). Deste modo, pode-se dizer que ondas que não produzem rotação são propagadas com a velocidade $c_{3}$ :

$$
c_{3}=\sqrt{\frac{\lambda+2 \mu}{\rho}} .
$$


Para o outro caso particular em que as deformações produzidas pelas ondas sejam somente resultado de distorção e rotação, tal que a dilatação $\Delta$ seja zero, $\varepsilon_{x x}+\varepsilon_{y y}+\varepsilon_{z z}=0$, ou seja, a expansão volumétrica é nula, as expressões da equação (3.12) tomam a seguinte forma, conforme demonstrado por Love (1927); Kolsky (1963) e Timoshenko \& Goodier (1980). As quais representam as chamadas ondas de distorção.

$$
\begin{aligned}
& \rho \frac{\partial^{2} u}{\partial \mathrm{t}^{2}}=\mu \nabla^{2} u, \\
& \rho \frac{\partial^{2} v}{\partial \mathrm{t}^{2}}=\mu \nabla^{2} v \\
& \rho \frac{\partial^{2} w}{\partial \mathrm{t}^{2}}=\mu \nabla^{2} w
\end{aligned}
$$

Comparando-se as expressões da equação acima com a equação de onda (3.13), tem-se que as ondas de distorção se propagam no meio com a velocidade $c_{4}$, a qual depende somente da densidade e do módulo de cisalhamento do meio, ou seja:

$$
c_{4}=\sqrt{\frac{\mu}{\rho}} .
$$

Deste modo no interior do sólido tem-se duas velocidades de ondas que se propagam: i) a velocidade $c_{1}$ da onda de dilatação e a velocidade $c_{3}$ da onda irrotacional as quais possuem numericamente o mesmo valor; ii) a velocidade $c_{2}$ da onda de rotação e a velocidade $c_{4}$ da onda de distorção as quais também são numericamente idênticas entre si.

\subsubsection{Ondas longitudinais e transversais}

Quando uma perturbação é produzida no interior de um meio elástico, em um certo ponto $P$, observa-se a propagação de ondas em todas as direções a partir deste ponto. A uma distância suficientemente afastada, estas ondas podem ser consideradas como ondas planas. Tomando uma direção particular, a onda na qual a direção de propagação é a mesma da direção do deslocamento, ou seja, é paralela a direção considerada, é chamada de onda longitudinal, neste caso a 
onda se propaga através de um processo de compressão e expansão das partículas do meio. De outro modo, quando o deslocamento da partícula se dá perpendicularmente à direção de propagação da onda, tem-se a chamada onda transversal. Aqui também a partícula não se desloca, ela oscila de um lado para outro em torno da sua região de equilíbrio e perpendicularmente ao eixo de propagação.

\subsubsection{Ondas longitudinais}

Considerando-se a onda propagando na direção do eixo $x$, quando $v=w=0$ e que o deslocamento normal $u$ é função somente de $x$ e de $t$, tem-se a condição de onda longitudinal plana. Então, da equação (3.12a) obtém-se:

ou

$$
\begin{aligned}
& \rho \frac{\partial^{2} u}{\partial \mathrm{t}^{2}}=(\lambda+\mu) \frac{\partial}{\partial x}(\frac{\partial u}{\partial x}+\underbrace{\frac{\partial v}{\partial y}+\frac{\partial w}{\partial z}}_{0})+\mu(\frac{\partial^{2} u}{\partial x^{2}}+\underbrace{\frac{\partial^{2} u}{\partial y^{2}}+\frac{\partial^{2} u}{\partial z^{2}}}_{0}), \\
& \rho \frac{\partial^{2} u}{\partial t^{2}}=(\lambda+2 \mu) \frac{\partial^{2} u}{\partial x^{2}} .
\end{aligned}
$$

Comparando a equação (3.23) com a equação de onda (3.13), concluise que a onda longitudinal se propaga com a velocidade $c_{L}$ dada pela equação (3.24), ou seja, na velocidade da onda de dilatação:

$$
c_{L}=\sqrt{\frac{\lambda+2 \mu}{\rho}} .
$$

\subsubsection{Ondas transversais}

Considerando agora o deslocamento perpendicular à direção de propagação $x$, tem-se que $u=w=0$ e que $v$ é uma função de $x$ e $t$ apenas, então da equação (3.12b) tem-se: 


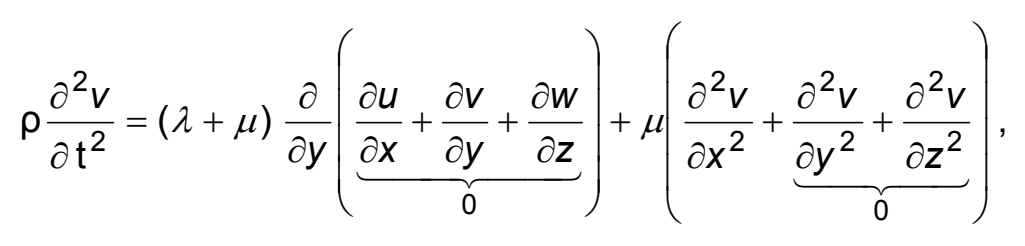

ou

$$
\rho \frac{\partial^{2} v}{\partial \mathrm{t}^{2}}=\mu \frac{\partial^{2} v}{\partial x^{2}}
$$

Igualmente, comparando-se a equação (3.25) com a equação característica (3.13), conclui-se que a onda transversal se propaga com a velocidade $c_{T}$ dada pela equação (3.26), ou seja, na velocidade da onda de distorção:

$$
c_{T}=\sqrt{\frac{\mu}{\rho}}
$$

\subsection{Ondas de superfície}

Como visto anteriormente, no interior de um meio sólido isotrópico, homogêneo e infinito, as ondas se propagam com apenas duas velocidades distintas. Lorde Rayleigh, em 1887, demonstrou que quando existirem contornos livres, ondas de superfície podem aparecer confinadas nas vizinhanças do contorno, ou seja, em uma fina camada próxima da superfície e que se propaga com uma velocidade diferente das duas primeiras, (Love, 1927; Kolsky, 1963; Timoshenko \& Goodier, 1980). Essa propagação é semelhante à que ocorre na superfície da água em repouso, quando esta é perturbada em um ponto na superfície.

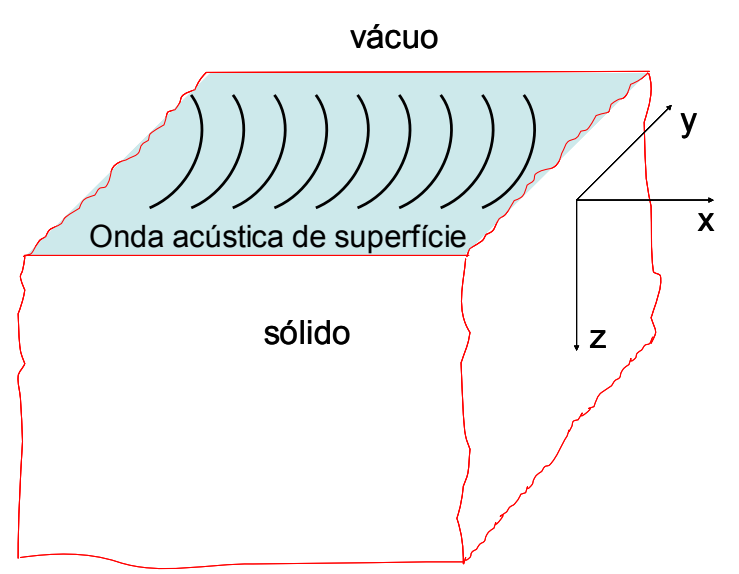

FIGURA 3.3 - Onda acústica se propagando na superfície livre de um corpo sólido com velocidade $c_{R}$. 
Considere um meio semi-infinito com uma superfície plana $x y$, em $z=0$, a qual é livre de tensões no contorno, e direção positiva no eixo $z$ para o interior do sólido. Suponha agora uma onda plana propagando na superfície do corpo sólido na direção $x$ com uma velocidade $c_{R}$, FIG. 3.3. Com base nas equações gerais do movimento (3.12), considerando as condições de contorno, Rayleigh demonstrou em seu trabalho: "On Waves Propagated Along the Plane Surfaces of an Elastic Solid", Proc. London Math. Soc., vol.17, 1887, o qual é reproduzido e comentado por Love (1927), Kolsky (1963), Timoshenko \& Goodier (1980) e Kino (1987), que a onda de superfície é uma combinação de componentes longitudinais e de cisalhamento parcialmente acopladas e que esta onda se propaga com uma velocidade ligeiramente inferior às ondas de distorção. Estas ondas de superfície são conhecidas como ondas de Rayleigh. A velocidade da onda de superfície $c_{R}$ é dada pela relação:

$$
c_{R}=\alpha c_{T}
$$

sendo $\alpha$ definido em Love (1927) e Timoshenko \& Goodier (1980) como:

$$
\alpha^{6}-8 \alpha^{4}+8\left(3-\frac{1-2 v}{1-v}\right) \alpha^{2}-16\left(1-\frac{1-2 v}{2(1-v)}\right)=0 .
$$

Pode ser visto da equação (3.26) que $c_{T}$ depende somente de $\mu$ e $\rho$, e que a grandeza $\alpha$ na equação (3.28) também só depende das constantes elásticas do material. Sendo assim, a velocidade de propagação da onda de superfície é independente da freqüência e só depende das características do meio elástico. Na FIG. 3.4 pode ser vista a dependência de $\alpha$ com o coeficiente de Poisson, onde se nota uma boa linearidade do alfa na região entre Poisson 0,2 e 0,5 o qual se aplica aos sólidos como metais, vidros, cristais e polímeros.

A título de exemplo, para um aço com $\mu=7,384610^{10} \mathrm{~Pa}$, $\rho=7800 \mathrm{Kg} / \mathrm{m}^{2}$ e $v=0,3$ tem-se a velocidade transversal $c_{T}=3077 \mathrm{~m} / \mathrm{s}$, o coeficiente $\alpha=0,9274$ e finalmente a velocidade de superfície $c_{R}=2853,6 \mathrm{~m} / \mathrm{s}$. 


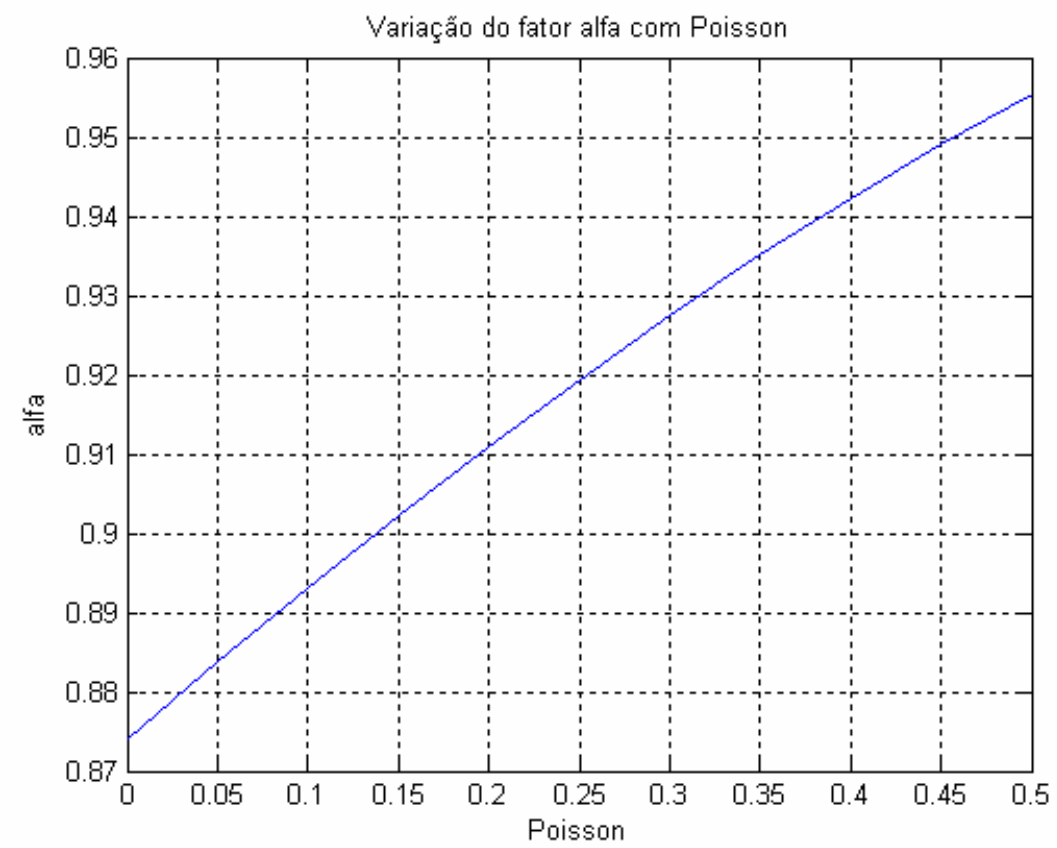

FIGURA 3.4 - Fator $\alpha$ em função do coeficiente de Poisson

As ondas de Rayleigh possuem a característica de atenuarem rapidamente com o aumento da profundidade $z$ perpendicular à superfície e com o aumento da freqüência da onda, com fatores diferentes na direção de propagação $x$ e na direção normal à superfície. Conforme apresentado em Kolsky (1963), estes fatores de atenuação são dados pelas relações dos deslocamentos $u / u_{0}$ e $w / w_{0}$ nas direções $x$ e $z$ respectivamente, representados nas equações a seguir. Os deslocamentos $u$ e $w$ são os deslocamentos nas direções $x$ e $z$ para uma dada profundidade $z$ e os deslocamentos $u_{0}$ e $w_{0}$ são os deslocamentos em uma posição $x$ qualquer sobre a superfície livre do corpo.

e

$$
\frac{u}{u_{0}}=\left(e^{-q z}-2 q s\left(s^{2}+K^{2}\right)^{-1} e^{-s z}\right)\left(1-2 q s\left(s^{2}+K^{2}\right)^{-1}\right)
$$

$$
\frac{w}{w_{0}}=\left(e^{-q z}-2 K^{2}\left(s^{2}+K^{2}\right)^{-1} e^{-s z}\right) /\left(1-2 K^{2}\left(s^{2}+K^{2}\right)^{-1}\right)
$$

O fator $K$ é dado pela relação $K=\frac{\omega}{c_{R}}=\frac{2 \pi}{\Lambda}$, sendo $\omega=2 \pi f \mathrm{e}$ $\Lambda$ o comprimento da onda. 
Os fatores $q$ e $s$ das equações (3.29) e (3.30) são dados por:

$$
q^{2}=\left(1-\left(\frac{1-2 v}{2-2 v}\right) \alpha^{2}\right) K^{2}
$$

e

$$
s^{2}=\left(1-\alpha^{2}\right) K^{2}
$$

Através da FIG. 3.5, pode ser visto o efeito da profundidade $z$ na atenuação da onda. Para o deslocamento das partículas na direção normal à superfície, FIG. $3.5 \mathrm{~b}$, observa-se que a amplitude do deslocamento diminui com o aumento da profundidade na direção $z$, tornando-se assíntota a zero para $z$ maior que 1,5 vezes o comprimento da onda de Rayleigh. Contudo para pequenas profundidades o deslocamento $w$ primeiramente aumenta, tendo um máximo em torno de 0,085 do comprimento da onda, iniciando a partir deste ponto uma diminuição com o aumento de $z$. Para $z$ maior que 1,015 do comprimento da onda, observa-se que o deslocamento $w$ possui valores menores que $20 \%$ do valor na superfície.

a)

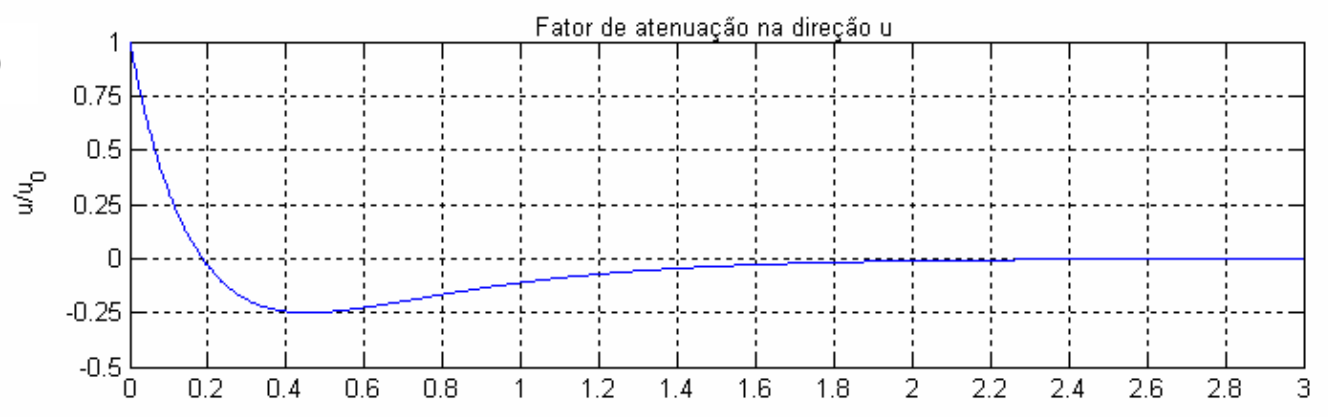

b)

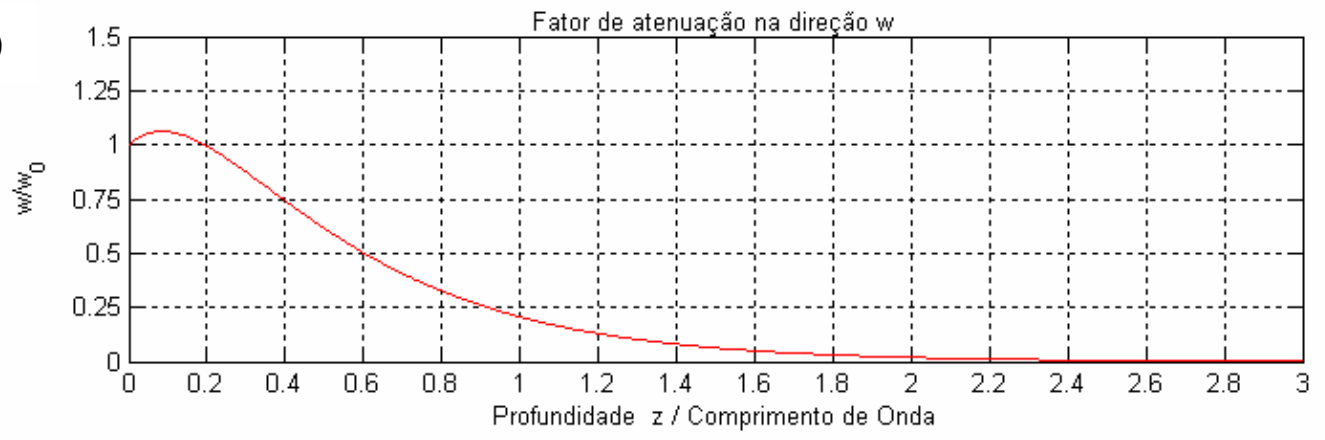

FIGURA 3.5 - Efeito da profundidade nos deslocamentos $u$ e $w$ para coeficiente de Poisson $v=0,28$. 
Os deslocamentos das partículas na direção da propagação, ou seja, paralelo à superfície, ilustrados na FIG. 3.5a, decrescem rapidamente com o aumento da profundidade, atingindo zero em $z$ igual a 0,186 vezes 0 comprimento da onda. A partir desta profundidade observa-se uma inversão da fase de vibração das partículas, ou seja, as partículas passam a vibrar em uma órbita elíptica em sentido contrário ao das partículas próximas à superfície, as quais estão vibrando em uma órbita também elíptica, mas em sentido contrário à propagação da onda.

Na FIG. 3.6 pode-se observar o fenômeno mencionado anteriormente. Nota-se que a partícula da superfície está se movimentando em uma órbita elíptica (azul) a qual é em sentido contrário ao sentido de propagação da onda. Neste exemplo, a onda está indo para a direita e a partícula para a esquerda. Observa-se que uma segunda partícula localizada em uma profundidade maior que $0,186 \Lambda$ está se movimentando em uma órbita também elíptica (verde) no sentido da onda, ou seja, para a direita, mostrando a inversão de fase comentada anteriormente.

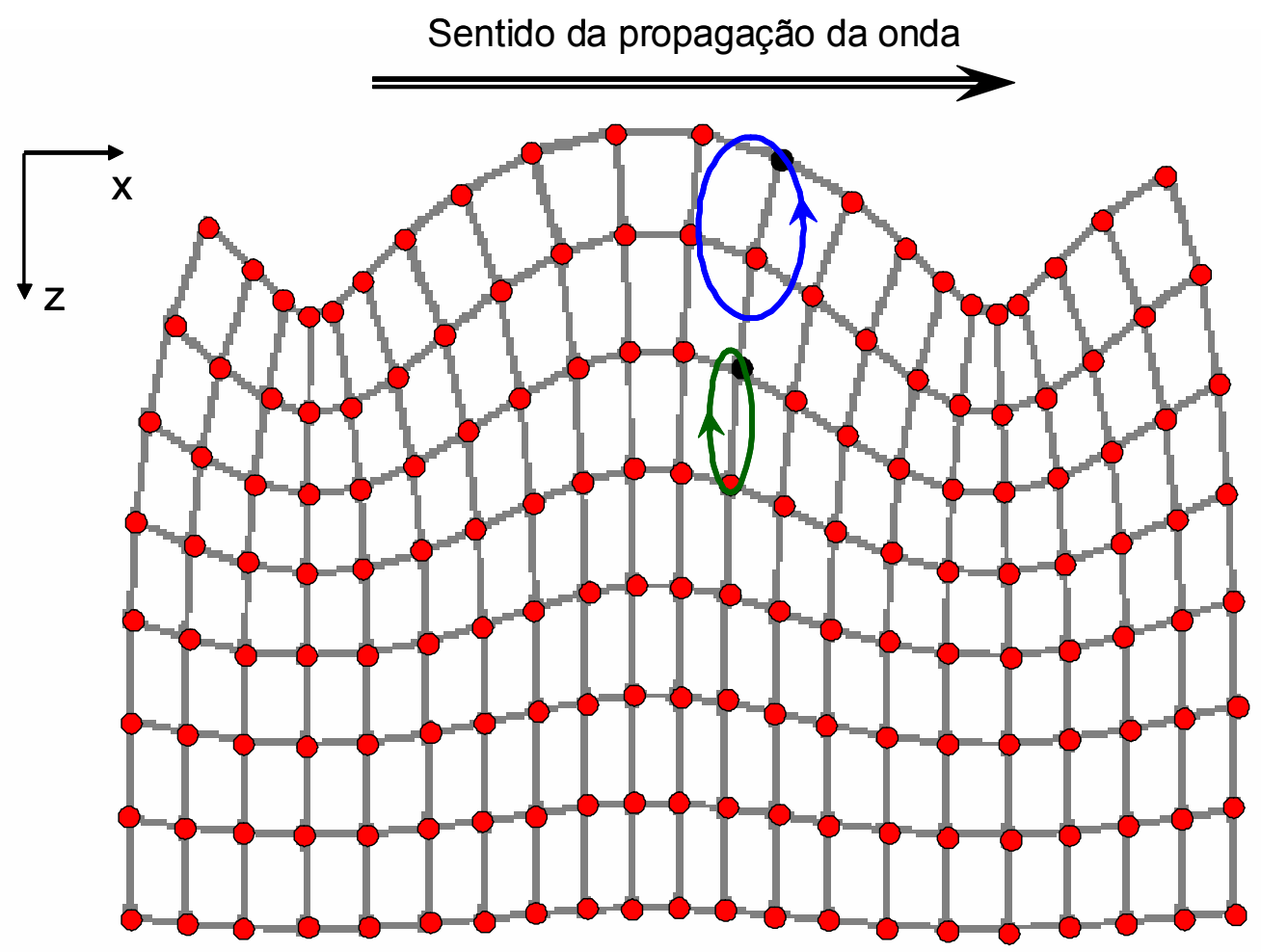

FIGURA 3.6 - Movimento das partículas na onda de Rayleigh 


\section{EQUAÇÃO DE ONDA EM UMA CASCA CILÍNDRICA FINA}

A equação do movimento em uma geometria cilíndrica de casca fina é apresentada em Junger \& Feit (1986), Kraus (1967), Blevins (1995), Feng (1994), Amabili (1996) e Ming et al. (2000). Esta equação tem como base a equação de equilíbrio simplificada descrita por L. H. Donnell em 1935 e reapresentada em Batdorf (1947) e Timoshenko \& Krieger (1985).

\subsection{Equação de equilíbrio para a casca cilíndrica}

Considere uma casca cilíndrica, composta de material elástico, homogêneo e isotrópico, de raio médio a e espessura constante $h$, sendo a espessura pequena comparada ao raio. Considere também, que os deslocamentos são pequenos comparados com a espessura, e que as linhas retas perpendiculares à superfície média da parede da casca cilíndrica permaneçam retas e perpendiculares à superfície média. Assume-se que somente cargas externas atuam normalmente à superfície cilíndrica da casca a qual é representada por $p_{a}(\theta, x)$. Deseja-se estabelecer as equações do equilíbrio em função dos deslocamentos $u, v$ e $w$. Sendo $u$ na direção axial, $v$ na direção circunferencial da casca e $w$ normal à superfície da casca cilíndrica. Para isto, em algum ponto da superfície média da casca é retirado um elemento de área, conforme mostra a FIG.4.1, o qual acompanha a curvatura da casca. Neste mesmo ponto são referenciados três eixos cartesianos $x, y$ e $z$, os quais antes da deformação da superfície possuíam a direção axial, a direção da tangente à circunferência e a direção normal à superfície média da casca cilíndrica, respectivamente. Após a deformação, a qual é assumida ser pequena, estas direções são ligeiramente mudadas, de tal modo que $y$ acompanha a curvatura da casca, $x$ pode tornar-se curvada em função das deformações e $z$ mantém-se normal à superfície média deformada. 


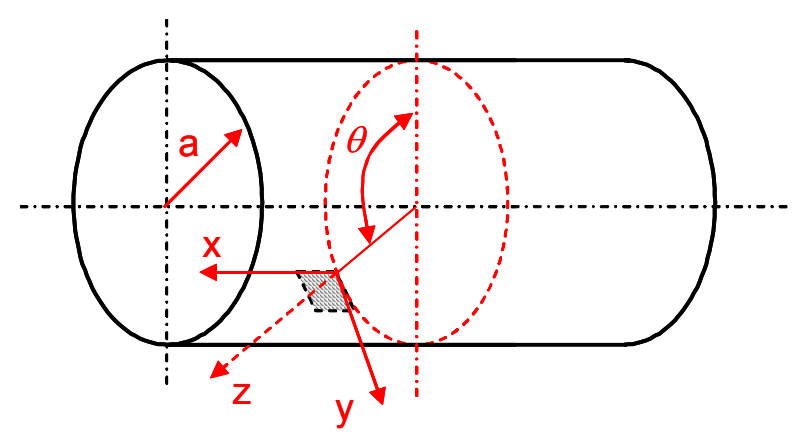

FIGURA 4.1 - Superfície cilíndrica.

Na FIG. 4.2 observam-se as forças resultantes, as quais possuem as direções ligeiramente mudadas em função das curvaturas, e os momentos resultantes, conforme descritos por Love (1927) e Timoshenko \& Krieger (1985).
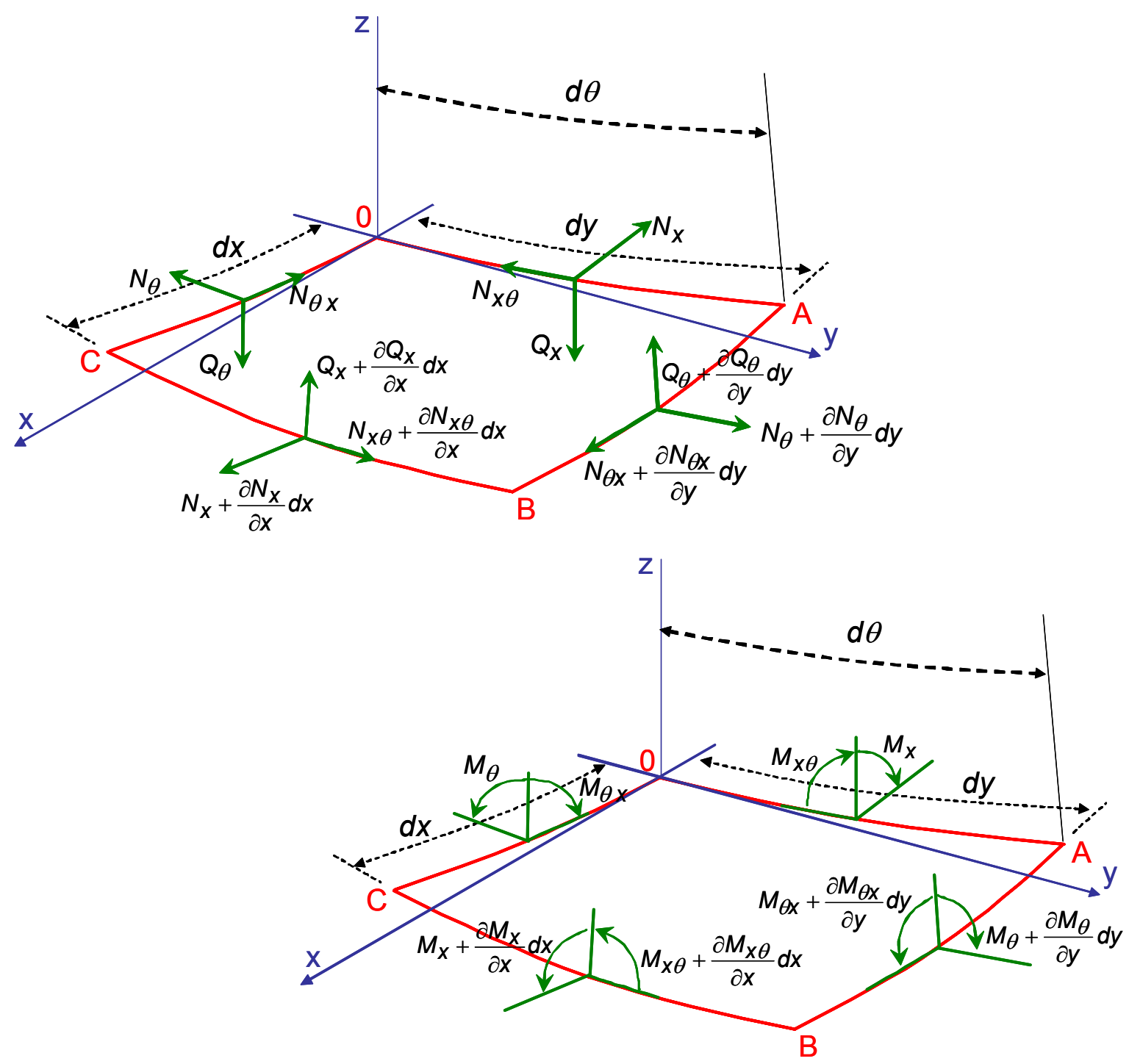

FIGURA 4.2 - Detalhe do elemento de área retirado da superfície cilíndrica. 
Sendo: $\quad N_{x} \quad$ força normal na direção $x$

$N_{\theta} \quad$ força normal na direção $\theta$

$N_{x \theta} \quad$ força cisalhante na direção $\theta$ e perpendicular $a x$

$N_{\theta x} \quad$ força cisalhante na direção $x$ e perpendicular a $\theta$

$Q_{x} \quad$ força cisalhante paralela a $z$ e perpendicular $a x$

$Q_{\theta} \quad$ força cisalhante paralela a $z$ e perpendicular a $\theta$

$M_{x} \quad$ momento perpendicular a $\mathrm{x}$

$M_{\theta} \quad$ momento perpendicular a $\theta$

$M_{x \theta} \quad$ momento de torção em $\theta$ e perpendicular $a \mathrm{x}$

$M_{\theta x} \quad$ momento de torção em $\mathrm{x}$ e perpendicular a $\theta$

Considerando os deslocamentos $u, v$ e $w$ muito pequenos e calculando o movimento angular produzido por cada um destes deslocamentos, obtêm-se os deslocamentos angulares relativos dos lados $B C$ e $A B$ com referência aos lados $\mathrm{AO}$ e $\mathrm{OC}$ do elemento da FIG. 4.2 sobre os eixos $x, y$ e $z$. Conhecendo-se assim os ângulos, podem-se obter as seis equações do equilíbrio para o elemento $0 A B C$ pelas projeções das forças e dos momentos sobre os eixos $x, y$ e $z$, Timoshenko \& Krieger (1985). Considerando a existência de forças externas atuando sobre o elemento, na forma da pressão normal de intensidade $p_{a}$, as projeções destas forças sobre os eixos $x$ e y são nulas, só existindo assim, forças na direção $z$. As expressões da equação (4.1) mostram as resultantes de todas as projeções das forças somadas para as três direções e as expressões da equação (4.2) mostram as projeções dos momentos somados.

$$
\begin{gathered}
a \frac{\partial N_{x}}{\partial x}+\frac{\partial N_{\theta x}}{\partial \theta}+a Q_{x} \frac{\partial^{2} w}{\partial x^{2}}-a N_{x \theta} \frac{\partial^{2} v}{\partial x^{2}}+Q_{\theta}\left(\frac{\partial v}{\partial x}+\frac{\partial^{2} w}{\partial x \partial \theta}\right)-N_{\theta}\left(\frac{\partial^{2} v}{\partial x \partial \theta}-\frac{\partial w}{\partial x}\right)=0 \\
\begin{array}{c}
\frac{\partial N_{\theta}}{\partial \theta}+a \frac{\partial N_{x} \theta}{\partial x}+a N_{x} \frac{\partial^{2} v}{\partial x^{2}}+Q_{x}\left(\frac{\partial v}{\partial x}+\frac{\partial^{2} w}{\partial x \partial \theta}\right)+N_{\theta x}\left(\frac{\partial^{2} v}{\partial x \partial \theta}-\frac{\partial w}{\partial x}\right) \\
+Q_{\theta}\left(1+\frac{\partial v}{a \partial \theta}+\frac{\partial^{2} w}{a \partial \theta^{2}}\right)=0 \\
-a \frac{\partial Q_{x}}{\partial x}-\frac{\partial Q_{\theta}}{\partial \theta}+N_{x \theta}\left(\frac{\partial v}{\partial x}+\frac{\partial^{2} w}{\partial x \partial \theta}\right)+a N_{x} \frac{\partial^{2} w}{\partial x^{2}}+N_{\theta}\left(1+\frac{\partial v}{a \partial \theta}+\frac{\partial^{2} w}{a \partial \theta^{2}}\right) \\
+N_{\theta x}\left(\frac{\partial v}{\partial x}+\frac{\partial^{2} w}{\partial x \partial \theta}\right)-a p_{a}=0
\end{array}
\end{gathered}
$$




$$
\begin{gathered}
a \frac{\partial M_{x \theta}}{\partial x}-\frac{\partial M_{\theta}}{\partial \theta}-a M_{x} \frac{\partial^{2} v}{\partial x^{2}}-M_{\theta x}\left(\frac{\partial^{2} v}{\partial x \partial \theta}-\frac{\partial w}{\partial x}\right)-a Q_{\theta}=0 \\
\frac{\partial M_{\theta x}}{\partial \theta}+a \frac{\partial M_{x}}{\partial x}+a M_{x} \frac{\partial^{2} v}{\partial x^{2}}-M_{\theta}\left(\frac{\partial^{2} v}{\partial x \partial \theta}-\frac{\partial w}{\partial x}\right)+a Q_{x}=0 \\
M_{x}\left(\frac{\partial v}{\partial x}+\frac{\partial^{2} w}{\partial x \partial \theta}\right)+a M_{x \theta} \frac{\partial^{2} w}{\partial x^{2}}+M_{\theta x}\left(1+\frac{\partial v}{a \partial \theta}+\frac{\partial^{2} w}{a \partial \theta^{2}}\right) \\
-M_{\theta}\left(\frac{\partial v}{\partial x}+\frac{\partial^{2} w}{\partial x \partial \theta}\right)+a\left(N_{x \theta}-N_{\theta x}\right)=0
\end{gathered}
$$

Através da substituição das duas primeiras expressões da equação (4.2) nas três expressões da equação (4.1) eliminam-se as forças de cisalhamento $Q_{x}$ e $Q_{\theta}$, obtendo-se assim as três expressões da equação do equilíbrio em função das forças e dos momentos:

$$
\begin{aligned}
& a \frac{\partial N_{x}}{\partial x}+\frac{\partial N_{\theta x}}{\partial \theta}=0 \\
& \frac{\partial N_{\theta}}{\partial \theta}+a \frac{\partial N_{x \theta}}{\partial x}+\frac{\partial M_{x} \theta}{\partial x}-\frac{1}{a} \frac{\partial M_{\theta}}{\partial \theta}=0 \\
& N_{\theta}+\frac{\partial^{2} M_{\theta x}}{\partial x \partial \theta}+a \frac{\partial^{2} M_{x}}{\partial x^{2}}-\frac{\partial^{2} M_{x} \theta}{\partial x \partial \theta}+\frac{1}{a} \frac{\partial^{2} M_{\theta}}{\partial \theta^{2}}+a p_{a}=0
\end{aligned}
$$

De Love (1927), e Timoshenko \& Krieger (1985) obtém-se as deformações $\varepsilon_{x}, \varepsilon_{\theta}$, a deformação de cisalhamento $\varepsilon_{x \theta}$ e as mudanças de curvatura $\chi_{x}, \chi_{\theta}$ e $\chi_{x \theta}$, sendo que, esta última representa a torção da casca cilíndrica.

$$
\begin{aligned}
& \varepsilon_{x}=\frac{\partial u}{\partial x}, \quad \varepsilon_{\theta}=\frac{\partial v}{a \partial \theta}+\frac{w}{a}, \quad \varepsilon_{x \theta}=\frac{\partial u}{a \partial \theta}+\frac{\partial v}{\partial x} \\
& \chi_{x}=\frac{\partial^{2} w}{\partial x^{2}}, \quad \chi_{\theta}=\frac{1}{a^{2}}\left(\frac{\partial v}{\partial \theta}+\frac{\partial^{2} w}{\partial \theta^{2}}\right), \quad \chi_{x \theta}=\frac{1}{a}\left(\frac{\partial v}{\partial x}+\frac{\partial^{2} w}{\partial x \partial \theta}\right) .
\end{aligned}
$$

Pelo relacionamento entre deformação e tensão, dada pela lei de Hooke e Poisson, pode-se expressar as forças e os momentos em função de $\varepsilon_{\chi}$, 
$\varepsilon_{\theta}$ e $\varepsilon_{x \theta}$ como mostram as expressões da equação (4.5), Donnell (1935) e Timoshenko \& Krieger (1985):

$$
\begin{gathered}
N_{x}=\frac{E h}{1-v^{2}}\left(\varepsilon_{x}+v \varepsilon_{\theta}\right), \quad N_{\theta}=\frac{E h}{1-v^{2}}\left(\varepsilon_{\theta}+v \varepsilon_{x}\right), \quad N_{x \theta}=N_{\theta x}=\frac{E h}{2(1+v)} \varepsilon_{x \theta} \\
M_{x}=\frac{E h^{3}}{12\left(1-v^{2}\right)}\left(\chi_{x}+v \chi_{\theta}\right), \quad M_{\theta}=\frac{E h^{3}}{12\left(1-v^{2}\right)}\left(\chi_{\theta}+v \chi_{x}\right) \\
M_{\theta x}=-M_{x \theta}=\frac{E h^{3}}{12\left(1-v^{2}\right)}(1-v) \chi_{x \theta} .
\end{gathered}
$$

Substituindo as expressões das equações (4.4) e (4.5) nas da equação (4.3), procedendo as simplificações e desconsiderando o alongamento da superfície média da casca, Timoshenko \& Krieger (1985), resulta na equação do equilíbrio para uma casca fina cilíndrica em função dos deslocamentos $u, v$ e $w$ em coordenadas cilíndricas:

$$
\begin{aligned}
& \frac{\partial^{2} u}{\partial x^{2}}+\frac{1-v}{2 a^{2}} \frac{\partial^{2} u}{\partial \theta^{2}}+\frac{1+v}{2 a} \frac{\partial^{2} v}{\partial x \partial \theta}+\frac{v}{a} \frac{\partial w}{\partial x}=0, \\
& \frac{1+v}{2} \frac{\partial^{2} u}{\partial x \partial \theta}+a \frac{1-v}{2} \frac{\partial^{2} v}{\partial x^{2}}+\frac{1}{a} \frac{\partial^{2} v}{\partial \theta^{2}}+\frac{1}{a} \frac{\partial w}{\partial \theta}=0, \\
& v \frac{\partial u}{\partial x}+\frac{1}{a} \frac{\partial v}{\partial \theta}+\frac{w}{a}+\frac{h^{2}}{12}\left(a \frac{\partial^{4} w}{\partial x^{4}}+\frac{2}{a} \frac{\partial^{4} w}{\partial x^{2} \partial \theta^{2}}+\frac{1}{a^{3}} \frac{\partial^{4} w}{\partial \theta^{4}}\right)-\frac{a p_{a}\left(1-v^{2}\right)}{E h}=0 .
\end{aligned}
$$

\subsection{Equação de movimento para a casca cilíndrica}

Adicionando-se a força de inércia nas expressões da equação de forças (4.1), pela segunda lei de Newton, sendo $\rho$ a densidade do material, desprezando as deformações causadas pelas forças gravitacionais e procedendo a um desenvolvimento análogo ao realizado para a equação do equilíbrio, obtêmse a equação para o movimento para a casca cilíndrica nas três direções descrita em (4.7), Junger \& Feit (1986) e Kraus (1967). 


$$
\begin{aligned}
& \frac{\partial^{2} u}{\partial x^{2}}+\frac{(1-v)}{2 a^{2}} \frac{\partial^{2} u}{\partial \theta^{2}}+\frac{(1+v)}{2 a} \frac{\partial^{2} v}{\partial x \partial \theta}+\frac{v}{a} \frac{\partial w}{\partial x}-\frac{1}{c_{p}^{2}} \frac{\partial^{2} u}{\partial t^{2}}=0 \\
& \frac{(1+v)}{2 a} \frac{\partial^{2} u}{\partial x \partial \theta}+\frac{(1-v)}{2} \frac{\partial^{2} v}{\partial x^{2}}+\frac{1}{a^{2}} \frac{\partial^{2} v}{\partial \theta^{2}}+\frac{1}{a^{2}} \frac{\partial w}{\partial \theta}-\frac{1}{c_{p}^{2}} \frac{\partial^{2} v}{\partial t^{2}}=0 \\
& \frac{v}{a} \frac{\partial u}{\partial x}+\frac{1}{a^{2}} \frac{\partial v}{\partial \theta}+\frac{w}{a^{2}}+\beta^{2}\left(a^{2} \frac{\partial^{4} w}{\partial x^{4}}+2 \frac{\partial^{4} w}{\partial x^{2} \partial \theta^{2}}+\frac{1}{a^{2}} \frac{\partial^{4} w}{\partial \theta^{4}}\right) \\
& \quad+\frac{1}{c_{p}^{2}} \frac{\partial^{2} w}{\partial t^{2}}-\frac{p_{a}\left(1-v^{2}\right)}{E h}=0
\end{aligned}
$$

$\beta$ é o parâmetro de espessura da casca, definido pela relação entre a espessura $h$ e o raio médio a, dado pela equação a seguir:

$$
\beta^{2}=\frac{h^{2}}{12 a^{2}}
$$

A velocidade de propagação da onda longitudinal plana em uma placa fina, $c_{p}$, é definida em Junger \& Feit (1986), Feng (1994), Fuller (1982 e 1983) e Kolsky (1963) como:

$$
c_{p}=\sqrt{\frac{E}{\left(1-v^{2}\right) \rho}}=\sqrt{\frac{4 \mu(\lambda+\mu)}{(\lambda+2 \mu) \rho}} .
$$

A equação (4.7) é definida como equação de Donnell para o movimento de uma casca cilíndrica, sendo apresentada na sua forma final em Junger \& Feit (1986), Kraus (1967) e Amabili (1996) e citadas em Fuller (1982 e 1983) e Blevins (1995), ou apresentadas como equações de Flügger simplificadas em Feng (1994) e Xu (1998, 1999 e 2000).

Esta equação é válida para cascas de paredes finas com pequenos deslocamentos e excluem os efeitos da energia cinética de rotação e cisalhamento transversal, Fuller (1982). Ou de outra forma, são considerados desprezíveis, Kraus (1967) e Junger \& Feit (1986). 


\subsection{Considerações sobre vibrações acústicas provocadas por jatos}

Em alta pressão, um vazamento através de uma fratura na parede de um tubo gera vibrações na parede deste tubo com uma larga faixa de freqüências, Loth (2004).

Segundo Blake (1986), conforme é aumentada a velocidade do gás por um bocal na forma de fenda, a tendência para geração de tom de borda fica menos aparente, de forma que tons só podem ser gerados sob situações relativamente controladas. Conseqüentemente, as emissões acústicas são de natureza menos intensa e faixa larga. Quando a velocidade do gás no bocal fica sônica, ou seja, na pressão crítica ou acima, as características de ruído e a estrutura do jato mudam notadamente. Superimposto ao som de faixa larga está um tom acústico que é associado com a existência de um padrão celular estável com zonas de expansão e compressão ao longo do eixo do jato. Uma fotografia deste tipo de padrão induzido em um jato bidimensional é mostrada na FIG. 4.3.

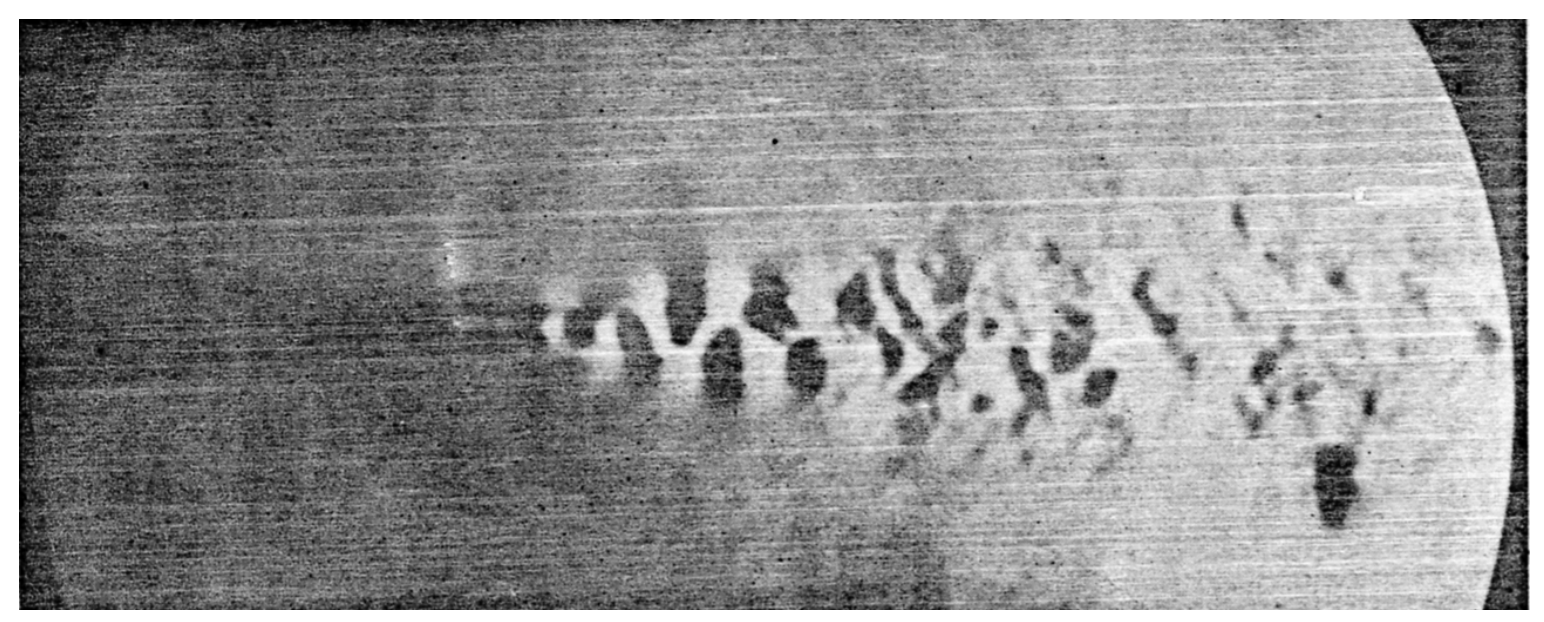

FIGURA 4.3 - Fotografia Schlieren de jato blocado e propagação das ondas de som, Blake (1986).

No caso blocado, as fontes sonoras são estacionárias com referência à saída de jato, e a fonte de oscilação surge da passagem de estruturas regulares de vórtices pelas células. Conseqüentemente, os tons mais fortes são gerados quando as fases das pressões individuais emitidas de cada célula são tais que as contribuições reforçam-se umas às outras na saída do bocal. Estas realimentações de pressões impulsionam a camada de cisalhamento do jato produzindo as perturbações aerodinâmicas as quais "pulsam" as células de choque. As ondas de som emitidas são claramente visíveis como padrões 
semicirculares de claro e escuro na fotografia da FIG. 4.3 para o jato de fenda, Blake (1986).

Próximo do bocal, a força da fonte será relativamente pequena, pois as instabilidades do jato ainda estão crescendo. Algumas células à frente a força diminuirá por causa da geração de desordem e perda de correlação induzida pela turbulência. As fontes acústicas mais dominantes encerram-se entre estes extremos.

Para a condição de jatos bidimensionais, gerados pela passagem do gás em uma fenda, a freqüência do som gerado é dada pela equação (4.10), sendo $f s$ a freqüência do som em $\mathrm{Hz}, R c$ é a relação de pressão crítica $(R c=1,89$ para o ar), dado pela equação (4.12), Fox \& McDonald (1981) e Vennard \& Street (1978), $R_{g}$ é a relação entre a pressão de estagnação interna e a pressão ambiente externa, $c_{o}$ é a velocidade do som no meio, dada pela equação (4.13), Sonntag (1998) e $h$ é a altura da fenda.

$$
f_{S}=\frac{c_{0.0,2}}{h \sqrt{R_{g}-R_{C}}}
$$

A freqüência do som, para a condição de jatos gerados pela passagem do gás em um orifício, é dada pela equação (4.11), sendo $D$ o diâmetro do furo.

$$
\begin{gathered}
f_{S}=\frac{c_{0.0,33}}{D \sqrt{R_{g}-R_{C}}}, \\
R_{C}=\left[1+\frac{k-1}{2}\right]^{k / k-1},
\end{gathered}
$$

sendo k a constante adiabática dada pelo quociente das capacidades caloríficas a pressão e a volume constantes.

$$
c_{O}=\sqrt{k R T}
$$

sendo $R$ a constante do gás dada em $\mathrm{KJ} /\left(\mathrm{Kg}^{\circ} \mathrm{K}\right)$ ou $10^{3} \mathrm{~m}^{2} /\left(\mathrm{s}^{2}{ }^{\circ} \mathrm{K}\right)$.

Uma vez estabelecido um vazamento, o jato supersônico do escape do gás gera energia acústica. Estas emissões acústicas são contínuas e têm um espectro de freqüência de faixa larga entre $1 \mathrm{kHz}$ e $1 \mathrm{MkHz}$, a maioria do qual é 
confinado na porção de freqüência moderadamente alta entre 175 kHz e 750 kHz, Loth (2004).

Na FIG. 4.4 são apresentadas as curvas das freqüências dos tons gerados por um escape de gás blocado, em um orifício circular em função do diâmetro, para várias pressões acima da pressão crítica, considerando a pressão externa como sendo $1 \mathrm{~atm}$. A velocidade do som no ar é adotada como sendo $c_{0}=340 \mathrm{~m} / \mathrm{s}$.

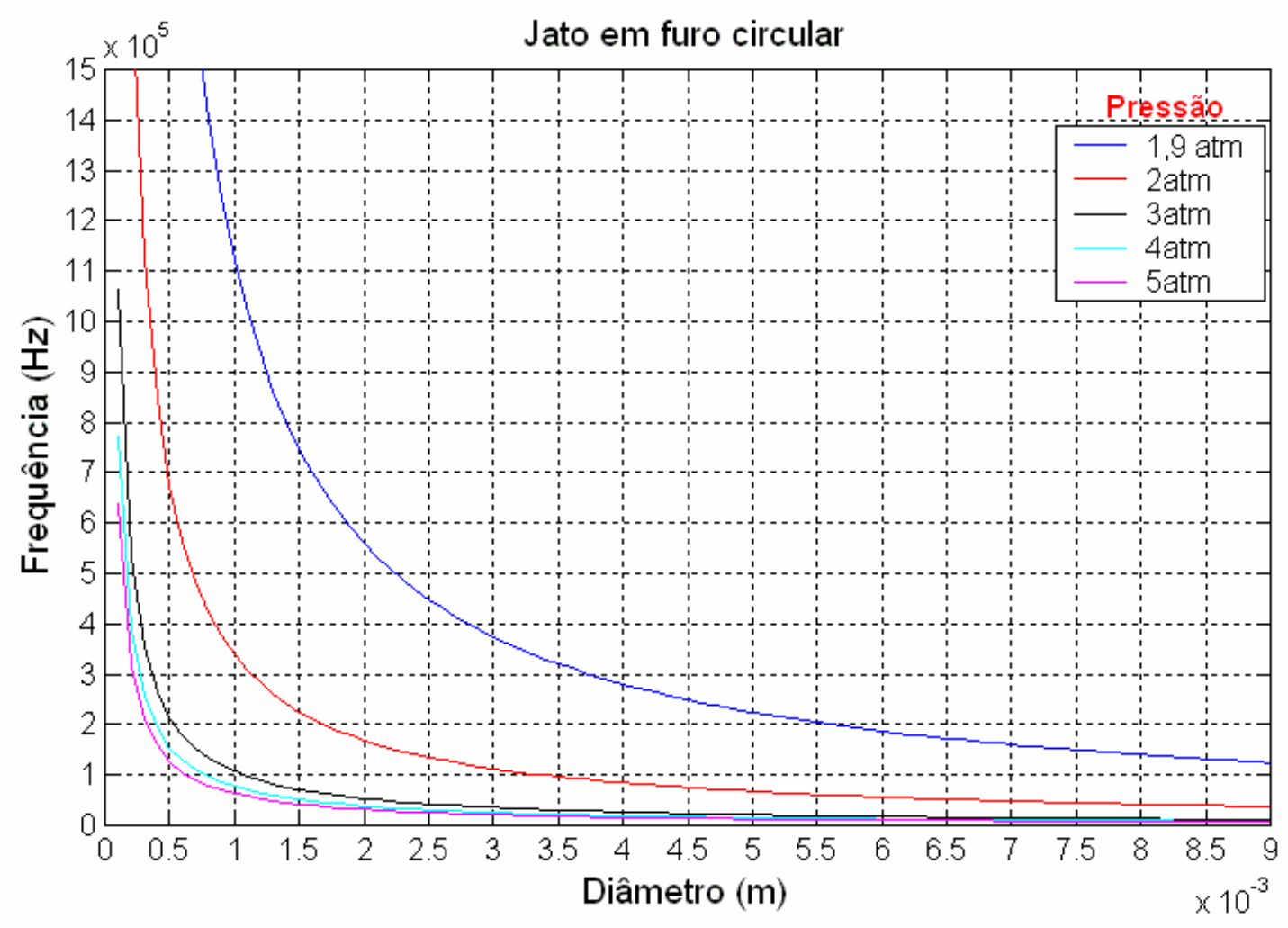

FIGURA 4.4 - Freqüência em função do diâmetro para várias pressões.

Tomando a FIG. 4.4 conclui-se que:

- Para uma pressão constante, a freqüência diminui com o aumento do diâmetro do furo. Nesta condição, por exemplo 3 atm, observa-se que a freqüência varia rapidamente para a faixa de furos de pequenos diâmetros, variando mais lentamente para a faixa de furos de grandes diâmetros. Observa-se também que esta estabilidade na variação da freqüência torna-se mais rápida para pressões elevadas.

- Para um diâmetro de furo constante, a freqüência diminui com o aumento da pressão, a qual cai rapidamente para pressões logo 
acima da blocagem, caindo mais lentamente para pressões mais altas. Exemplo: considerando o diâmetro de $1 \mathrm{~mm}$, observa-se que a variação da freqüência entre as pressões de 1,9 atm e 2 atm é muito mais acentuada que as variações de freqüências entre as pressões de $3 \mathrm{~atm}, 4 \mathrm{~atm}$ e $5 \mathrm{~atm}$.

- Para as pressões e os diâmetros considerados na confecção deste gráfico, as freqüências variaram de valores acima do $\mathrm{MHz}$ até a faixa de $10 \mathrm{KHz}$.

A título de exemplo, na FIG. 4.5 são apresentadas as curvas de freqüência em função do diâmetro do furo para diferentes gases em diferentes pressões e temperaturas de trabalho.

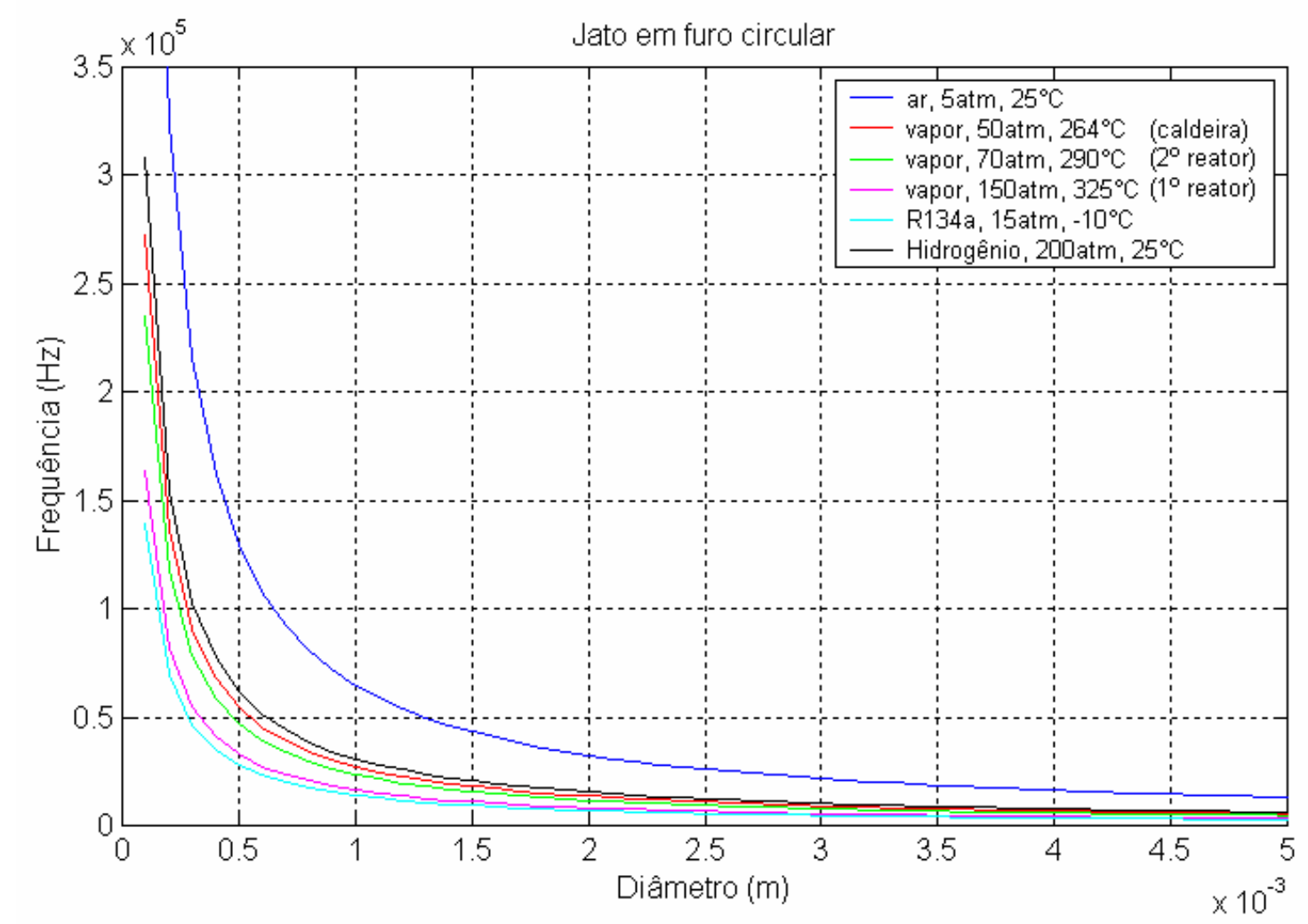

FIGURA 4.5 - Freqüência em função do diâmetro para diferentes gases em diferentes pressões e temperaturas.

Para pressões abaixo da crítica, o jato é não blocado, neste caso segundo Blake (1986) a freqüência da onda no jato é dada pela relação: 


$$
f=\frac{S_{D} U_{J}}{D}
$$

sendo, $D$ o diâmetro do furo; $S_{D}$ o número de Strouhal; $U_{J}$ a velocidade do jato no bocal e $f$ a freqüência no jato.

Segundo Blake (1986), o número de Strouhal para orifícios com bordas retangulares, varia geralmente entre 0,4 e 1,0.

Enquanto o fluxo possuir números de Reynolds com valores abaixo do valor crítico, o fluxo do jato é laminar. A geração de vórtices no jato ocorre somente para números de Reynolds acima do valor crítico. As perturbações que acontecem nos jatos são dependentes do tipo do bocal usado e da velocidade média da emanação no bocal. No caso de um furo com borda retangular, FIG. 4.6a o Reynolds crítico é 600 e para um furo com borda afiada tipo faca, FIG. 4.6b o Reynolds crítico é 500, Blake (1986).

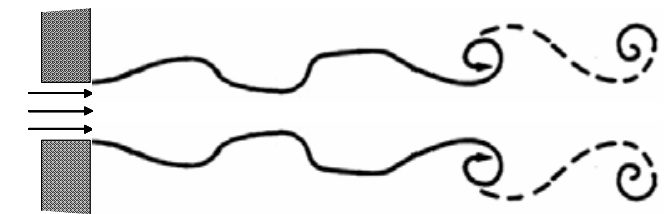

a)

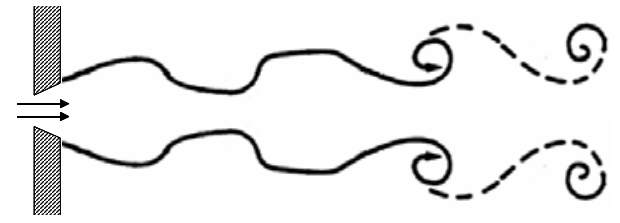

b)

FIGURA 4.6 - Esboço de bordas: a) retangular; b) afiada, tipo faca.

A relação entre o número de Reynolds com a velocidade no jato, o diâmetro e a viscosidade do fluído é dada pela equação abaixo:

$$
\Re=\frac{U_{J} D}{v},
$$

sendo, $\mathfrak{R}$ o número de Reynolds; v a viscosidade do fluído.

Na FIG. 4.7, é apresentada a título de exemplo, a variação da freqüência com a viscosidade para um furo constante de diâmetro $D=1 \mathrm{~mm}$, supondo um $S_{D}=0,7$ e um Reynolds $\Re=650$. Nestas condições a velocidade $U_{J}$ variou de $0,065 \mathrm{~m} / \mathrm{s}$ até $65 \mathrm{~m} / \mathrm{s}$, muito abaixo da velocidade $c_{o}$ do caso blocado. 


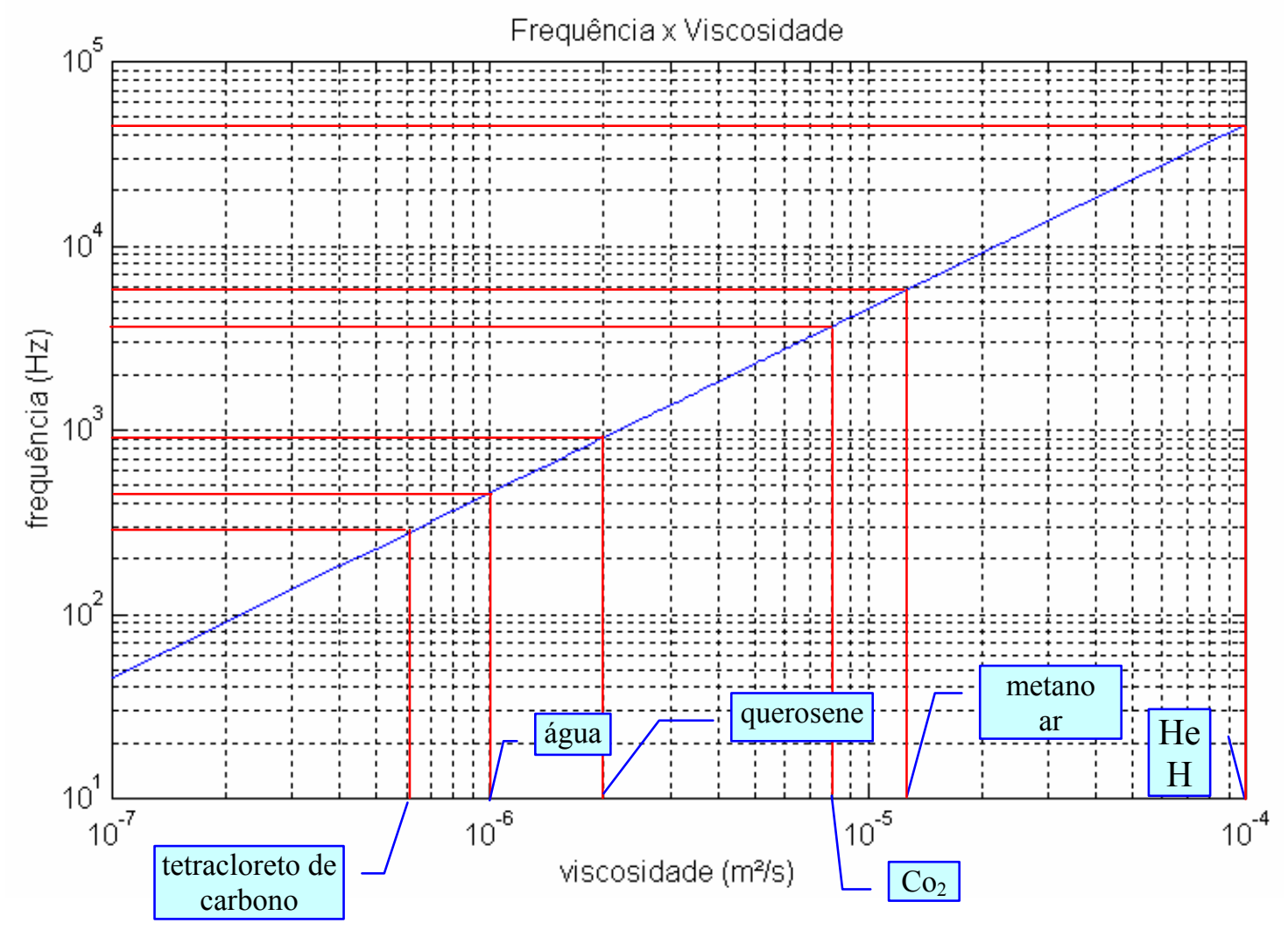

FIGURA 4.7 - Variação da freqüência com a viscosidade para jato não blocado.

Nos capítulos seguintes serão apresentadas as soluções para as equações de movimento da casca cilíndrica em geometrias e condições de contornos tais, que permitam uma melhor compreensão do comportamento das ondas nas condições do problema proposto. 


\section{SOLUÇÃO ANALÍTICA DA EQUAÇÃO DE MOVIMENTO EM CILINDRO DE CASCA FINA}

Segundo Fuller (1983), um sistema real de tubos compõe-se da combinação de forças de vibração, momentos da tubulação e descontinuidades, as quais podem ser na forma de curvas, mudanças de espessura ou restrições aplicadas às paredes pelas fixações e suportes.

Neste capítulo são descritos os movimentos harmônicos para uma casca cilíndrica infinita envolvida por vácuo, constituída de material elástico, homogêneo e isotrópico. O objetivo aqui é encontrar a solução analítica para a equação do movimento (4.7), obtendo assim um modelo teórico para o tubo cilíndrico quando uma força de excitação harmônica externa e pontual atua na sua superfície na direção radial. Um segundo objetivo é entender o comportamento dos deslocamentos da superfície deste tubo cilíndrico tanto no tempo como no espaço em função desta excitação.

\subsection{Solução analítica para a obtenção do modelo matemático}

Como já mencionado, considere o tubo como uma casca cilíndrica infinita constituída de material elástico, homogêneo e isotrópico, sem fluído em seu interior, referenciada pelo sistema de coordenadas cilíndricas $(x, \theta, r)$, descrito pela FIG. 5.1, onde $x$ é alinhado com a direção axial da casca, $\theta$ mede o ângulo na direção circunferencial, $r$ é dirigido para fora ao longo da direção radial, a é o raio médio da casca e $h$ é a espessura da sua parede, sendo a espessura pequena comparada ao raio, caracterizando uma casca fina, e constante ao longo do tubo. Os valores $u, v$ e $w$ representam as componentes de deslocamento da superfície média da casca nas direções axial, circunferencial e radial, respectivamente. 


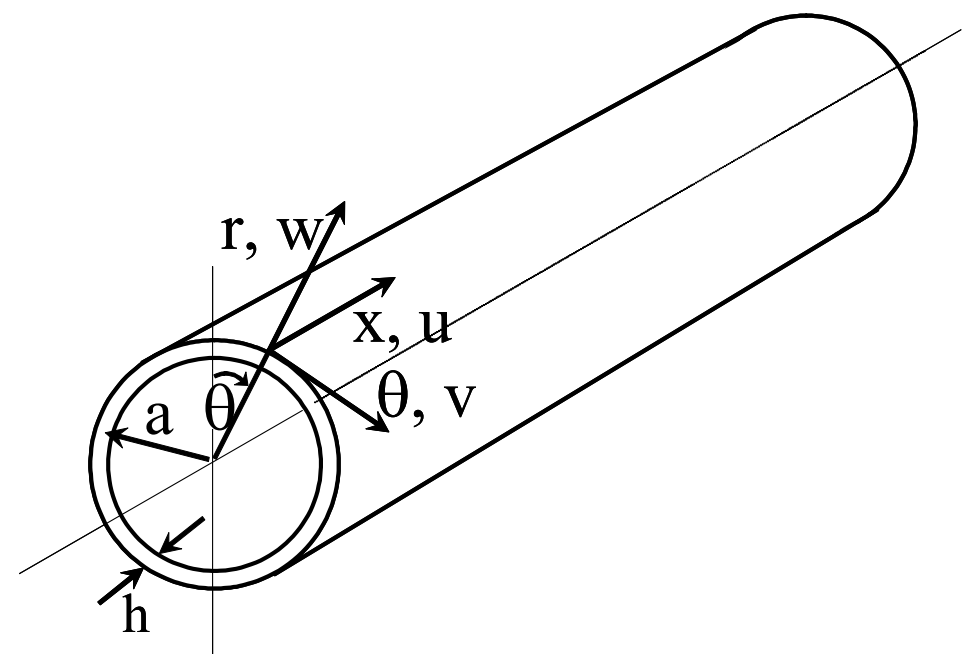

FIGURA 5.1 - Sistema de coordenadas na casca cilíndrica.

As componentes de deslocamento da onda que se propaga em uma casca cilíndrica fina, as quais são soluções das equações (4.7) para as condições apresentadas, pode ser expressa na forma de uma série harmônica, como mostram as equações (5.1), (5.2) e (5.3), de acordo com Fuller (1982, 1983), Xu et al. (1998, 1999), Feng (1994) e Ming et al. (2000).

$$
\begin{aligned}
& u=\sum_{s=0}^{\infty} \sum_{n=0}^{\infty} U_{n s} \cos (n \theta) e^{i k_{n s} x} e^{i \omega t} e^{i \pi / 2} \\
& v=\sum_{s=0}^{\infty} \sum_{n=0}^{\infty} v_{n s} \operatorname{sen}(n \theta) e^{i k_{n s} x} e^{i \omega t} e^{-i \pi / 2} \\
& w=\sum_{s=0}^{\infty} \sum_{n=0}^{\infty} W_{n s} \cos (n \theta) e^{i k_{n s} x} e^{i \omega t}
\end{aligned}
$$

Nas equações acima, $\omega$ é a freqüência angular em radiano por segundo, $n$ é o número modal circunferencial, o qual pode ser visto na FIG. 5.2, $k_{n s}$ é o número de onda axial e o subscrito $s$ corresponde às soluções dos números de ondas axiais.

Para $n=0$, modo respiração (breathing mode), a componente tangencial de deslocamento é zero, Ming et al. (2000), o que justifica a presença do termo $\operatorname{sen}(n \theta)$ na direção do deslocamento v, equação (5.2).

As equações (5.1), (5.2) e (5.3) representam uma onda progressiva que se propaga na direção helicoidal sobre a superfície da casca cilíndrica, onde os termos $e^{i \pi / 2}$ e $e^{-i \pi / 2}$ das equações (5.1), (5.2) são incluídos para compensar 
os desvios de fase entre os deslocamentos paralelos e o normal à superfície da casca, Smith (1955).

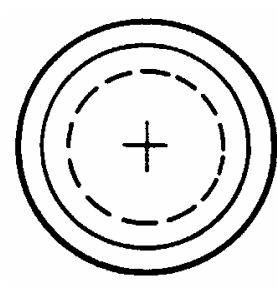

$\mathrm{n}=0$

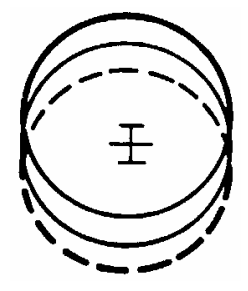

$n=1$

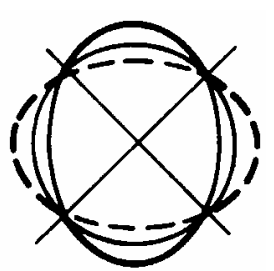

$\mathrm{n}=2$

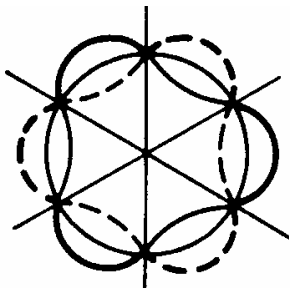

$\mathrm{n}=3$

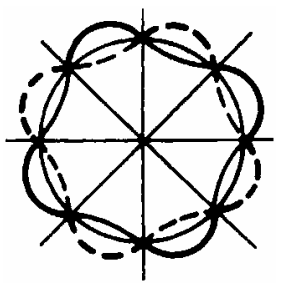

$n=4$

FIGURA 5.2 - Padrões modais circunferenciais da casca cilíndrica.

Como excitação pontual, será considerada uma força harmônica de amplitude $F_{0}$ aplicada nas posições $x=0 \mathrm{~m} \mathrm{e} \theta=0^{\circ}$ do tipo:

$$
P_{a}(t)=F_{0} \delta(x) \delta(\theta) e^{i \omega t}
$$

conforme descrito na seção 4.3.

Em função da presença dos Dirac em $x=0 \mathrm{~m}$ e $\theta=0^{\circ}$, é conveniente expressar os deslocamentos e a força aplicada em função das transformadas de Fourier. Em função disto, aplica-se à dupla transformada de Fourier, nos domínios de $x$ e $\theta$, para as equações (5.1) até (5.4), antes da realização das derivadas parciais necessárias para a solução da equação (4.7). Deste modo obtém-se:

$$
\begin{gathered}
\bar{u}=\left(\frac{1}{\sqrt{2 \pi}}\right)^{2} \int_{-\infty}^{\infty} \int_{-\infty}^{\infty} \sum_{n=0}^{\infty} \sum_{s=0}^{\infty} U_{n s} \cos (n \theta) e^{i k_{n s} x} e^{i \omega t} e^{i \pi / 2} e^{-i k_{n s} x} e^{-i n \theta} d x d \theta, \\
=\bar{u}=\sum_{n=0}^{\infty} \sum_{s=0}^{\infty} \overline{\overline{U_{n s}}} e^{i \omega t} e^{i \pi / 2} .
\end{gathered}
$$

sendo $\overline{\overline{U_{n s}}}$ a parte transformada da função (5.5) dependente de x e $\theta$.

Aplicando-se agora a dupla transformada de Fourier inversa, obtém-se:

$$
u=\left(\frac{1}{\sqrt{2 \pi}}\right)^{2} \int_{-\infty}^{\infty} \int_{-\infty}^{\infty} \sum_{n=0}^{\infty} \sum_{s=0}^{\infty} \overline{\overline{U_{n s}}} e^{i \omega t} e^{i \pi / 2} e^{i k_{n s} x} e^{i n \theta} d k_{n s} d n
$$


De forma análoga, obtém-se $\mathrm{v}, \mathrm{w}$ e $p_{a}$ em função de suas duplas transformadas de Fourier.

$$
\begin{gathered}
\bar{v}=\sum_{n=0}^{\infty} \sum_{s=0}^{\infty} \overline{\overline{V_{n s}}} e^{i \omega t} e^{-i \pi / 2}, \\
v=\left(\frac{1}{\sqrt{2 \pi}}\right)^{2} \int_{-\infty}^{\infty} \int_{-\infty}^{\infty} \sum_{n=0}^{\infty} \sum_{s=0}^{\infty} \overline{\overline{V_{n s}}} e^{i \omega t} e^{-i \pi / 2} e^{i k_{n s} x} e^{i n \theta} d k_{n s} d n, \\
\overline{\bar{w}}=\sum_{n=0}^{\infty} \sum_{s=0}^{\infty} \overline{\overline{W_{n s}}} e^{i \omega t}, \\
p_{a}=\left(\frac{1}{\sqrt{2 \pi}}\right)^{2} \int_{-\infty}^{\infty} \int_{-\infty}^{\infty} \sum_{n=0}^{\infty} \sum_{-\infty}^{\infty} \sum_{s=0}^{\infty} \overline{\overline{W_{n s}}} e^{i \omega t} e^{i k_{n s} x} e^{i n \theta} d k_{n s} d n, \\
\sum_{n=0}^{\infty} \sum_{s=0}^{\infty} \frac{F_{0}}{2 \pi} e^{i \omega t} e^{i k_{n s} x} e^{i n \theta} d k_{n s} d n .
\end{gathered}
$$

Desenvolvendo-se as derivadas parciais das equações (5.7), (5.9) e (5.11), e aplicando estas derivadas na primeira expressão da equação do movimento (4.7), obtém-se:

$$
\begin{aligned}
& \frac{1}{2 \pi} \int_{-\infty}^{\infty} \int_{-\infty}^{\infty} \sum_{n=0}^{\infty} \sum_{s=0}^{\infty} \overline{\overline{U_{n s}}} e^{i \omega t} e^{i \pi / 2}\left(-k_{n s}^{2}\right) e^{i k_{n s} x} e^{i n \theta} d k_{n s} d n+ \\
& +\frac{1-v}{2 a^{2}} \frac{1}{2 \pi} \int_{-\infty}^{\infty} \int_{-\infty}^{\infty} \sum_{n=0}^{\infty} \sum_{s=0}^{\infty} \overline{\overline{U_{n s}}} e^{i \omega t} e^{i \pi / 2} e^{i k_{n s} x}\left(-n^{2}\right) e^{i n \theta} d k_{n s} d n+ \\
& +\frac{1+v}{2 a} \frac{1}{2 \pi} \int_{-\infty}^{\infty} \int_{-\infty}^{\infty} \sum_{n=0}^{\infty} \sum_{s=0}^{\infty} \overline{\overline{V_{n s}}} e^{i \omega t} e^{-i \pi / 2} i k_{n s} e^{i k_{n s} x} i n e^{i n \theta} d k_{n s} d n+ \\
& +\frac{v}{a} \frac{1}{2 \pi} \int_{-\infty}^{\infty} \int_{-\infty}^{\infty} \sum_{n=0}^{\infty} \sum_{s=0}^{\infty} \overline{\overline{W_{n s}}} e^{i \omega t} i k_{n s} e^{i k_{n s} x} e^{i n \theta} d k_{n s} d n+ \\
& -\frac{1}{c_{p}{ }^{2}} \frac{1}{2 \pi} \int_{-\infty}^{\infty} \int_{-\infty}^{\infty} \sum_{n=0}^{\infty} \sum_{s=0}^{\infty} \overline{\overline{U_{n s}}}\left(-\omega^{2}\right) e^{i \omega t} e^{i \pi / 2} e^{i k_{n s} x} e^{i n \theta} d k_{n s} d n=0
\end{aligned}
$$


Reorganizando:

$$
\begin{aligned}
\frac{1}{2 \pi} \int_{-\infty}^{\infty} \int_{-\infty}^{\infty} & \sum_{n=0}^{\infty} \sum_{s=0}^{\infty}\left\{\overline{\overline{U_{n s}}} e^{i \pi / 2}\left(-k_{n s}^{2}\right)+\frac{1-v}{2 a^{2}} \overline{\overline{U_{n s}}} e^{i \pi / 2}\left(-n^{2}\right)+\frac{1+v}{2 a} \overline{\overline{V_{n s}}} e^{-i \pi / 2} i k_{n s} i n+\right. \\
+ & \left.\frac{v}{a} \overline{\overline{W_{n s}}} i k_{n s}-\frac{1}{c_{p}{ }^{2}} \overline{\overline{U_{n s}}}\left(-\omega^{2}\right) e^{i \pi / 2}\right\} e^{i \omega t} e^{i k_{n s} x} e^{i n \theta} d k_{n s} d n=0
\end{aligned}
$$

Para que a equação (5.14) seja igual a zero basta fazer o termo dentro da chave igual a zero para todos os $n$ e todos os $s$. Multiplicando-o por $a^{2}$, dividindo por $i$ e rearranjando os termos obtém-se:

$$
\left(-k_{n s}^{2} a^{2}-\frac{n^{2}}{2}(1-v)+\frac{\omega^{2} a^{2}}{c_{p}{ }^{2}}\right) \overline{\overline{U_{n s}}}+\frac{(1+v)}{2} n k_{n s} a \overline{\overline{V_{n s}}}+v k_{n s} a \overline{\overline{W_{n s}}}=0
$$

Sendo a freqüência normalizada $\Omega$ definida por $\Omega=\frac{\omega a}{c_{p}}$, Fuller (1982 e 1983), Junger \& Feit (1986), Feng (1994) e Xu(1998, 1999 e 2000), na qual a velocidade $c_{p}$ é definida pela equação (4.9), tem-se:

$$
\left(-k_{n s}^{2} a^{2}-\frac{n^{2}(1-v)}{2}+\Omega^{2}\right) \overline{\overline{U_{n s}}}+\frac{(1+v)}{2} n k_{n s} a \overline{\overline{V_{n s}}}+v k_{n s} a \overline{\overline{W_{n s}}}=0
$$

Realizando um procedimento análogo para a segunda e terceira expressões da equação do movimento (4.7), não esquecendo do termo $p_{a}$ na terceira expressão, obtêm-se as outras duas expressões da solução:

$$
\begin{gathered}
-\frac{(1+v)}{2} n k_{n s} a \overline{\overline{U_{n s}}}+\left(\frac{1-v}{2} k_{n s}^{2} a^{2}+n^{2}-\Omega^{2}\right) \overline{\overline{V_{n s}}}+n \overline{\overline{W_{n s}}}=0 \\
-v k_{n s} a \overline{\overline{U_{n s}}}+n \overline{\overline{V_{n s}}}+\left(1+\beta^{2}\left(k_{n s}^{2} a^{2}+n^{2}\right)^{2}-\Omega^{2}\right) \overline{\overline{W_{n s}}}-\frac{F_{0}\left(1-v^{2}\right) a^{2}}{2 \pi E h}=0 .
\end{gathered}
$$


Reorganizando as equações (5.16), (5.17) e (5.18) na forma matricial tem-se:

$$
\left[\begin{array}{ccc}
\Omega^{2}-\frac{n^{2}(1-v)}{2}-k_{n s}^{2} a^{2} & \frac{n(1+v)}{2} k_{n s} a & v k_{n s} a \\
-\frac{n(1+v)}{2} k_{n s} a & -\Omega^{2}+n^{2}+\frac{1-v}{2} k_{n s}^{2} a^{2} & n \\
-v k_{n s} a & n & 1+\beta^{2}\left(k_{n s}^{2} a^{2}+n^{2}\right)^{2}-\Omega^{2}
\end{array}\right] \cdot\left[\begin{array}{l}
\overline{\overline{U n s}_{n s}} \\
\overline{\frac{W_{n s}}{W_{n s}}}
\end{array}\right]=\left[\begin{array}{c}
0 \\
0 \\
\frac{F_{0}\left(1-v^{2}\right) a^{2}}{2 \pi E h}
\end{array}\right]
$$

Chamando de [A] a matriz dos coeficientes em (5.19) e [I] a sua inversa, isolando-se as incógnitas chega-se a:

$$
\left[\begin{array}{c}
\overline{\overline{U_{n s}}} \\
\overline{\overline{\bar{V}_{n s}}}
\end{array}\right]=\left[\begin{array}{lll}
\mathrm{I}_{11} & \mathrm{I}_{12} & \mathrm{I}_{13} \\
\mathrm{I}_{21} & \mathrm{I}_{22} & \mathrm{I}_{23} \\
\mathrm{I}_{31} & \mathrm{I}_{32} & \mathrm{I}_{33}
\end{array}\right] \cdot\left[\begin{array}{c}
0 \\
0 \\
\frac{F_{0}\left(1-v^{2}\right) a^{2}}{2 \pi E h}
\end{array}\right]
$$

A qual é reduzida a:

$$
\left[\begin{array}{c}
\overline{\overline{U_{n s}}} \\
\overline{\overline{W_{n s}}}
\end{array}\right]=\frac{F_{0}\left(1-v^{2}\right) a^{2}}{2 \pi E h}\left[\begin{array}{l}
\mathrm{I}_{13} \\
\mathrm{I}_{23} \\
\mathrm{I}_{33}
\end{array}\right]
$$

sendo:

$$
\begin{aligned}
& \mathrm{I}_{13}=\frac{\mathrm{A}_{12} \mathrm{~A}_{23}-\mathrm{A}_{22} \mathrm{~A}_{13}}{\operatorname{Det}[\mathrm{A}]}, \\
& \mathrm{I}_{23}=\frac{\mathrm{A}_{21} \mathrm{~A}_{13}-\mathrm{A}_{11} \mathrm{~A}_{23}}{\operatorname{Det}[\mathrm{A}]}, \\
& \mathrm{I}_{33}=\frac{\mathrm{A}_{11} \mathrm{~A}_{22}-\mathrm{A}_{12} \mathrm{~A}_{21}}{\operatorname{Det}[\mathrm{A}]} .
\end{aligned}
$$

Substituindo-se $\overline{\overline{U_{n s}}}, \overline{\overline{V_{n s}}}$ e $\overline{\overline{W_{n s}}}$ da equação (5.21) nas equações (5.7), (5.9) e (5.11) e aplicando-se a dupla transformada inversa de Fourier, obtêm-se os deslocamentos nas três direções: 


$$
\left[\begin{array}{l}
u \\
v \\
w
\end{array}\right]=\frac{F_{0}\left(1-v^{2}\right) a^{2}}{2 \pi E h} e^{i \omega t} \sum_{n=0}^{\infty} \sum_{s=0}^{\infty}\left[\begin{array}{c}
\left(\frac{1}{\sqrt{2 \pi}}\right)^{2} \int_{-\infty}^{\infty} \int_{-\infty}^{\infty}\left(\mathrm{I}_{13}\right)_{n s} e^{i \pi / 2} e^{i k_{n s} x} d k_{n s} e^{i n \theta} d n \\
\left.\left(\frac{1}{\sqrt{2 \pi}}\right)^{2} \int_{-\infty}^{\infty} \int_{-\infty}^{\infty}\left(\mathrm{I}_{23}\right)_{n s} e^{-i \pi / 2} e^{i k_{n s} x} d k_{n s} e^{i n \theta} d n\right] \\
\left(\frac{1}{\sqrt{2 \pi}}\right)^{2} \int_{-\infty}^{\infty} \int_{-\infty}^{\infty}\left(\mathrm{I}_{33}\right)_{n s} e^{i k_{n s} x} d k_{n s} e^{i n \theta} d n
\end{array}\right]
$$

Considerando-se que a solução da integral em $n$ existe apenas para $n=0,1,2,3, \ldots, \infty$, esta integral torna-se uma somatória em $n$. A outra integral pode ser resolvida através do teorema dos resíduos, como descrito em Churchill (1975), Ahlfors (1966), Medeiros (1972) e Hauser (1972):

$$
\left[\begin{array}{c}
u \\
v \\
w
\end{array}\right]=\frac{F_{0}\left(1-v^{2}\right) a^{2}}{2 \pi E h} e^{i \omega t}\left[\begin{array}{l}
\frac{1}{2 \pi} \sum_{n=0}^{\infty} 2 \pi i\left(\sum_{s=0}^{\infty}\left(\operatorname{Res}\left(\left(\mathrm{I}_{13}\right)_{n s} e^{i k_{n s} x}\right)\right) e^{i \pi / 2} e^{i n \theta}\right. \\
\frac{1}{2 \pi} \sum_{n=0}^{\infty} 2 \pi i\left(\sum_{s=0}^{\infty}\left(\operatorname{Res}\left(\left(\mathrm{I}_{23}\right)_{n s} e^{i k_{n s} x}\right)\right) e^{-i \pi / 2 e^{i n \theta}}\right. \\
\frac{1}{2 \pi} \sum_{n=0}^{\infty} 2 \pi i\left(\sum_{s=0}^{\infty}\left(\operatorname{Re} s\left(\left(\mathrm{I}_{33}\right)_{n s} e^{i k_{n s} x}\right)\right) e^{i n \theta}\right.
\end{array}\right]
$$

Em Ahlfors (1966) e Churchill (1975), observa-se que a solução pelo teorema dos resíduos é consistente para os pólos pertencentes à parte imaginária positiva do plano complexo.

A equação (5.24) é facilmente resolvida utilizando-se técnica computacional, ou seja, através de um software matemático. Neste caso foi utilizado o software Matlab ${ }^{1}$ para a obtenção da solução numérica de $u, v$ e $w$ para todos os $n$ e $s$ em função de $x, \theta$ e $t$. Os resultados da solução desta equação são encontrados em Boaratti \& Ting (Inac - 2005, COBEM - 2005 e IMAACA - 2005).

A equação (5.24) mostra como um observador em um ponto $(x, \theta)$ qualquer enxerga a sobreposição das ondas que se propagam pelo tubo partindo

\footnotetext{
${ }^{1}$ Marca registrada da The Math Works, Inc.
} 
de uma excitação pontual em $x=0 \mathrm{~m}$ e $\theta=0^{\circ}$, representada na equação (5.4) pelos $\delta(x)$ e $\delta(\theta)$.

Considerando agora que este mesmo observador em $(x, \theta)$, enxerge uma fonte em um ponto $x_{0}$ e $\theta_{0}$ qualquer diferente do ponto $\left(0 \mathrm{~m}, 0^{\circ}\right)$. Nesta situação os deltas de Dirac presentes na equação (5.4) devem ser substituídos por deltas de Dirac deslocados em $x$ e em $\theta$, conforme indicado na equação (5.25) a seguir.

$$
P_{a}(t)=F_{0} \delta\left(x-x_{0}\right) \delta\left(\theta-\theta_{0}\right) e^{i \omega t} .
$$

Realizando o mesmo procedimento descrito anteriormente, obtém-se a solução para a excitação deslocada, o que equivale na equação (5.24) alterar os termos $e^{i k_{n s} x}$ e $e^{i n \theta}$ por $e^{i k_{n s}\left(x-x_{0}\right)}$ e $e^{i n\left(\theta-\theta_{0}\right)}$. Como pode ser visto na equação (5.26).

$$
\left[\begin{array}{l}
u \\
v \\
w
\end{array}\right]=\frac{F_{0}\left(1-v^{2}\right) a^{2}}{2 \pi E h} e^{i \omega t}\left[\begin{array}{l}
\frac{1}{2 \pi} \sum_{n=0}^{\infty} 2 \pi i\left(\sum_{s=0}^{\infty}\left(\operatorname{Res}\left(\left(\mathrm{I}_{13}\right)_{n s} e^{i k_{n s}\left(x-x_{0}\right)}\right)\right) e^{i \pi / 2} e^{i n\left(\theta-\theta_{0}\right)}\right. \\
\frac{1}{2 \pi} \sum_{n=0}^{\infty} 2 \pi i\left(\sum_{s=0}^{\infty}\left(\operatorname{Res}\left(\left(\mathrm{I}_{23}\right)_{n s} e^{i k_{n s}\left(x-x_{0}\right)}\right)\right) e^{-i \pi / 2} e^{i n\left(\theta-\theta_{0}\right)}\right. \\
\frac{1}{2 \pi} \sum_{n=0}^{\infty} 2 \pi i\left(\sum_{s=0}^{\infty}\left(\operatorname{Res}\left(\left(\mathrm{I}_{33}\right)_{n s} e^{i k_{n s}\left(x-x_{0}\right)}\right)\right) e^{i n\left(\theta-\theta_{0}\right)}\right.
\end{array}\right]
$$

\subsection{Descrição do fenômeno de interferência de ondas}

Como já mencionado no capítulo 3, quanto à propagação de ondas em meio sólido, sabe-se que ondas geradas na superfície da casca cilíndrica irão se propagar nesta superfície.

Supondo que uma fonte pontual gere uma excitação sobre uma superfície homogênea, plana e infinita, a onda que se propaga nesta superfície possui cristas concêntricas que se afastam radialmente do ponto de excitação, como por exemplo, uma pedra jogada em um lago. No caso de uma fonte puntiforme, o movimento das frentes de onda pode ser descrito por raios retos perpendiculares às frentes de ondas, se afastando da fonte, Tipler (2000). 
Segundo Alonso \& Finn (1972), com base no Teorema de Malus, uma frente de onda é uma superfície que passa por todos os pontos do meio atingidos pelo movimento ondulatório no mesmo instante. A perturbação em todos esses pontos tem a mesma fase. Pode-se traçar uma série de linhas perpendiculares às sucessivas frentes de onda. Estas linhas são chamadas raios e correspondem às linhas de propagação da onda. A relação entre raios e frente de ondas é similar à relação entre linhas de força e superfícies equipotenciais. O tempo que separa pontos correspondentes das superfícies de onda é o mesmo para todos os pares de pontos correspondentes.

$\mathrm{Na}$ FIG. 5.3 pode ser visto o movimento da frente de onda junto às setas ilustrando as direções deste movimento.

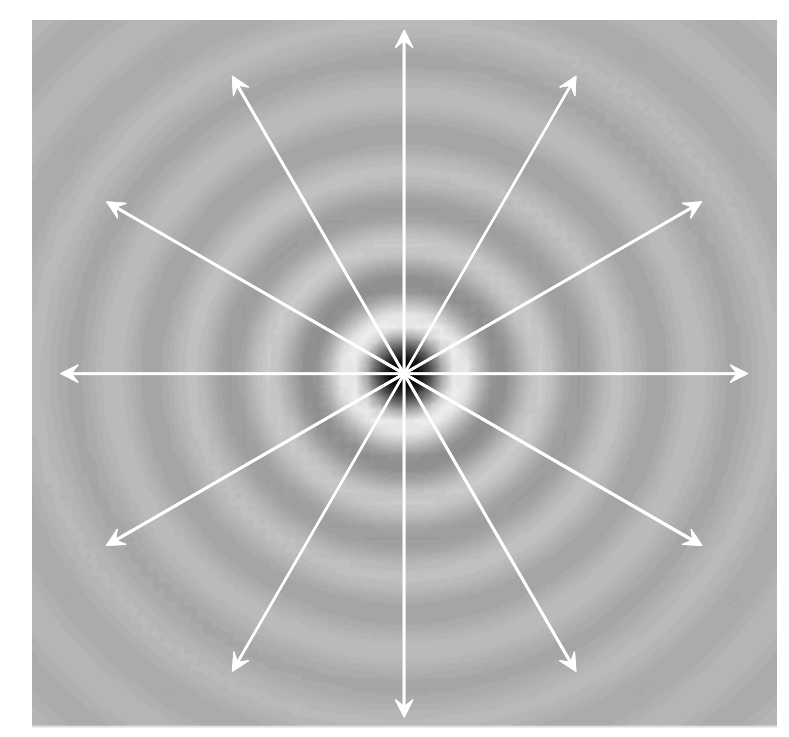

FIGURA 5.3- Ondas esféricas propagando-se radialmente em todas as direções, a partir de uma fonte puntiforme na superfície plana.

De modo semelhante, este efeito é observado na superfície da casca cilíndrica. Como a superfície cilíndrica é um meio fechado na direção circunferencial, tal fato produz interações entre as ondas que se propagam na direção horária e as que se propagam na direção anti-horária, em ângulos crescentes a partir do eixo axial, gerando contribuições que se somam ou que se anulam, em função das características do material, da geometria, e da freqüência desta onda. Na FIG. 5.4 pode ser visto um esboço deste movimento e as interações através das cristas de ondas que se afastam da fonte pontual. 


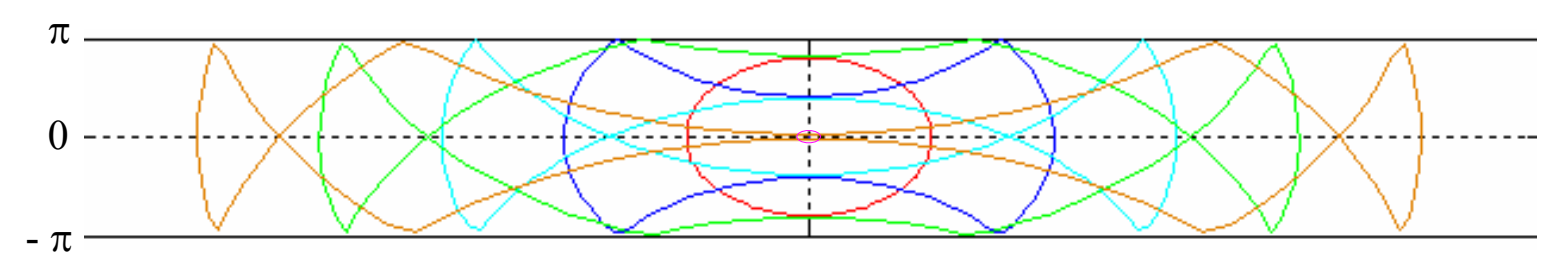

FIGURA 5.4 - Esboço das ondas propagando-se em todas as direções na superfície da casca cilíndrica, planificada de $-\pi$ até $\pi$.

Após um tempo suficiente de propagação, formam-se pontos de picos e vales na superfície da casca. Pode-se dizer que ondas de superfície com trajetos helicoidais embrulham-se ao redor da superfície cilíndrica, de modo que a onda que parte com um ângulo menor em relação à direção axial, chega a um certo ponto $A$ na superfície do cilindro antes da onda que parte com ângulo maior e necessita realizar várias laçadas ao redor do cilindro antes de atingir o mesmo ponto A, (Hinders, 2003), FIG. 5.5. Este fenômeno gera atrasos de fase entre as ondas que se propagam por caminhos diferentes ao redor do cilindro antes de se reencontrarem. Se a fonte de excitação possuir uma freqüência definida, após um tempo suficiente, uma estacionariedade é atingida, criando pontos de picos e vales na superfície da casca. Tal fato pode ser observado através das FIG. 5.7 e 5.8 obtidas pela implementação numérica da equação (5.24).

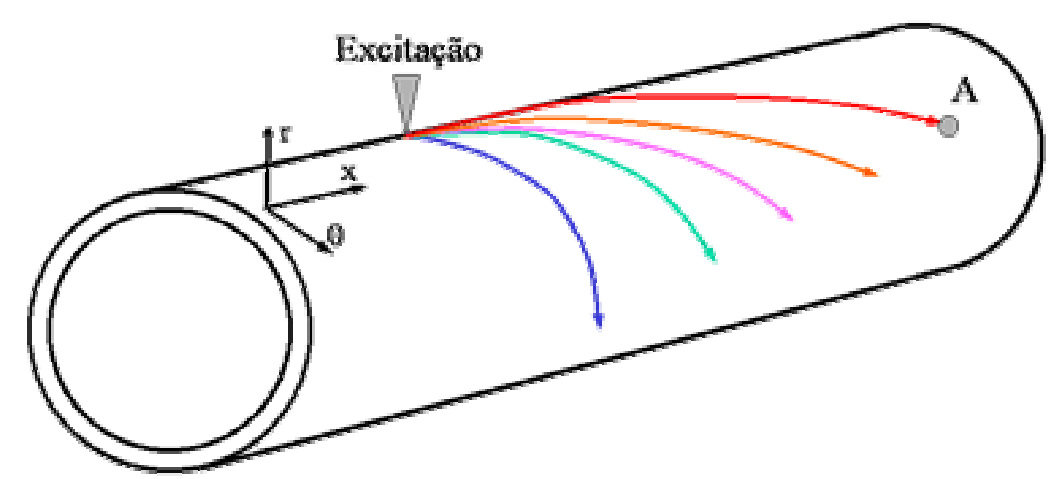

FIGURA 5.5- Alguns raios de ondas propagando-se helicoidalmente na superfície da casca cilíndrica.

Para ilustrar, considere uma fonte localizada na posição $x=0$ e um sensor localizado na posição $x=L$, na FIG. 5.6. Observa-se que as ondas partem em vários ângulos em todas as direções. A onda que parte do ponto de excitação com ângulo $\phi_{1}=0^{\circ}$ e percorre o caminho $\ell_{1}$ é a primeira a chegar no sensor. A 
segunda a chegar parte no mesmo instante com um ângulo $\phi_{2}$ e percorre o caminho $\ell_{2}$ mais longo. A onda que parte com um ângulo $\phi_{3}$ não atinge o sensor. Sabe-se que infinitas ondas partem da fonte com ângulos entre $0^{\circ}$ e $\phi_{2}$ contudo nenhuma delas atinge o sensor, somente as ondas que percorrem os caminhos $\ell_{2}, \ell_{4}, \ell_{6}, \ell_{8}$, e assim por diante, é que o atingem após desenvolverem laçadas helicoidais ao redor do tubo.

Utilizando-se de geometria sobre a superfície planificada do tubo entre $-\pi$.r até $\pi$.r, sendo $\mathrm{r}$ o raio do tubo, obtém-se as relações para o comprimento do caminho $\ell_{p}$ percorrido pela onda e do ângulo $\phi_{p}$ de partida, equações (5.27) e (5.28), para $p=2,4,6,8, \ldots$

$$
\begin{gathered}
\ell_{p}=\sqrt{x^{2}+(p \pi r)^{2}} \\
\phi_{p}=\arccos \left(\frac{x}{\ell_{p}}\right)
\end{gathered}
$$

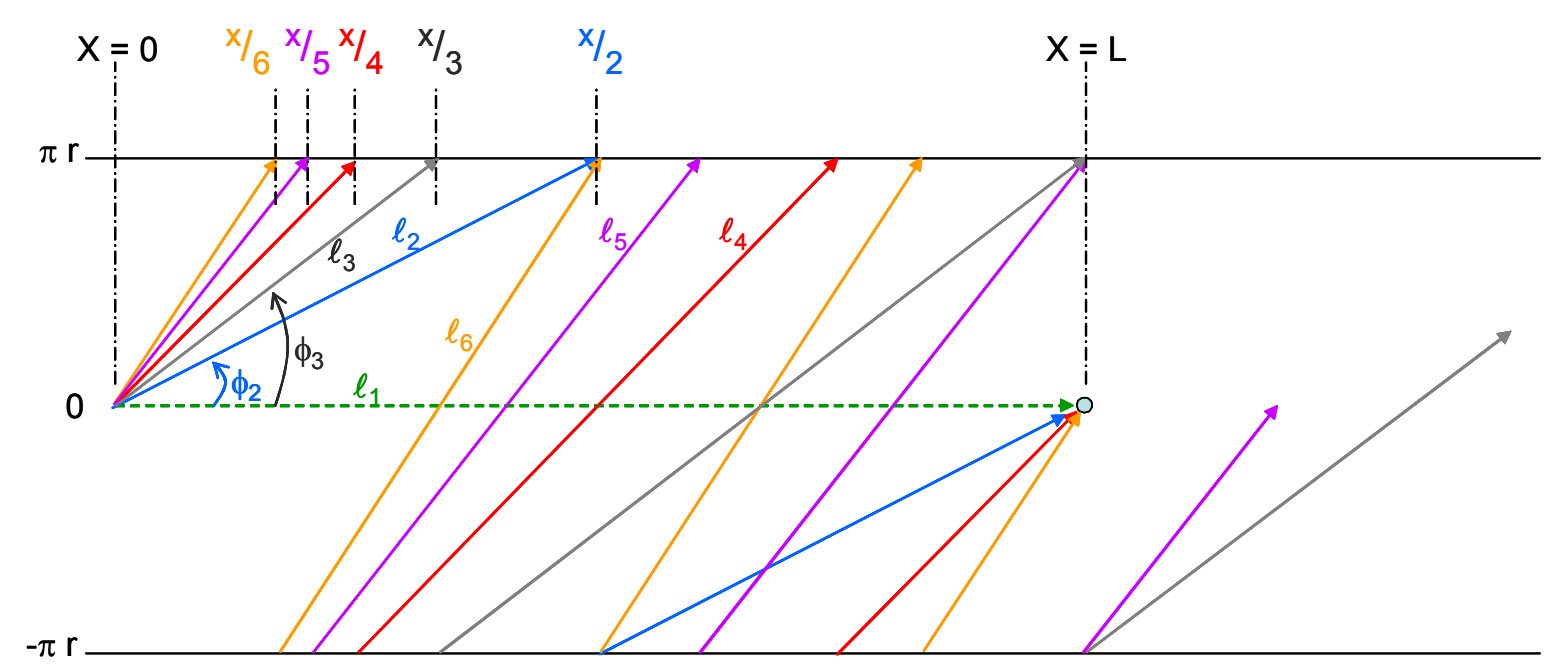

FIGURA 5.6 - Caminhos percorridos por algumas ondas propagando-se helicoidalmente na superfície da casca cilíndrica.

\subsection{Implementação numérica do modelo matemático}

Considere um tubo de aço infinito de raio médio $a=10 \mathrm{~cm}$, espessura média $h=4,6 \mathrm{~mm}$, módulo de elasticidade $E=19,210^{10} \mathrm{~N} / \mathrm{m}^{2}$, densidade $\rho=7800 \mathrm{~kg} / \mathrm{m}^{3}$, Poisson $v=0,3$ e constantes de Lamé: $\lambda=11,07710^{10} \mathrm{~Pa}$ e 
$\mu=7,384610^{10} \mathrm{~Pa}$. Considere também uma excitação harmônica pontual de freqüência $2 \mathrm{KHz}$, aplicada na posição axial $x=0 \mathrm{~m}$ e na posição circunferencial $\theta=0^{\circ}$ do tubo. Resolvendo-se a equação dos deslocamentos (5.24) para a direção $r$, obtém-se o deslocamento $w$ ao longo da superfície do tubo.

Supondo que o tubo já está vibrando por um tempo suficiente a fim de garantir a estacionariedade, pode ser visto na FIG. 5.7 a solução para a distância axial variando no intervalo $\pm x_{\text {máximo }}= \pm 6 \mathrm{~m}$ e a distância circunferencial variando de - $\pi a$ até $\pi$ a para um dado instante de tempo qualquer, aqui adotado como zero por simplicidade.

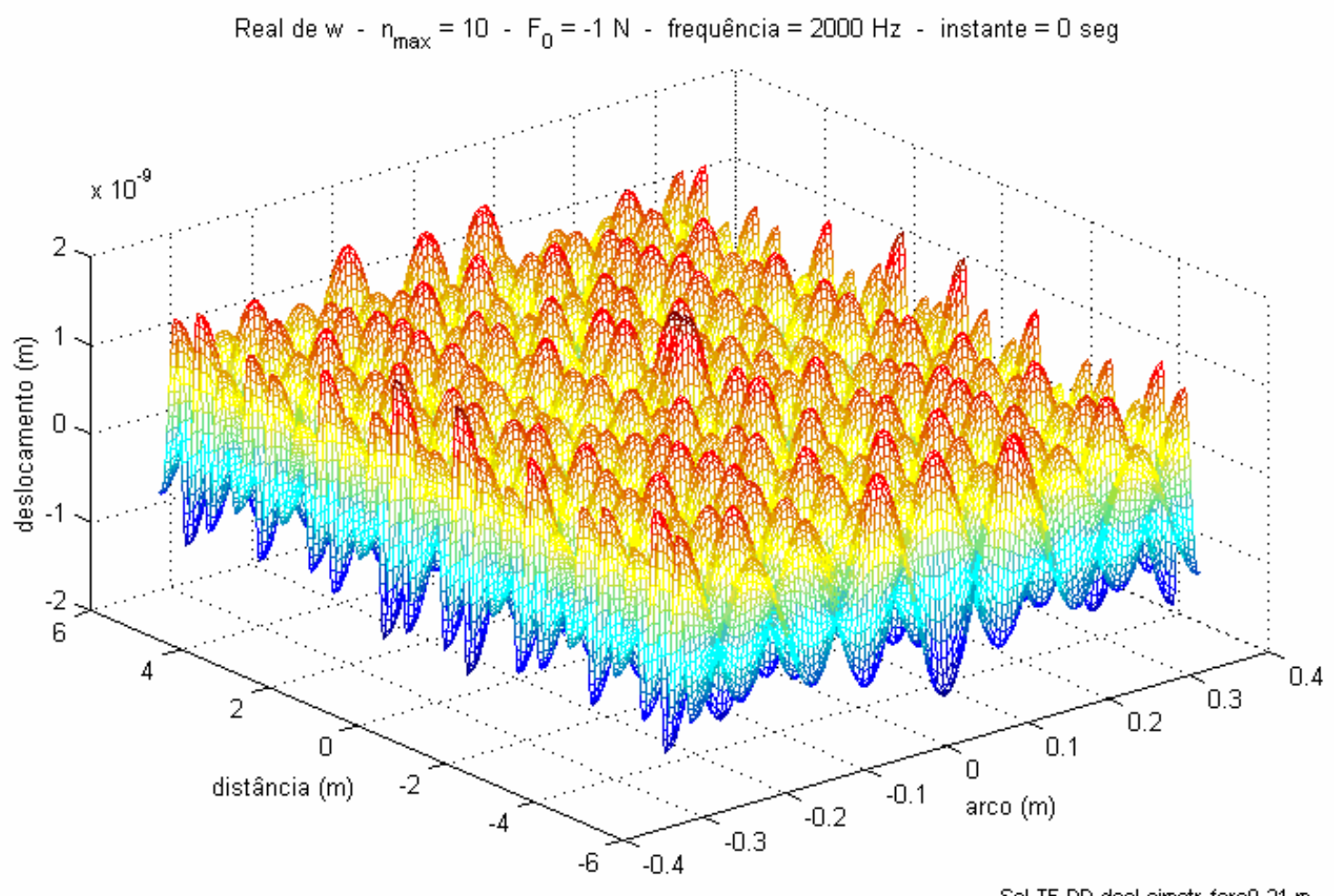

FIGURA 5.7 - Vista das ondas propagando-se em todas as direções na superfície da casca cilíndrica, planificada de $-\pi a$ até $\pi a$.

Na FIG. 5.8, observa-se a mesma solução da FIG. 5.7 apresentada na forma de uma vista superior, onde podem ser vistos os picos e os vales formados pelas ondas estacionárias na superfície do tubo. Os picos são representados em vermelho, os vales em azul escuro e os zeros em verde claro. 
Conforme descrito em 5.2, partindo do ponto de excitação, ondas irão propagar-se em todas as direções. Sendo o tubo uma superfície fechada na direção circunferencial, estas ondas irão se sobrepor de modo construtivo ou destrutivo, formando a composição vista nas FIG. 5.7 e 5.8. Pode-se notar a presença de uma forma de onda estacionária na superfície do tubo, a qual depende das características do material, da geometria e da freqüência de excitação.

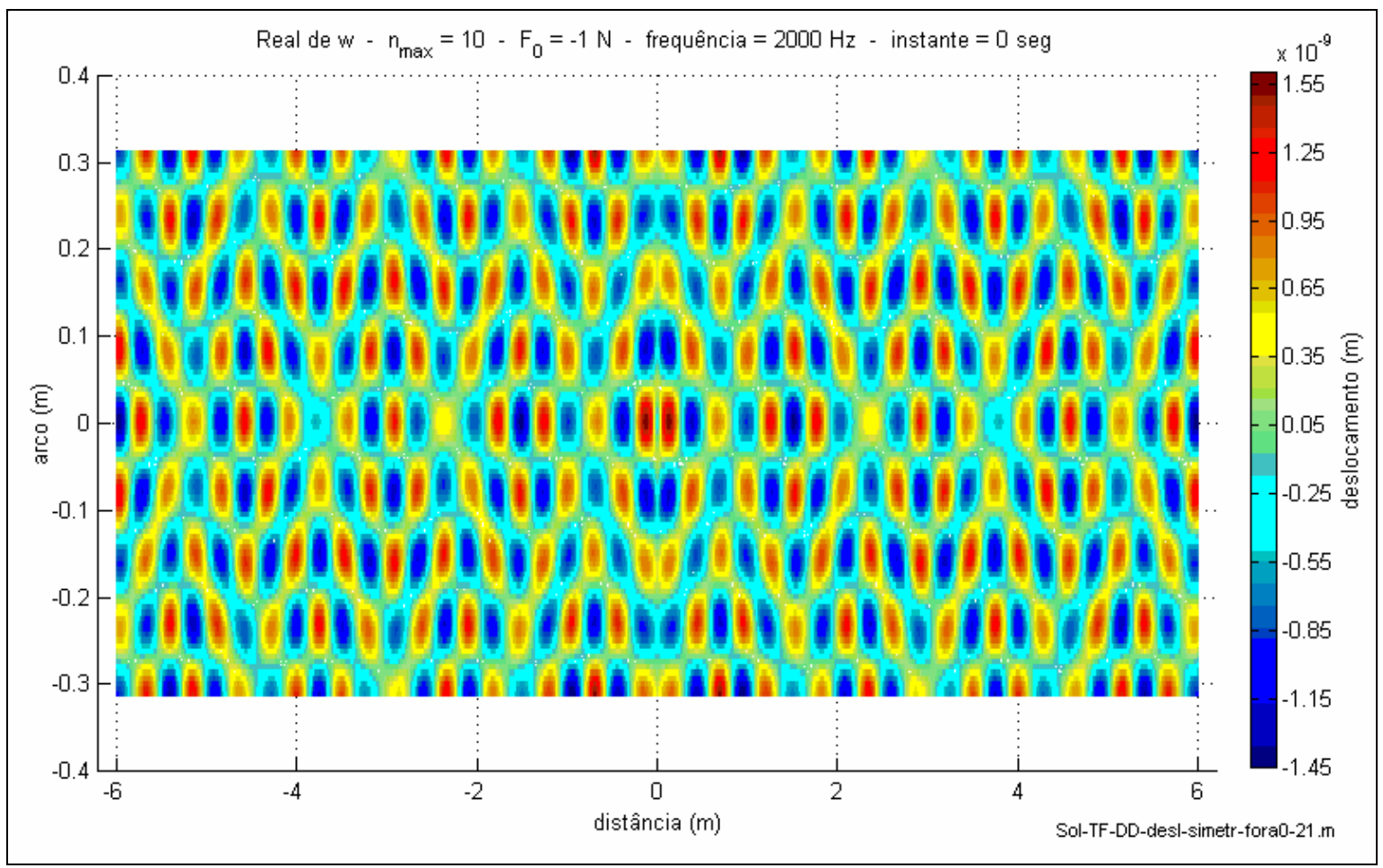

FIGURA 5.8 - Vista superior das ondas propagando-se em todas as direções na superfície da casca cilíndrica, planificada de $-\pi a$ até $\pi a$.

Tomando-se um caminho na direção axial sobre um ângulo qualquer, por exemplo zero, tirando-se uma fatia do gráfico da FIG. 5.8, obtém-se a FIG. 5.9, na qual é possível observar o comportamento da onda resultante que se propaga sobre o tubo em uma direção específica e determinar seu comprimento de onda em função da freqüência. Deve-se ter em mente que esta forma espacial da onda é o resultado da somatória de inúmeras ondas chegando por caminhos diferentes a cada ponto do espaço. Na FIG. 5.10 é mostrado o espectro em ciclos por metro, no qual se observa uma raia predominante em 1,82 ciclos/metro, cujo 
inverso equivale a um comprimento de onda de $0,55 \mathrm{~m}$. A raia de 2,5 ciclos/metro é responsável pela modulação do sinal observado na FIG. 5.9, gerando pontos com picos mais altos que outros, o que na FIG. 5.8 pode ser observado como picos em vermelho mais ou menos realçados.

$\mathrm{Na}$ FIG. 5.11 é apresentado um outro modo para se determinar o comprimento de onda através da autocorrelação no espaço desta mesma função de propagação, na qual são observados picos a cada $0,55 \mathrm{~m}$, o que pode ser entendido como o comprimento de onda médio da propagação.

Outra observação que pode ser feita quanto aos gráficos das FIG. 5.8 e 5.9 é a simetria apresentada na propagação da onda. O que era de se esperar, pois as ondas partem simultaneamente em todas as direções e de forma simetricamente oposta, em conformidade com o exposto no item 5.2 anterior.

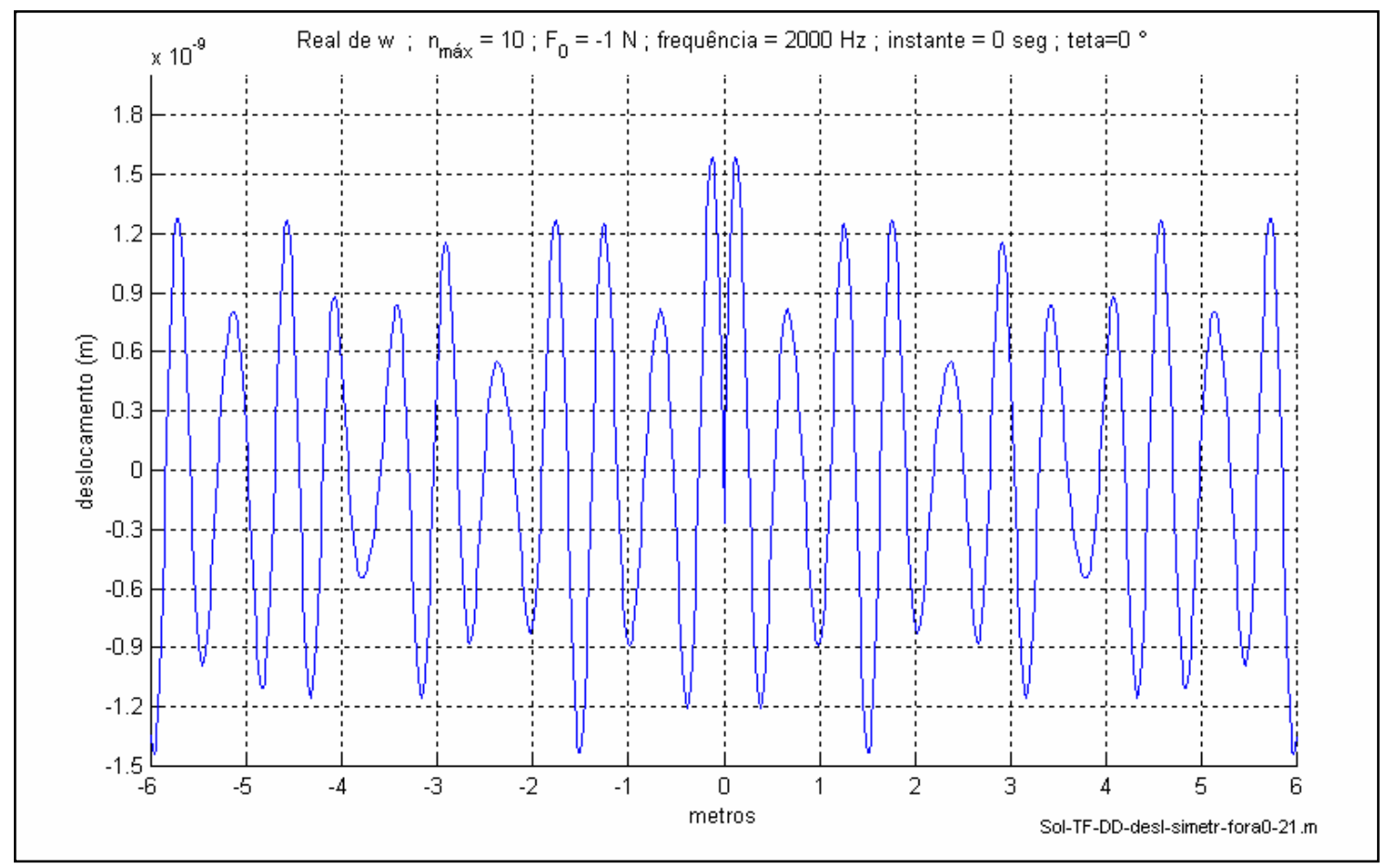

FIGURA 5.9 - Vista em corte da FIG 5.8 sobre a linha de ângulo zero. 


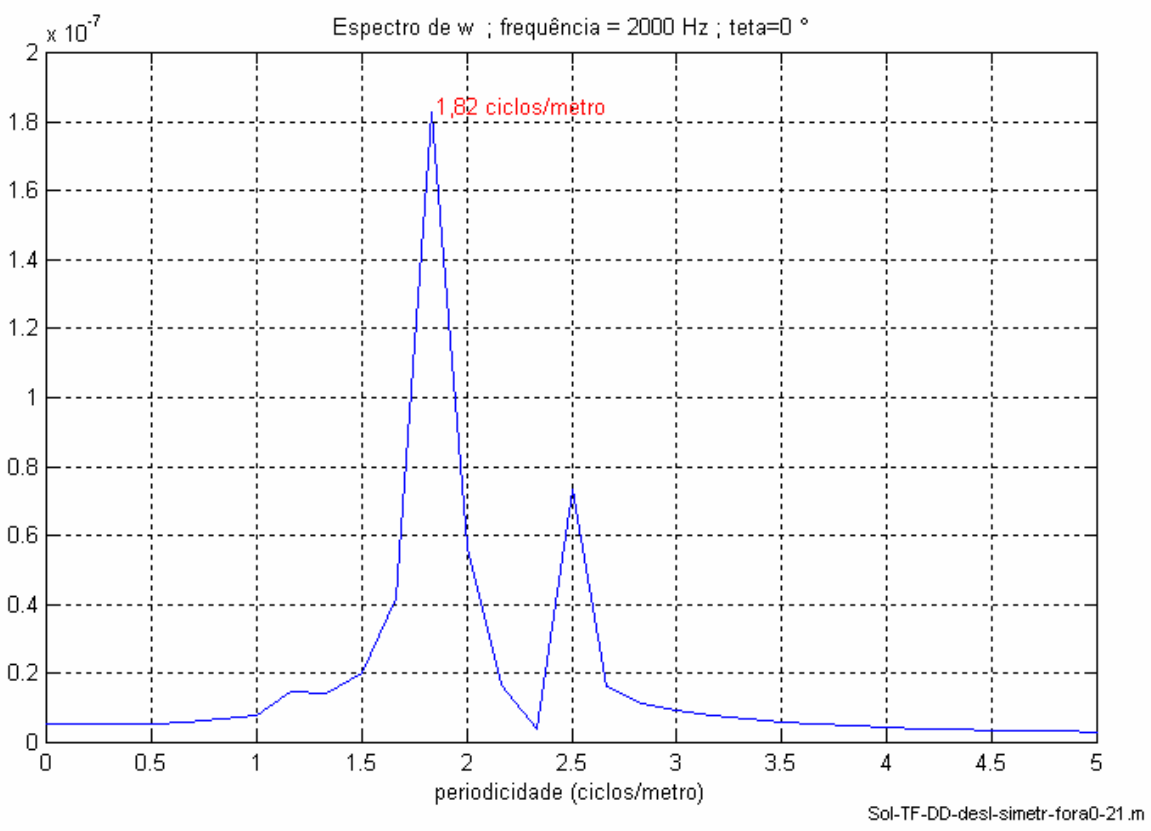

FIGURA 5.10 - Espectro da propagação sobre o ângulo zero.

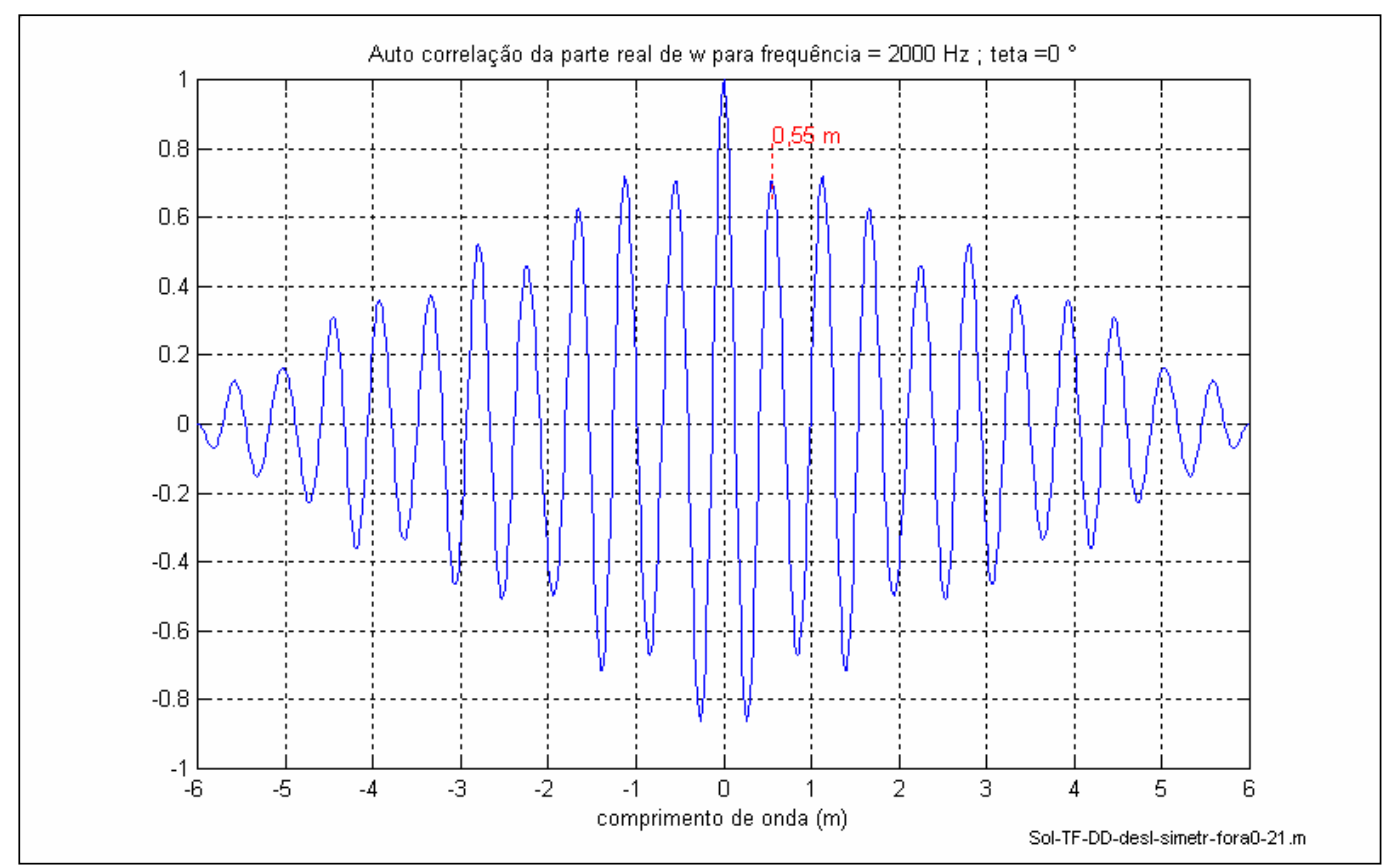

FIGURA 5.11 - Autocorrelação normalizada da propagação sobre o ângulo zero, indicando um comprimento de onda de $0,55 \mathrm{~m}$.

Sendo a freqüência de excitação $2 \mathrm{KHz}$, através da relação $\Lambda=c / f$, onde $\Lambda$ é o comprimento de onda, tem-se que a velocidade efetiva da onda estacionária na superfície do tubo na direção axial é de $1100 \mathrm{~m} / \mathrm{s}$. Bem inferior à 
velocidade de propagação da onda extensional na casca $c_{p}=5200 \mathrm{~m} / \mathrm{s}$, equação (4.9) e da onda transversal no sólido $c_{T}=3077 \mathrm{~m} / \mathrm{s}$, equação ( 3.26 ).

O que se tem na verdade, é a velocidade efetiva da onda estacionária na direção analisada. Este efeito é o resultado da sobreposição de várias ondas chegando de direções distintas em um dado ponto da superfície do tubo, como já mencionado no item 5.2. Este efeito gera uma onda resultante a qual possui uma velocidade própria. Esta velocidade foi definida como velocidade efetiva da onda estacionária, pois é equivalente a de uma única onda se propagando na direção analisada. De outro modo, pode-se pensar no atraso efetivo como sendo resultante da sobreposição dos atrasos de cada onda em um dado ponto da superfície do tubo.

Olhando agora para a propagação na direção circunferencial sobre um arco em uma posição axial constante, por exemplo $x=0 \mathrm{~m}$ da FIG. 5.8, observase um comprimento de onda diferente do observado na direção axial, FIG. 5.12. Das FIG. 5.13 e 5.14, tem-se uma periodicidade de 6,6 ciclos/metro e um comprimento de onda de $0,15 \mathrm{~m}$, respectivamente. Pela relação $\Lambda=\mathrm{c} / \mathrm{f}$ tem-se que a velocidade da onda estacionária na superfície do tubo na direção circunferencial é de $300 \mathrm{~m} / \mathrm{s}$.

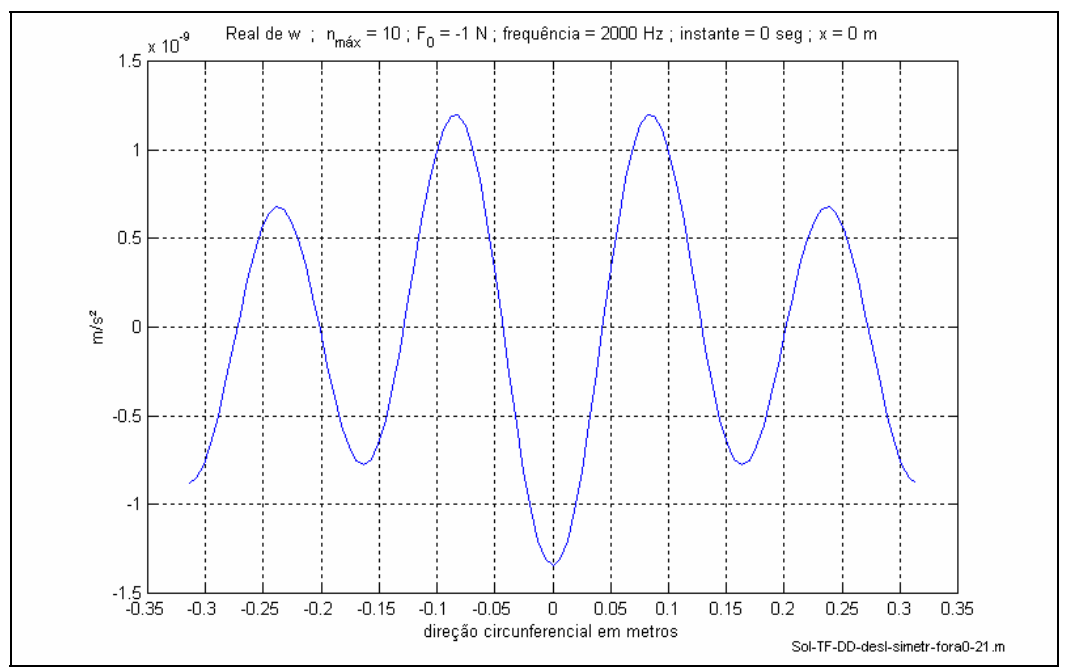

FIGURA 5.12 - Vista em corte sobre o arco na posição $x=0 \mathrm{~m}$ na superfície da casca cilíndrica na direção circunferencial. 


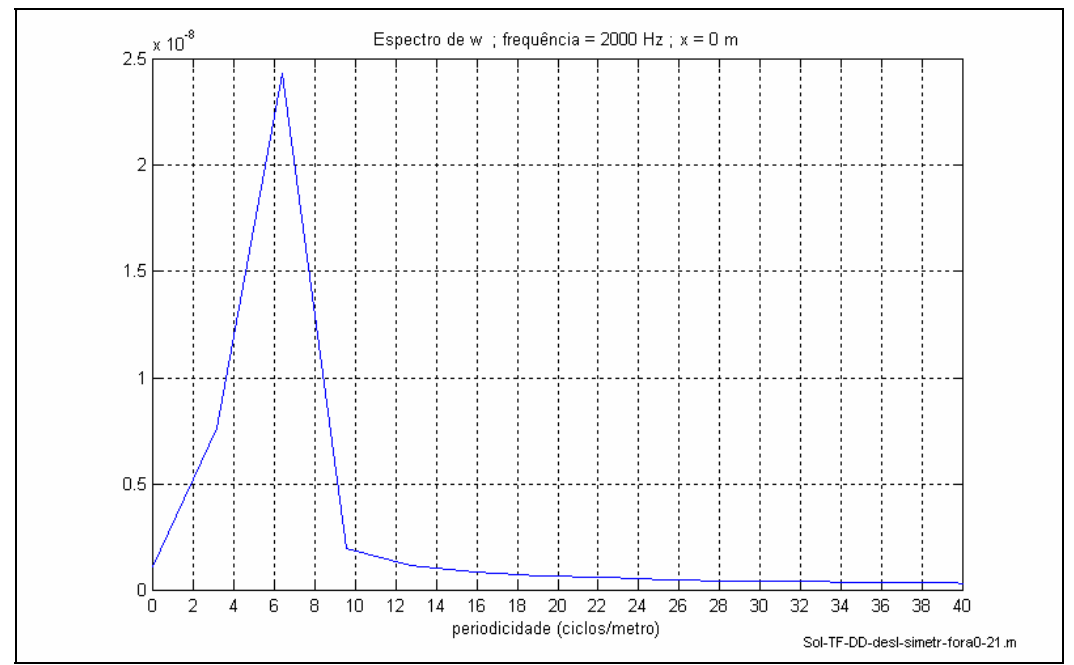

FIGURA 5.13 - Espectro da propagação sobre o arco em $x=0 \mathrm{~m}$.

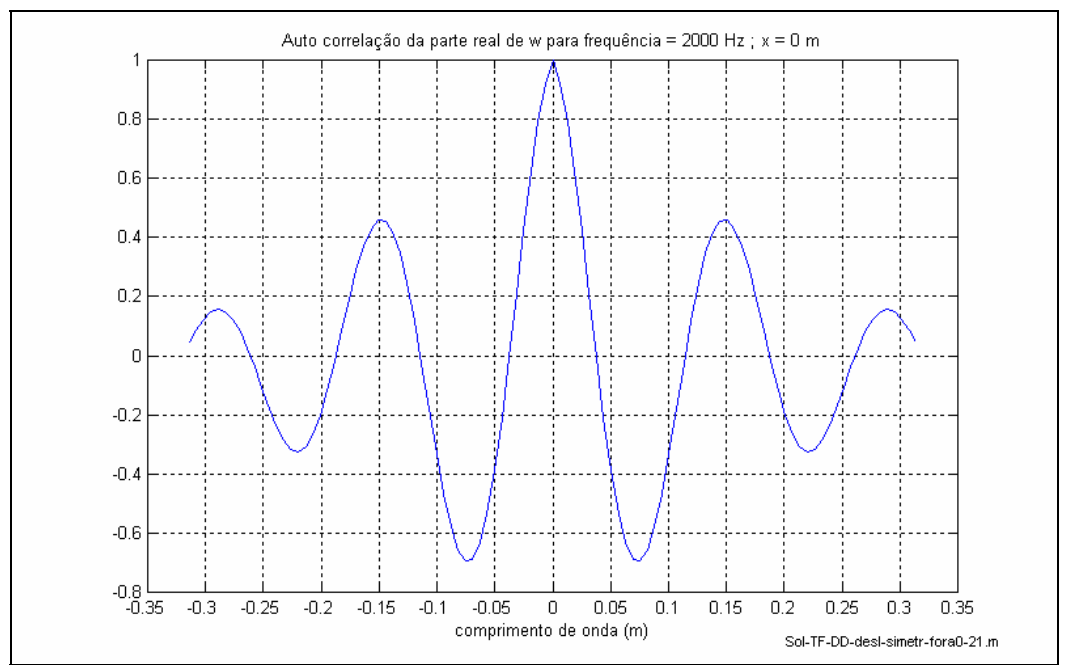

FIGURA 5.14 - Autocorrelação normalizada da propagação sobre o arco em $x=0 \mathrm{~m}$, indicando um comprimento de onda de $0,15 \mathrm{~m}$.

Conforme descrito por Junger \& Feit (1986), desenrolando o tubo em uma tira, o traço da superfície de fase constante sobre este plano forma uma elipse cujo eixo maior é paralelo ao eixo axial do cilindro. Isto indica uma velocidade de fase na direção axial maior que a velocidade de fase na direção circunferencial. Ou de outro modo, considerando que a freqüência é a mesma, o comprimento de onda axial é maior que o comprimento de onda circunferencial.

Realizando um procedimento semelhante, ao realizado para as direções de propagação axial $\left(0^{\circ}\right)$ e circunferencial $\left(90^{\circ}\right)$, também para as direções de $30^{\circ}, 45^{\circ}$ e $60^{\circ}$, obtêm-se os comprimentos de ondas apresentados na TAB. 5.1 juntamente com suas respectivas velocidades, considerando a 
freqüência de excitação de $2 \mathrm{KHz}$. Na FIG. 5.15, pode-se observar que a variação do comprimento de onda com o ângulo de propagação forma uma figura elíptica. Isto significa que a onda propagante apresenta cristas de fase constante na forma de uma elipse. Mesmo não estando em relação de escala, é possível perceber na FIG. 5.8 a presença destas cristas elípticas, comprovando através da solução analítica da equação (5.24) o apresentado no parágrafo anterior.

TABELA 5.1 - Comprimentos de onda e velocidades de propagação.

\begin{tabular}{c|c|c}
\hline Ângulo & Comprimento de onda & Velocidade \\
\hline $0^{\circ}$ & $0,55 \mathrm{~m}$ & $1100 \mathrm{~m} / \mathrm{s}$ \\
\hline $30^{\circ}$ & $0,21 \mathrm{~m}$ & $420 \mathrm{~m} / \mathrm{s}$ \\
\hline $45^{\circ}$ & 0,187 & $374 \mathrm{~m} / \mathrm{s}$ \\
\hline $60^{\circ}$ & $0,164 \mathrm{~m}$ & $328 \mathrm{~m} / \mathrm{s}$ \\
\hline $90^{\circ}$ & $0,15 \mathrm{~m}$ & $300 \mathrm{~m} / \mathrm{s}$ \\
\hline
\end{tabular}

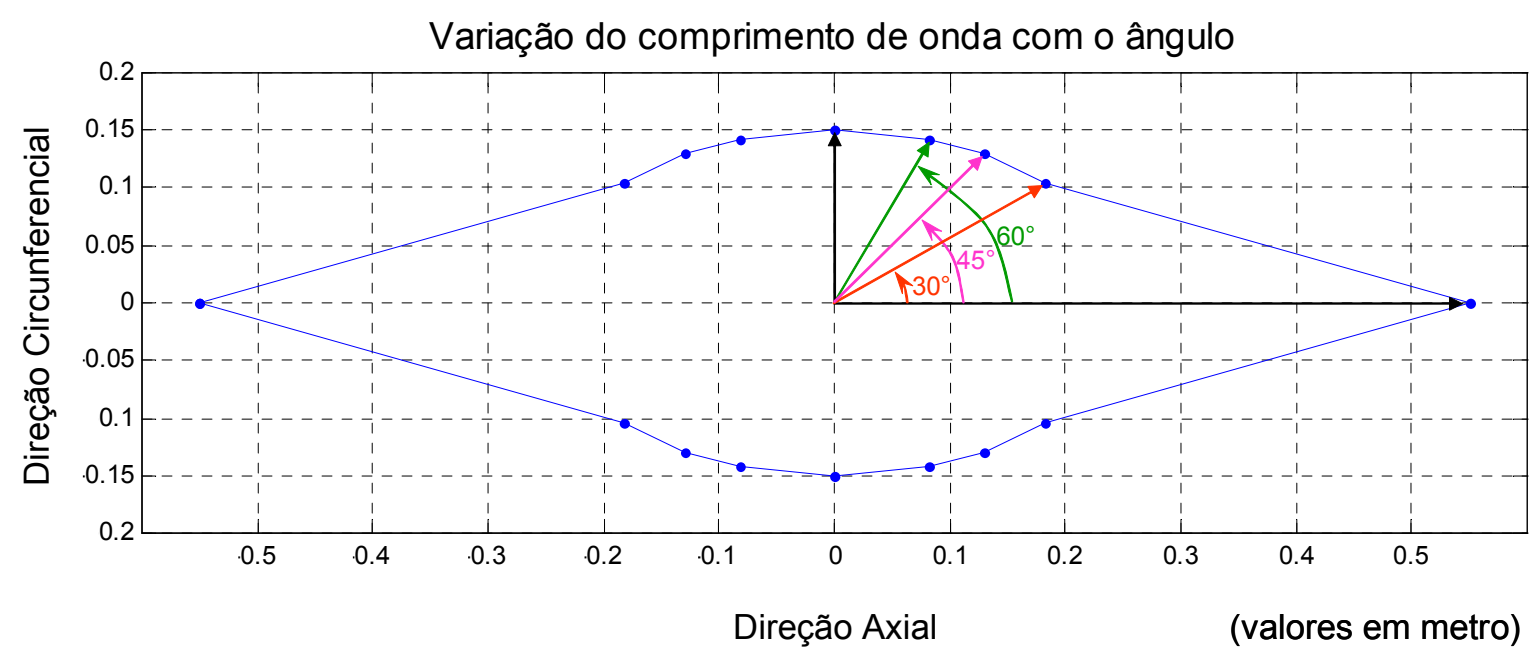

FIGURA 5.15 - Cristas de fase constante em função do ângulo de propagação.

A equação (5.26) descreve o comportamento da superfície do tubo quando a fonte de excitação está em um ponto qualquer desta superfície. Aplicando na equação (5.26) os mesmos parâmetros apresentados no início do item 5.3, e adotando por exemplo uma fonte situada em um ponto $x_{0}=1 \mathrm{~m} \mathrm{e}$ $\theta_{0}=50^{\circ}$, obtém-se a FIG.5.16, na qual pode-se ver o comportamento da superfície do tubo para esta nova excitação. Comparando a FIG. $5.16 \mathrm{com}$ a FIG. 5.8, pode-se observar que o comportamento da superfície mantém as 
mesmas características vistas anteriormente, apresentando apenas como diferença o deslocamento dos pontos de picos e vales proporcionais ao novo ponto de excitação. Isto mostra que o comportamento da superfície do tubo independe do ponto de excitação. Contudo, para um observador situado em uma certa posição fixa desta superfície, a mudança do local da fonte irá gerar uma mudança de como este observador enxerga o sinal oriundo da fonte. Esta é uma das premissas para a proposta de localização sugerida no capítulo 9 .

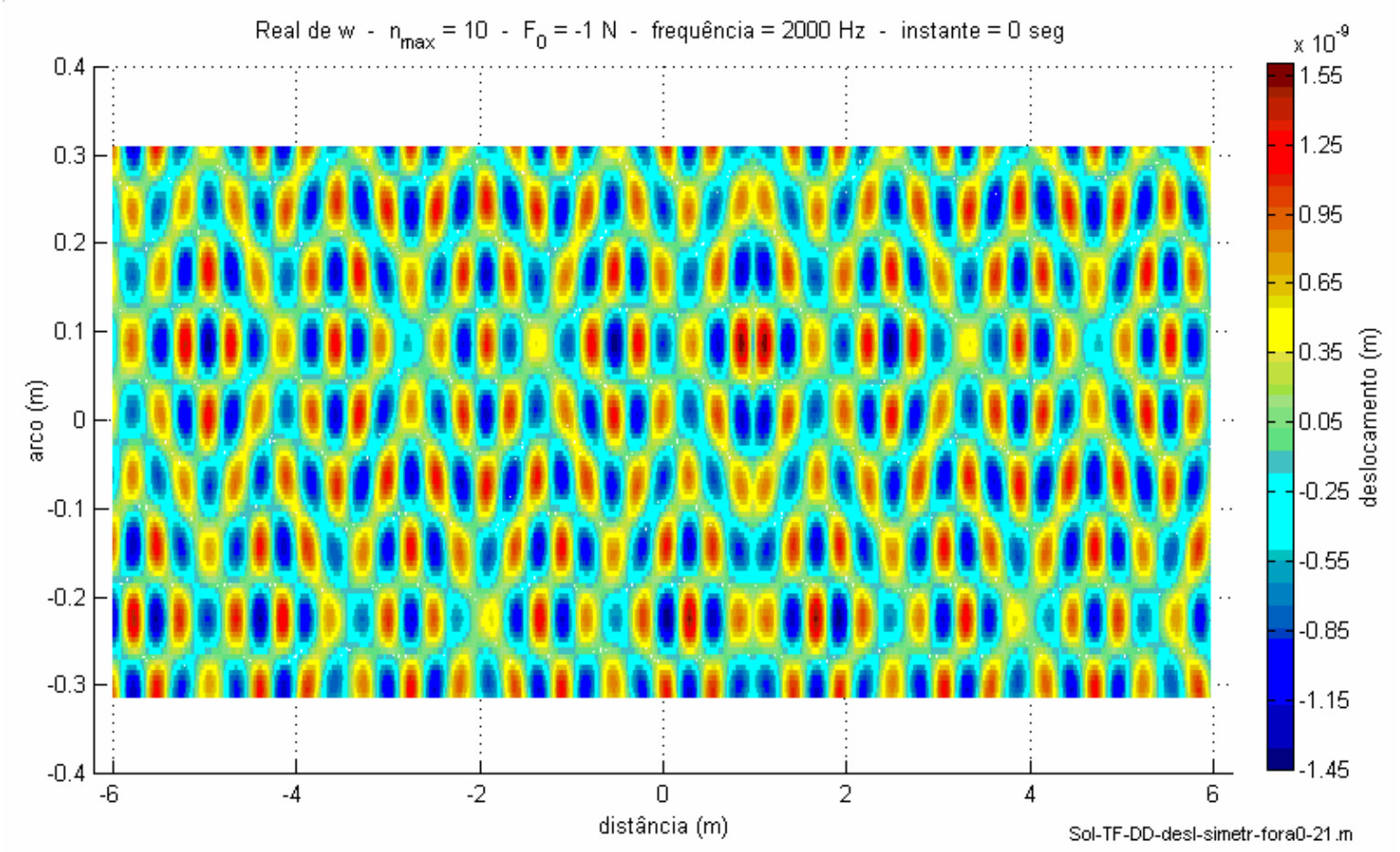

FIGURA 5.16 - Vista superior das ondas propagando-se em todas as direções na superfície da casca cilíndrica, planificada de $-\pi a$ até $\pi a$, para fonte em $x_{0}=1 \mathrm{~m} \mathrm{e} \theta_{0}=50^{\circ}$.

\subsection{Análise dos modos circunferenciais na implementação numérica do modelo matemático}

Em todo o estudo realizado adotou-se o número modal circunferencial $n=10$, o que representa utilizar os onze primeiros modos circunferenciais, $(n=0$ até $n=10$ ), sem perda de precisão na solução. Para demonstrar que a escolha de $n=10$ é suficiente para a estabilidade do modelo, foi preparada a TAB. 5.2 a qual apresenta os RMS do sinal para as somatórias dos modos de zero até $n$, na freqüência em questão. Dos resultados, observa-se que a partir do modo de 
vibração circunferencial $n=10$ as variações nos resultados da solução, para todas as freqüências entre $1 \mathrm{KHz}$ e $10 \mathrm{KHz}$ na fonte de excitação pontual, ficam abaixo de $0,12 \%$ quando se compara o valor para somatória de $n=0$ até 10 com a somatória até o modo onde ocorre a estabilidade. Local na tabela onde o valor do RMS deixa de variar. Observa-se também que nas freqüências de $1 \mathrm{KHz}$, $2 \mathrm{KHz}, 3 \mathrm{KHz}$ e $5 \mathrm{KHz}$ a estabilidade ocorreu com $n<10$.

A estabilidade no tempo e na forma da onda também é satisfeita para a somatória dos modos até $n=10$. Esta constatação foi evidenciada com base na análise das formas de ondas geradas pela equação (5.24) com a variação deste parâmetro. A FIG. 5.17 ilustra estes resultados para a freqüência de $1 \mathrm{KHz}$, onde se observa que para $n \geq 3$ não são notadas variações significativas na forma de onda. As linhas do gráfico tornam-se indistintas. Idem para as FIG. 5.18 e 5.19 onde a estabilidade ocorre para $n \geq 4$ e $n \geq 5$, respectivamente.

TABELA 5.2 - Análise de desvio da solução em função do máximo valor do modo $n$ utilizado no cálculo teórico

\begin{tabular}{|c|c|c|c|c|c|c|}
\hline & \multicolumn{6}{|c|}{ RMS (aceleração) } \\
\hline$\sum_{n}$ Freqüência & $1 \mathrm{KHz}$ & $2 \mathrm{KHz}$ & $3 \mathrm{KHz}$ & $4 \mathrm{KHz}$ & $5 \mathrm{KHz}$ & $10 \mathrm{KHz}$ \\
\hline 0 & $4,86 \mathrm{e}-5$ & $1,94 \mathrm{e}-4$ & $4.68 \mathrm{e}-4$ & $9.68 \mathrm{e}-4$ & 0.0020 & 0.1424 \\
\hline 1 & 0,0022 & 0,0038 & 0.0064 & 0.0109 & 0.020 & 0.2038 \\
\hline 2 & 0,0070 & 0,0110 & 0.0174 & 0.0282 & 0.0467 & 0.2292 \\
\hline 3 & 0,0449 & 0,0219 & 0.0305 & 0.0445 & 0.0677 & 0.2889 \\
\hline 4 & 0,0448 & 0,0616 & 0.0426 & 0.0627 & 0.0837 & 0.3594 \\
\hline 5 & 0,0448 & 0,0614 & 0.1514 & 0.0847 & 0.1054 & 0.3672 \\
\hline 6 & 0,0447 & 0,0613 & 0.1513 & 0.0836 & 0.1415 & 0.3758 \\
\hline 7 & 0,0447 & 0,0613 & 0.1512 & 0.0837 & 0.1400 & 0.3893 \\
\hline 8 & 0,0447 & 0,0613 & 0.1512 & 0.0838 & 0.1399 & 0.4097 \\
\hline 9 & 0,0447 & 0,0613 & 0.1512 & 0.0839 & 0.1399 & 0.4897 \\
\hline 10 & 0,0447 & 0,0613 & 0.1512 & 0.0840 & 0.1399 & 0.4880 \\
\hline 11 & 0,0447 & 0,0613 & 0.1512 & 0.0840 & 0.1399 & 0.4878 \\
\hline 12 & 0,0447 & 0,0613 & 0.1512 & 0.0840 & 0.1399 & 0.4876 \\
\hline 13 & 0,0447 & 0,0613 & 0.1512 & 0.0840 & 0.1399 & 0.4875 \\
\hline 14 & 0,0447 & 0,0613 & 0.1512 & 0.0840 & 0.1399 & 0.4874 \\
\hline 15 & 0,0447 & 0,0613 & 0.1512 & 0.0840 & 0.1399 & 0.4874 \\
\hline Estável a partir de & $n=6$ & $n=6$ & $n=7$ & $n=10$ & $n=8$ & $n=14$ \\
\hline $\begin{array}{c}\text { Erro se parar em } \\
n=10\end{array}$ & $0 \%$ & $0 \%$ & $0 \%$ & $0 \%$ & $0 \%$ & $0,12 \%$ \\
\hline
\end{tabular}




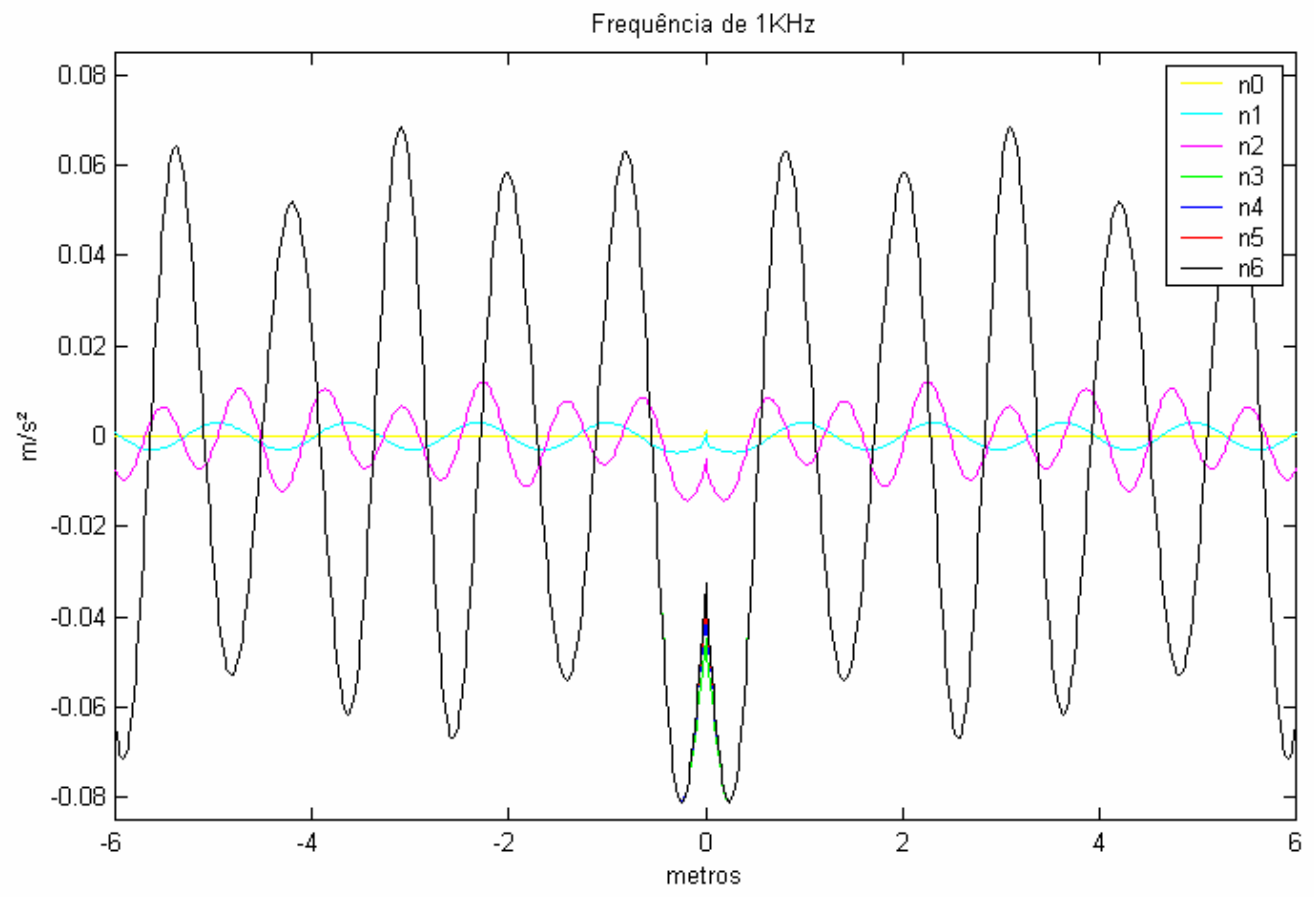

FIGURA 5.17 - Variação da forma de onda em função da somatória dos modos de vibração circunferenciais para $1 \mathrm{KHz}$.

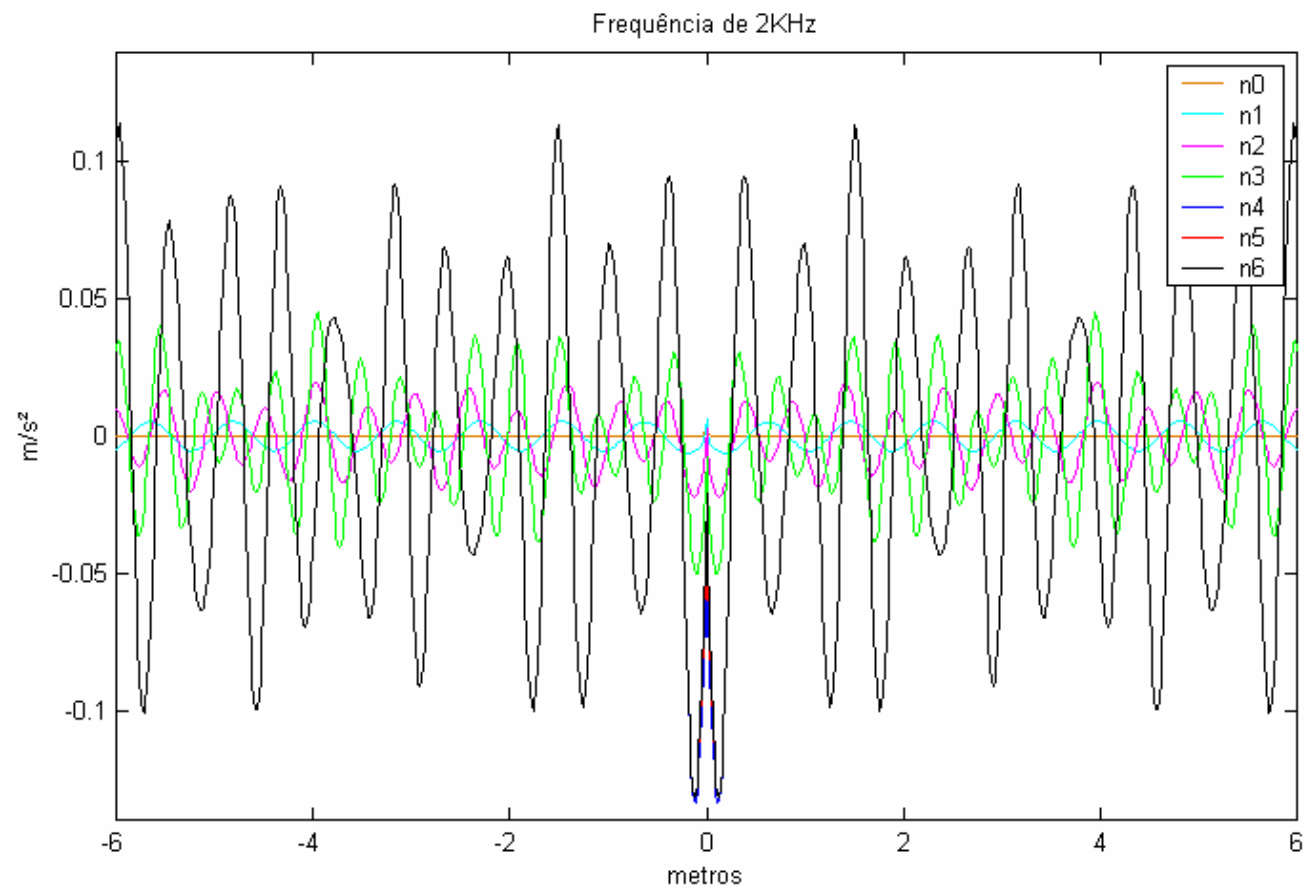

FIGURA 5.18 - Variação da forma de onda em função da somatória dos modos de vibração circunferenciais para $2 \mathrm{KHz}$. 


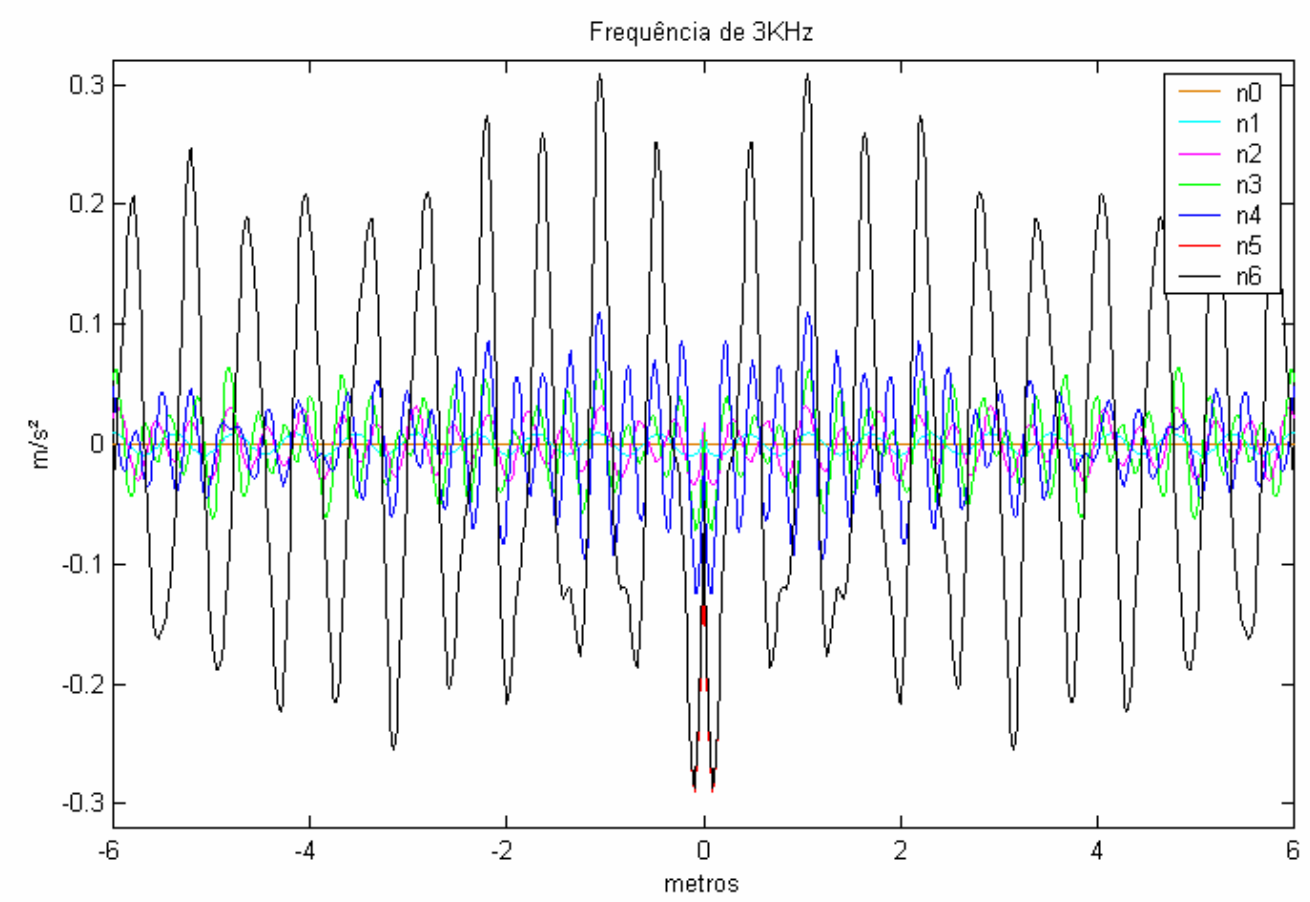

FIGURA 5.19 - Variação da forma de onda em função da somatória dos modos de vibração circunferenciais para $3 \mathrm{KHz}$.

\subsection{Análise dos números de onda axiais na implementação numérica do modelo matemático}

O termo $k_{n s}$ é definido como sendo o número de onda axial. O subscrito $s$ corresponde às possíveis soluções dos números de ondas axiais para cada modo circunferencial $n$. Como o sistema de equações definido em (5.19) é de oitava ordem, para cada par $(\Omega, n)$ tem-se oito $K_{n s}$ os quais podem ser complexos, puramente reais ou puramente imaginários.

Conforme já comentado, a solução é consistente para pólos pertencentes ao plano imaginário positivo, o que gera quatro possíveis soluções para um par $(\Omega, n)$ particular, correspondendo a diferentes campos de ondas propagando em ambas as direções positiva e negativa, os quais possuem módulo e fase.

Segundo Fuller (1981), o comportamento da casca cilíndrica em vibração livre pode ser dividido em duas regiões de freqüência, uma abaixo da freqüência de ring e outra acima. A freqüência de ring é a freqüência na qual o comprimento de onda da onda extensional é igual à circunferência média da parede da casca. Acima da freqüência de ring $(\Omega>1)$ a resposta da casca é 
similar à da placa plana enquanto para freqüências abaixo da freqüência de ring a resposta é bem mais complicada devido ao aumento dos efeitos da curvatura da parede da casca

No APÊNDICE A são apresentadas duas tabelas contendo os valores de $k_{n s}$ para $n=0$ e $n=1$ e freqüências $\Omega$ entre 0,1 até 2 vezes a freqüência de ring. Observa-se que para $\Omega \leq 1$ os $k_{n s}$ nomeados de $\mathrm{S} 1$, S2, S3 e S4 apresentam valores complexos. Acima de $\Omega=1$, todos os $k_{n s}$ ou são puramente reais ou puramente imaginários. Já os $k_{n s}$ nomeados de S5, S6, S7 e S8 são sempre puramente reais ou puramente imaginários.

Outra característica dos $k_{n s}$ é que eles são sempre simétricos dois a dois no plano real-imaginário.

Os $k_{n s}$ representam também os autovalores da matriz dos coeficientes [A] na equação (5.19), ou os pólos nos respectivos termos da matriz inversa, $\mathrm{I}_{13}$, $\mathrm{I}_{23}$ e $\mathrm{I}_{33}$, utilizados na solução da equação (5.24) através do teorema dos resíduos.

Através das medidas, observou-se que entre dois pontos na superfície do tubo existe uma diferença de fase entre os sinais medidos. Contudo, utilizando-se na solução todos os $k_{n s}$ com parte imaginária positiva, conforme descrito anteriormente no final do item 5.1, observou-se a não existência de fase entre dois pontos sobre a superfície do tubo para a solução teórica. Tal fato é evidenciado analisando-se um pedaço da solução (5.24) o qual trata da somatória dos resíduos para alguns pares de $k_{n s}$ simétricos em relação ao eixo imaginário, equação (5.29), onde os $k_{n s}$ são os pólos de $\mathrm{I}_{33}$.

$$
\left(i \sum_{s=0}^{\infty}\left(\operatorname{Re} s\left(\left(\mathrm{I}_{33}\right)_{n s} e^{i k_{n s} x}\right)\right) .\right.
$$

Em (5.29) um par de $k_{n s}$ do tipo $\pm a+i b$, pela simetria dos pólos em relação ao eixo imaginário geram resíduos do tipo $\mp A-i B$, o que implica em:

$$
i\left((A-i B)\left(e^{i(-a+i b) x}\right)+(-A-i B)\left(e^{i(a+i b) x}\right)\right) .
$$

Resolvendo (5.30) obtém-se:

$$
e^{-b x}(2 A \operatorname{sen}(a x)+2 B \cos (a x)) \text {. }
$$


Que possui parte imaginária sempre zero. Isto implica na perda da informação de fase da solução em relação à direção $x$.

Para que a solução mantenha a informação de fase em relação à $x$, e tenha resposta adequada às medidas realizadas, como será visto no capítulo 7 , somente os pólos com parte real negativa e imaginária positiva foram utilizados na solução. Semiplano hachurado indicado na FIG. 5.20.

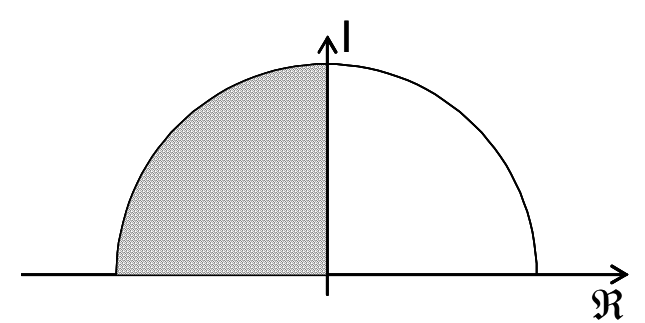

FIGURA 5.20 - Região dos pólos utilizados na solução.

\subsection{Solução não senoidal da equação do movimento}

A série de Fourier na sua forma exponencial complexa é dada pela expressão:

$$
x(t)=\sum_{N=-\infty}^{\infty} X_{N} e^{i N 2 \pi f_{0} t}
$$

sendo:

$$
x_{N}=\frac{a_{N}-i b_{N}}{2}
$$

Considerando que a excitação periódica $p_{a}(\mathrm{t})$ proposta na equação (5.4) pode assumir uma forma qualquer, pode-se escrevê-la na forma da série de Fourier conhecendo-se para isto os seus coeficientes. Neste caso, $F_{0}$ passa a ser $F_{O N}=X_{N}$ da série, e o termo $e^{i \omega t}$ passa a ser $e^{i N \omega t}$. Como se trata de um sistema linear, o desenvolvimento das equações até a obtenção da equação (5.24) é o mesmo, de modo que apenas os termos dependentes da freqüência sofrem alteração e a solução ganha uma somatória em $N$. Sendo assim, a freqüência normalizada $\Omega$ definida por $\Omega=\frac{\omega a}{c_{p}}$, presente na equação (5.19) ganha a forma $\Omega=\frac{N \omega a}{c_{p}}$, fazendo com que a matriz I se torne dependente de $N$ na equação (5.34). 


$$
\left[\begin{array}{l}
u \\
v \\
w
\end{array}\right]=\sum_{N=0}^{\infty} \frac{F_{0 N}\left(1-v^{2}\right) a^{2}}{2 \pi E h} e^{i N \omega t}\left[\begin{array}{l}
\frac{1}{2 \pi} \sum_{n=0}^{\infty} 2 \pi i\left(\sum_{s=0}^{\infty}\left(\operatorname{Res}\left(\left(\mathrm{I}_{13_{N}}\right)_{n s} e^{i k_{n s} x}\right)\right) e^{i \pi / 2} e^{i n \theta}\right. \\
\frac{1}{2 \pi} \sum_{n=0}^{\infty} 2 \pi i\left(\sum_{s=0}^{\infty}\left(\operatorname{Res}\left(\left(\mathrm{I}_{23_{N}}\right)_{n s} e^{i k_{n s} x}\right)\right) e^{-i \pi / 2} e^{i n \theta}\right. \\
\frac{1}{2 \pi} \sum_{n=0}^{\infty} 2 \pi i\left(\sum_{s=0}^{\infty}\left(\operatorname{Re} s\left(\left(\mathrm{I}_{33_{N}}\right)_{n s} e^{i k_{n s} x}\right)\right) e^{i n \theta}\right.
\end{array}\right]
$$

Supondo que a excitação é, por exemplo, uma onda quadrada alternada e centrada, os termos da série são: $a_{N}=0$ e $b_{N}=4 A / N \pi$, sendo $A$ a amplitude da onda quadrada. Logo, $F_{O N}=-\mathrm{i} 2 \mathrm{~A} / N \pi$.

Desenvolvendo a solução para a equação (5.34) e apresentando a solução na forma de aceleração, têm-se os resultados apresentados nas FIG. 5.21 e 5.22 a seguir. Como era de se esperar, a onda estacionária formada na superfície do tubo é diferente daquela observada quando a excitação era senoidal, FIG. 5.21. Na FIG. 5.22, pode-se observar a natureza impulsiva da onda quadrada alternada. Observa-se também que no ponto de excitação a amplitude do sinal é bastante elevada, comparada com um sinal observado em um ponto afastado da excitação. Contudo para outros pontos também afastados, os sinais observados mantêm uma constância de amplitude.

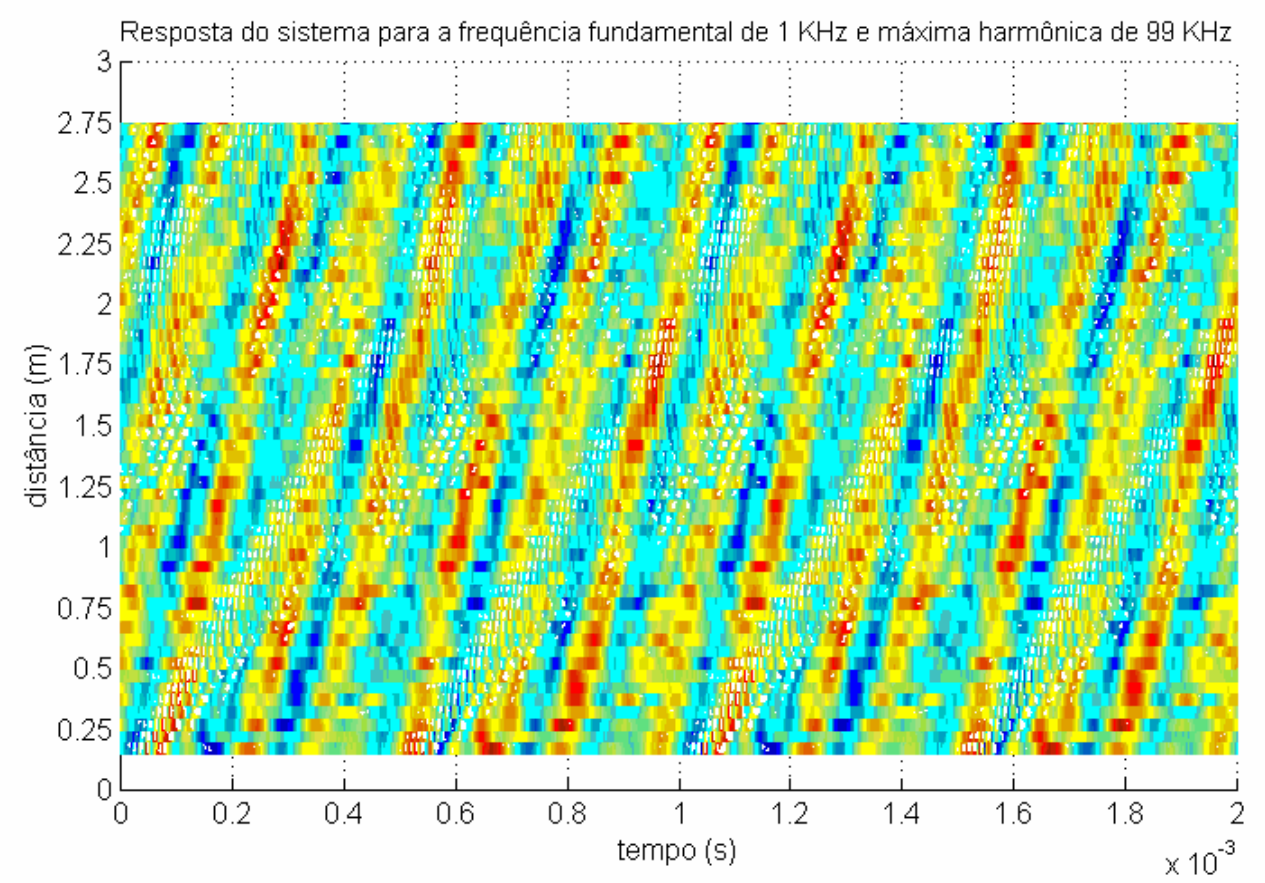

FIGURA 5.21 - Propagação da excitação da onda quadrada de $1 \mathrm{KHz}$ até a $99^{a}$ harmônica. O eixo que indica a aceleração está direcionado saindo do papel. 


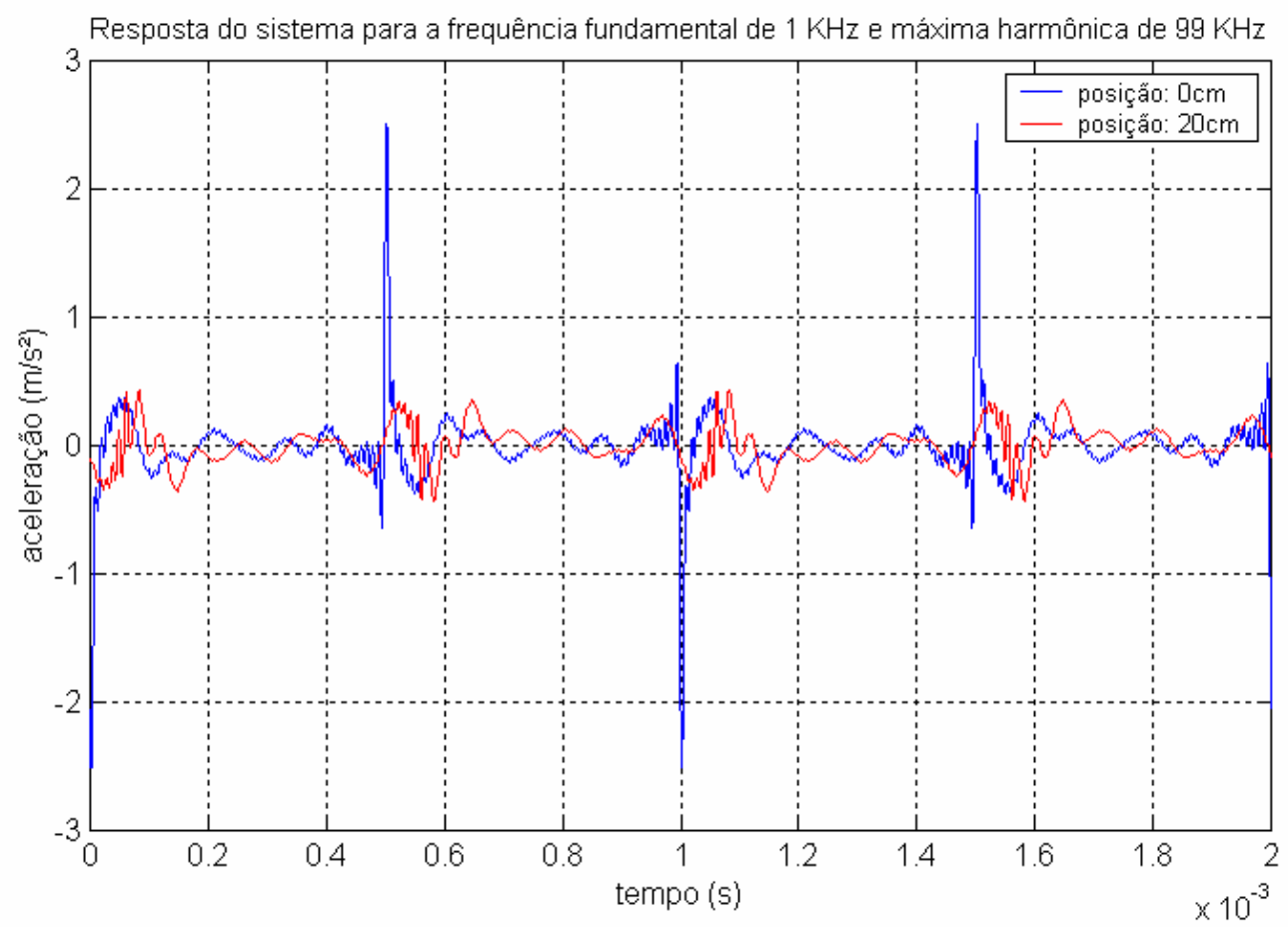

FIGURA 5.22 - Resposta para a onda quadrada de $1 \mathrm{KHz}$ até a 99a harmônica.

$\mathrm{Na}$ sua forma mais geral, o modelo poderia ser implementado para analisar excitações com diferentes timbres, oriundos de diferentes formas de excitações. Bastando para isto, conhecer os coeficientes da série de Fourier do sinal de excitação e seguir os mesmos passos mostrados até aqui. 


\section{MEDIDAS DAS VELOCIDADES DE PROPAGAÇÃO LONGITUDINAL E TRANSVERSAL}

Neste capítulo são descritas as medidas das velocidades de propagação longitudinal e transversal na superfície da casca cilíndrica. O objetivo é confirmar os valores teóricos definidos nos capítulos 3 e 4 , bem como a influência do ruído de fundo e da sua filtragem na capacidade desta determinação, associado ao ganho de amplificação dado ao sinal medido.

A metodologia adotada para a determinação da velocidade é o "time-of-flight" da onda de impacto propagando na parede do tubo e utilização da Transformada de Wavelet para reduzir o ruído a fim de aumentar a resolução, Misiti et al. (2002). Quando é conhecida a distância relativa entre os sensores, pela medida do tempo de atraso da chegada das ondas nestes sensores, obtém-se a velocidade da onda propagante. A dificuldade está em saber determinar $\mathrm{o}$ instante de chegada destas ondas.

Em um primeiro momento foi estabelecido um conjunto de testes realizado em um tubo de ferro de $3 \mathrm{~m}$ de comprimento, $6 \mathrm{~cm}$ de diâmetro e parede de $2 \mathrm{~mm}$ de espessura, caracterizando assim uma casca cilíndrica fina, suspensa em suas extremidades por fios finos. Adotando: $v=0,29$, $\rho=7800 \mathrm{Kg} / \mathrm{m}, \quad E=1,9810^{11} \mathrm{~Pa}, \lambda=1,059810^{11} \mathrm{~Pa}, \mu=7,674410^{10} \mathrm{~Pa}$. Para medir os sinais do impacto e de propagação foram usados dois acelerômetros fixos na parede do tubo. O primeiro foi fixado na posição $A$ localizada a $0,75 \mathrm{~m}$ da extremidade esquerda do tubo e o segundo fixado na posição $B$ localizada a 1,5 $\mathrm{m}$ da extremidade esquerda, estando os dois alinhados. Sobre o acelerômetro A foram gerados os impactos. Os sinais oriundos deste sensor serviram de gatilho do osciloscópio digital ajustado para uma única aquisição. Detalhes dos instrumentos utilizados estão descritos no APÊNDICE B. Os resultados apresentados estão em conformidade com o artigo publicado no "International Nuclear Atlantic Conference - INAC 2005 - ENFIR “, Boaratti e Ting (2005, INAC). 


\subsection{Resultados para o tubo de $3 \mathrm{~m}$ de comprimento e diâmetro de $6 \mathrm{~cm}$}

A FIG. 6.1 registra o instante de impacto no acelerômetro $A$, ocorrido em $0,88710^{-3} \mathrm{~s}$ e a chegada no acelerômetro $B$ da primeira frente de onda transversal da onda propagante, ocorrida em $1,10510^{-3} \mathrm{~s}$, resultando assim em um $\Delta t=0,21810^{-3} \mathrm{~s}$. Sendo a distância entre os dois acelerômetros de 0,75 m, a relação espaço-tempo fornece uma velocidade de $3440 \mathrm{~m} / \mathrm{s}$. Comparando esta velocidade com a velocidade teórica definida pela equação (3.26), a qual resulta em $3137 \mathrm{~m} / \mathrm{s}$, pode-se dizer que a velocidade medida corresponde a velocidade da onda transversal, considerando-se um erro de $9,7 \%$.

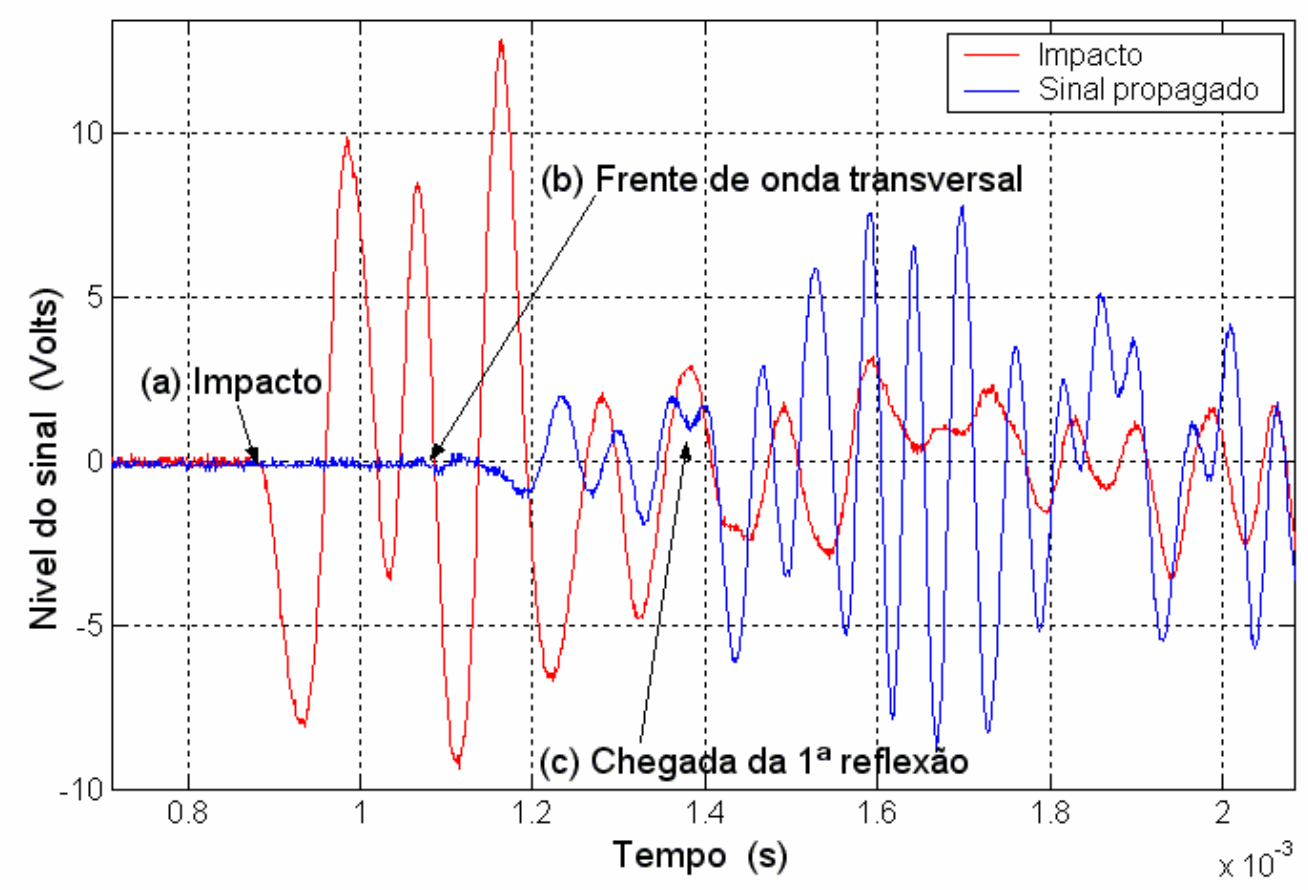

FIGURA 6.1 - Propagação da onda de impacto. Condições: distância entre os dois acelerômetros de $0,75 \mathrm{~m}, 1 \mathrm{M}$ amostras/s e ganho do amplificador de $10 \mathrm{mV} / \mathrm{ms}^{-2}$.

Da teoria sabe-se que existe uma onda longitudinal se propagando na parede do tubo, contudo ela não aparece na FIG. 6.1. Olhando agora para a FIG. 6.2 ponto (b) para as mesmas condições de teste utilizando-se um ganho maior no amplificador de carga do acelerômetro $B$ observa-se uma onda chegando em $1,02710^{-3} \mathrm{~s}$, o que resulta em um $\Delta t=0,14310^{-3} \mathrm{~s}$ indicando uma velocidade de $5245 \mathrm{~m} / \mathrm{s}$. Esta velocidade comparada com a velocidade teórica, definida pela equação (3.24), a qual fornece $5768 \mathrm{~m} / \mathrm{s}$, mostra que a velocidade medida está relacionada com a velocidade de uma onda longitudinal. 
Olhando agora para a equação (4.9), a qual representa a velocidade da onda longitudinal plana em uma placa fina, observa-se que para o material apresentado a velocidade é $c_{p}=5265 \mathrm{~m} / \mathrm{s}$. Esta velocidade $c_{p}$ apresenta uma maior afinidade com a velocidade medida, com erro de apenas 0,4\%, mostrando que a velocidade da onda que se propaga na parede do tubo está relacionada com a velocidade de propagação da placa fina, conforme descrito no capítulo 4 , e não com a velocidade longitudinal do sólido.

Na mesma FIG. 6.2, é encontrado um ponto (c) em $1,10410^{-3} \mathrm{~s}$ o que resulta em $\Delta t=0,2210^{-3} \mathrm{~s}$ e conseqüentemente em uma velocidade transversal de $3409 \mathrm{~m} / \mathrm{s}$.

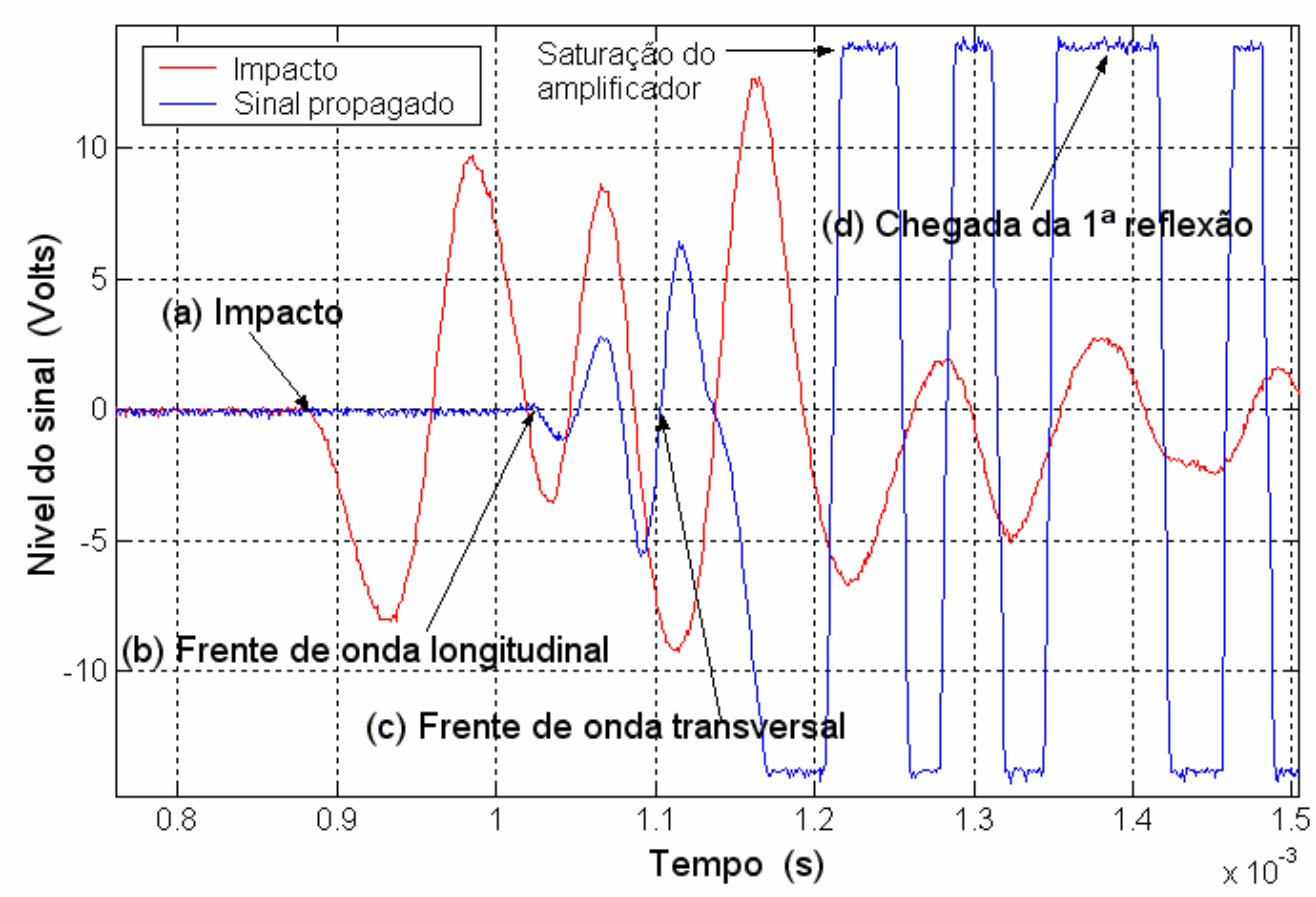

FIGURA 6.2 - Propagação da onda de impacto. Condições: distância entre os dois acelerômetros de $0,75 \mathrm{~m}, 1 \mathrm{M}$ amostras/s e ganho do amplificador de $316 \mathrm{mV} / \mathrm{ms}^{-2}$.

Dois fatos devem ser relatados: Primeiro, o aumento do ganho do amplificador melhorou a relação entre o sinal da onda propagante e o ruído de fundo de alta freqüência gerado pela eletrônica, por radiações eletromagnéticas externa e outras fontes. Sendo assim, a correta escolha do ganho do amplificador e da sensibilidade do acelerômetro é um fator importante na capacidade de localização da onda longitudinal, que neste caso apresenta uma intensidade menor em função da direção do impacto e a direção de trabalho do acelerômetro 
privilegiarem as ondas transversais. Segundo, na FIG. 6.2 nota-se um pico entre os pontos (b) e (c) o qual força a acreditar na chegada da onda transversal neste instante. Contudo este pico refere-se à chegada de um novo máximo da mesma onda longitudinal que se propaga mais rápido que a transversal. Este efeito é potencializado quando a distância entre os acelerômetros é aumentada, como pode ser visto na FIG. 6.3, onde se tem agora dois máximos da onda longitudinal chegando antes da primeira onda transversal.

a) Baixo ganho no amplificador
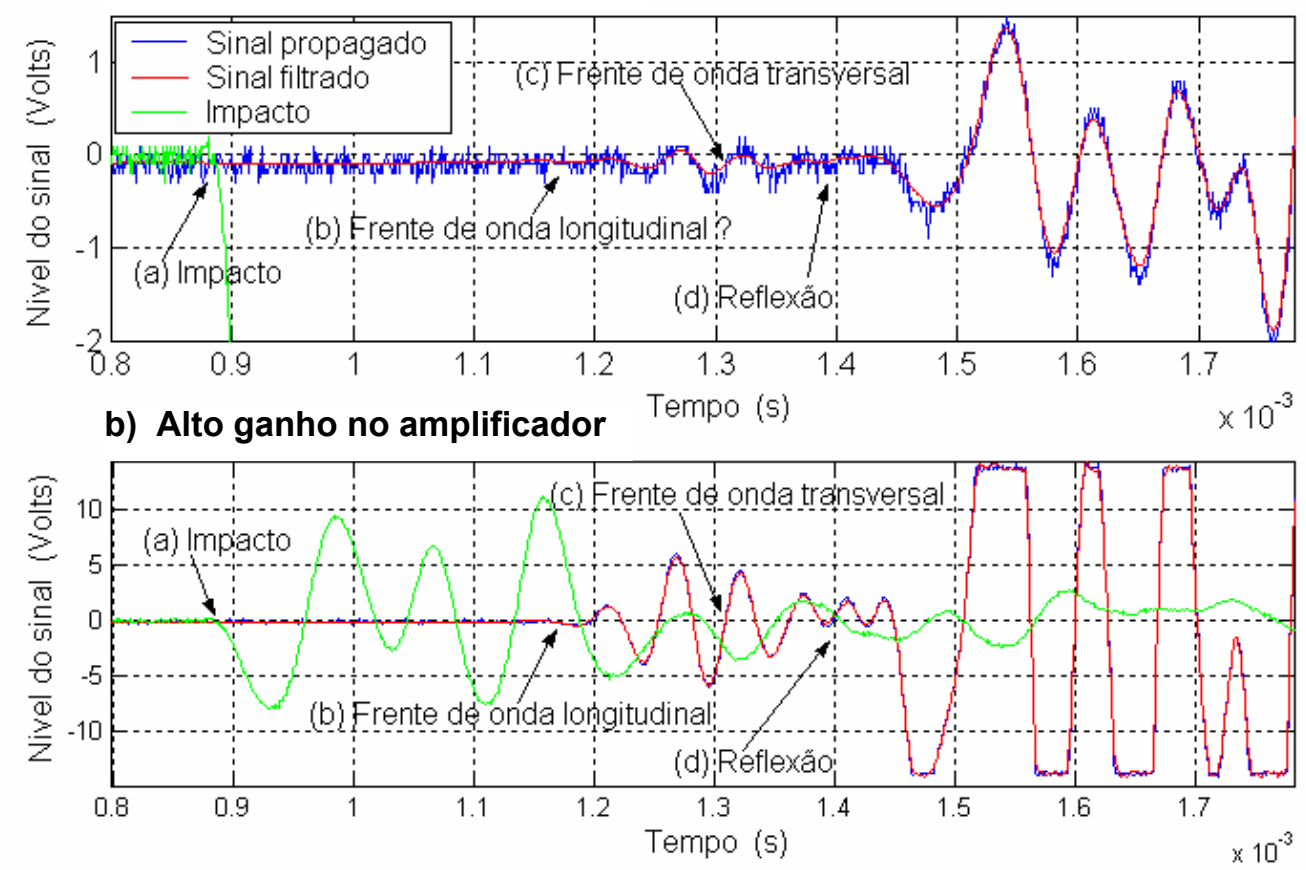

FIGURA 6.3 - Propagação da onda de impacto. Condições: distância entre os dois acelerômetros de $1,5 \mathrm{~m}, 1 \mathrm{M}$ amostras/s e ganho do amplificador: a) $10 \mathrm{mV} / \mathrm{ms}^{-2}$; b) $316 \mathrm{mV} / \mathrm{ms}^{-2}$.

A FIG. 6.3 registra o mesmo tipo de ensaio para o acelerômetro B recolocado à 2,25 $\mathrm{m}$ da extremidade esquerda do tubo, gerando uma nova distância relativa de 1,5 m entre os sensores. Nota-se que o aumento do ganho do amplificador do acelerômetro $B$ garante uma maior certeza na determinação do instante de chegada da onda longitudinal, FIG. 6.3b.

Para diminuir o efeito do ruído de alta freqüência e possibilitar uma melhor visualização das ondas propagantes, o sinal foi filtrado através da técnica de wavelet-denoise, representado pela linha vermelha na FIG.6.3. A wavelet utilizada na decomposição do sinal foi a Wavelet Daubechies 10 com 12 níveis de 
decomposição. A escolha da Wavelet Daubechies deveu-se ao fato desta wavelet ser a que melhor se encaixou nos sinais adquiridos dos sensores. Contudo notou-se que se o sinal for muito pequeno, isso é, da ordem da sensibilidade do equipamento de medida, o uso de wavelet-denoise para eliminar o ruído de alta freqüência por si só não permitiu recuperar o sinal da onda propagante. Neste caso a determinação do instante de chegada da onda longitudinal não é possível visto que este está perdido entre os sinais, como pode ser visto na FIG. 6.3a ponto (b). Contudo na FIG. 6.3b, na qual se tem um ganho maior no amplificador do sensor B, o instante de chegada da onda longitudinal é encontrado. Isto mostra que a escolha do ganho de amplificação é um fator importante na capacidade de detecção das ondas longitudinal e transversal.

Além disso deve-se destacar que o impacto se deu na direção transversal e o acelerômetro foi posicionado, por questões construtivas, de modo a privilegiar a detecção na direção transversal. O uso de um acelerômetro posicionado na direção axial do tubo com certeza melhoraria a detecção das ondas longitudinais.

Outro fato interessante de ser comentado são as singularidades registradas como chegada da primeira reflexão, pontos (c) e (d) respectivamente nas FIG. 6.1 e FIG. 6.2. Estas singularidades no sinal encontram-se no intervalo de tempo que se inicia em aproximadamente $0,4410^{-3} \mathrm{~s}$ e termina em $0,5410^{-3} \mathrm{~s}$ após o instante de impacto ocorrido no ponto A. Em função desta faixa de tempo, notou-se que estas singularidades referiam-se à primeira reflexão da onda longitudinal na extremidade esquerda do tubo. Ou seja é o tempo que a onda que sai em sentido contrário chega à extremidade esquerda do tubo, reflete, caminha para a direita e chega ao sensor $B$ juntamente com as ondas diretas provenientes do impacto na posição $A$, gerando assim um efeito de sobreposição de ondas.

Na FIG. 6.3 ponto (d) também são encontradas estas singularidades. Sendo que neste caso o acelerômetro B está em uma posição mais próxima da extremidade direita, tem-se ondas chegando tanto desta extremidade quanto ondas chegando da extremidade esquerda. A onda que sai para a esquerda anda $0,75 \mathrm{~m}$, reflete, anda mais $2,25 \mathrm{~m}$ e encontra o sensor $B$. A onda que sai para a direita anda $2,25 \mathrm{~m}$, reflete, anda mais $0,75 \mathrm{~m}$ e também encontra o sensor $B$, gerando o efeito de sobreposição de ondas. 


\subsection{Resultados para o tubo de $6 \mathrm{~m}$ de comprimento e diâmetro de $20 \mathrm{~cm}$}

Com o objetivo de verificar a velocidade de propagação da onda longitudinal $c_{p}$, para o tubo utilizado nos ensaios de validação do modelo matemático da equação (5.26), foram realizados ensaios semelhantes aos relatados em Boaratti e Ting (2005, INAC) e descritos no item anterior.

A estrutura experimental utilizada é composta de um tubo de aço carbono com $6 \mathrm{~m}$ de comprimento, raio médio $a=10 \mathrm{~cm}$, espessura de parede média $h=4,6 \mathrm{~mm}$, módulo de elasticidade $E=19,210^{10} \mathrm{~N} / \mathrm{m}^{2}$, densidade $\rho=7800 \mathrm{~kg} / \mathrm{m}^{3}$, Poisson $v=0,3$ e constantes de Lamé: $\lambda=11,07710^{10} \mathrm{~Pa} \mathrm{e}$ $\mu=7,384610^{10} \mathrm{~Pa}$. Com a finalidade de simular uma condição de tubo infinito, as extremidades do tubo foram introduzidas em caixas de areia seca, técnica também utilizada por Feng (1996) e Ming et al. (2000). Neste caso a areia funciona como uma armadilha para as ondas que chegam, evitando que estas encontrem o caminho de volta para a parede do tubo gerando reflexões. Nesta montagem as extremidades do tubo foram introduzidas $30 \mathrm{~cm}$ dentro da areia. Para a geração do impacto foi utilizado um martelo instrumentado.

O impacto foi realizado na posição $2 \mathrm{~m}$ da extremidade esquerda do tubo e o acelerômetro foi posicionado à $4 \mathrm{~m}$ dessa mesma extremidade e na mesma linha do impacto.

Na FIG. 6.4, observa-se o sinal medido no acelerômetro na condição do amplificador ajustado para ganho 10. Pode-se notar que a frente de onda longitudinal não é perceptível. Já na FIG. 6.5, para um ajuste de 100 no ganho do amplificador, é notada a chegada da frente de onda longitudinal em $0,75510^{-3} \mathrm{~s}$ para um impacto em $0,37510^{-3} \mathrm{~s}$, gerando um intervalo de tempo de $0,3810^{-3} \mathrm{~s}$. Sendo a distância relativa entre o ponto de impacto e o acelerômetro de $2 \mathrm{~m}$, isto fornece uma velocidade de $5263 \mathrm{~m} / \mathrm{s}$, ou seja, equivalente à velocidade da onda longitudinal da placa fina para o aço que é de $5200,9 \mathrm{~m} / \mathrm{s}$.

Retornando à FIG. 6.4, observa-se que a primeira parte do sinal a apresentar uma amplitude visível, que se destaca do sinal de fundo, a qual pode ser considerada como a chegada de uma frente de onda ocorreu em 2,55 $10^{-3} \mathrm{~s}$. Isto gera um intervalo de tempo de $0,6110^{-3} \mathrm{~s}$ em relação ao impacto ocorrido em $1,9410^{-3} \mathrm{~s}$, determinando uma velocidade de $3279 \mathrm{~m} / \mathrm{s}$, ou seja, equivalente a da onda transversal teórica para o aço definida pela equação (3.26), a qual fornece uma velocidade de $3077 \mathrm{~m} / \mathrm{s}$, com um erro de $6,6 \%$. 


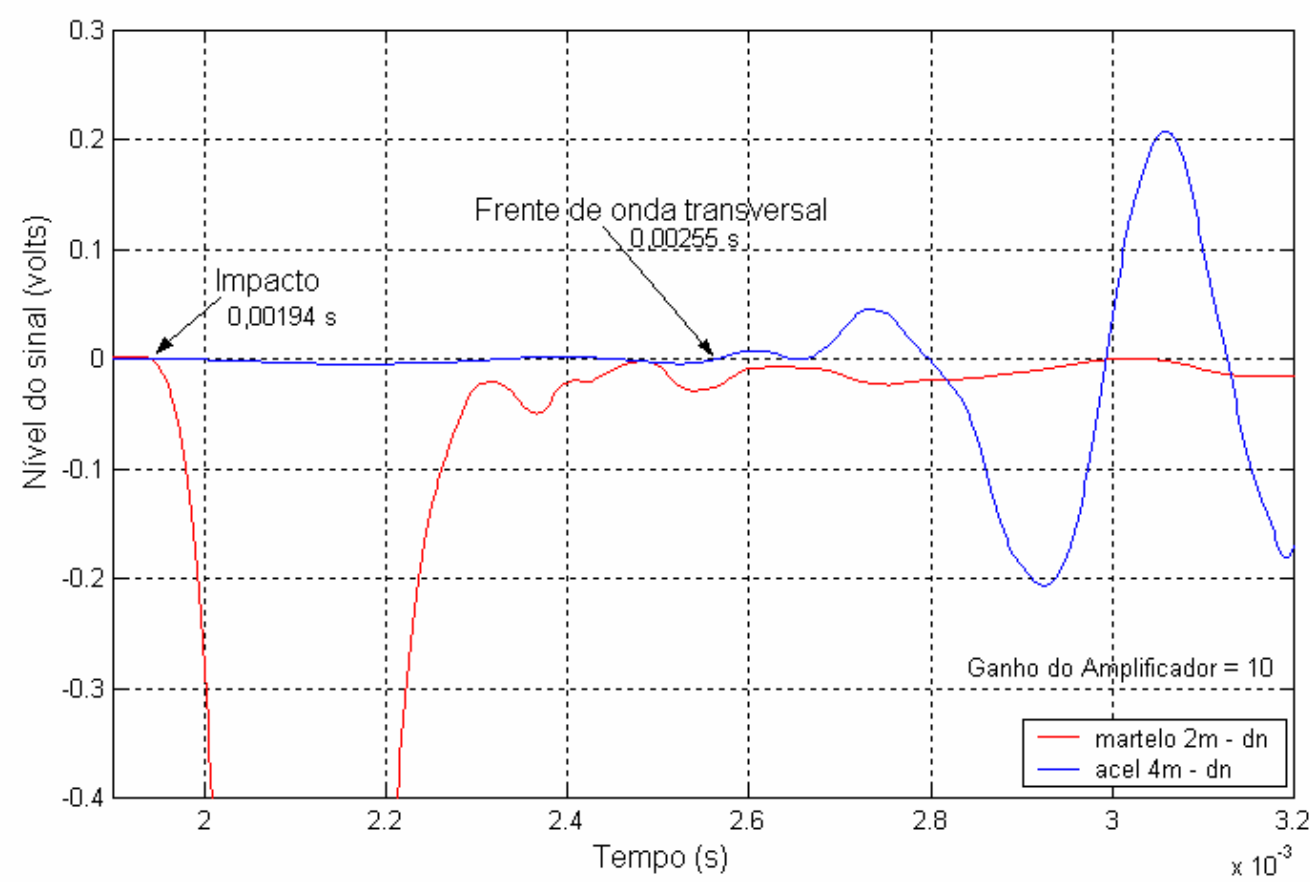

FIGURA 6.4 - Visualização da propagação da onda de impacto para amplificador com ganho 10.

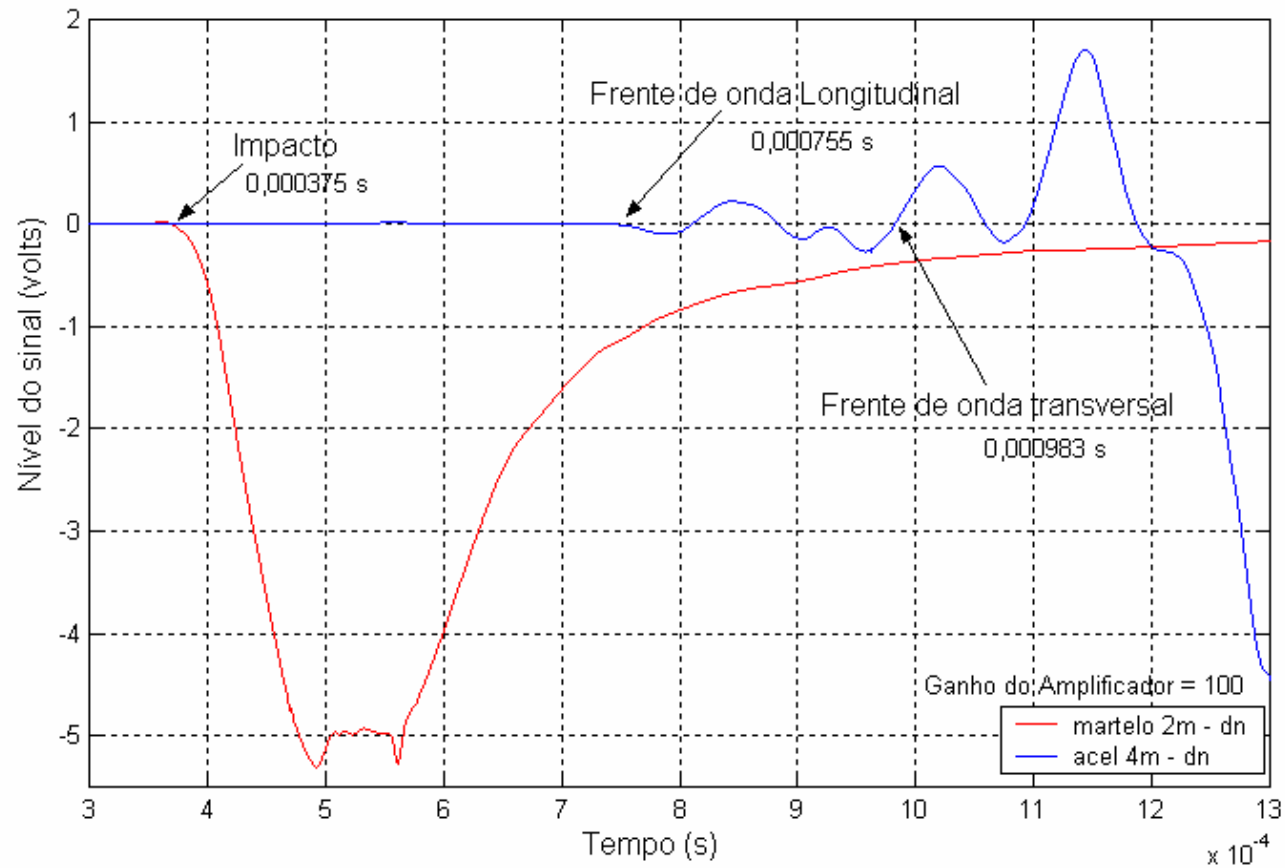

FIGURA 6.5 - Visualização da propagação da onda de impacto para amplificador com ganho 100.

Tanto neste último ensaio, como nos ensaios descritos no item anterior, não foi possível a determinação direta da velocidade onda de Rayleigh. Primeiro por ela ser a mais lenta de todas, a sua chegada acontece após a chegada das 
outras duas e em um instante não singular na figura da onda propagante. Segundo, conforme descrito por Lorde Rayleigh e relatado no capítulo 3, a onda de superfície é uma combinação das componentes longitudinais e transversais parcialmente acopladas o que dificulta sua visualização.

Os erros entre as medias e o esperado teoricamente, devem estar relacionados com a dificuldade de se determinar com exatidão os momentos de chegada das ondas propagante, somado às imperfeições do material e contornos que geram distorções nestas ondas. Além disso deve-se levar em conta que as propriedades físicas utilizadas para os cálculos teóricos são valores médios podendo variar com o tipo de aço usado.

Para os cálculos da solução analítica da equação do movimento da casca cilíndrica, equações (5.24) e (5.26), adotou-se como velocidade longitudinal, o valor teórico da velocidade da onda longitudinal plana em uma placa fina, obtida com base nas propriedades físicas do material que compunham o tubo estudado. 


\section{VALIDAÇÃO DO MODELO VIA MEDIDAS EXPERIMENTAIS}

Neste capítulo será tratada a validação experimental do modelo matemático apresentado no capítulo 5 , descrito pela equação (5.24) ou pela equação (5.26). Os ensaios foram realizados sobre a estrutura experimental descrita no capítulo 6 , a qual é recordada a seguir.

\subsection{Estrutura experimental}

A estrutura experimental, definida como bancada de testes, é composta de um tubo de aço carbono com $6 \mathrm{~m}$ de comprimento, raio médio $\mathrm{a}=10 \mathrm{~cm}$, espessura média de parede $h=4,6 \mathrm{~mm}$, cujas extremidades foram introduzidas $30 \mathrm{~cm}$ em caixas de areia seca com a finalidade de simular uma condição de tubo infinito. A FIG.7.1 mostra a fotografia da bancada utilizada nos ensaios, com detalhe para as terminações em caixas de areia seca, as quais possuem dimensões de $40 \mathrm{~cm} \times 40 \mathrm{~cm} \times 40 \mathrm{~cm}$.

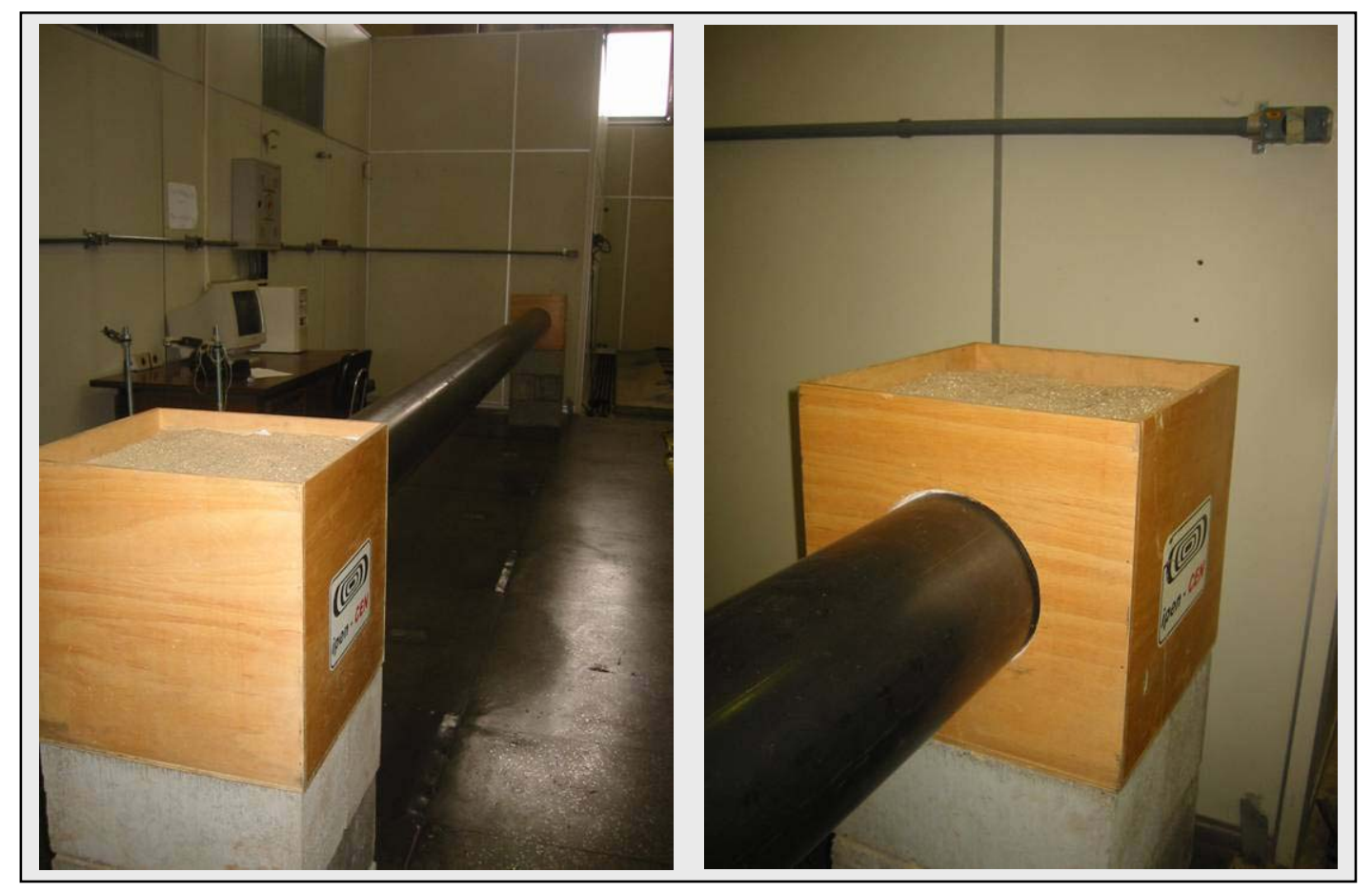

FIGURA 7.1 - Bancada de testes e detalhe do apoio em caixa de areia. 


\subsection{Experimentos e seus resultados}

\subsubsection{Mapeamento do tubo}

Para verificar o comportamento das propagações das ondas na superfície da casca cilíndrica, a superfície do tubo foi mapeada tanto na direção axial como circunferencial. As medidas foram realizadas por meio de acelerômetros devidamente espalhados sobre a superfície do tubo e fixados a esta por intermédio de cera de abelha. Em estudo realizado previamente, a cera de abelha apresentou resultados superiores quanto a repetibilidade do experimento e gerou menor interferência na resposta do sistema quando comparada com fixações magnéticas ou blocos de fixação. No APÊNDICE D encontra-se a análise deste tipo de fixação.

Como fonte de excitação pontual utilizou-se uma pastilha piezelétrica , acoplada a um pino com ponta, conectada em um gerador senoidal de freqüência ajustável e tensão de saída também ajustável. Sob a fonte de excitação, fixa na posição $0 \mathrm{~m}$, foi instalado um acelerômetro, o qual tem a finalidade de sincronizar todas as medidas provenientes dos outros sete acelerômetros. Estes últimos foram deslocados nas direções axial e circunferencial de forma a cobrir a região de estudo sobre o tubo.

As características técnicas de todos os instrumentos e sensores utilizados nos experimentos podem ser vistas no APÊNDICE B. No APÊNDICE C, têm-se os detalhes dos dispositivos criados para suportar os experimentos.

\subsubsection{Mapeamento sobre o ângulo zero}

Para o primeiro mapeamento tomou-se uma linha imaginária sobre a superfície do tubo na direção axial, a qual é definida como sendo o ângulo zero grau na direção circunferencial. Mantendo-se a fonte de excitação fixa no centro geométrico localizado a $3 \mathrm{~m}$ das extremidades e sobre esta linha $0^{\circ}$, instalou-se um conjunto de sete acelerômetros espaçados entre si de $5 \mathrm{~cm}$, os quais foram movidos sobre a linha axial, a partir do centro até os limites das caixas de areia, ou seja 2,7 m do centro, conforme mostram as FIG. 7.2 e FIG. 7.3. Com isto, obteve-se o mapeamento das propagações das ondas em uma direção na superfície do tubo em função do tempo. 


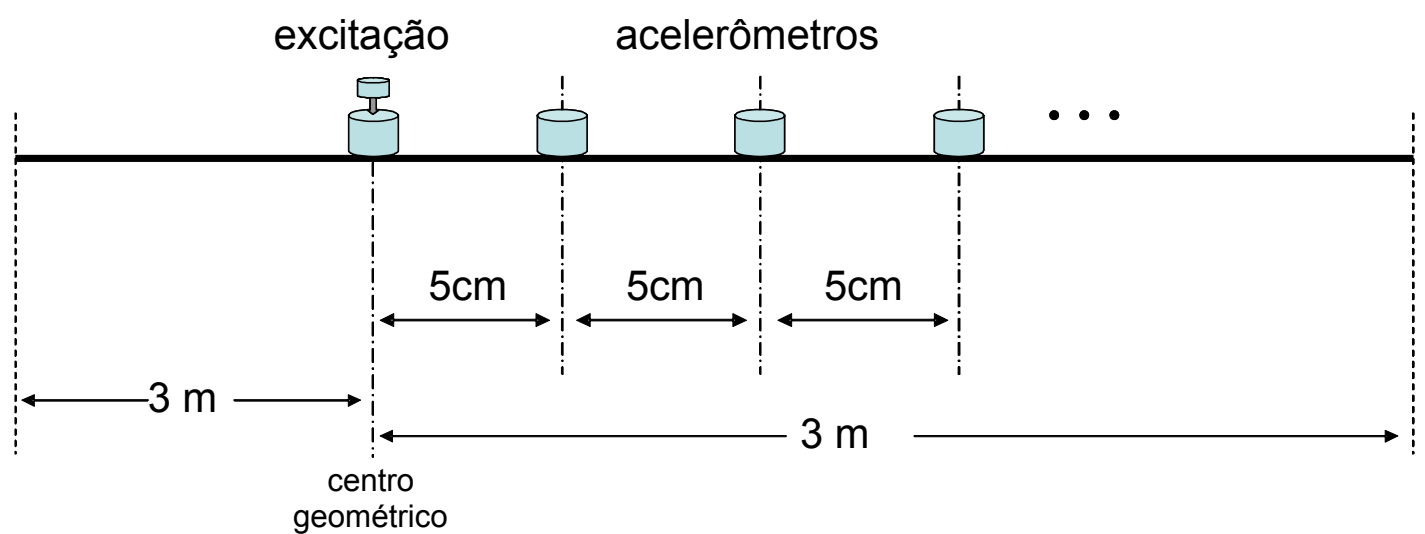

FIGURA 7.2 - Esboço da distribuição da fonte e dos acelerômetros na superfície do tubo.

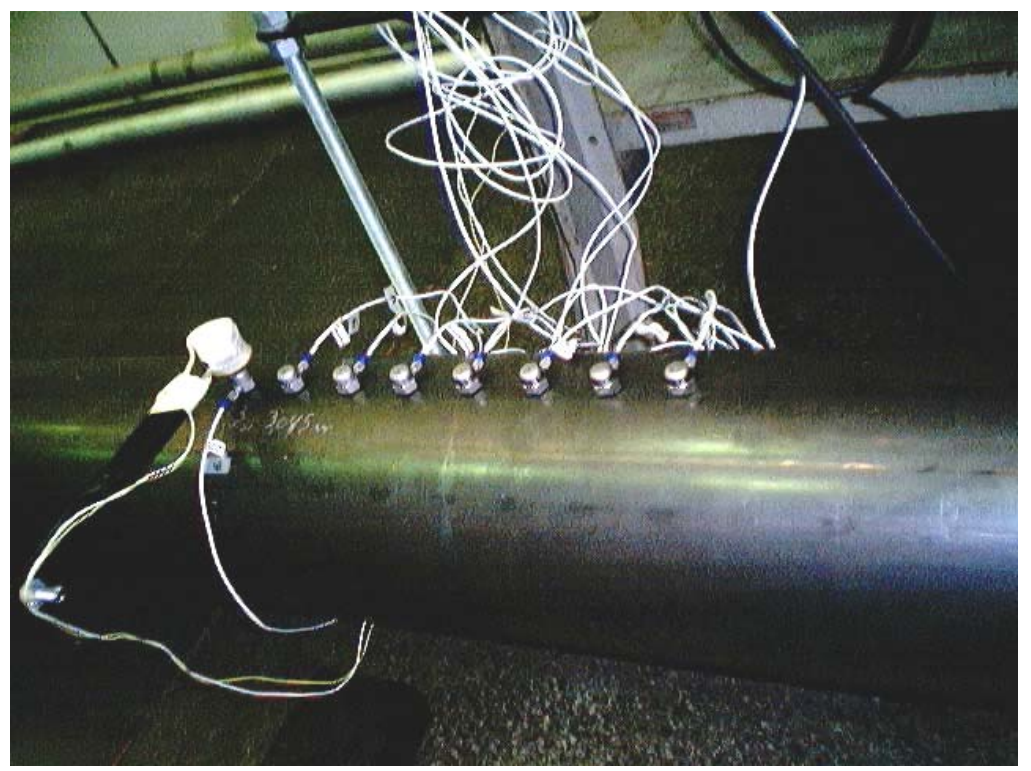

FIGURA 7.3 - Vista da distribuição dos acelerômetros na superfície do tubo e a fonte de excitação para uma seqüência de medidas.

Após o tratamento dos dados obtidos, utilizando-se do software matemático Matlab ${ }^{1}$, obtém-se a imagem das propagações das ondas na parede do tubo em função da distância e do tempo para as freqüências de $1 \mathrm{KHz}, 2 \mathrm{KHz}$ e $3 \mathrm{KHz}$. Na FIG.7.4, tem-se a imagem da propagação da onda medida na freqüência de $2 \mathrm{KHz}$, onde se vê os pontos de máximos representados em vermelho, os pontos de mínimos representados em azul e os valores próximos dos zeros representados em verde ou amarelo. Nas FIG. 7.4 até 7.7, o eixo $x$

\footnotetext{
${ }^{1}$ Marca registrada da The Math Works, Inc.
} 
representa o tempo, o eixo y a distância axial e o eixo z, o qual está direcionado para fora do papel, representa a aceleração.

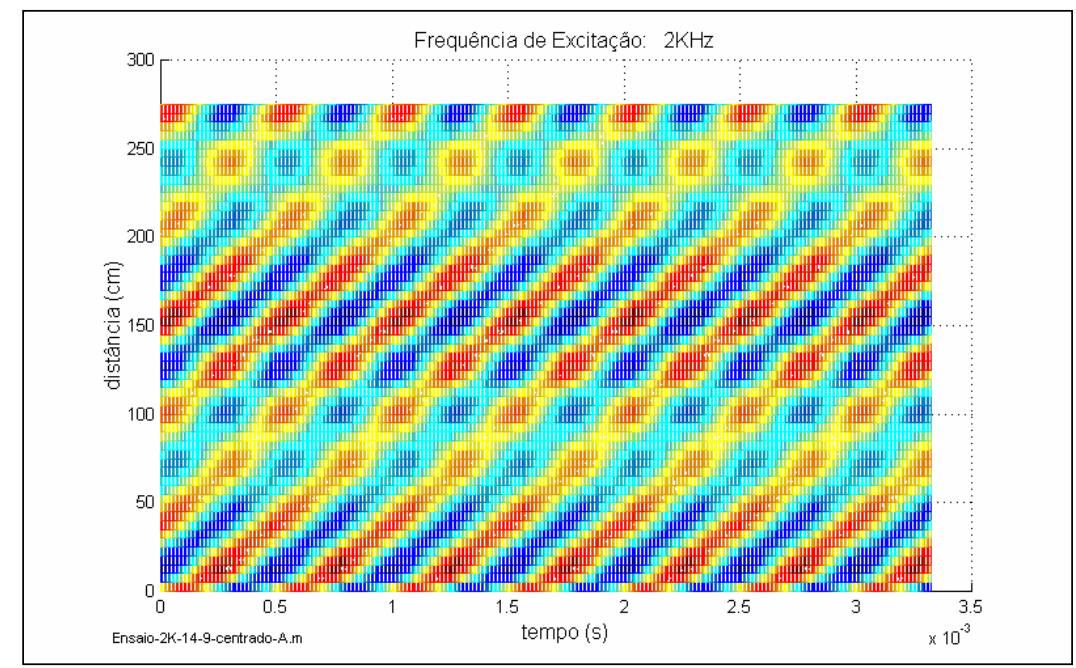

FIGURA 7.4 - Mapa da propagação da onda medida sobre a linha $0^{\circ}$ na direção axial na superfície do tubo.

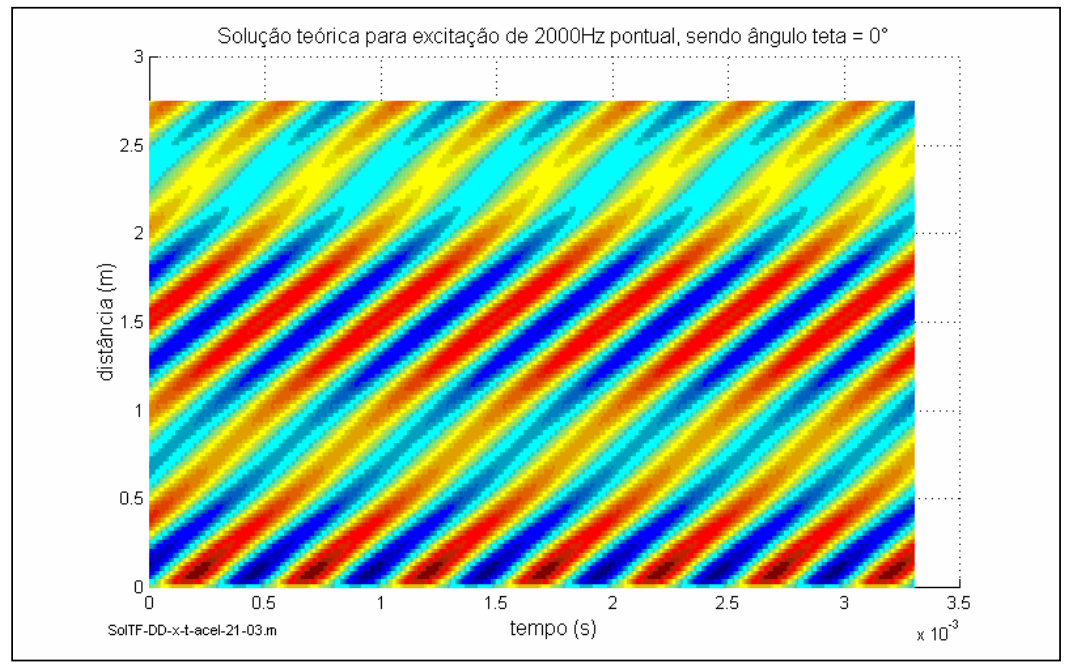

FIGURA 7.5 - Mapa da propagação da onda simulada sobre a linha $0^{\circ}$ na direção axial na superfície do tubo.

Comparando-se a FIG 7.4 com a FIG 7.5, as quais apresentam os resultados do mapeamento medido e simulado através da equação (5.24), respectivamente, vê-se em uma primeira análise qualitativa, uma semelhança nos padrões apresentados no que diz respeito às posições dos pontos de máximo e mínimo ao longo da propagação da onda. Estes padrões mostram como a superfície do tudo se comporta ao longo do eixo axial e do tempo. 
Tomando-se uma linha diagonal formada pelos picos da onda medida, a qual representa a onda resultante propagando sobre o tubo no tempo, observa-se que as variações na intensidade da amplitude da onda no mapeamento coincidem com os padrões apresentados no resultado simulado. Estas concordâncias entre medida e simulação mantiveram-se para outras freqüências de excitação como pode ser visto nas FIG.7.6 e 7.7, as quais apresentam os padrões de medida e simulação para as freqüências de $1 \mathrm{KHz} e$ $3 \mathrm{KHz}$ respectivamente.

(a)

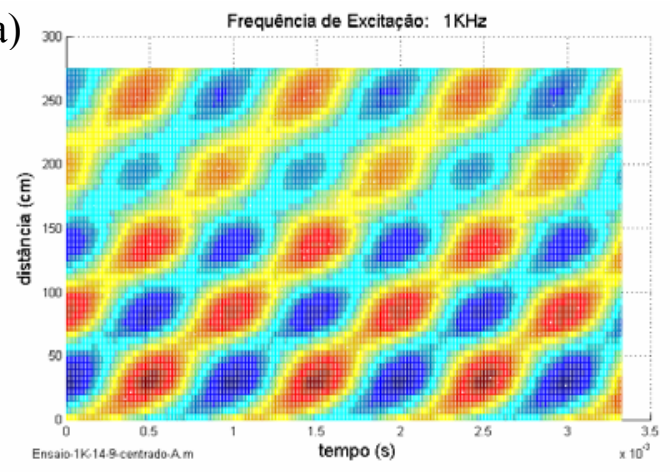

(b)

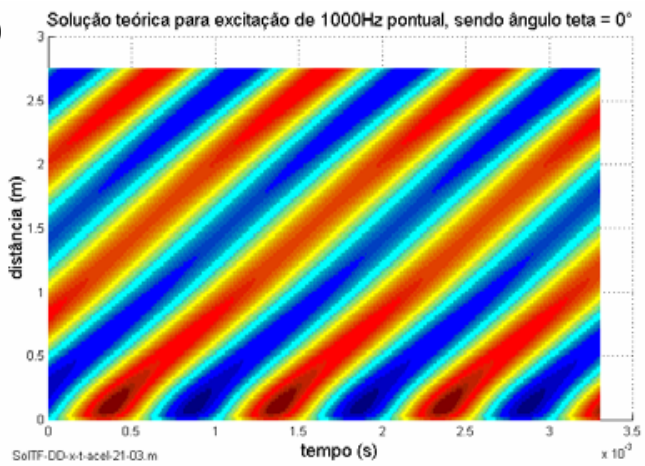

FIGURA 7.6 - Mapas das propagações das ondas medidas (a) e simuladas (b), para $1 \mathrm{KHz}$.

(a)

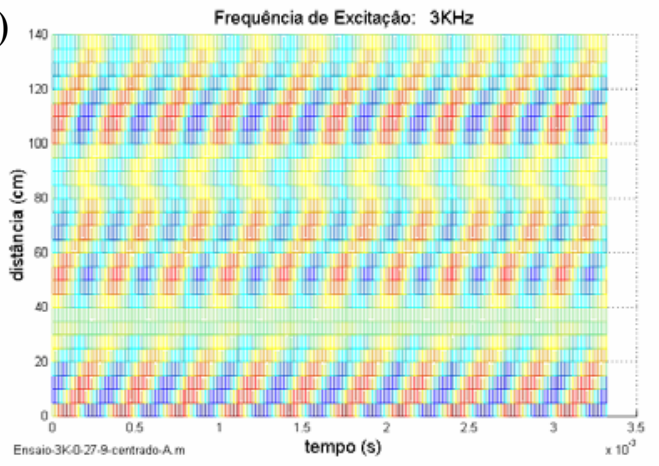

(b)

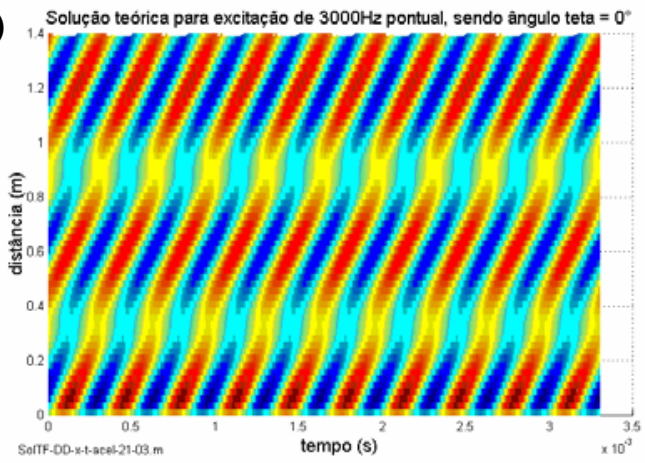

FIGURA 7.7 - Mapas das propagações das ondas medidas (a) e simuladas (b), para $3 \mathrm{KHz}$.

Tomando-se agora, algumas posições sobre a superfície do tubo em relação ao local de excitação, semelhante a fatias retiradas das FIG 7.4 até 7.7, observam-se os atrasos no tempo das chegadas das ondas nestas posições. As FIG. 7.8, 7.9 e 7.10, a seguir, mostram os atrasos provenientes das medidas e das simulações teóricas para as posições $40 \mathrm{~cm}, 60 \mathrm{~cm}$ e $80 \mathrm{~cm}$, afastadas da excitação (sensor de referência). 

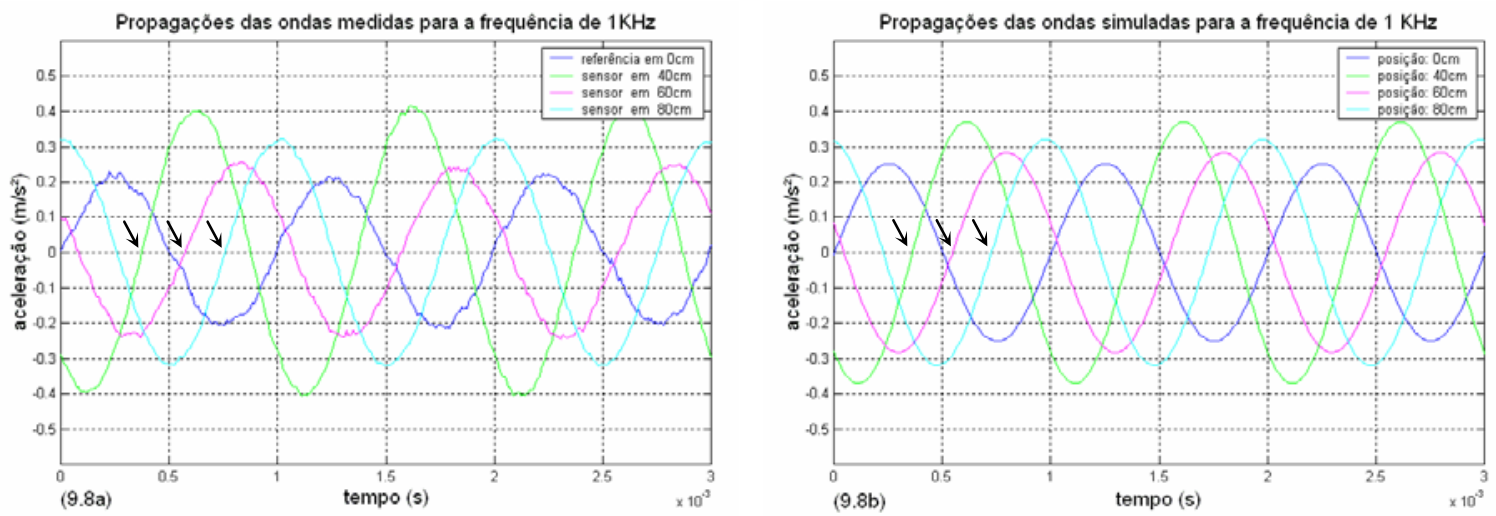

FIGURA 7.8 - Comparação no tempo entre propagação medida (a) e simulada (b), para $1 \mathrm{KHz}$.
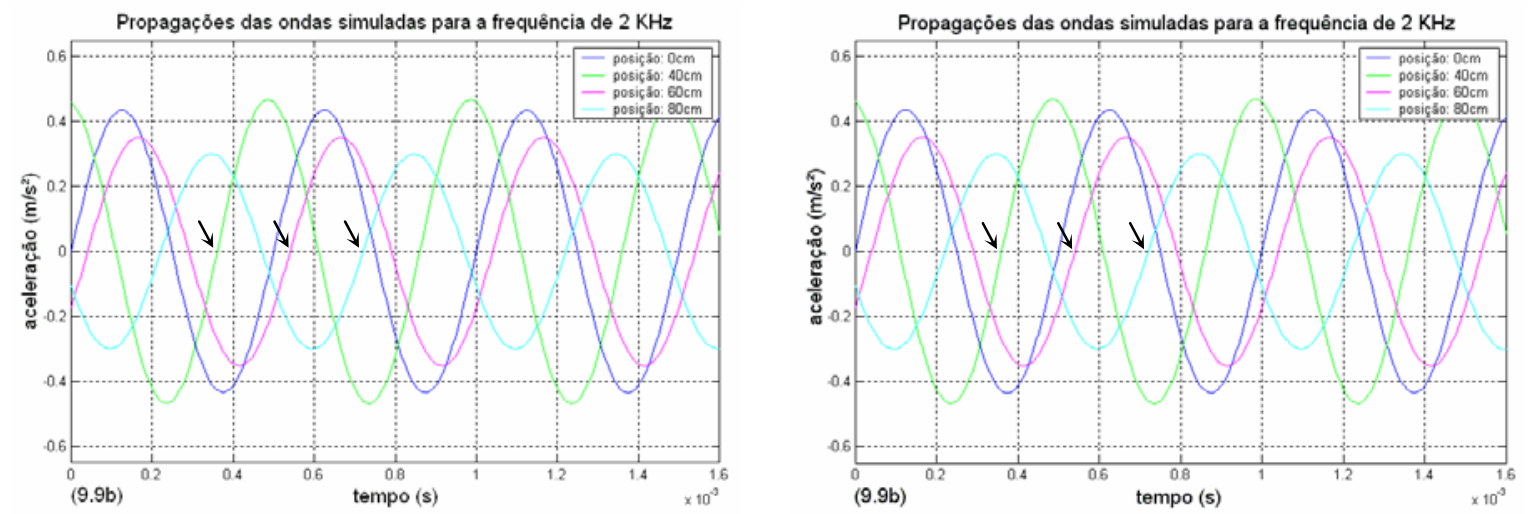

FIGURA 7.9 - Comparação no tempo entre propagação medida (a) e simulada (b), para $2 \mathrm{KHz}$.
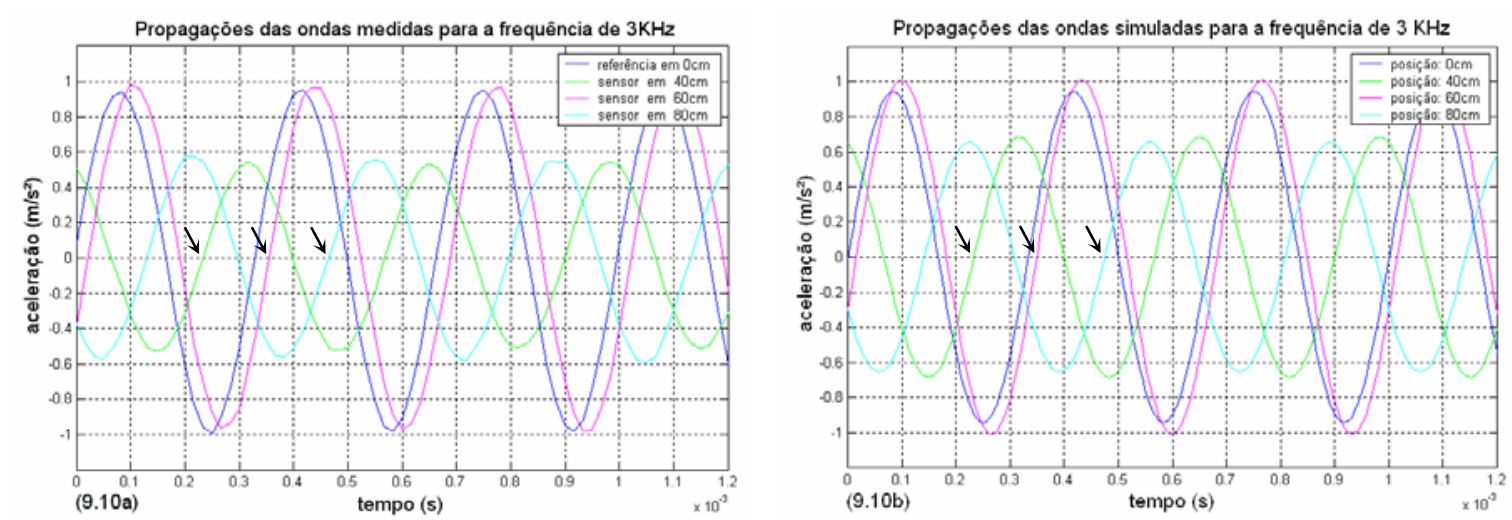

FIGURA 7.10 - Comparação no tempo entre propagação medida (a) e simulada (b), para $3 \mathrm{KHz}$.

Os atrasos das chegadas das ondas nos sensores estão relacionados com as velocidades efetivas das ondas estacionárias geradas na superfície do tubo e com as distâncias dos sensores em relação ao sensor $A$ de referência. 
Com base nas FIG. 7.8, 7.9 e 7.10, são obtidos os atrasos entre a onda de excitação, em azul escuro nos gráficos, e as ondas que chegam aos sensores distantes. Para a determinação dos atrasos no tempo, são tomados os instantes de cruzamento das ondas pelo zero, pontos marcados com pequenas setas nos gráficos. Conhecendo-se as distâncias destes sensores em relação à excitação, obtêm-se as velocidades efetivas das propagações, as quais são diferentes das velocidades longitudinais e transversais, dado que os sensores enxergam a somatória das ondas que chegam a eles pelos diversos caminhos possíveis sobre a superfície do tubo, conforme estudado no capítulo 5. Estes atrasos $(\Delta t)$ e suas

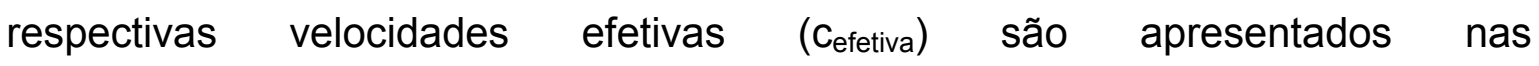
TAB. 7.1, 7.2 e 7.3 .

TABELA 7.1 - Atrasos e velocidades para a freqüência de $1 \mathrm{KHz}$

\begin{tabular}{c|c|c}
\cline { 2 - 3 } & \multicolumn{2}{|c}{ Medido } \\
\hline distância & $\Delta \mathrm{t}(\mathrm{s})$ & Cefetiva $(\mathrm{m} / \mathrm{s})$ \\
\hline $40 \mathrm{~cm}$ & $3,7310^{-4}$ & 1072 \\
\hline $60 \mathrm{~cm}$ & $5,7410^{-4}$ & 1045 \\
\hline $80 \mathrm{~cm}$ & $7,6010^{-4}$ & 1053 \\
\hline \multirow{3}{*}{} & Cefetiva média $_{1}$ & $\mathbf{1 0 5 7}$ \\
\cline { 2 - 3 } & $\Lambda$ médio & $\mathbf{1 , 0 5 7} \mathbf{~ m}$ \\
\cline { 2 - 3 }
\end{tabular}

\begin{tabular}{|r|c|}
\hline \multicolumn{2}{|c|}{ Simulado } \\
\hline$\Delta \mathrm{t}(\mathrm{s})$ & $\mathrm{C}_{\text {efetiva }}(\mathrm{m} / \mathrm{s})$ \\
\hline $3,6510^{-4}$ & 1096 \\
\hline $5,4910^{-4}$ & 1093 \\
\hline $\mathbf{7 , 3 0 1 0 ^ { - 4 }}$ & 1095 \\
\hline \hline C $_{\text {efetiva } \text { média }}$ & $\mathbf{1 0 9 4 , 7}$ \\
\hline$\Lambda$ médio & $\mathbf{1 , 0 9 5} \mathbf{~}$ \\
\hline
\end{tabular}

TABELA 7.2 - Atrasos e velocidades para a freqüência de $2 \mathrm{KHz}$

\begin{tabular}{c|c|c}
\cline { 2 - 3 } & \multicolumn{2}{|c}{ Medido } \\
\hline distância & $\Delta \mathrm{t}(\mathrm{s})$ & Cefetiva $(\mathrm{m} / \mathrm{s})$ \\
\hline $40 \mathrm{~cm}$ & $3,6510^{-4}$ & 1096 \\
\hline $60 \mathrm{~cm}$ & $5,4510^{-4}$ & 1101 \\
\hline $80 \mathrm{~cm}$ & $7,3310^{-4}$ & 1091 \\
\hline \multirow{3}{*}{} & Cefetiva média & $\mathbf{1 0 9 6}$ \\
\cline { 2 - 3 } & $\Lambda$ médio & $\mathbf{0 , 5 4 8} \mathbf{~ m}$ \\
\cline { 2 - 3 }
\end{tabular}

\begin{tabular}{|r|c|}
\hline \multicolumn{2}{|c|}{ Simulado } \\
\hline$\Delta \mathrm{t}(\mathrm{s})$ & $\mathrm{C}_{\text {efetiva }}(\mathrm{m} / \mathrm{s})$ \\
\hline $3,6110^{-4}$ & 1108 \\
\hline $5,4110^{-4}$ & 1109 \\
\hline $7,2010^{-4}$ & 1111 \\
\hline \hline $\mathbf{C}_{\text {efetiva } \text { média }}$ & $\mathbf{1 1 0 9 , 3}$ \\
\hline$\Lambda$ médio & $\mathbf{0 , 5 5 5} \mathbf{~}$ \\
\hline
\end{tabular}

TABELA 7.3 - Atrasos e velocidades para a freqüência de $3 \mathrm{KHz}$

\begin{tabular}{c|c|c}
\cline { 2 - 3 } & Medido & \\
\hline distância & $\Delta \mathrm{t}(\mathrm{s})$ & C $_{\text {efetiva }}(\mathrm{m} / \mathrm{s})$ \\
\hline $40 \mathrm{~cm}$ & $2,3310^{-4}$ & 1716 \\
\hline $60 \mathrm{~cm}$ & $3,5210^{-4}$ & 1704,5 \\
\hline $80 \mathrm{~cm}$ & $4,6510^{-4}$ & 1720 \\
\hline \multirow{3}{*}{} & Cefetiva média & $\mathbf{1 7 1 3 , 5}$ \\
\cline { 2 - 3 } & $\Lambda$ médio & $\mathbf{0 , 5 7 1} \mathbf{~}$ \\
\cline { 2 - 3 }
\end{tabular}

\begin{tabular}{|r|c}
\hline \multicolumn{1}{|c|}{ Simulado } & \\
\hline$\Delta \mathrm{t}(\mathrm{s})$ & $\mathrm{C}_{\text {efetiva }}(\mathrm{m} / \mathrm{s})$ \\
\hline $2,3410^{-4}$ & 1709 \\
\hline $3,5010^{-4}$ & 1714 \\
\hline $4,7010^{-4}$ & 1702 \\
\hline \hline $\mathbf{C}_{\text {efetiva }}$ média & $\mathbf{1 7 0 8 , 3}$ \\
\hline$\Lambda$ médio & $\mathbf{0 , 5 6 9} \mathbf{~}$ \\
\hline
\end{tabular}


Nas tabelas também são apresentados os comprimentos de onda médios, os quais são obtidos através da relação $\Lambda=c / f$, onde $\Lambda$ é o comprimento de onda. Das FIG. 7.4 até 7.7, pode-se observar os comprimentos de onda teórico e simulado, bastando para isto tomar um instante de tempo e medir a distância entre as cristas das ondas na direção das distâncias, eixo y dos gráficos.Por exemplo, da FIG. 7.6, no instante zero segundo, observa-se uma crista em aproximadamente $0,95 \mathrm{~m}$ e a seguinte em aproximadamente $2 \mathrm{~m}$, o que resulta em um comprimento de onda de $1,05 \mathrm{~m}$, conforme relata a TAB. 7.1. A mesma análise pode ser feita com os gráficos de $2 \mathrm{KHz}$ e $3 \mathrm{KHz}$, confirmando os resultados das respectivas tabelas.

Nas FIG. 7.9 e 7.10, é interessante observar que os pontos de cruzamento com o zero escolhidos para $60 \mathrm{~cm}$ e $80 \mathrm{~cm}$ não são os primeiros dos gráficos, ou seja, os mais próximos do instante zero segundo. Isto se deve ao fato que em função da velocidade de propagação e da distância, o tempo de chegada da onda no sensor é superior ao período desta onda no tempo. Deste modo, se fosse feita à correlação cruzada, por exemplo, da excitação contra o sinal obtido no sensor distante $60 \mathrm{~cm}$, para a freqüência de $2 \mathrm{KHz}$, seria obtido um ponto de máximo no instante $0,4510^{-4} \mathrm{~s}$ ao invés de $5,4510^{-4} \mathrm{~s}$ que é o atraso real. Tal valor resultaria em uma velocidade de $13333 \mathrm{~m} / \mathrm{s}$ e em um comprimento de onda de 6,7 m, o qual não condiz com o observado pelo gráfico da FIG. 7.4.

\subsubsection{Mapeamento nas direções axial e circunferencial}

Nas FIG. 5.7 e 5.8 do capítulo 5, foram observados pontos de máximos e mínimos formados pelas ondas estacionárias na superfície do tubo, com relação às distâncias axial e circunferencial. Com o objetivo de verificar a consistência dos resultados teóricos gerados pela equação (5.24), realizou-se o mapeamento real da superfície do tubo nas direções axial e circunferencial para um trecho deste tubo. Um exemplo da disposição dos acelerômetros sobre a superfície para um dado local de medida pode ser visto na FIG. 7.11. 


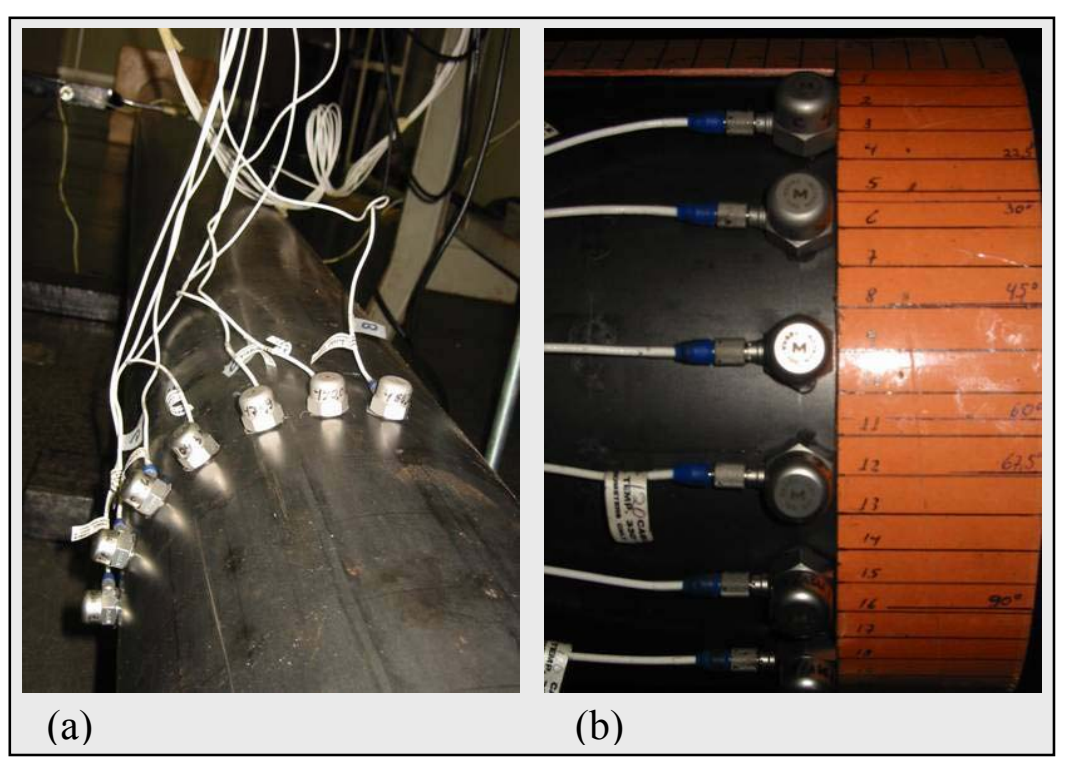

FIGURA 7.11 - a) Disposições dos sensores para o mapeamento da superfície do tubo.

b) Detalhe dos sensores junto com a régua de posicionamento.

O procedimento adotado, consistiu em manter um acelerômetro junto com a fonte de excitação na posição central definida como $x=0 \mathrm{~m}$ e $\theta=0^{\circ}$, situada a três metros das extremidades do tubo. Este acelerômetro serviu de referência na sincronização da placa de aquisição de dados. Os outros sete acelerômetros foram posicionados nos ângulos $0^{\circ}, 17^{\circ}, 34^{\circ}, 51^{\circ}, 68^{\circ}, 85^{\circ}$ e $102^{\circ}$, o que corresponde a um espaçamento de $3 \mathrm{~cm}$ de centro a centro dos acelerômetros. Estes sete acelerômetros foram sendo deslocados na direção axial de $5 \mathrm{~cm}$ em $5 \mathrm{~cm}$, até a posição máxima de $205 \mathrm{~cm}$ do centro.

As comparações entre os resultados medidos e os resultados teóricos obtidos da simulação podem ser vistas nas FIG. 7.12, 7.13 e 7.14. Nas figuras o eixo x representa a distância axial, o eixo y o ângulo em graus e o eixo z, o qual está direcionado para fora da superfície do papel, representa a aceleração. Os pontos em vermelho representam as maiores amplitudes, os azuis as menores e os verdes os zeros.

Para melhorar a visualização dos gráficos das medidas, foi realizada a interpolação linear destas medidas na direção axial com passo de $1 / 8$, ou seja entre dois pontos originais foram gerados sete novos pontos. Como as medidas foram realizadas com passo original de $5 \mathrm{~cm}$, isto representa um novo passo de $0,625 \mathrm{~cm}$ na direção $x$. 
(a) Medida: Distância $x$ Ângulo na frequência de $1 \mathrm{KHz}$ e instante 0 segundos

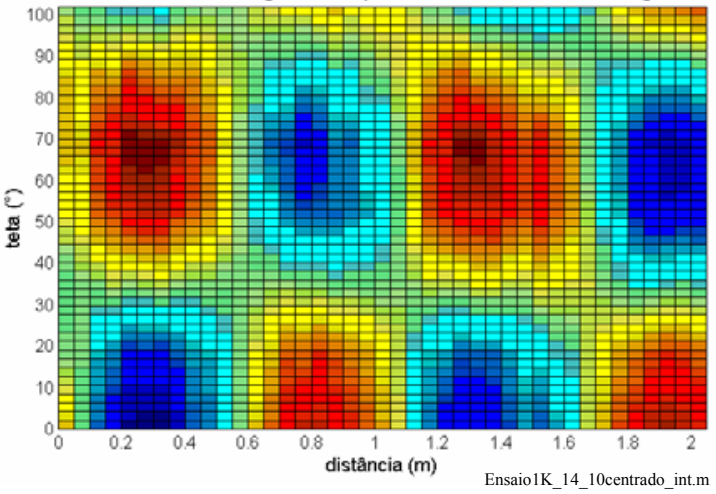

(b) Simulado: $\mathrm{n}=10$ - frequência $=1 \mathrm{KHz}-$ instante $=0 \mathrm{~s}$

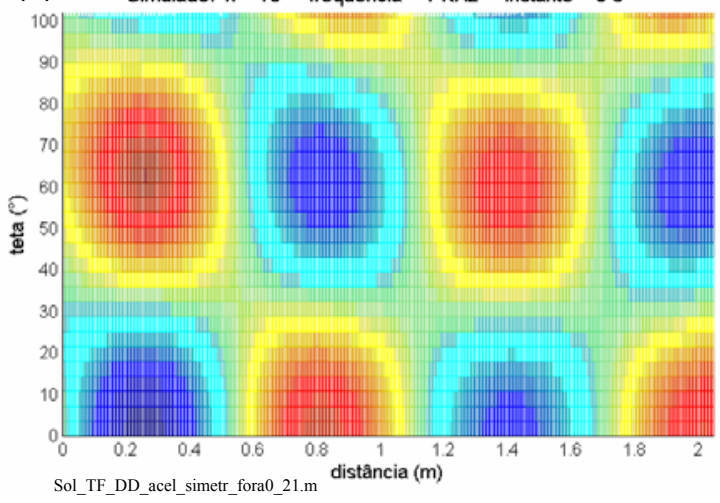

FIGURA 7.12 - a) Mapeamento da superfície do tubo na freqüência de $1 \mathrm{KHz}$. b) Solução teórica do mapeamento para $1 \mathrm{KHz}$ e $n=10$.

(a)

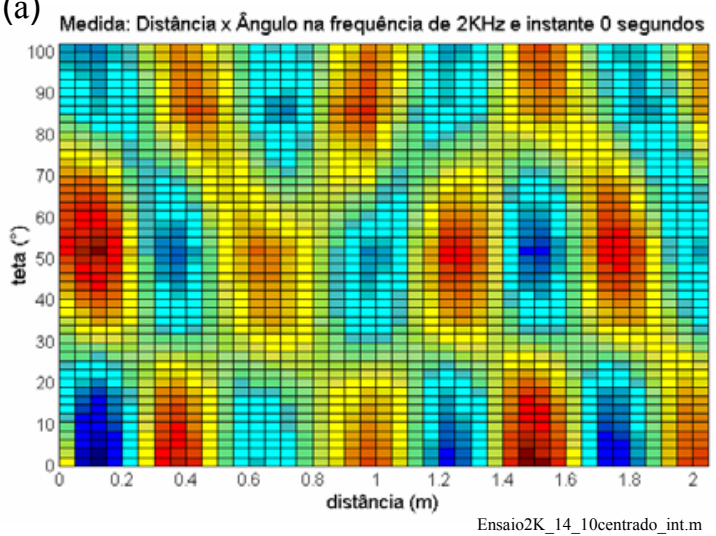

(b)

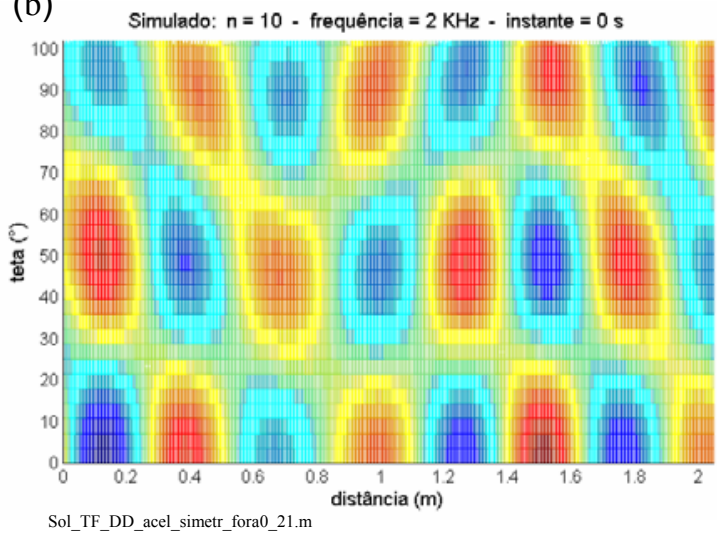

FIGURA 7.13 - a) Mapeamento da superfície do tubo na freqüência de $2 \mathrm{KHz}$. b) Solução teórica do mapeamento para $2 \mathrm{KHz}$ e $n=10$.

(a)

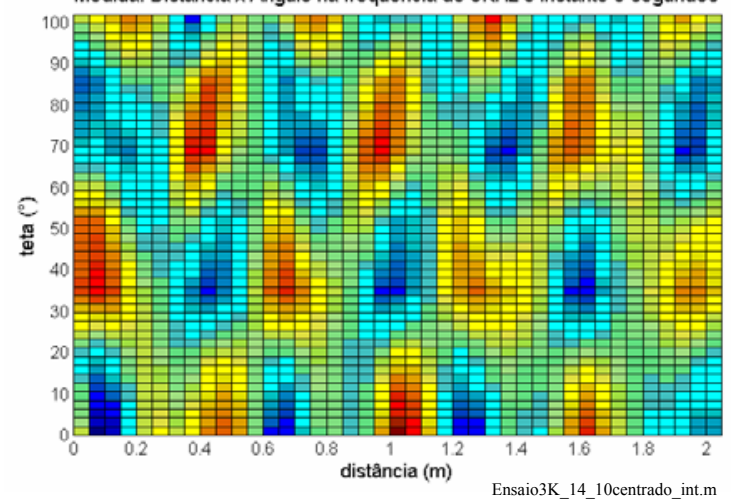

(b)

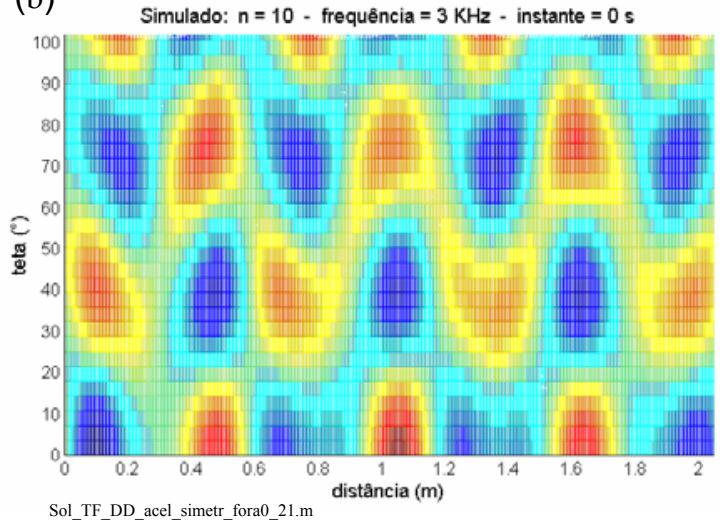

FIGURA 7.14 - a) Mapeamento da superfície do tubo na freqüência de $3 \mathrm{KHz}$. b) Solução teórica do mapeamento para $3 \mathrm{KHz}$ e $n=10$.

É observado para as três freqüências usadas como exemplo, que há uma boa correlação entre o modelo teórico e o mapeamento real de um trecho do tubo escolhido, no que se refere à distribuição dos pontos de máximos e mínimos 
na superfície da casca cilíndrica. Esta distribuição é provocada pela estacionariedade da onda. Ou de outro modo pode-se dizer que a distribuição em cada ponto é a sobreposição das ondas chegando por vários caminhos ao redor do tubo, como descrito no item 5.2.

É notável também, que existem regiões com pontos nas cores amarelo e verde claro, os quais apresentam valores próximos de zero. Ou seja, são pontos de nós da superfície do tubo que ficam "parados". Isto significa que um acelerômetro colocado neste ponto não irá indicar aceleração. No capítulo 9, serão analisados casos em que esta situação dificulta e até impossibilita o processo de localização da fonte.

\subsubsection{Determinação da relação entre as amplitudes medidas nos acelerômetros e a amplitude da força $F_{0}$ da solução teórica}

Com o objetivo de determinar a relação entre a força real aplicada na superfície do tubo pela excitação pontual com a força $F_{0}$ da solução teórica, equação (5.24), foi feita uma análise do erro percentual médio entre os valores RMS das medidas contra os RMS dos resultados calculados. Onde, para cada posição $x$ - $\theta$ medida no mapeamento foi realizada uma comparação com a equivalente posição $x$ - $\theta$ teórica para valores de $F_{0}$ variando de $-3 \mathrm{~N}$ até $0 \mathrm{~N}$ na equação (5.24). A comparação teve como objetivo encontrar o valor de $F_{0}$ que produzisse a menor diferença entre medida e cálculo teórico. Os resultados desta comparação podem ser vistos na FIG.7.15, a qual mostra que para as freqüências analisadas a força obtida está entre $-2,2 \mathrm{~N}$ e $-2,5 \mathrm{~N}$, para a condição experimental de 10 volts pico a pico senoidal aplicado no piezelétrico de excitação pontual. Esta variação no resultado da força de excitação é esperada por se tratar de um sistema dinâmico, que com certeza apresenta variações na resposta em freqüência tanto do dispositivo de excitação, como do tubo e também do sensor de medida. Por se tratar de um sistema dinâmico, possivelmente para freqüências diferentes da faixa estudada, para a mesma tensão de excitação, obtenham-se respostas distintas das obtidas aqui. No futuro novas avaliações poderão ser realizadas em função de outras freqüências de excitação a serem estudadas. 
Os valores apresentados nos gráficos foram os utilizados nas análises anteriores, principalmente as apresentadas nas FIG.7.8, 7.9 e 7.10, cujos resultados confirmam, a validade do modelo teórico no que diz respeito às amplitudes das ondas propagantes comparadas com os resultados práticos em ralação ao tempo.

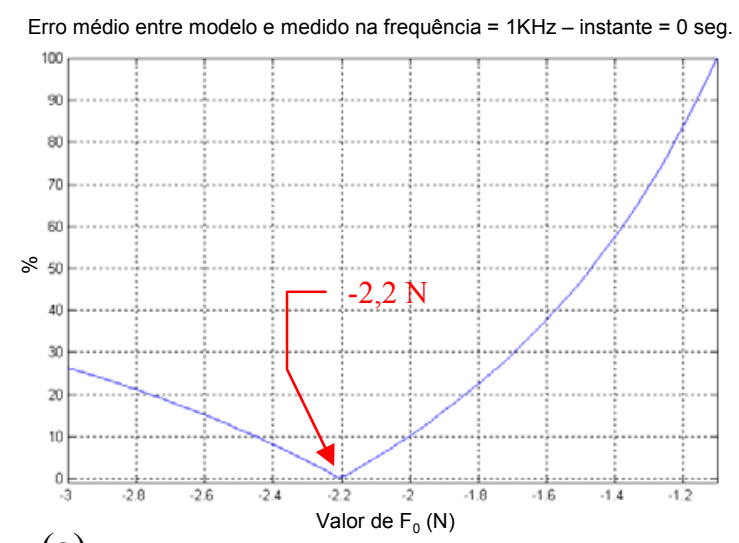

(a)

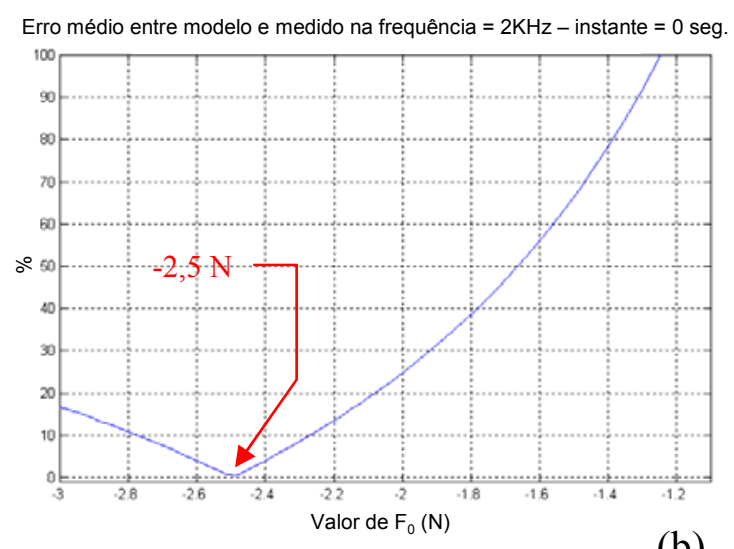

(b)

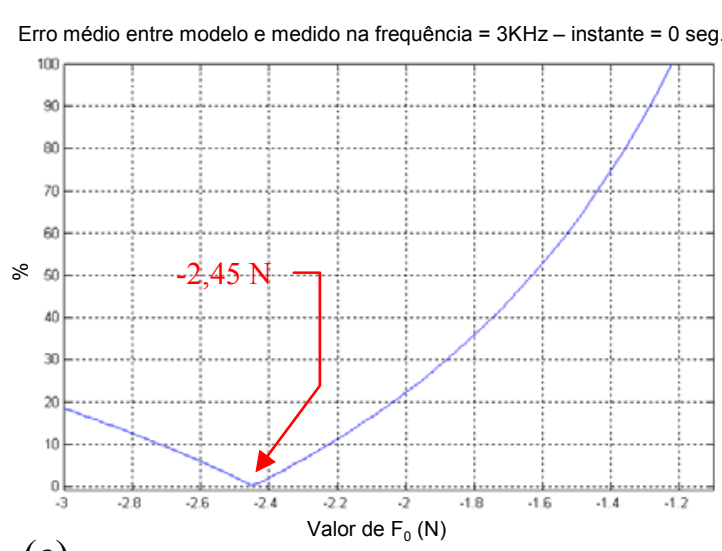

(c)

FIGURA 7.15 - Determinação da força de excitação nas freqüências:
a) $1 \mathrm{KHz}$;
b) $2 \mathrm{KHz}$;
c) $3 \mathrm{KHz}$

Aplicando-se os valores de $F_{0}$, obtidos anteriormente, na solução teórica da equação (5.24) para as respectivas freqüências e escolhendo-se alguns ângulos para comparação com os equivalentes medidos, em um determinado instante de tempo, observa-se através das FIG. 7.16, 7.17 e 7.18 uma excelente correlação qualitativa e quantitativa dos resultados no que diz respeito às formas das ondas e das amplitudes encontradas na direção do eixo axial. Esta análise vem novamente demonstrar a validade do modelo teórico para um tubo de casca fina de comprimento infinito. 

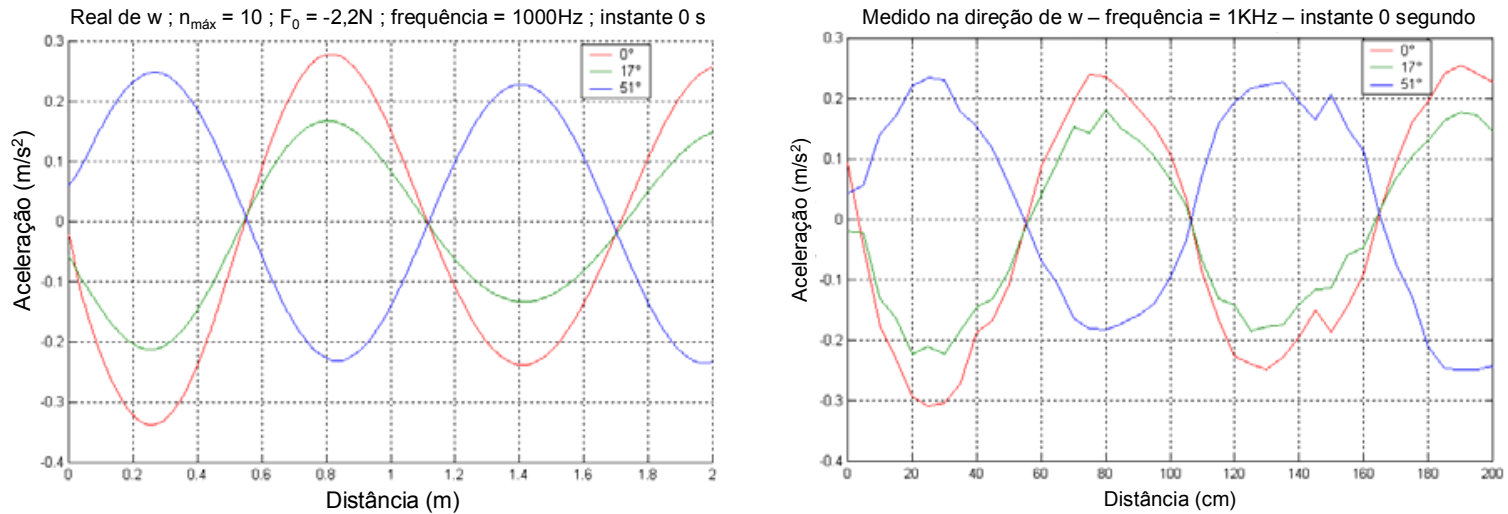

FIGURA 7.16 - Comparação entre solução teórica e medida em $1 \mathrm{KHz}$ para três ângulos ao longo da direção axial, no instante zero segundo.
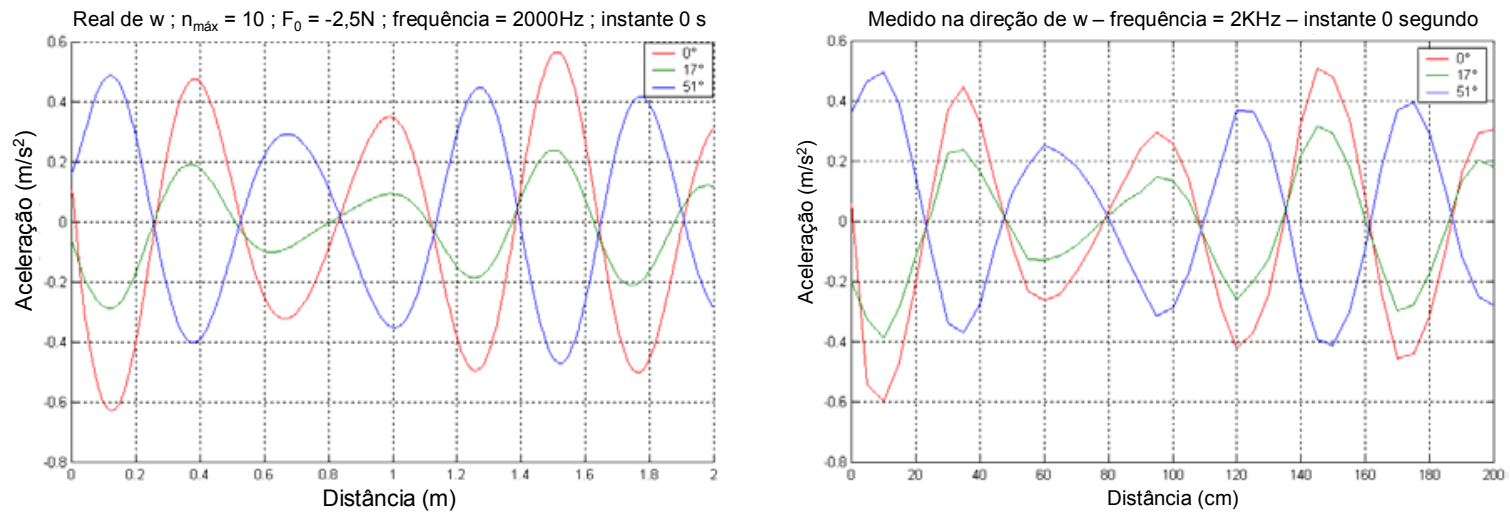

FIGURA 7.17 - Comparação entre solução teórica e medida em $2 \mathrm{KHz}$ para três ângulos ao longo da direção axial, no instante zero segundo.
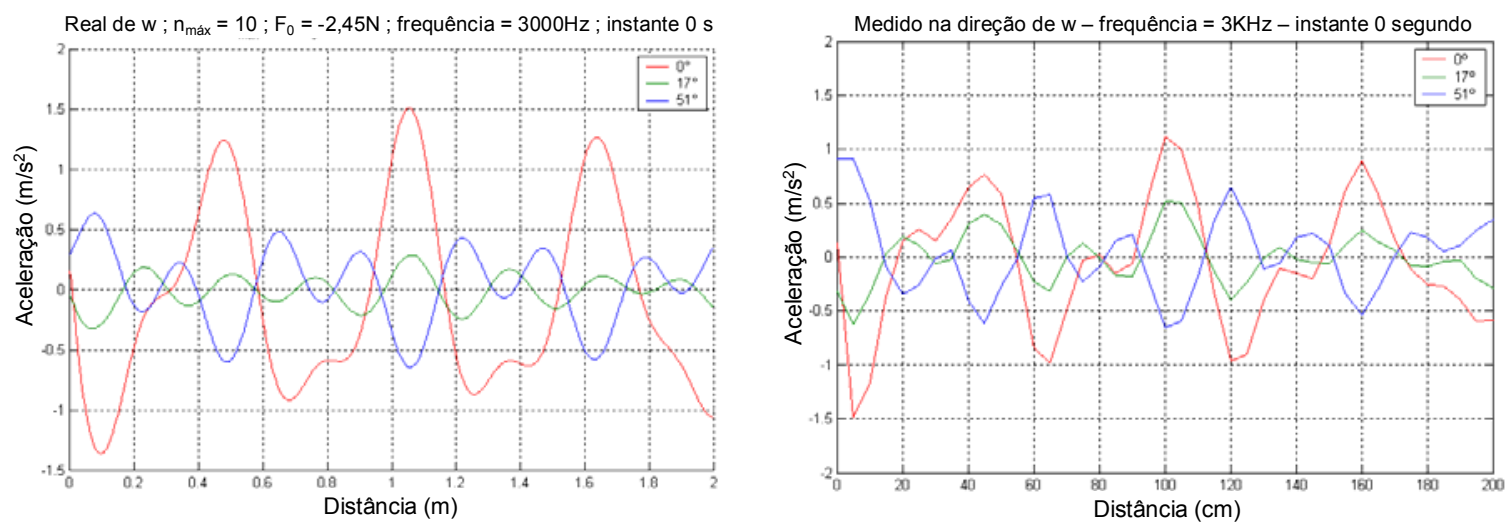

FIGURA 7.18 - Comparação entre solução teórica e medida em 3KHz para três ângulos ao longo da direção axial, no instante zero segundo. 


\subsubsection{Determinação das freqüências de ressonância por meio do modelo teórico e das medidas no sistema real}

$\mathrm{Na}$ solução teórica, equação (5.24), mantendo-se $x=0 \mathrm{~m}, \theta=0^{\circ} \mathrm{e}$ instante $t=0 \mathrm{~s}$, varrendo-se a freqüência de excitação de 0 até $15 \mathrm{KHz}$, obtém-se a resposta em freqüência para o tubo teórico, a qual é apresentada na FIG. 7.19. Do gráfico pode-se notar a existência de freqüências onde os níveis de aceleração apresentam picos. Estes picos podem ser entendidos como pontos de ressonâncias do sistema.

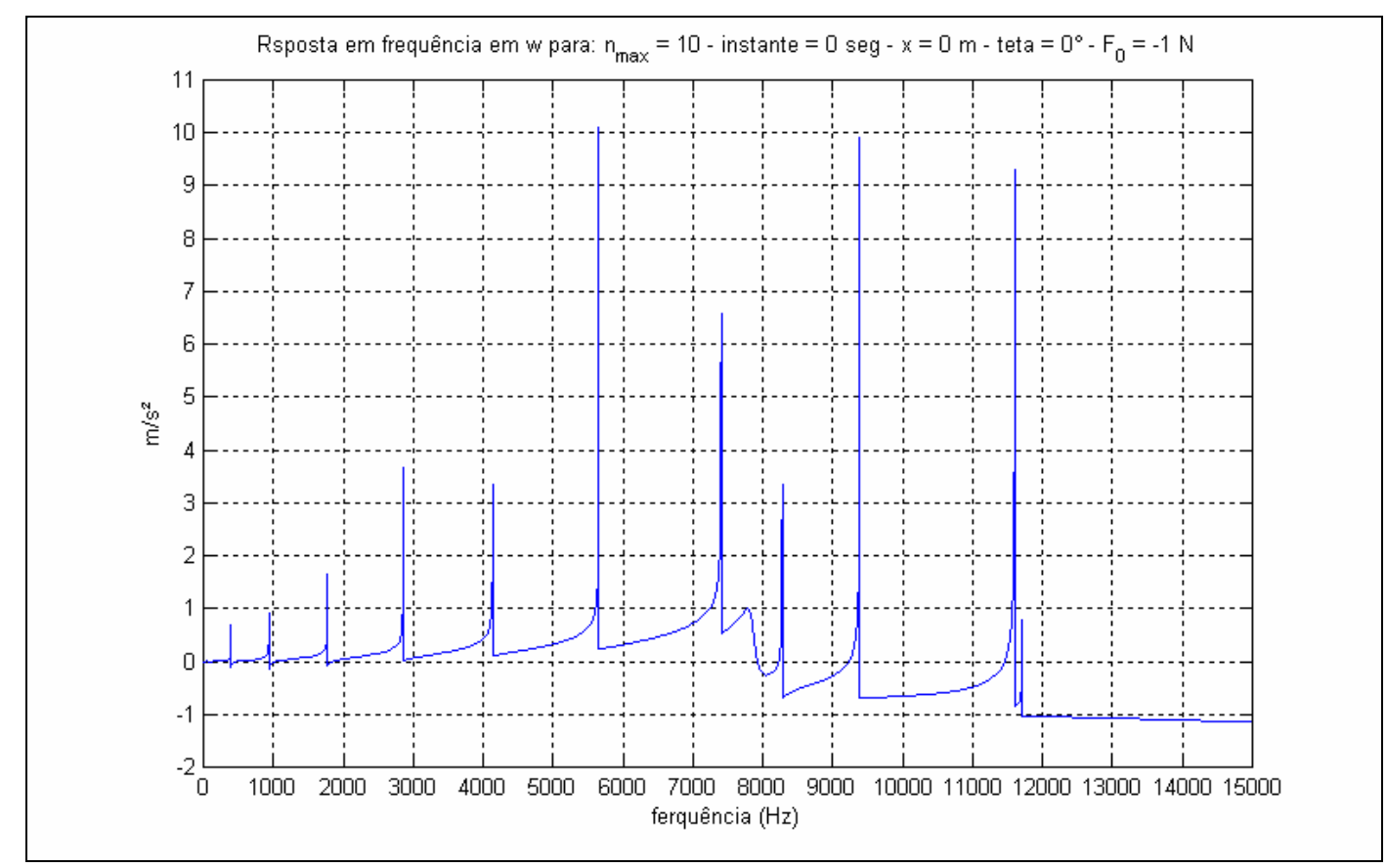

FIGURA 7.19 - Resposta em freqüência teórica.

Através de um simples ensaio é possível determinar os pontos de ressonância de um sistema, ou seja sua resposta em freqüência. No caso da bancada de teste, uma fonte de excitação pontual foi instalada no centro geométrico do tubo a três metros das extremidades. Outro acelerômetro foi posicionado a $5 \mathrm{~cm}$ da fonte de excitação. Mantendo-se a tensão constante e varrendo-se a freqüência foi possível perceber na tela do sistema de aquisição os instantes de ressonância. Além disso foram nitidamente audíveis os instantes destas ressonâncias, pois o nível de pressão acústica no meio apresentava um pico na freqüência em questão. 


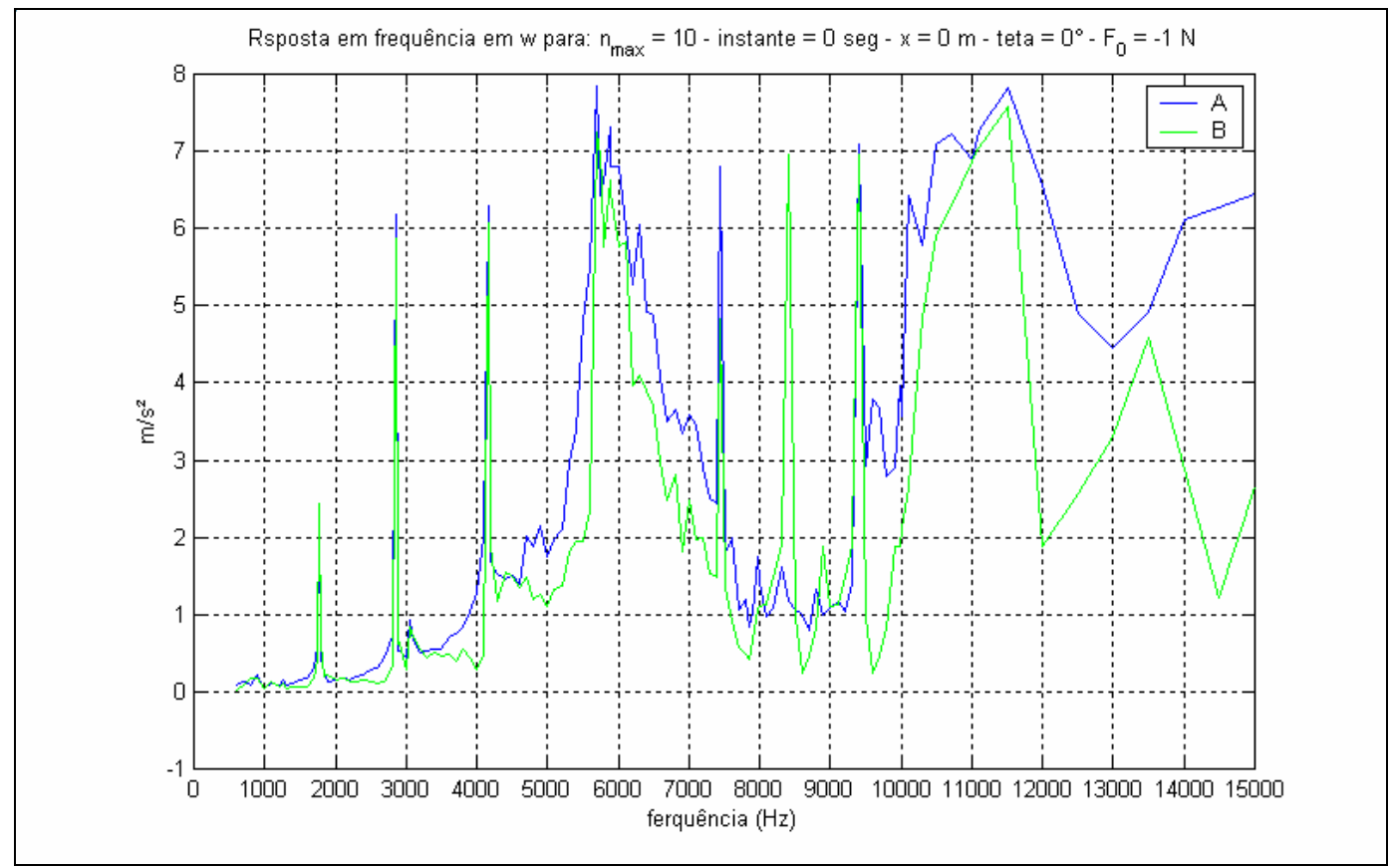

FIGURA 7.20 - Resposta em freqüência medida: A é o sensor junto à fonte de excitação, B é o sensor a $5 \mathrm{~cm}$ da fonte de excitação.

Na FIG. 7.20 são apresentados os resultados obtidos sendo a curva em azul referente ao sensor $\underline{A}$ colocado junto à fonte de excitação e a curva em verde a resposta do sensor $\underline{B}$ colocado a $5 \mathrm{~cm}$ da fonte de excitação. Comparando-se as curvas das Fig. 7.19 e 7.20, observa-se nitidamente que o modelo teórico determinou com boa precisão as freqüências de ressonância do sistema real. Os valores das freqüências e a comparação relativa entre teoria e medida podem ser vistos na TAB. 7.4.

TABELA 7.4 - Freqüências de ressonância

\begin{tabular}{c|c|c}
\hline Medida $(\mathrm{Hz})$ & Teórica $(\mathrm{Hz})$ & Erro \% (ref. na medida) \\
\hline 900 & 938 & $-4,2 \%$ \\
\hline 1780 & 1779 & $0,1 \%$ \\
\hline 2850 & 2858 & $-0,3 \%$ \\
\hline 4160 & 4139 & $0,5 \%$ \\
\hline 5700 & 5656 & $0,8 \%$ \\
\hline 7450 & 7403 & $0,6 \%$ \\
\hline 8350 & 8276 & $0,9 \%$ \\
\hline 9400 & 9386 & $0,1 \%$ \\
\hline 11500 & 11600 & $-0,9 \%$ \\
\hline
\end{tabular}


Deve-se levar em conta que o modelo é uma aproximação do sistema real. Vale ressaltar que o tubo utilizado no experimento possui imperfeições, não é homogêneo pois é soldado ao longo do eixo axial e mesmo estando apoiado em caixa de areia não pode ser considerado, no termo estrito da palavra, como infinito. Outra consideração é quanto à resposta em freqüência do acelerômetro utilizado na medida, o qual é relativamente linear até $10 \mathrm{KHz}$, subindo a partir desta freqüência. Guardando-se estas considerações e com base nas análises apresentadas anteriormente, pode-se dizer que o modelo é consistente quando comparado com as medidas realizadas. 


\section{ANÁLISE PARAMÉTRICA DO MODELO TEÓRICO}

Este capítulo tem por objetivo realizar a análise da influência dos parâmetros de espessura da parede e do raio do tubo e dos parâmetros físicos do material no seu comportamento quanto à propagação da onda.

\subsection{Influência da espessura}

Considere um tubo de aço infinito de raio médio $a=10 \mathrm{~cm}$, módulo de elasticidade $E=19,210^{10} \mathrm{~N} / \mathrm{m}^{2}$, densidade $\rho=7800 \mathrm{~kg} / \mathrm{m}^{3}$, Poisson $v=0,3 \mathrm{e}$ constantes de Lamé: $\lambda=11,07710^{10} \mathrm{~Pa}$ e $\mu=7,384610^{10} \mathrm{~Pa}$. Pela equação (4.9), tem-se a velocidade longitudinal em uma placa $c_{p}=5200,9 \mathrm{~m} / \mathrm{s}$, a qual é adotada para os cálculos. Considere também uma excitação harmônica pontual de freqüência $1 \mathrm{KHz}$, aplicada na posição axial $x=0 \mathrm{~m}$ e na posição circunferencial $\theta=0^{\circ}$ do tubo. Resolvendo-se a equação do movimento (5.24) para os deslocamentos na direção radial, variando-se a espessura $h$, obtém-se o deslocamento $\mathrm{w}$ ao longo da superfície do tubo para várias condições de espessura da parede do tubo.

$\mathrm{Na}$ FIG. 8.1, podem ser observados os mapas de um pedaço da superfície do tubo, relacionando distância com o tempo de propagação, para espessuras variando entre $4,4 \mathrm{~mm}$ até $5,1 \mathrm{~mm}$, ou seja, relação $h / a$ entre 0,044 até 0,051 respectivamente. Os pontos de máximo da aceleração são representados em vermelho, os pontos de mínimo em azul escuro e os zeros em verde claro. Para facilitar a visualização dos mapas, foi traçada uma linha cheia tendo como referência a relação $h / a=0,046$ e replicada em todos os mapas. A linha pontilhada, com origem também em zero metro e zero segundo, mostra a variação da propagação no tempo com a variação da relação $h / a$ em comparação com $h / a=0,046$ de referência.

Tomando-se os resultados que geraram os mapas anteriores para um instante de tempo qualquer, por exemplo zero segundo, e aplicando-se a Transformada de Fourier no espaço obtêm-se os espectros em ciclos por metro e por conseqüência os comprimentos de ondas para as várias condições da espessura, como pode ser visto na FIG. 8.2. 

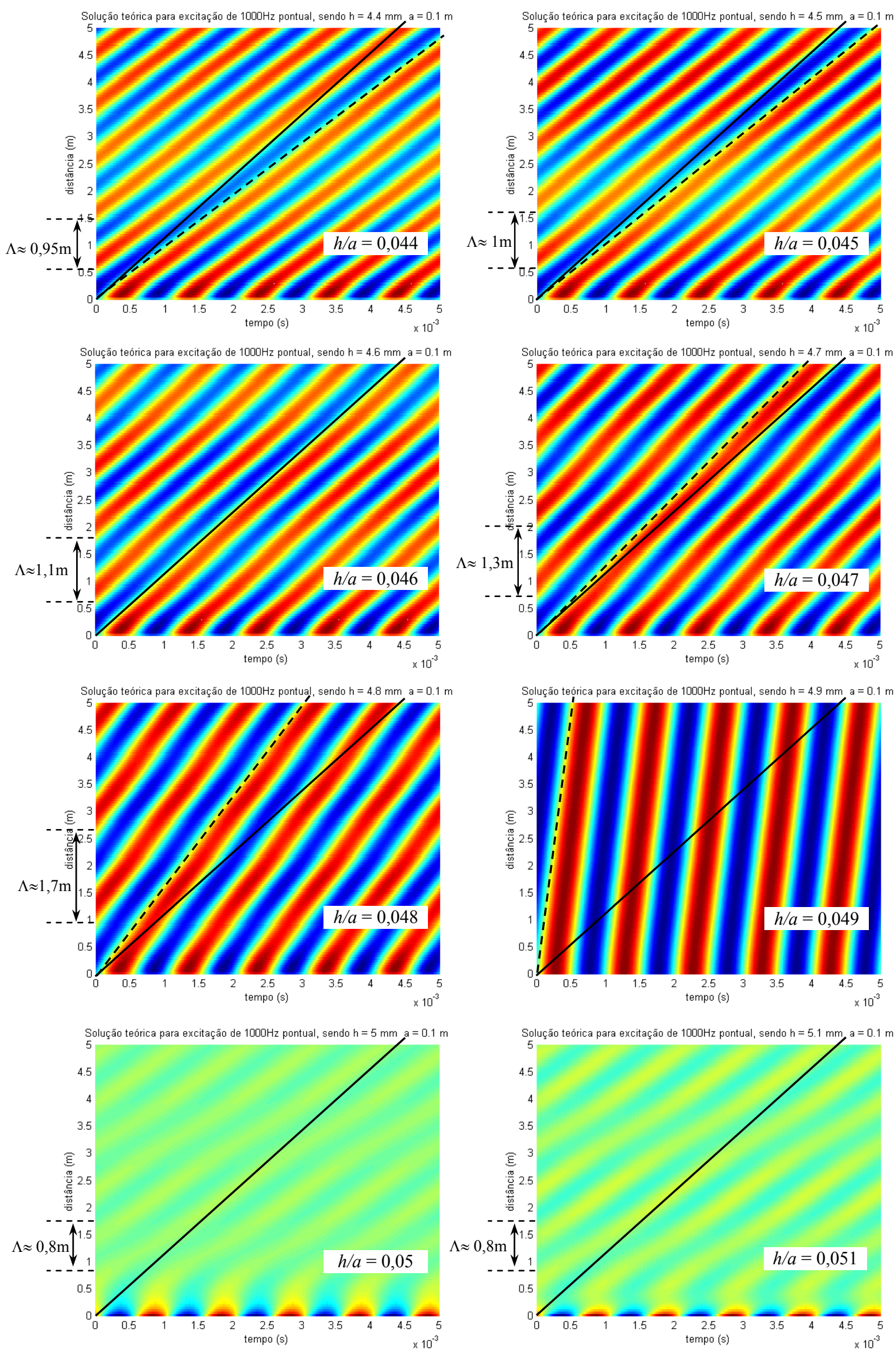

FIGURA 8.1 - Mapas de um pedaço da superfície do tubo, relacionando distância com o tempo de propagação para espessura variando. 

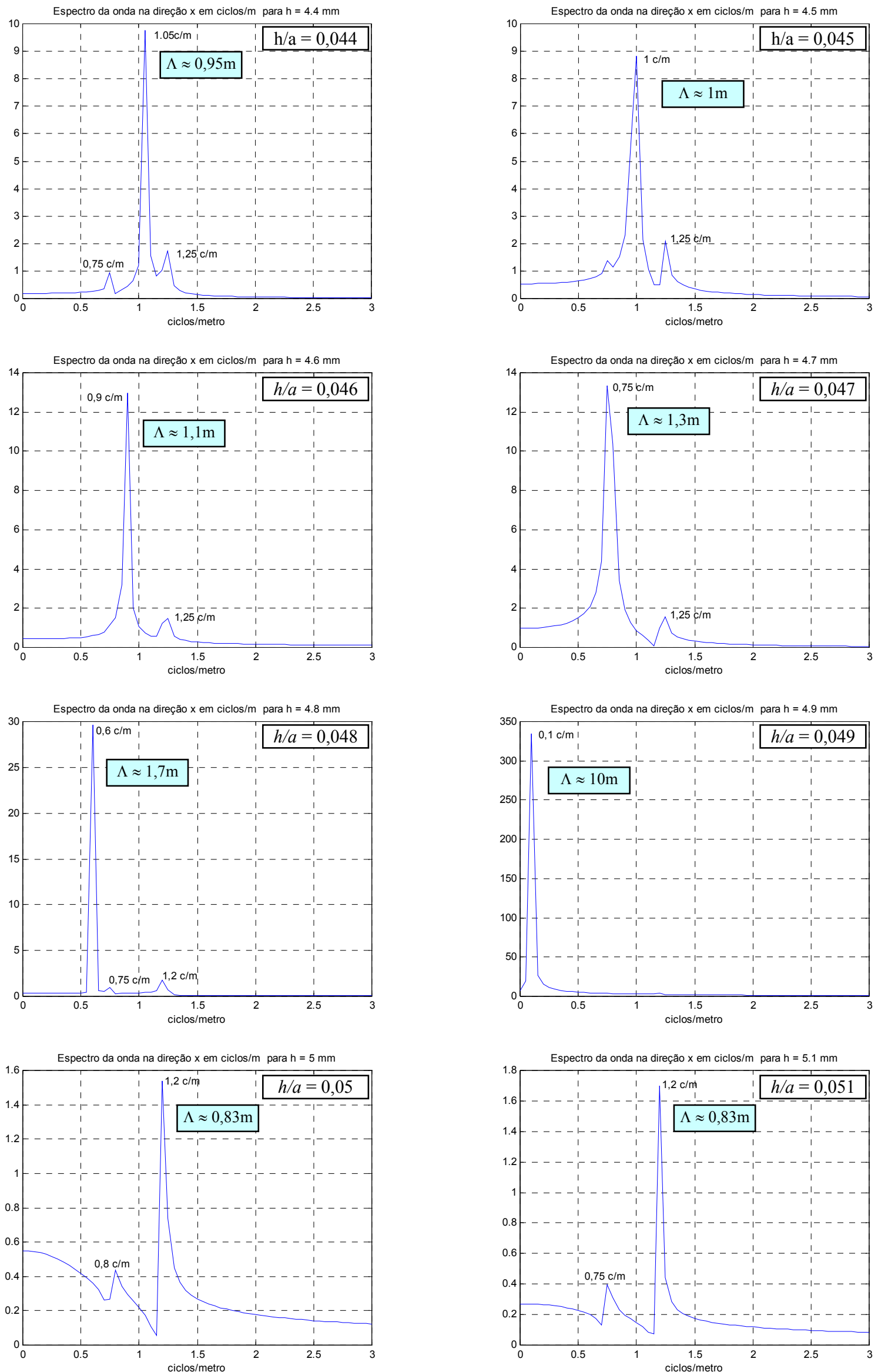

FIGURA 8.2 - Espectro no espaço para o instante zero segundo, $h$ variando. 
Conforme a relação $h / a$ aproxima-se de 0,05 , o comprimento de onda cresce rapidamente, indo de valores próximos de $1 \mathrm{~m}$ para $10 \mathrm{~m}$ na espessura de $4,9 \mathrm{~mm}(h / a=0,049)$. Este efeito pode também ser observado na FIG. $8.1 \mathrm{com}$ base nas variações dos ângulos nos mapas, formados entre a linha de propagação (linha formada por exemplo pelos pontos de máximos) e o eixo dos tempos, onde se observa que o ângulo cresce com o aumento da relação $h / a$. Isto reflete no aumento do comprimento de onda e por conseqüência no aumento da velocidade efetiva de propagação da onda estacionária.

Em $h / a=0,05$ e valores superiores, a superfície assume um comportamento anormal, observa-se que a onda propagante praticamente desaparece logo após o ponto de excitação. Pode-se entender que o tubo sai da condição de casca fina, ou de outro modo, o modelo matemático perde a capacidade de representar o comportamento deste tubo, já que no estabelecimento das equações do movimento, a hipótese de casca fina foi utilizada. Isto estabelece uma limitação para a condição de casca fina em $h / a<0,05$. Tal fato também poderá ser observado no próximo item, onde a espessura é fixa e o raio é variado. Lá para valores próximos da relação limite o modelo também começa a apresentar comportamento anormal, FIG. 8.5.

Na FIG. 8.3, pode-se ver o comportamento da propagação da onda no espaço para um certo instante de tempo, aqui em particular para o instante zero segundo, considerando o raio fixo e variando-se a espessura de $4,4 \mathrm{~mm}$ até $5 \mathrm{~mm}$. Observa-se que para $h=5 \mathrm{~mm}$ a onda "morre" logo após sua partida em $x=0 \mathrm{~m}$. Para $h=4,9 \mathrm{~mm}$ a onda propagante assume valores em amplitude muito elevados comparado com as ondas em outras espessuras e apresenta um comprimento de onda da ordem de $10 \mathrm{~m}$.

O crescimento do comprimento de onda $\Lambda$, com a variação da espessura, pode ser observado na FIG. 8.4 a seguir. Dá para se notar, que a variação do comprimento de onda diminui com a diminuição da espessura, ou seja, a casca torna-se cada vez mais casca fina e o efeito da espessura torna-se menos significativo. 


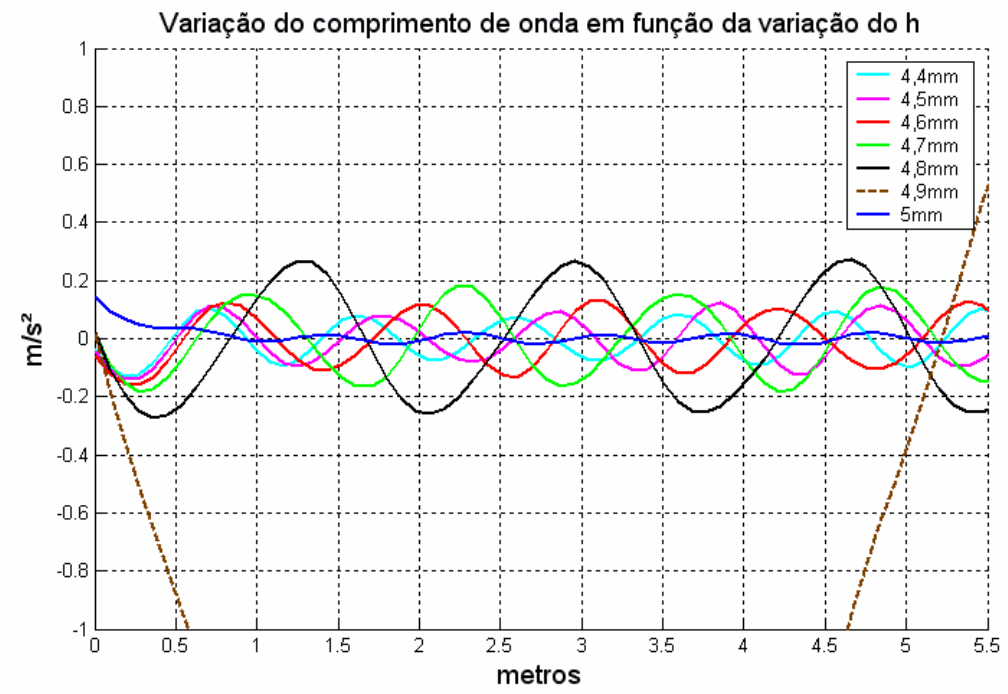

FIGURA 8.3 - Propagação da onda no espaço para o instante zero segundo.
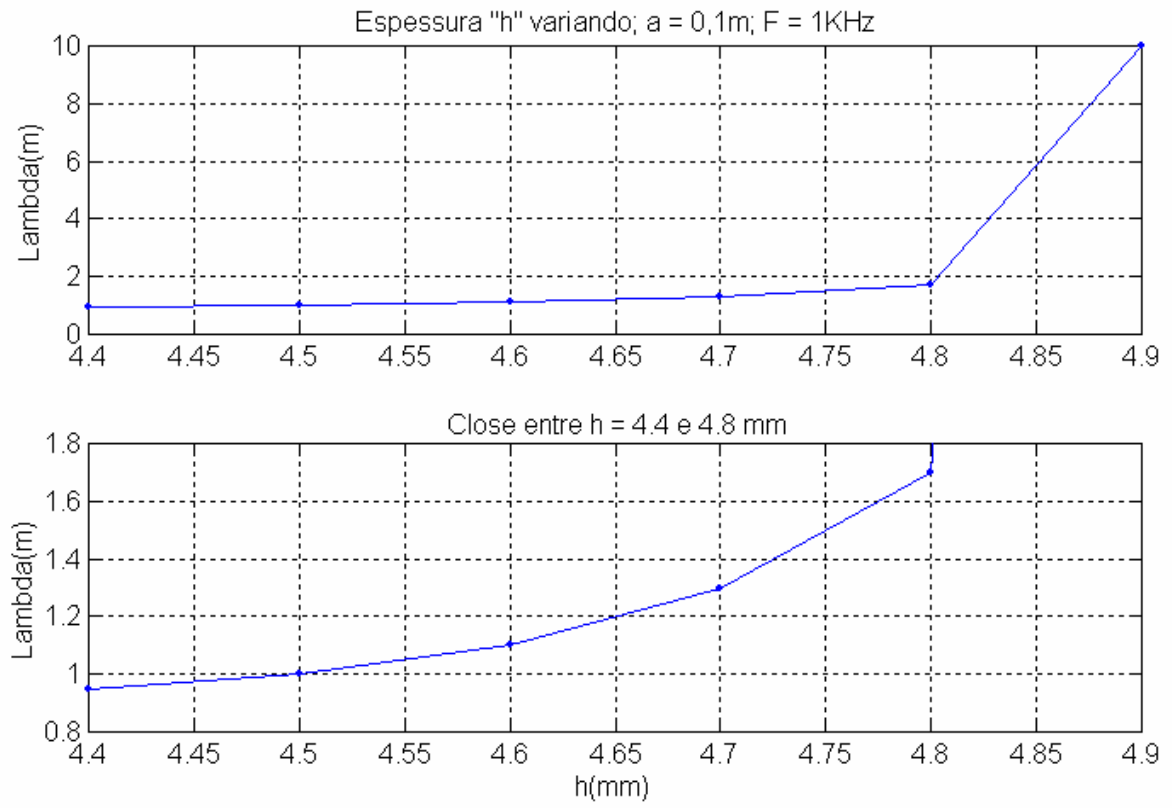

FIGURA 8.4 - Variação do comprimento de onda com a espessura.

\subsection{Influência do raio}

Como era de se esperar a variação do raio do tubo influi na relação $h / a$ e por conseqüência gera alterações nas propagações das ondas, semelhantes às observadas anteriormente. Contudo, quando a relação h/a torna-se 0,048 o comportamento torna-se anormal. Outro ponto que deve ser notado, é que os comprimentos de ondas observados aqui, para relações $h / a$ semelhantes às geradas anteriormente pelas variações de espessura, geram agora comprimentos de ondas diferentes, veja FIG. 8.5, FIG. 8.6 e TAB. 8.1, a seguir. 

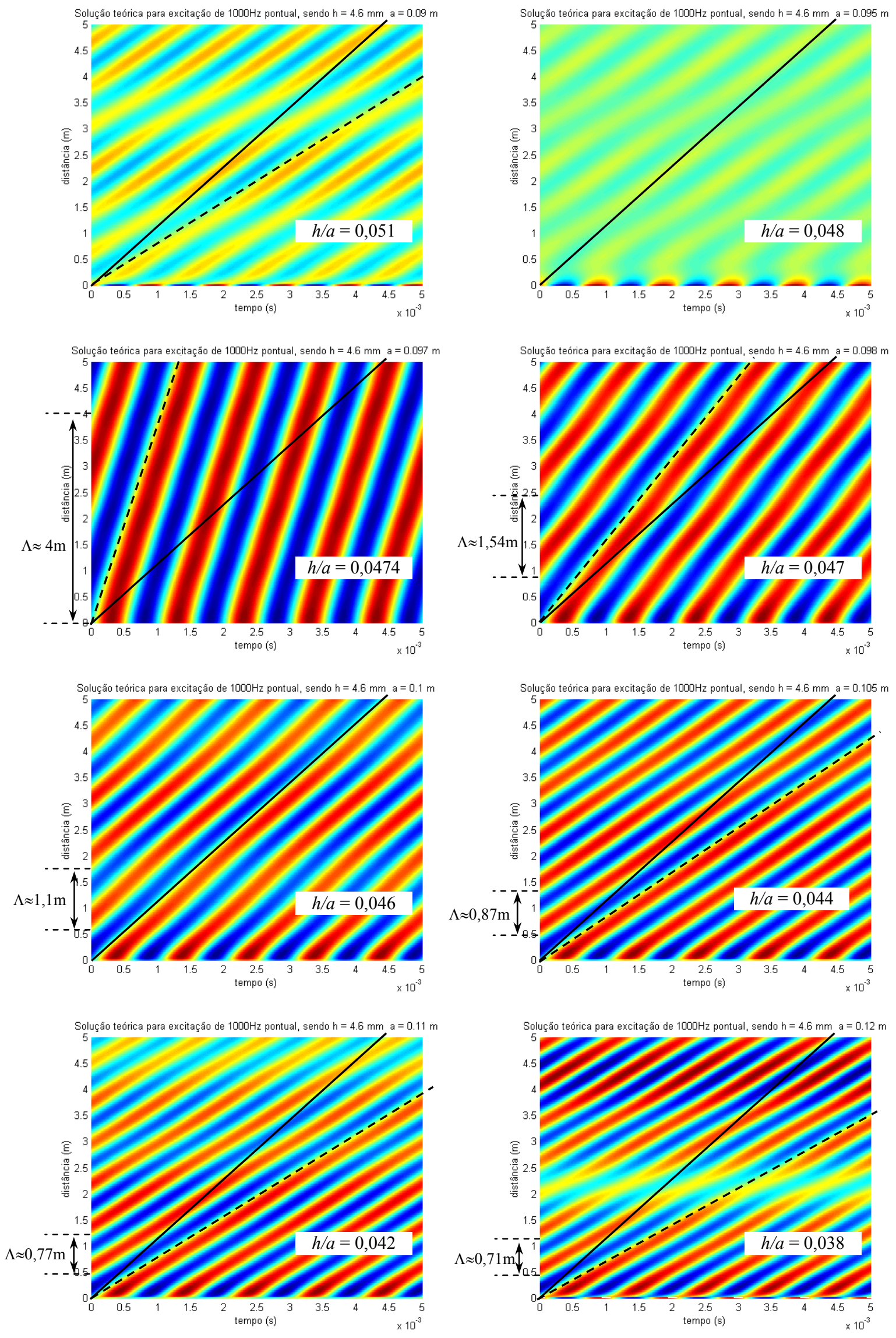

FIGURA 8.5 - Mapas de um pedaço da superfície do tubo, relacionando distância com o tempo de propagação, para raio variando. 

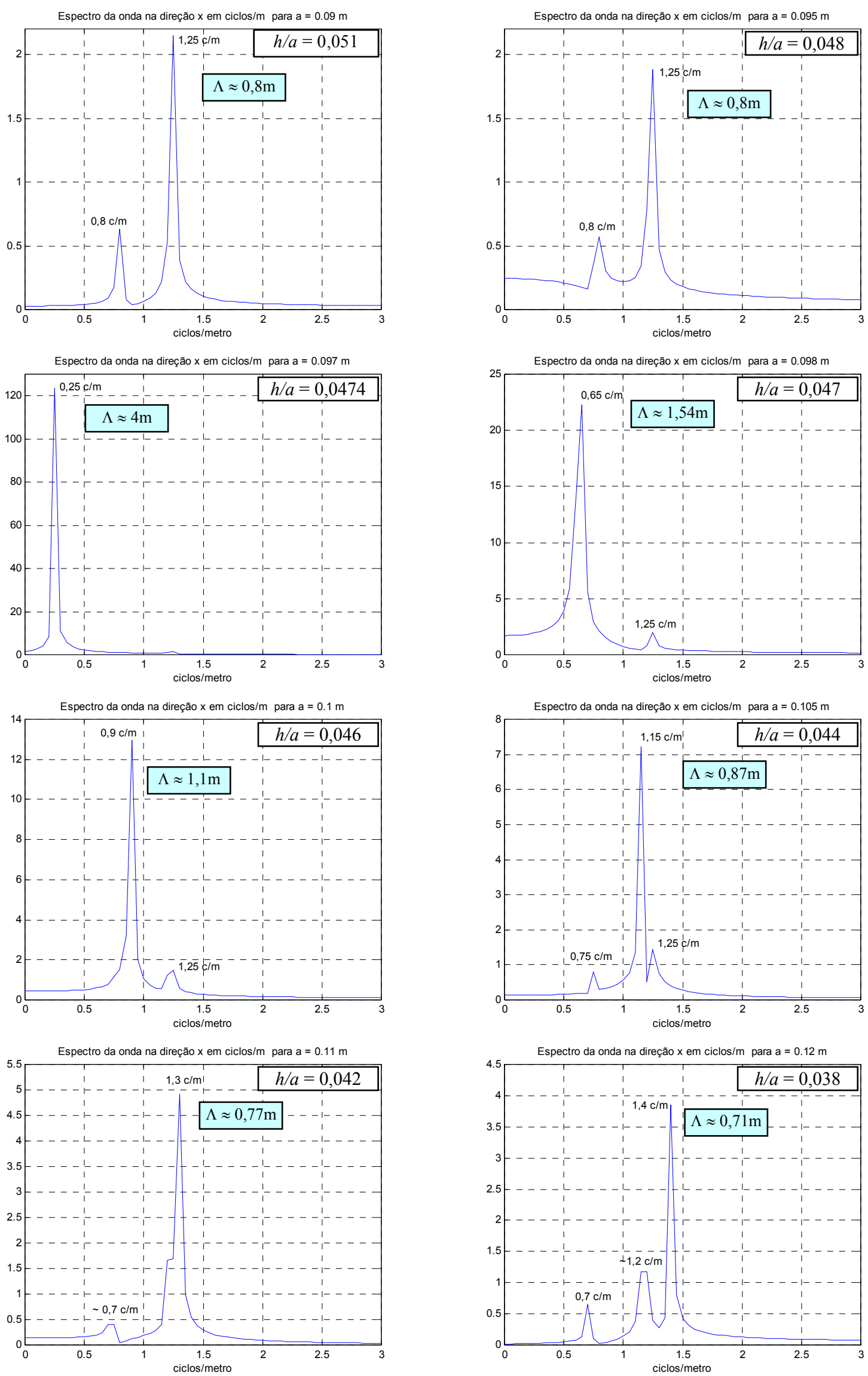

FIGURA 8.6 - Espectro no espaço para o instante zero segundo, para raio variando. 
TABELA 8.1 - Comportamento do comprimento de onda com as relações $h / a$

\begin{tabular}{c|c|c|c|c} 
& \multicolumn{2}{c}{$\boldsymbol{a}=\mathbf{0 , 1} \mathbf{m}$ e $\boldsymbol{h}=$ variando } & \multicolumn{2}{c}{$\boldsymbol{h}=\mathbf{4 , 6} \mathbf{m m}$ e $\boldsymbol{a}=$ variando } \\
\hline $\boldsymbol{h} / \mathbf{a}$ & $\boldsymbol{h}$ & $\Lambda$ & $\mathbf{a}$ & $\Lambda$ \\
\hline 0,044 & $4,4 \mathrm{~mm}$ & $0,95 \mathrm{~m}$ & $0,105 \mathrm{~m}$ & $0,87 \mathrm{~m}$ \\
\hline 0,046 & $4,6 \mathrm{~mm}$ & $1,1 \mathrm{~m}$ & $0,1 \mathrm{~m}$ & $1,1 \mathrm{~m}$ \\
\hline 0,047 & $4,7 \mathrm{~mm}$ & $1,3 \mathrm{~m}$ & 0,098 & $1,54 \mathrm{~m}$ \\
\hline 0,048 & $4,8 \mathrm{~mm}$ & $1,7 \mathrm{~m}$ & 0,095 & --- \\
\hline
\end{tabular}

O que se verifica, é que o comportamento da propagação da onda é mais sensível à variação do raio do que à variação da espessura da parede. Isto porque a variação no raio além de gerar uma variação na relação h/a, gera também uma variação no perímetro do tubo, o que altera os comprimentos dos caminhos de propagações das ondas sobre a superfície do tubo, alterando as sobreposições das ondas propagantes.

\subsection{Influência dos parâmetros do material}

Considerando, do ponto de vista geométrico, um tubo com raio médio $0,1 \mathrm{~m}$ e espessura de parede $4,6 \mathrm{~mm}$, para uma freqüência de excitação pontual de $1 \mathrm{KHz}$, variando-se um dos três parâmetros do material, elasticidade $(E)$, densidade $(\rho)$ ou o Poisson $(v)$, foram gerados os gráficos do comprimento de onda $(\Lambda)$, da velocidade da onda extensional $\left(c_{p}\right)$ e da freqüência de ring ( $\left.f_{\text {ring }}\right)$ em função do parâmetro variado, os quais podem ser vistos nas FIG. 8.7, 8.8 e 8.9.

Da equação (4.9) observa-se que a velocidade $c_{p}$ depende diretamente da elasticidade, inversamente da densidade e inversamente ao termo um menos Poisson ao quadrado, conforme mostra a FIG. 8.7. A freqüência de ring, como pode ser visto na equação (8.1), depende diretamente da velocidade $c_{p} \mathrm{e}$ inversamente ao raio, o qual é mantido constante. Logo como é de se esperar a freqüência de ring assume um comportamento semelhante à velocidade $c_{p}$, a menos de uma constante, conforme mostra a FIG. 8.8. A freqüência de ring, como já relatado anteriormente, é a freqüência para a qual o comprimento de onda na direção circunferencial assume o mesmo comprimento da circunferência média do tubo.

$$
f_{\text {ring }}=\frac{c_{p}}{2 \pi a}
$$



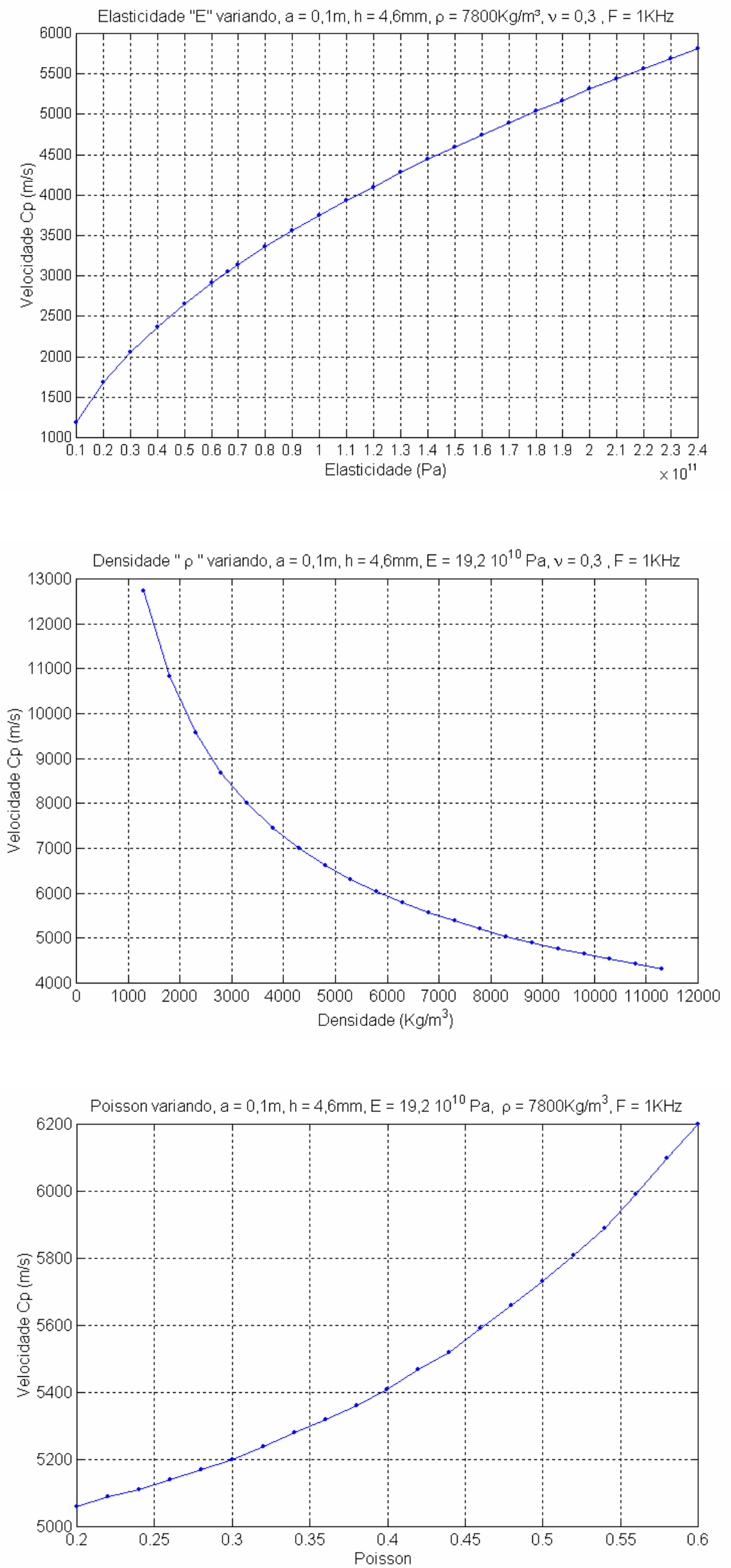

FIGURA 8.7 - Comportamento da velocidade $c_{p}$ com $E, \rho$ e v. 

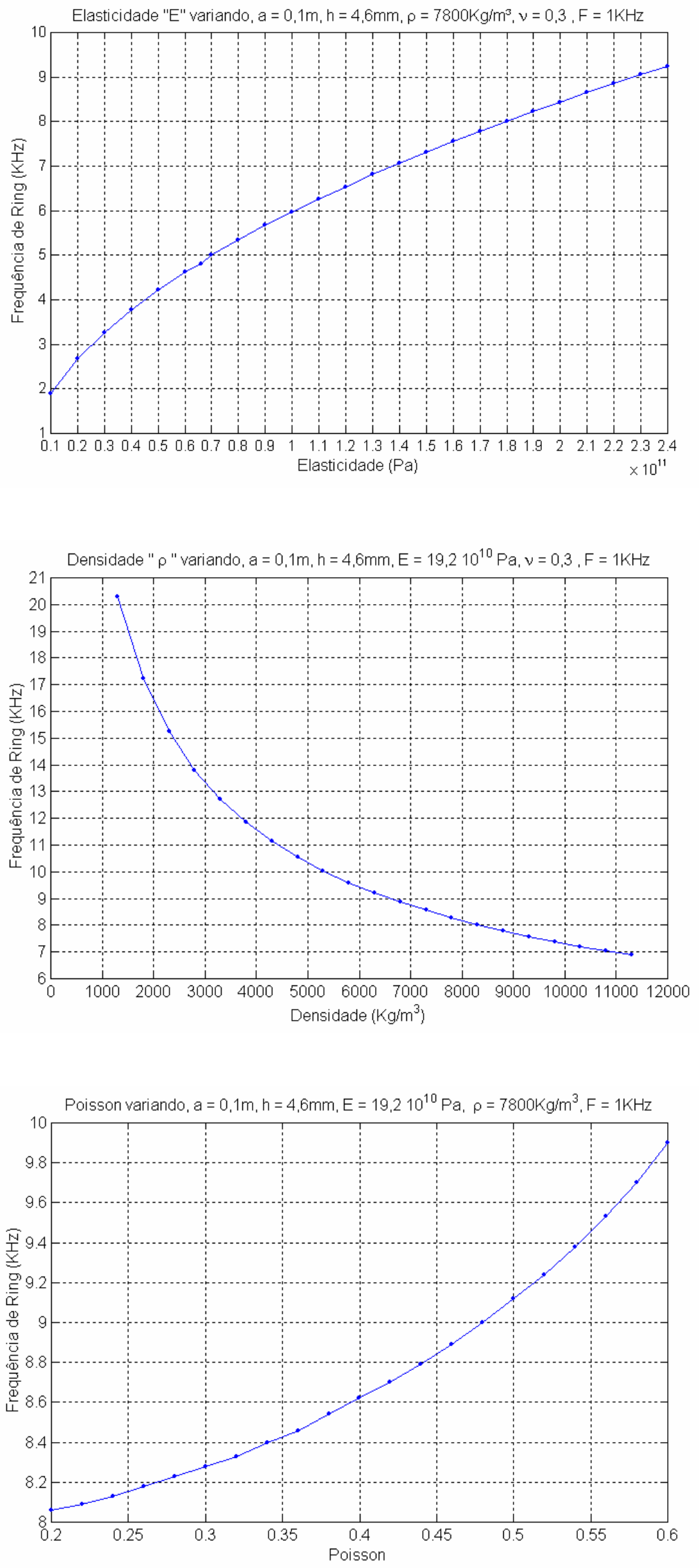

FIGURA 8.8 - Comportamento da freqüência de ring com $E, \rho$ e $v$. 

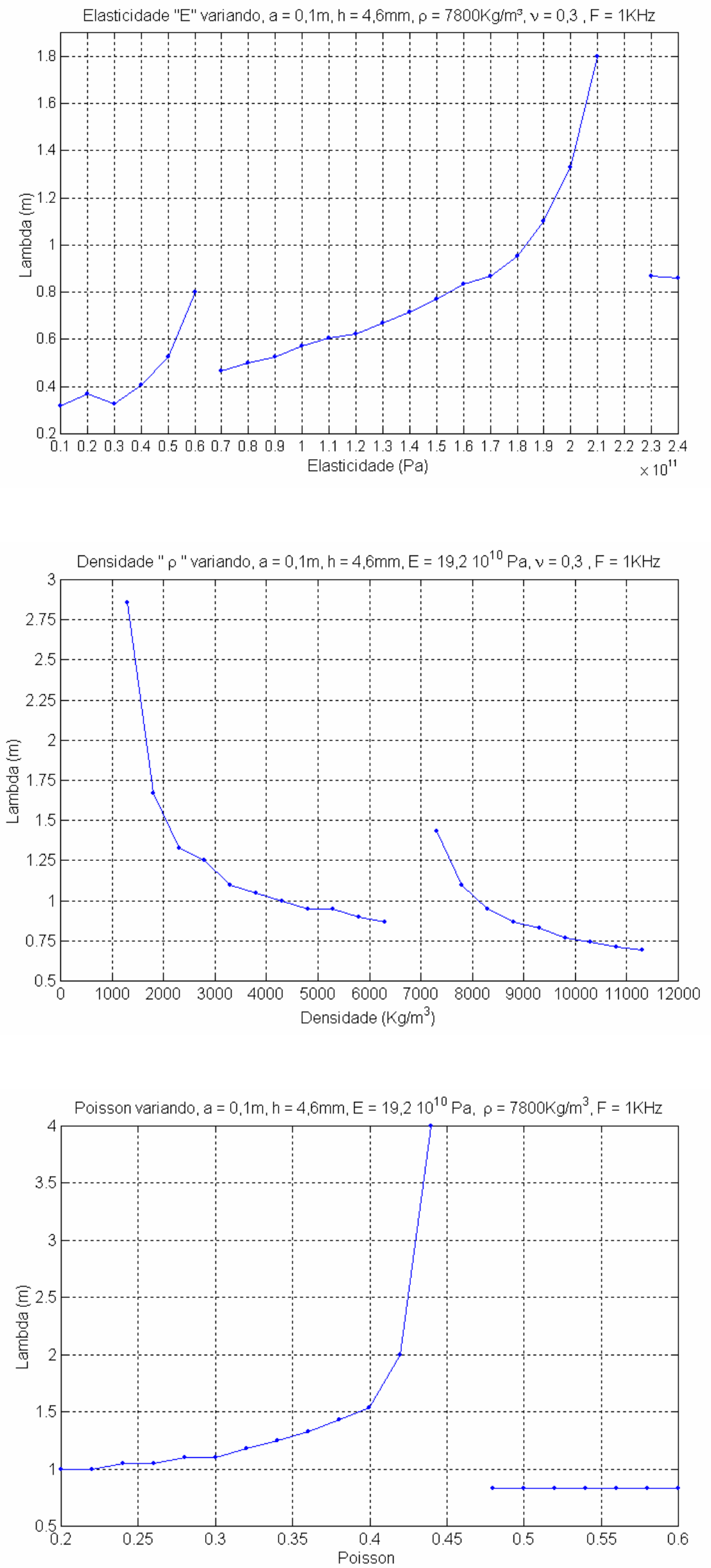

FIGURA 8.9 - Comportamento do comprimento de onda com $E, \rho$ e v. 
O comprimento de onda $(\Lambda)$ é mais complexo, pois depende da propagação da onda sobre a superfície e de suas interações ao redor desta superfície. Logo a variação de qualquer um dos parâmetros que afete a velocidade de propagação ou a freqüência de ring com certeza irá afetar o comprimento de onda. Não se deve esquecer que os parâmetros geométricos também influenciam no comprimento de onda, como já visto acima.

Nos gráficos da FIG. 8.9, da página anterior, são apresentados os comportamentos do comprimento de onda $(\Lambda)$ com os parâmetros do material. Os pontos de inflexão nos gráficos, mostram que $\Lambda \rightarrow \infty$, estas condições, indicam situações em que a onda desaparece logo após a sua partida do ponto de excitação. Ou seja, não há movimento ondulatório sobre a superfície do tubo pois $\frac{1}{\Lambda} \rightarrow 0$ ciclos / metro. O que se tem na realidade é a somatória de todos os movimentos axiais e circunferenciais, os quais se anulam mutuamente.

\subsection{Influência dos parâmetros para alguns materiais reais}

Os gráficos anteriores mostram o comportamento de $\Lambda, c_{p}$ e $f_{\text {ring }}$ para variações individuais de cada parâmetro do material. A título de exemplo, na TAB. 8.2, são apresentados os resultados para alguns materiais reais, considerando espessura $h=4,6 \mathrm{~mm}$, raio $a=0,1 \mathrm{~m}$ e freqüência de excitação $1 \mathrm{KHz}$.

TABELA 8.2 - Exemplo do comportamento de alguns materiais.

\begin{tabular}{c|c|c|c|c|c|c|c}
\hline Material & $E\left(\mathbf{N} / \mathbf{m}^{2}\right)$ & $\rho\left(\mathbf{k g} / \mathbf{m}^{3}\right)$ & $v$ & $c_{p}(\mathbf{m} / \mathbf{s})$ & $f_{\text {ring }}(\mathrm{Hz})$ & $\Lambda(\mathbf{m})$ & $c_{\text {efetiva }}(\mathbf{m} / \mathbf{s})$ \\
\hline Aço & $19,210^{10}$ & 7800 & 0,3 & 5200,9 & 8277 & 1,1 & 1100 \\
\hline $\begin{array}{c}\text { ferro- } \\
\text { fundido }\end{array}$ & $10,510^{10}$ & 7700 & 0,28 & 3846,6 & 6122 & 0,588 & 588 \\
\hline cobre & $12,210^{10}$ & 8900 & 0,35 & 3952 & 6290 & 0,588 & 588 \\
\hline Alumínio & $7,110^{10}$ & 2700 & 0,33 & 5432 & 8645 & 1,667 & 1667 \\
\hline PVC & $0,1510^{10}$ & 1400 & 0,42 & 1141 & 1815 & 0.274 & 274 \\
\hline
\end{tabular}


O PVC, como era de se esperar, por ser um material plástico, não responde bem para freqüências altas, ou seja, os gráficos das propagações mostraram que, para freqüências pouco acima de $1 \mathrm{KHz}$, os sinais desaparecem já próximo do ponto de excitação.

Outra observação interessante é que, independente dos valores dos parâmetros, se as velocidades $c_{p}$ entre materiais diferentes forem próximas, o comportamento do comprimento de onda e da velocidade efetiva são semelhantes. $O$ ferro fundido e o cobre, assim como o alumínio e o aço devem apresentar respostas similares. 


\section{DETECÇÃO E LOCALIZAÇÃO DA FONTE PONTUAL}

\subsection{Detecção de uma falha}

A detecção da existência de vazamento em tubo pressurizado é descrita em vários trabalhos, os quais utilizam-se da análise de variações da pressão do fluído que escoa no tubo ou da intensidade do sinal acústico externo oriundo do vazamento, comparando-se com um sinal de referência conhecida sem a presença da falha, Fukushima et al. (2000), Souza et al. (2000), Hsiung e Himmelblau (1996), Srinivasan et al (2000), Kunze (1999).

Tomando-se como referência um evento contínuo gerado por um vazamento pontual, um método simples consiste em monitorar as saídas dos sensores e observar a forma do sinal no tempo ou o aparecimento de raias em freqüência as quais se sobressaiam do ruído de fundo. Sendo conhecido o sinal de fundo, no domínio do tempo, pode-se estabelecer um limiar acima do qual considera-se a existência de um evento anormal. Este sinal de fundo pode ser gerado pelo funcionamento do sistema analisado ou por ruídos externos a este. Para separar a existência perene do sinal de falha de um sinal espúrio, é comum adotar como parâmetro o RMS do sinal com falha, comparando com o sinal de fundo. Uma vez que o RMS do sinal supere um limiar pré-estabelecido tem-se a indicação de que um evento anormal está ocorrendo. Através da análise do espectro deste sinal em conjunto com o RMS, se torna possível detectar a presença da falha, pela existência de raias de freqüências diferentes das anteriormente observadas. Neste caso um limiar também pode ser estabelecido acima do sinal de fundo, o qual ultrapassado indica a presença da falha.

Um exemplo simples é mostrado na FIG. 9.1, onde o máximo valor do sinal de fundo é $16,610^{-3} \mathrm{~V}$ e seu RMS é $9,6610^{-3} \mathrm{~V}$, o máximo valor do sinal de falha é $47,910^{-3} \mathrm{~V}$ e seu RMS é $19,110^{-3} \mathrm{~V}$. Neste caso adotando-se, por exemplo, um limiar para o sinal temporal de $20,010^{-3} \mathrm{~V}$ ou um limiar de $12,010^{-3} \mathrm{~V}$ para o RMS, pode-se observar a existência de valores acima destes no sinal de falha, caracterizando a presença da falha. Nos gráficos do espectro, também é notória a presença das raias de freqüências se destacando do sinal de fundo, aqui também um limiar poderia ter sido estabelecido. Sendo o máximo 
valor do espectro do ruído igual a $3,010^{-4} \mathrm{~V}$, um limiar de $5,010^{-4} \mathrm{~V}$ garantiria uma folga quanto ao sinal de fundo e a presença de várias raias do sinal de falha acima deste. A escolha do limiar deve levar em conta características do sistema analisado para não se correr o risco de um alarme falso.
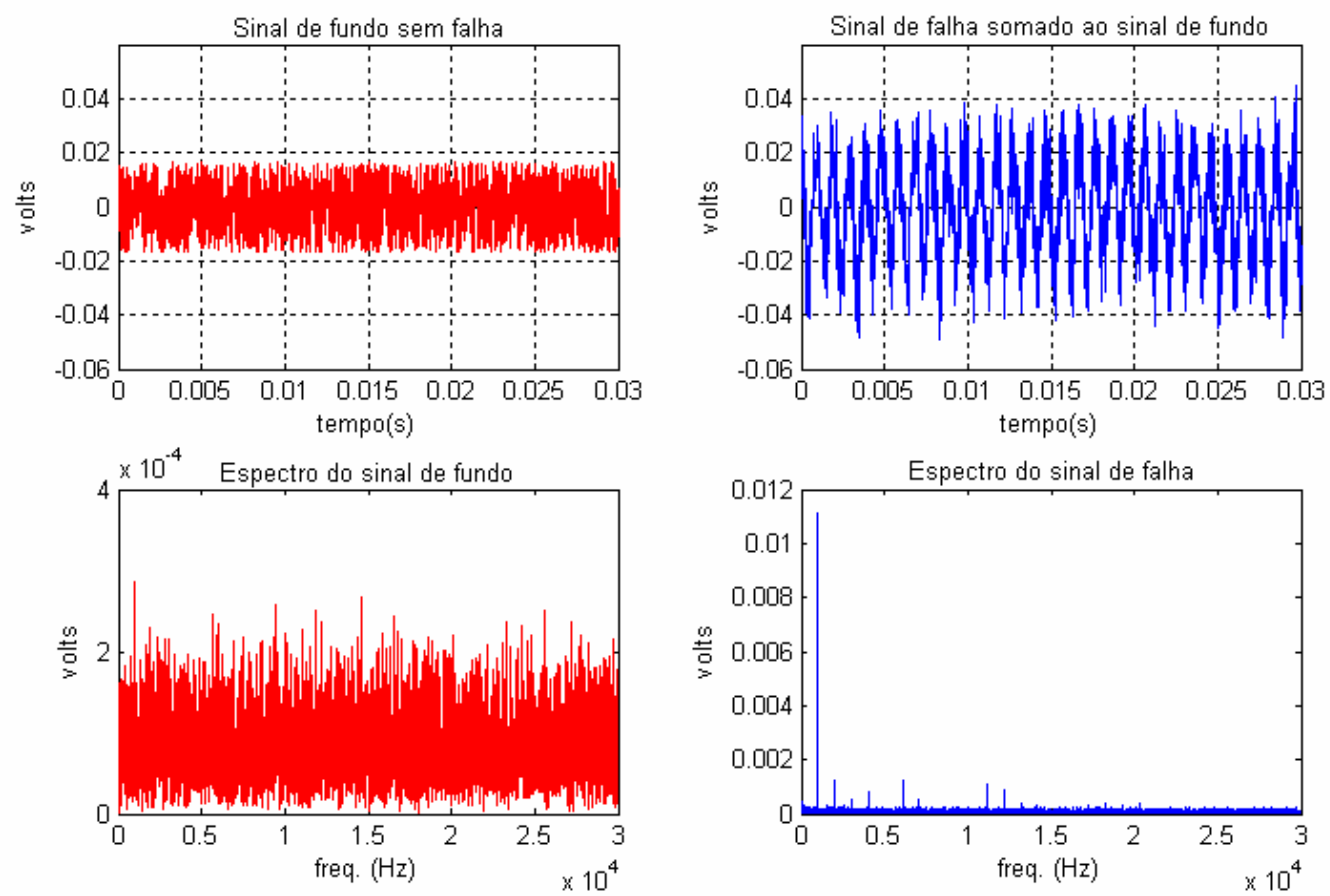

FIGURA 9.1 - Exemplo de sinais de fundo e de falha

\subsection{Localização de uma falha}

A localização envolve um procedimento mais trabalhoso e complexo, por este motivo, neste capítulo, a ênfase dada é para a localização de uma fonte pontual.

Em função da estacionariedade do sinal, estabelecida na superfície da casca cilíndrica e considerando-se que o sensor colocado na sua superfície enxerga a onda resultante que é a somatória dos modos axiais e circunferenciais, não é possível a localização da fonte de excitação pela simples colocação de sensores na superfície do tubo e da medida dos atrasos das chegadas das ondas nestes sensores. Isto se deve ao fato de que para distâncias maiores que um comprimento de onda não se pode dizer qual é o atraso real em função da repetibilidade da onda a cada período. Exemplificando, para um comprimento de onda de $1 \mathrm{~m}$, os sensores localizados a 0,1 m, 1,1 m, 2,1 m e assim por diante, 
apresentarão a mesma diferença de tempo em relação a um outro usado como referência.

Outro fato é que a velocidade efetiva da onda estacionária é menor que as velocidades longitudinais e transversais do material. Sendo assim, pelos motivos expostos, aqui não se pode utilizar a relação que diz que a distância é igual à velocidade longitudinal ou transversal vezes o atraso de tempo entre os sensores.

\subsection{Metodologia de localização proposta}

A metodologia proposta consiste em supor quatro sensores fixos na superfície do tubo e através das soluções desenvolvidas no capítulo 5 , gerar os mapas teóricos dos atrasos temporais relativos entre os sensores e os mapas teóricos dos seus respectivos RMS, supondo uma fonte pontual em todas as possíveis posições sobre a superfície do tubo, considerando um passo na direção axial e um passo na direção circunferencial. Efetuada a medida, comparam-se os atrasos entre os sensores com os atrasos dos mapas teóricos para as respectivas posições dos sensores. A idéia é resolver o problema inverso, ou seja, conhecido o atraso, buscar o local da fonte que gera este atraso. Como mais que uma resposta pode ser obtida, para apontar a resposta correta, utiliza-se de um segundo conjunto de mapas contendo as informações dos RMS dos sinais, os quais variam com a posição ao longo da superfície do tubo. Em resumo, a solução deve atender aos atrasos temporais e aos RMS dos sinais medidos comparados com a solução teórica.

Para entender o método é apresentada uma primeira geometria de sensores dispostos em L. Para isto, foi fixado um sensor próximo a uma extremidade do tubo, nomeado de $A$ e três próximos da outra extremidade, nomeados de $\mathrm{B}, \mathrm{C}$ e $\mathrm{E}$. $\mathrm{O}$ sensor $\mathrm{A}$, colocado na posição $-2,5 \mathrm{~m}$ do centro do tubo e em um ângulo de $0^{\circ}$, é o sensor de referência e serve para sincronizar a placa de aquisição de dados, servindo também de referência nos cálculos dos tempos e dos RMS. $O$ ângulo de $0^{\circ}$ é uma linha imaginária sobre a superfície do tubo adotada como referência. $O$ sensor $B$ foi posicionado $a+2,5 \mathrm{~m}$ do centro do tubo em um ângulo de $0^{\circ}$, o sensor $C$ foi posicionado a $+2,6 \mathrm{~m}$ do centro do tubo em um ângulo de $0^{\circ}$ e o sensor $E$ foi posicionado $a+2,5 \mathrm{~m}$ do centro do tubo em um 
ângulo de $60^{\circ}$. A FIG. 9.2 esboça esta distribuição, onde $\circ$ ponto $0 \mathrm{~m}$ e $0^{\circ}$ representa o centro geométrico de referência para o tubo.

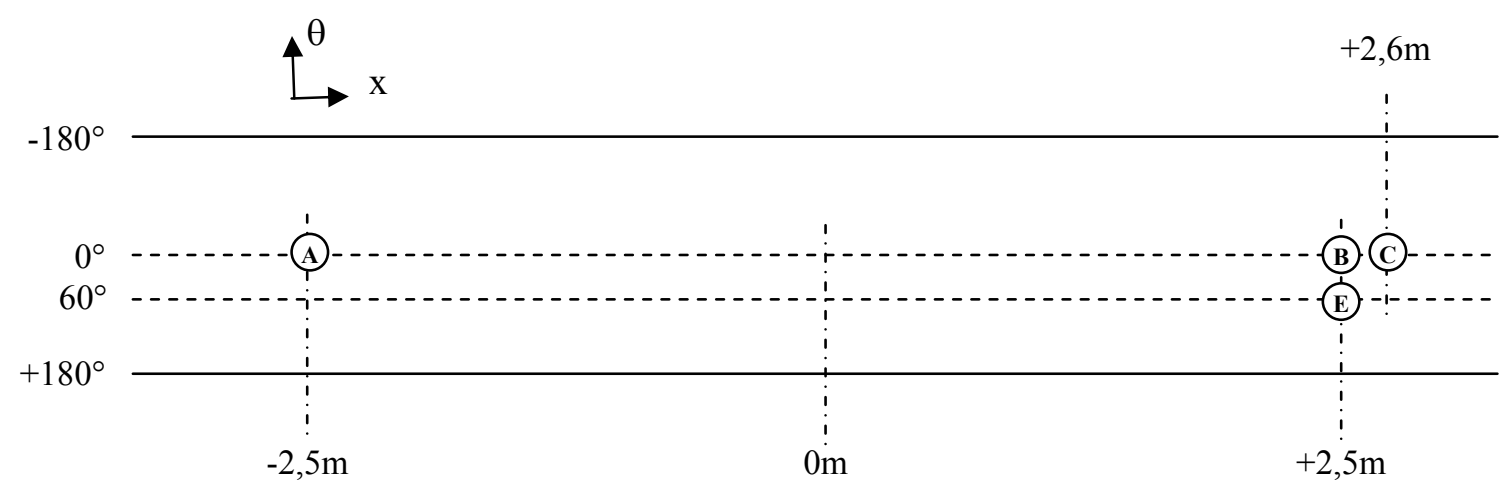

FIGURA 9.2 - Esboço da disposição dos sensores na superfície do tubo.

Considerando as posições de fixação dos sensores, com base na solução analítica, são gerados mapas teóricos dos atrasos relativos de chegada entre os sensores A e B, A e C, A e E, através da determinação do desvio do ponto de máximo da correlação cruzada em relação ao zero, para a excitação em todas posições do tubo de $10 \mathrm{~cm}$ em $10 \mathrm{~cm}$ na direção axial e de $15^{\circ} \mathrm{em} 15^{\circ}$ na direção circunferencial. Com o objetivo de gerar os valores teóricos dos atrasos para cada sensor, é utilizado o modelo analítico considerando a posição $(x, \theta)$ fixa, a qual representa o ponto de observação de cada sensor, ou seja, seu local de fixação, na seqüência a posição $\left(x_{0}, \theta_{0}\right)$ que representa o local da fonte de excitação é variada de modo a cobrir a superfície do tubo. Para as mesmas condições são gerados os mapas dos RMS dos sensores $B$, C e E normalizados em relação ao sensor $A$ para as mesmas posições da fonte de excitação utilizadas nos mapas dos atrasos temporais. A idéia básica é gerar mapas contendo informações de como os sensores estão enxergando a fonte em todas as suas possíveis posições sobre a superfície do tubo. Os passos em $x$ e em $\theta$ podem ser alterados conforme a resolução espacial necessária.

A normalização dos sensores em relação ao sensor A consiste em dividir o RMS de cada sensor pelo RMS do sensor A. Com isto a amplitude do sinal fica independente da amplitude da fonte de excitação. 
Tomando-se os passos nas direções axial e circunferencial definidos, para uma distância axial de $5 \mathrm{~m}$ entre os sensores $\mathrm{A}$ e $\mathrm{B}$, tem-se um mapa teórico com 51 por 25 pontos, ou seja, 1275 possíveis posições de excitação. Cada ponto de excitação induz uma onda temporal chegando aos sensores. Esta onda é amostrada em cada um dos sensores com um número de pontos conveniente, o qual pode variar por exemplo de $1 \mathrm{~K}$ a $10 \mathrm{~K}$ pontos.

Para a configuração estabelecida, se uma fonte de excitação é ativada na superfície do tubo, os quatro sensores irão receber sinais provenientes deste ponto de excitação. Fazendo-se a correlação cruzada dos sensores $B, C$ e E em relação ao sensor $A$, tenta-se encontrar um ou mais pontos nos mapas dos atrasos teóricos que satisfaçam aos três sensores simultaneamente. De posse destes possíveis pontos, geram-se os RMS dos valores medidos normalizados em relação ao sensor $A$. Em seguida comparam-se estes resultados com os mapas dos RMS teóricos para encontrar o provável ponto de localização da fonte. Caso a busca não gere resultados, uma nova busca é iniciada aumentando-se as tolerâncias nos atrasos ou nos RMS. De modo semelhante ao executado para o trio de sensores, buscam-se os pontos que satisfaçam os sensores aos pares, isto é: $B$ e $C$; $B$ e E; C e E. Esta nova série de buscas tem por finalidade complementar as informações para a decisão quanto ao correto ponto de localização.

No APÊNDICE $E$ são apresentados os diagramas lógicos dos programas criados para gerar os mapas e para proceder à localização da fonte.

\subsection{Posicionamento dos sensores}

Com objetivo de avaliar a capacidade de localização do método proposto, oito acelerômetros foram posicionados sobre a superfície de um tubo de $6 \mathrm{~m}$ de comprimento, tendo suas extremidades terminadas $30 \mathrm{~cm}$ em caixa de areia, conforme esboça a FIG. 9.3. Tal disposição dos sensores tem como objetivo verificar como a geometria entre eles pode influenciar na capacidade de localização.

O sensor A, o qual serve de referência de sincronismo do sistema de aquisição, é posicionado no lado oposto aos outros sensores exatamente para garantir que as variações nos atrasos relativos das chegadas das ondas nos 
sensores em função das variações das posições da fonte sejam percebidas. Se todos os sensores estiverem do mesmo lado em relação à fonte, não importa a posição da fonte, os atrasos relativos serão sempre os mesmos, pois as distâncias relativas entre os sensores e a fonte permanecerão constantes. Ou de outro modo, o atraso do tempo de passagem da onda entre os dois sensores será constante.

Os ensaios foram realizados para vários pontos de excitação na superfície do tubo nos ângulos de $0^{\circ}, 30^{\circ}, 45^{\circ}$ e $60^{\circ}$ em três freqüências: $1 \mathrm{KHz}$, $2 \mathrm{KHz}$ e $3 \mathrm{KHz}$. Como fonte pontual foi utilizada uma pastilha piezelétrica em forma de disco, fixa a uma ponta metálica a qual foi alimentada com uma tensão senoidal de amplitude $10 \mathrm{Vpp}$. Detalhes dos instrumentos e dispositivos utilizados podem ser encontrados no APÊNDICE B e no APÊNDICE C.

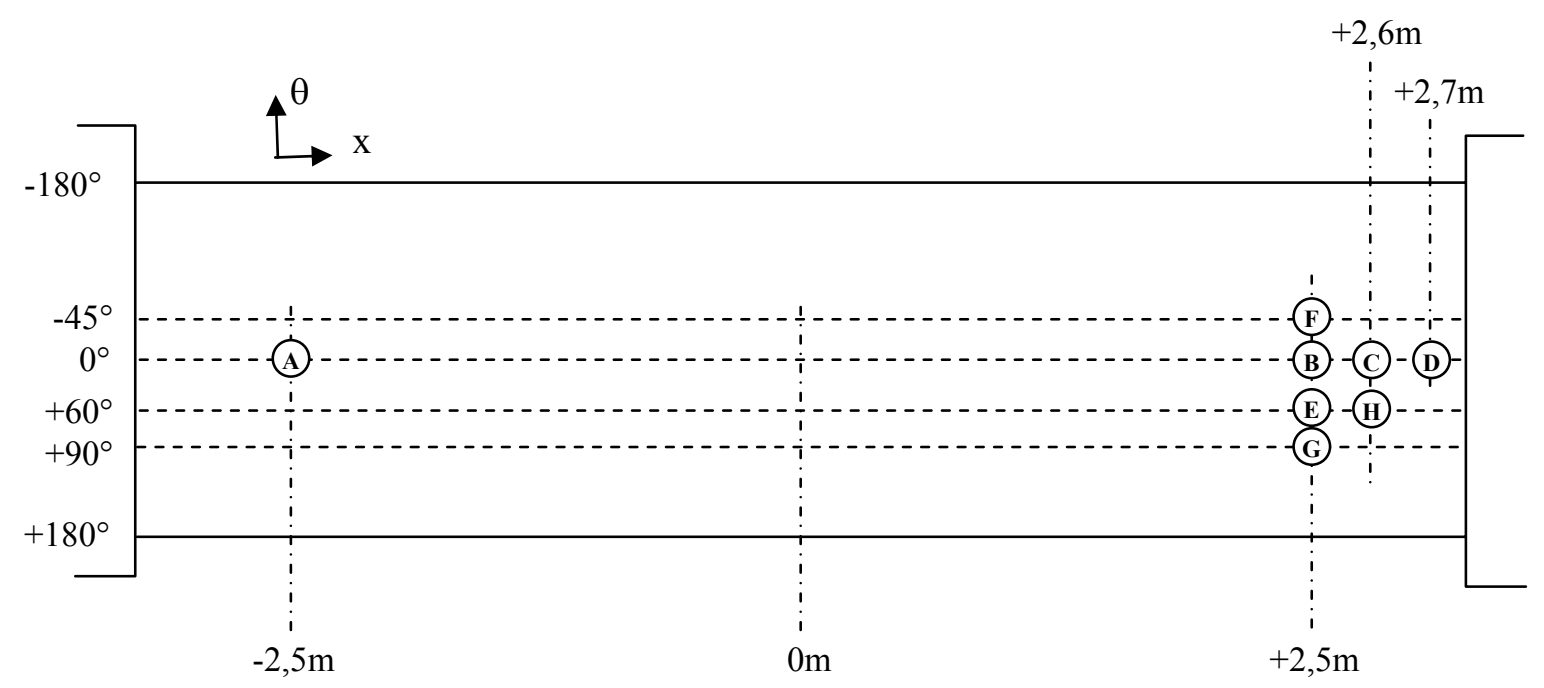

FIGURA 9.3 - Disposição dos sensores na superfície do tubo.

\subsection{Resultados da localização}

Com base no posicionamento descrito, algumas combinações de sensores foram avaliadas, tendo como objetivo a verificação da influência da disposição relativa entre eles na melhora ou piora da capacidade de localização da fonte. As combinações usadas podem ser vista na TAB. 9.1. 
TABELA 9.1 - Combinações entre os sensores

\begin{tabular}{|c|c|c|}
\hline Nome & \multicolumn{2}{|c|}{ Distribuição } \\
\hline ABCE & (A) & $\begin{array}{l}\text { (B) (C) } \\
\text { () }\end{array}$ \\
\hline$A B C D$ & (A) & (B) (C) (D) \\
\hline ABFE & (A) & $\begin{array}{l}\text { () } \\
\text { (B) } \\
\text { () }\end{array}$ \\
\hline ABGE & (A) & $\begin{array}{l}\text { B } \\
\text { () }\end{array}$ \\
\hline AGHD & (A) & (G) ${ }^{(1)}$ \\
\hline
\end{tabular}

Nas FIG. 9.4 e FIG. 9.5 são mostrados dois exemplos de resultados apresentados pelos programas de localização criados em Matlab ${ }^{1}$. Na FIG. 9.4 pode ser vista a resposta para uma fonte de excitação na posição $+0,3 \mathrm{~m}$ e $30^{\circ}$ com freqüência de $1 \mathrm{KHz}$ sendo avaliada pelos sensores B, C, e D. Na FIG. 9.5 tem-se a resposta para uma fonte de excitação na posição $-1,3 \mathrm{~m}$ e $0^{\circ} \mathrm{com}$ freqüência de $2 \mathrm{KHz}$ sendo avaliada pelos sensores $\mathrm{B}, \mathrm{C}$, e $\mathrm{E}$.

Nas FIG. 9.4 e 9.5, a primeira seqüência mostra os pontos de excitação que satisfazem os três sensores simultaneamente. Nesta avaliação, os mapas teóricos são matizes com 51 linhas por 25 colunas, sendo que as linhas representam as distâncias axiais de $-2,5 \mathrm{~m}$ até $2,5 \mathrm{~m}$ e as colunas os ângulos de $-180^{\circ}$ até $180^{\circ}$. No caso do mapa BCD a posição $29 \mathrm{em} x$ e $15 \mathrm{em}$ teta, na matriz representa $x=0,3 \mathrm{~m}$ e $\theta=30^{\circ}$, FIG. 9.4. Os Desvios apresentados como Delay $=7 \%$ e RMS $=16 \%$ representam as larguras das faixas de busca nos mapas, ou seja, $7 \%$ representa que no mapa dos atrasos os valores encontrados estão dentro de uma faixa de $\pm 7 \%$ em relação ao valor exato do atraso medido. De modo idêntico é realizado para o RMS. Este aumento na faixa de busca é incrementado a cada ciclo de busca, como pode ser visto no diagrama do APÊNDICE E.

\footnotetext{
${ }^{1}$ Marca registrada da The Math Works, Inc.
} 


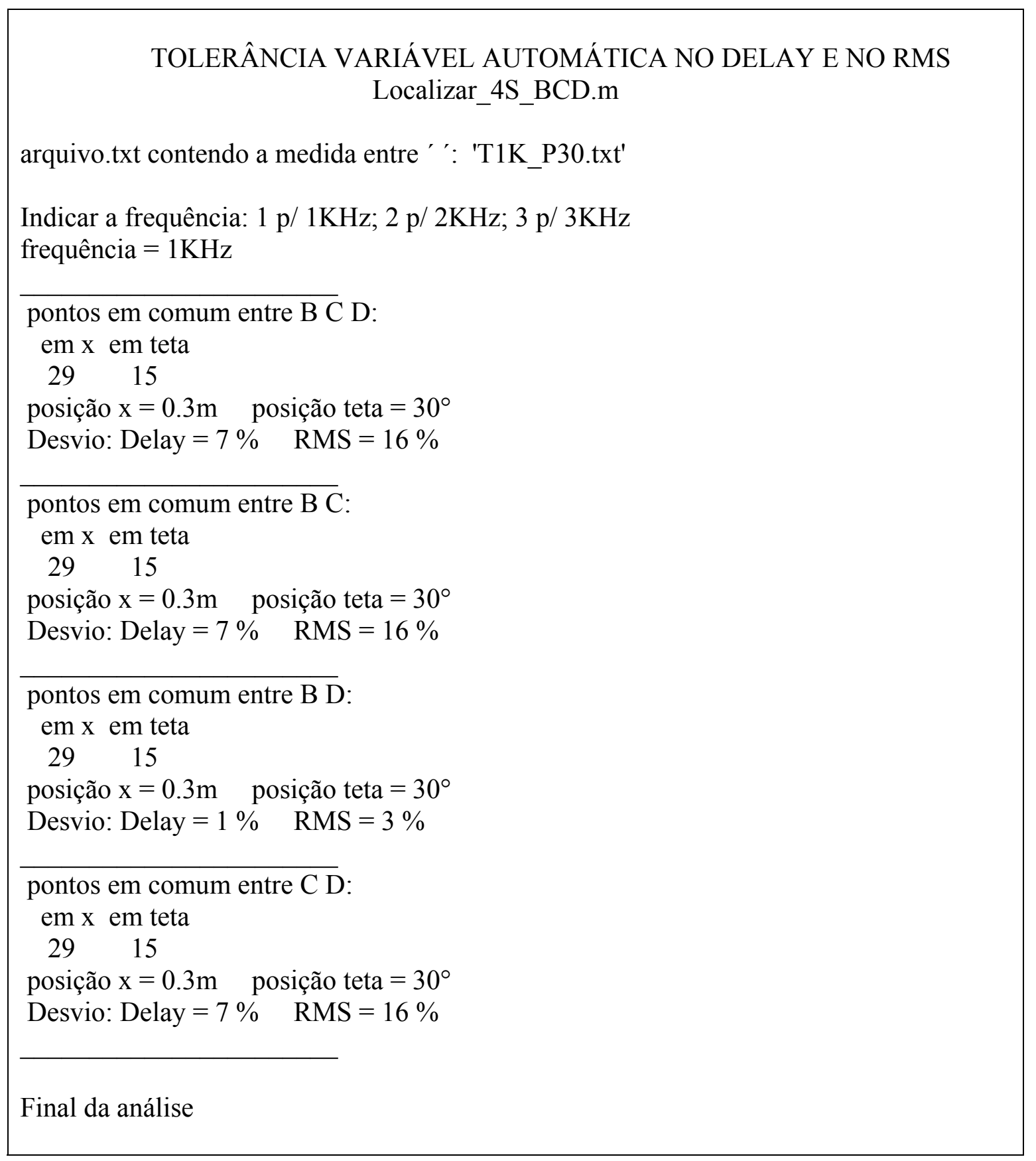

FIGURA 9.4 - Visualização da tela de resultados para fonte na posição +0,3 m e $30^{\circ}$ com freqüência de $1 \mathrm{KHz}$. 
Nota-se que o resultado pode conter mais que um possível ponto no mapa que satisfaça os três sensores simultaneamente no que diz respeito aos atrasos no tempo, FIG. 9.5. Neste instante as comparações entre os RMS é quem vão decidir qual dos possíveis pontos encontrados é a solução. Somente este será apresentado como resposta em metro e grau.

Uma outra possibilidade é a não existência de pontos comuns, neste caso uma mensagem é apresentada.

Terminada esta primeira análise, três outras são iniciadas avaliando as respostas dos sensores de par em par. Estas novas avaliações têm a finalidade de reforçar o resultado da primeira ou trazer novas informações para a decisão de onde a fonte se encontra.

Na FIG. 9.5 as análises entre BCE, BC e CE apresentam o resultado esperado, já a análise BE não. Isto se deve ao fato da busca ser encerrada quando as duas condições, que são encontrar o ponto em relação ao atraso e em relação ao RMS, são verificadas. Nesta versão a decisão quanto à adequação da resposta deve ser humana, em versões futuras será avaliada a possibilidade desta função fazer parte do programa.

Vários pontos de excitação sobre a superfície do tubo foram gerados e medidos pelos acelerômetros posicionados como indicado na FIG 9.3. É importante adiantar que o método mostrou-se eficiente na maioria dos casos ensaiados, gerando respostas corretas.

A seguir são apresentadas algumas situações onde ocorreram falhas no processo de localização da fonte de excitação e a análise de suas possíveis causas. Nas tabelas referentes aos casos estudados os $\Delta$ representam os desvios no atraso temporal e no RMS, os * representam falhas na localização da fonte de excitação. 


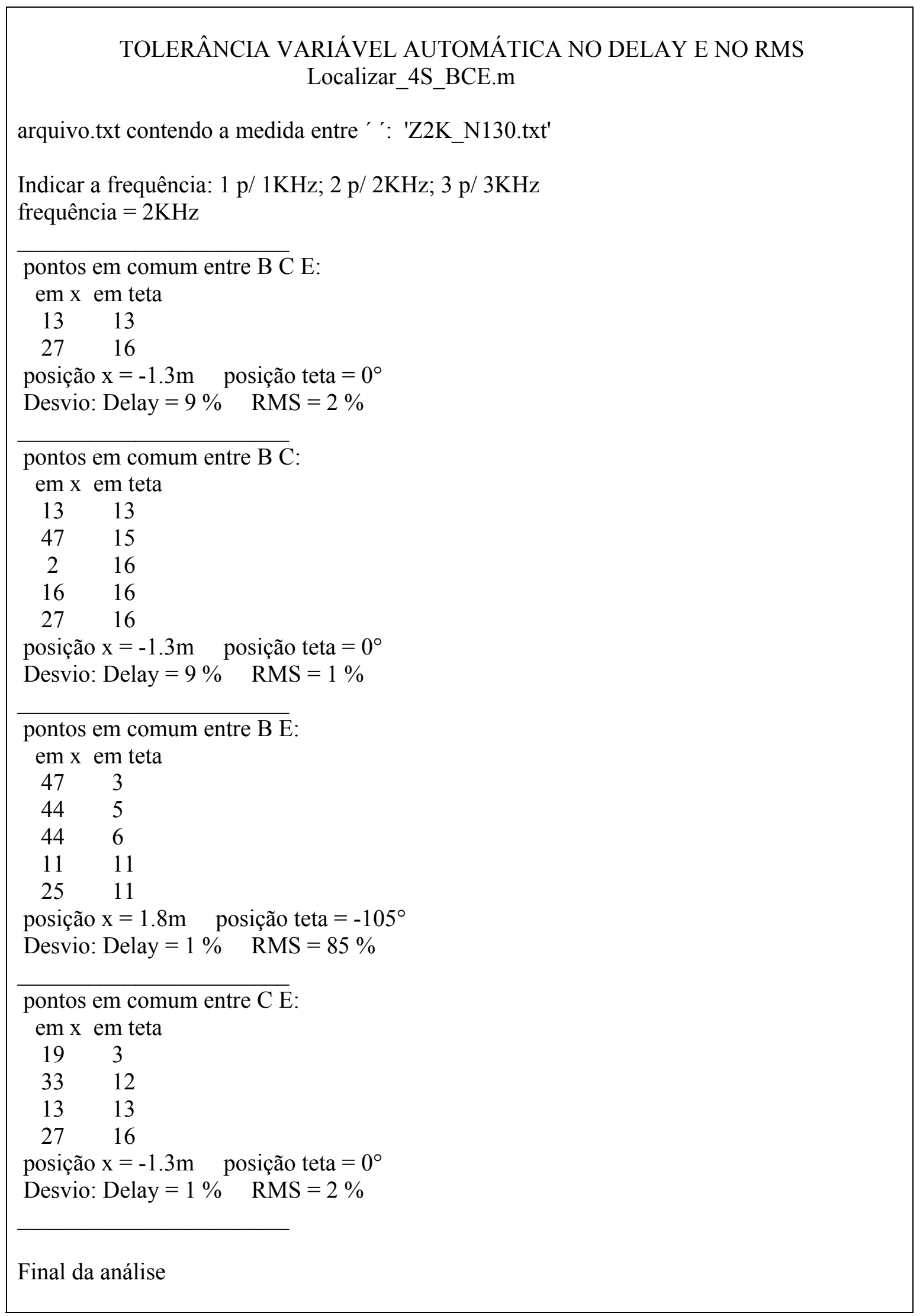

FIGURA 9.5 - Visualização da tela de resultados para fonte na posição -1,3 m e $0^{\circ}$ com freqüência de $2 \mathrm{KHz}$. 


\subsubsection{Caso 1}

$\mathrm{Na}$ TAB. 9.2 observa-se que todos os resultados dependentes do sensor B geraram respostas incorretas. Este fato é causado pela dúvida na determinação do primeiro ponto de máximo na correlação cruzada entre o sensor $A$ (referência) e o sensor $B$. Este evento ocorreu pois os sinais de A e B possuem defasagem de $180^{\circ}$, o que produz uma correlação cruzada simétrica em relação ao zero. Deste modo uma flutuação na fase de um dos sinais para mais ou para menos implica no ponto de máximo se deslocar para a direita ou para a esquerda do zero na correlação cruzada, o que pode levar a uma falha na localização. Neste caso o mapa teórico indicava $5,000010^{-4}$ segundos e o atraso medido indicava $-5,000010^{-4}$ segundos, ou seja, um valor simétrico em relação ao zero. Observa-se que este é meio período de $1 \mathrm{KHz}$.

TABELA 9.2 - Resultados encontrados para a fonte em -0,3 m e $0^{\circ}$ com freqüência de $1 \mathrm{KHz}$.

\begin{tabular}{|c|c|c|c|c|c|c|c|c|c|}
\hline $\begin{array}{l}\text { Posição da } \\
\text { fonte }\end{array}$ & arquivo & $\begin{array}{c}\Delta \\
\text { tempo }\end{array}$ & $\begin{array}{c}\Delta \\
\text { RMS }\end{array}$ & $\begin{array}{c}\Delta \\
\text { tempo }\end{array}$ & $\begin{array}{c}\Delta \\
\text { RMS }\end{array}$ & $\begin{array}{c}\Delta \\
\text { tempo }\end{array}$ & $\begin{array}{c}\Delta \\
\text { RMS }\end{array}$ & $\begin{array}{c}\Delta \\
\text { tempo }\end{array}$ & $\begin{array}{c}\Delta \\
\text { RMS }\end{array}$ \\
\hline \multirow{10}{*}{$-0,3 \mathrm{~m} \mathrm{e}^{\circ}$} & \multirow{10}{*}{ Z1K_N30.txt } & \multicolumn{2}{|c|}{ BCE } & \multicolumn{2}{|c|}{ BC } & \multicolumn{2}{|c|}{ BE } & \multicolumn{2}{|c|}{ CE } \\
\hline & & $*$ & $*$ & $*$ & $*$ & $*$ & $*$ & $1 \%$ & $1 \%$ \\
\hline & & \multicolumn{2}{|c|}{ BCD } & \multicolumn{2}{|c|}{ BC } & \multicolumn{2}{|c|}{ BD } & \multicolumn{2}{|c|}{ CD } \\
\hline & & $*$ & $*$ & $*$ & $*$ & $*$ & $*$ & $1 \%$ & $1 \%$ \\
\hline & & \multicolumn{2}{|c|}{ BFE } & \multicolumn{2}{|c|}{ BF } & \multicolumn{2}{|c|}{ BE } & \multicolumn{2}{|c|}{ FE } \\
\hline & & $*$ & * & $*$ & $*$ & $*$ & $*$ & $1 \%$ & $1 \%$ \\
\hline & & \multicolumn{2}{|c|}{ BGE } & \multicolumn{2}{|c|}{ BG } & \multicolumn{2}{|c|}{ BE } & \multicolumn{2}{|c|}{ GE } \\
\hline & & $*$ & $*$ & $*$ & $*$ & $*$ & $*$ & $1 \%$ & $1 \%$ \\
\hline & & \multicolumn{2}{|c|}{ GHD } & \multicolumn{2}{|c|}{ GH } & \multicolumn{2}{|c|}{ GD } & \multicolumn{2}{|c|}{ HD } \\
\hline & & $1 \%$ & $1 \%$ & $1 \%$ & $1 \%$ & $1 \%$ & $1 \%$ & $1 \%$ & $1 \%$ \\
\hline
\end{tabular}

\subsubsection{Caso 2}

$\mathrm{Na}$ TAB. 9.3 a linha sf apresenta o resultado para o sinal sem filtragem, a linha $\boldsymbol{d n}$ apresenta o resultado para o sinal filtrado através de wavelet-denoise. Para a filtragem do sinal foi escolhida a Wavelet Daubechies 10 com 12 níveis de decomposição do sinal. A escolha da Wavelet Daubechies deveu-se ao fato desta wavelet ser a que melhor se encaixa aos sinais adquiridos dos sensores.

A escolha da wavelet-denoise como filtro de ruído está no fato da Wavelet não gerar alterações na fase do sinal filtrado em relação ao sinal bruto. 
Para a realização da filtragem foi utilizado o toolbox wavemenu do Matlab ${ }^{2}$, o qual já prove as funções de decomposição do sinal original e a retirada do ruído de forma automática ou manual, mais detalhes em Misiti et al. (2002).

As componentes de ruído presentes na medida do sensor $B$ induzem um desvio no atraso desejado, de tal modo que um outro ponto do mapa teórico satisfaça as condições do atraso medido em primeira ocorrência, gerando uma falha na localização nas seguintes combinações: BCE, BFE e BGE. No caso da combinação BCD o acerto, mesmo com um desvio elevado, se deve ao fato de no processo de busca a condição correta ocorrer antes de uma outra incorreta. Para este caso, a filtragem com wavelet-denoise tornou possível a localização da fonte com excelente grau de precisão, apesar de que sabidamente, a Transformada de Wavelet ser mais adequada para sinais transientes, optou-se pelo uso e estudo da mesma, antevendo futuras aplicações para sinais não estacionários. Mesmo para a combinação $G H D$, a qual não depende do sensor $B$, a capacidade de localização foi mantida após a filtragem. Neste caso há uma piora na resposta quanto ao desvio do RMS, o que era de se esperar, pois o processo de filtragem implica na variação da amplitude do RMS do sinal.

TABELA 9.3 - Resultados encontrados para a fonte em $-2,5 \mathrm{~m}$ e $0^{\circ} \mathrm{com}$ freqüência de $2 \mathrm{KHz}$.

\begin{tabular}{|c|c|c|c|c|c|c|c|c|c|c|}
\hline $\begin{array}{l}\text { Posição da } \\
\text { fonte }\end{array}$ & arquivo & $\begin{array}{c}\Delta \\
\text { tempo }\end{array}$ & $\begin{array}{c}\Delta \\
\text { RMS }\end{array}$ & $\begin{array}{c}\Delta \\
\text { tempo }\end{array}$ & $\begin{array}{c}\Delta \\
\text { RMS }\end{array}$ & $\begin{array}{c}\Delta \\
\text { tempo }\end{array}$ & $\begin{array}{c}\Delta \\
\text { RMS }\end{array}$ & $\begin{array}{c}\Delta \\
\text { tempo }\end{array}$ & $\begin{array}{c}\Delta \\
\text { RMS }\end{array}$ & \\
\hline \multirow{15}{*}{$-2,5 \mathrm{~m} \mathrm{e} 0^{\circ}$} & \multirow{15}{*}{ Z2K_N250.txt } & \multicolumn{2}{|c|}{ BCE } & \multicolumn{2}{|c|}{ BC } & \multicolumn{2}{|c|}{ BE } & \multicolumn{2}{|c|}{ CE } & \\
\hline & & $*$ & $*$ & $*$ & $*$ & $*$ & $*$ & $1 \%$ & $3 \%$ & $s f$ \\
\hline & & $1 \%$ & $14 \%$ & $1 \%$ & $6 \%$ & $1 \%$ & $14 \%$ & $1 \%$ & $14 \%$ & $d n$ \\
\hline & & \multicolumn{2}{|c|}{ BCD } & \multicolumn{2}{|c|}{$B C$} & \multicolumn{2}{|c|}{ BD } & \multicolumn{2}{|c|}{ CD } & \\
\hline & & $17 \%$ & $2 \%$ & $*$ & $*$ & $17 \%$ & $2 \%$ & $1 \%$ & $1 \%$ & $s f$ \\
\hline & & $1 \%$ & $6 \%$ & $1 \%$ & $6 \%$ & $1 \%$ & $6 \%$ & $1 \%$ & $3 \%$ & $d n$ \\
\hline & & \multicolumn{2}{|c|}{ BFE } & \multicolumn{2}{|c|}{ BF } & \multicolumn{2}{|c|}{ BE } & \multicolumn{2}{|c|}{ FE } & \\
\hline & & $*$ & $*$ & $*$ & * & * & $*$ & $1 \%$ & $2 \%$ & $s f$ \\
\hline & & $1 \%$ & $15 \%$ & $1 \%$ & $6 \%$ & $1 \%$ & $15 \%$ & $1 \%$ & $15 \%$ & $d n$ \\
\hline & & \multicolumn{2}{|c|}{ BGE } & \multicolumn{2}{|c|}{ BG } & \multicolumn{2}{|c|}{$\mathrm{BE}$} & \multicolumn{2}{|c|}{ GE } & \\
\hline & & $*$ & $*$ & $*$ & $*$ & $*$ & $*$ & $1 \%$ & $2 \%$ & $s f$ \\
\hline & & $1 \%$ & $15 \%$ & $1 \%$ & $6 \%$ & $1 \%$ & $15 \%$ & $1 \%$ & $15 \%$ & $d n$ \\
\hline & & \multicolumn{2}{|c|}{ GHD } & \multicolumn{2}{|c|}{ GH } & \multicolumn{2}{|c|}{ GD } & \multicolumn{2}{|c|}{ HD } & \\
\hline & & $1 \%$ & $2 \%$ & $1 \%$ & $2 \%$ & $1 \%$ & $1 \%$ & $1 \%$ & $2 \%$ & $s f$ \\
\hline & & $1 \%$ & $13 \%$ & $1 \%$ & $13 \%$ & $1 \%$ & $5 \%$ & $1 \%$ & $13 \%$ & $d n$ \\
\hline
\end{tabular}

\footnotetext{
${ }^{2}$ Marca registrada da The Math Works, Inc.
} 


\subsubsection{Caso 3}

$\mathrm{Na}$ TAB. 9.4, observam-se os resultados para fonte de excitação em $-2,4 \mathrm{~m}$ e $0^{\circ}$ para a freqüência de $2 \mathrm{KHz}$. A linha sf apresenta o resultado para o sinal sem filtragem, a linha $\boldsymbol{d} \boldsymbol{n}$ apresenta o resultado para o sinal filtrado através de wavelet-denoise e a linha $\boldsymbol{f}-\boldsymbol{F}$ representa o resultado para o sinal filtrado com Filtro de Fourier, janela natural, banda de $\pm 18 \mathrm{~Hz}$ em relação à freqüência central real de $1998 \mathrm{~Hz}$ no sinal medido.

TABELA 9.4 - Resultados encontrados para a fonte em $-2,4 \mathrm{~m}$ e $0^{\circ} \mathrm{com}$ freqüência de $2 \mathrm{KHz}$.

\begin{tabular}{|c|c|c|c|c|c|c|c|c|c|c|}
\hline $\begin{array}{c}\text { Posição da } \\
\text { fonte }\end{array}$ & arquivo & $\begin{array}{c}\Delta \\
\text { tempo }\end{array}$ & $\begin{array}{c}\Delta \\
\text { RMS }\end{array}$ & $\begin{array}{c}\Delta \\
\text { tempo }\end{array}$ & $\begin{array}{c}\Delta \\
\text { RMS }\end{array}$ & $\begin{array}{c}\Delta \\
\text { tempo }\end{array}$ & $\begin{array}{c}\Delta \\
\text { RMS }\end{array}$ & $\begin{array}{c}\Delta \\
\text { tempc }\end{array}$ & $\begin{array}{c}\Delta \\
\text { RMS }\end{array}$ & \\
\hline \multirow{14}{*}{$-2,4 \mathrm{~m}$ e $0^{\circ}$} & \multirow{14}{*}{ Z2K_N240.txt } & \multicolumn{2}{|c|}{ BCE } & \multicolumn{2}{|c|}{ BC } & \multicolumn{2}{|c|}{$\overline{B E}$} & \multicolumn{2}{|c|}{$\overline{C E}$} & \\
\hline & & $8 \%$ & $13 \%$ & $*$ & $*$ & $8 \%$ & $13 \%$ & $1 \%$ & $13 \%$ & $s f$ \\
\hline & & $8 \%$ & $7 \%$ & $*$ & $*$ & $8 \%$ & $7 \%$ & $1 \%$ & $7 \%$ & $d n$ \\
\hline & & $1 \%$ & $1 \%$ & $1 \%$ & $1 \%$ & $1 \%$ & $1 \%$ & $1 \%$ & $1 \%$ & $f-F$ \\
\hline & & \multicolumn{2}{|c|}{ BCD } & \multicolumn{2}{|c|}{$B C$} & \multicolumn{2}{|c|}{ BD } & \multicolumn{2}{|c|}{ CD } & \\
\hline & & $8 \%$ & $1 \%$ & $*$ & $*$ & $8 \%$ & $1 \%$ & $1 \%$ & $1 \%$ & $s f$ \\
\hline & & $8 \%$ & $5 \%$ & $*$ & $*$ & $8 \%$ & $5 \%$ & $1 \%$ & $2 \%$ & $d n$ \\
\hline & & $1 \%$ & $1 \%$ & $1 \%$ & $1 \%$ & $1 \%$ & $1 \%$ & $1 \%$ & $1 \%$ & $f-F$ \\
\hline & & \multicolumn{2}{|c|}{ BFE } & \multicolumn{2}{|c|}{ BF } & \multicolumn{2}{|c|}{ BE } & \multicolumn{2}{|c|}{ FE } & \\
\hline & & $1 \%$ & $11 \%$ & $1 \%$ & $1 \%$ & $1 \%$ & $11 \%$ & $1 \%$ & $11 \%$ & $s f$ \\
\hline & & \multicolumn{2}{|c|}{ BGE } & \multicolumn{2}{|c|}{ BG } & \multicolumn{2}{|c|}{ BE } & \multicolumn{2}{|c|}{ GE } & \\
\hline & & $1 \%$ & $11 \%$ & $1 \%$ & $1 \%$ & $1 \%$ & $11 \%$ & $1 \%$ & $11 \%$ & $s f$ \\
\hline & & \multicolumn{2}{|c|}{ GHD } & \multicolumn{2}{|c|}{ GH } & \multicolumn{2}{|c|}{ GD } & \multicolumn{2}{|c|}{ HD } & \\
\hline & & $1 \%$ & $1 \%$ & $1 \%$ & $1 \%$ & $1 \%$ & $1 \%$ & $1 \%$ & $1 \%$ & $s f$ \\
\hline
\end{tabular}

TABELA 9.5 - Atrasos para o sensor B em relação ao sensor A, obtidos através de correlação cruzada entre eles.

\begin{tabular}{l|c|}
\hline & Atraso entre sensores A e B \\
\hline Encontrado no mapa & $2,3310^{-4} \mathrm{~s}$ \\
\hline Encontrado pela medida & $2,510^{-4} \mathrm{~s}$ \\
\hline Após Wavelet_denoise & $2,510^{-4} \mathrm{~s}$ \\
\hline Após filtragem com FFT & $2,3410^{-4} \mathrm{~s}$ \\
\hline
\end{tabular}

Analisando-se os atrasos contidos nos mapas teóricos no ponto esperado e os atrasos dos sinais medidos em relação a sensor $A$, observa-se que o desvio, o qual gera a falha de localização entre os sensores B e C (* na tabela), deve-se ao sensor $B$, como pode ser visto na TAB. 9.5. Este desvio entre o esperado e o medido também é a causa do erro de $8 \%$ observado para o trio BCE 
e o dueto BE, TAB. 9.4. Nota-se que para o dueto CE o desvio é de $1 \%$. Os mesmos valores são observados para o trio $B C D$ e os duetos $B D$ e $C D$.

Nestes dois casos, a filtragem com wavelet-denoise não mostrou melhorias nas respostas, mantendo os resultados semelhantes aos anteriores à filtragem. Tratando agora, o mesmo sinal com o filtro de Fourier do tipo passa banda, observa-se que a localização é obtida sem nenhuma falha e com excelente índice de acerto.

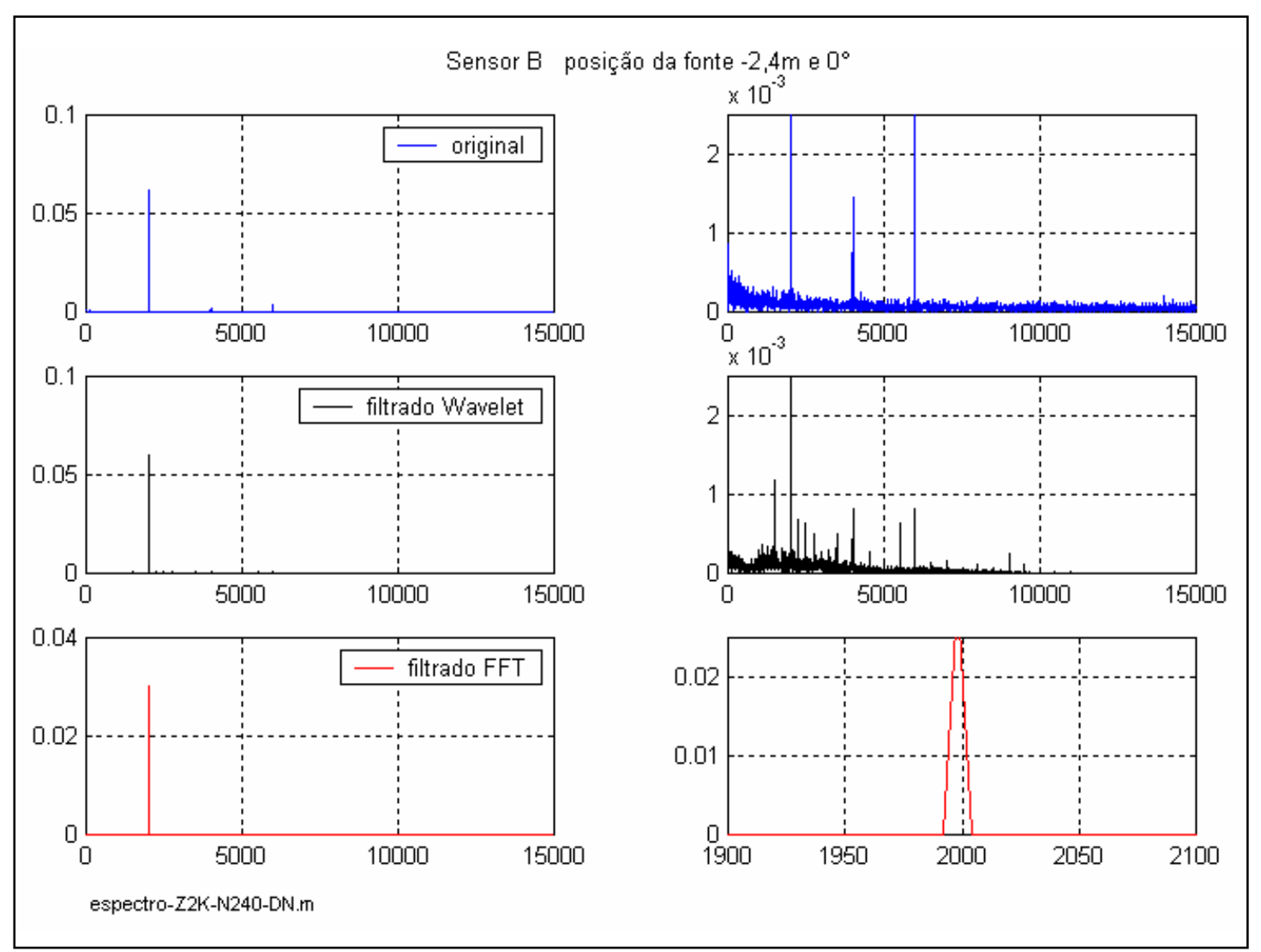

FIGURA 9.6 - Espectro do sinal do sensor B para fonte na posição $-2,4 \mathrm{~m} \mathrm{e} 0^{\circ}$ com freqüência de $2 \mathrm{KHz}$, antes e depois da filtragem.

Na FIG. 9.6 são apresentados os espectros do sinal do sensor B. À direita tem-se o mesmo espectro da esquerda ampliado para identificação das raias de níveis menores. Observa-se que a filtragem com wavelet-denoise eliminou as componentes de alta freqüência, mas em compensação aumentou ou criou novas raias com níveis destacados do ruído. A sensação é que parte da energia retirada das altas freqüências foi redistribuída para as raias de freqüências menores. No caso da filtragem com Fourier, as freqüências 
indesejadas são eliminadas zerando-se os coeficientes destas freqüências, só se preservando a energia da banda de freqüência de interesse e fazendo-se a transformada inversa para retornar ao domínio do tempo, técnica semelhante à utilizada por Cerqueira et al. (2000) para eliminação de ruídos em medidas.

Estas freqüências laterais mantidas ou geradas na filtragem com wavelet-denoise, mesmo tendo energia pequena, podem gerar desvios na correlação cruzada, suficientes para que um outro ponto seja encontrado. Esta situação é observada na $T A B$. 9.4, onde os trios BCE e BCD e dos duetos $B E$ e $B D$ indicam acerto enquanto $o$ dueto $B C$ não. Para o dueto $B C$ existem vários pontos no mapa dos atrasos entre $A B$ que satisfazem os atrasos medidos de $2,510^{-4} \mathrm{~s}$ e vários no mapa dos atrasos entre $A C$ que satisfazem os atrasos medidos de $-1,3310^{-4} \mathrm{~s}$. Destes possíveis pontos um deles satisfaz as duas condições simultaneamente, gerando assim uma resposta falsa em $-0,2 \mathrm{~m}$ e $0^{\circ}$, com erros de $1 \%$ para o atraso e $84 \%$ para o RMS. Esta situação de localização de um ponto falso já foi relatada no caso 2 .

Pensando agora no trio $\mathrm{BCE}$, o ponto da possível localização deve satisfazer aos atrasos dos três sensores e seus respectivos RMS. A parte do programa de localização que faz esta verificação, aumenta a faixa de atraso em $1 \%$ a cada busca de coincidência, após ter feito uma varredura de 0 à 100\% na amplitude RMS do sinal sem sucesso. Como a busca no trio é mais restritiva, a falsa localização de BC não é percebida.

Nesta versão o processo de localização se encerra quando são satisfeitas as duas condições, coincidência de atraso no tempo e coincidência da amplitude do RMS do sinal. Em versões futuras poderão ser estudadas ferramentas de otimização, com o objetivo de encontrar não o primeiro ponto e sim um ponto ótimo com maior probabilidade de acerto da localização.

Retornando ao caso 1, a filtragem com wavelet-denoise também não mostrou melhorias nas respostas. Contudo a filtragem com o filtro de Fourier do tipo passa banda apresentou um resultado satisfatório semelhante ao relatado aqui. Isto mostra que a filtragem com Fourier é uma ferramenta interessante para eliminação de freqüências indesejadas no sinal medido, propiciando uma melhoria da capacidade de localização da fonte de excitação. 


\subsubsection{Caso 4}

Na TAB. 9.6 são apresentados os resultados para a fonte de excitação em $+0,3 \mathrm{~m} \mathrm{e} 0^{\circ}$ com freqüência de $3 \mathrm{KHz}$. Este caso recai em uma situação semelhante ao caso 1 para a relação de atraso entre os sensores $A$ e $E$, onde se tem o atraso equivalente a meio período do sinal, ou seja, uma defasagem de $180^{\circ}$ entre os sinais. Neste caso o mapa teórico indicava $1,666710^{-4}$ segundos e o atraso medido indicava $-1,666710^{-4}$ segundos, ou seja, simétrico em relação ao zero. Nota-se aqui também, que este valor corresponde a meio período da freqüência de $3 \mathrm{KHz}$.

TABELA 9.6 - Resultados encontrados para a fonte em $+0,3 \mathrm{~m}$ e $0^{\circ}$ com freqüência de $3 \mathrm{KHz}$.

\begin{tabular}{|c|c|c|c|c|c|c|c|c|c|c|}
\hline $\begin{array}{l}\text { Posição da } \\
\text { fonte }\end{array}$ & arquivo & $\begin{array}{c}\Delta \\
\text { tempo }\end{array}$ & $\begin{array}{c}\Delta \\
\text { RMS }\end{array}$ & $\begin{array}{c}\Delta \\
\text { tempo }\end{array}$ & $\begin{array}{c}\Delta \\
\text { RMS }\end{array}$ & $\begin{array}{c}\Delta \\
\text { tempo }\end{array}$ & $\begin{array}{c}\Delta \\
\text { RMS }\end{array}$ & $\begin{array}{c}\Delta \\
\text { tempo }\end{array}$ & $\begin{array}{c}\Delta \\
\text { RMS }\end{array}$ & \\
\hline \multirow{20}{*}{$+0,3 \mathrm{~m} \mathrm{e} 0^{\circ}$} & \multirow{20}{*}{ Z3K_P30.txt } & \multicolumn{2}{|c|}{ BCE } & \multicolumn{2}{|c|}{$B C$} & \multicolumn{2}{|c|}{$\mathrm{BE}$} & \multicolumn{2}{|c|}{ CE } & \\
\hline & & * & * & $1 \%$ & $1 \%$ & $*$ & $*$ & $*$ & $*$ & $s f$ \\
\hline & & $1 \%$ & $2 \%$ & $1 \%$ & $1 \%$ & $1 \%$ & $2 \%$ & $1 \%$ & $2 \%$ & $d n$ \\
\hline & & $1 \%$ & $1 \%$ & $1 \%$ & $1 \%$ & $1 \%$ & $1 \%$ & $1 \%$ & $1 \%$ & $f-F$ \\
\hline & & \multicolumn{2}{|c|}{ BCD } & \multicolumn{2}{|c|}{ BC } & \multicolumn{2}{|c|}{ BD } & \multicolumn{2}{|c|}{ CD } & \\
\hline & & $1 \%$ & $1 \%$ & $1 \%$ & $1 \%$ & $1 \%$ & $1 \%$ & $1 \%$ & $1 \%$ & $s f$ \\
\hline & & $1 \%$ & $1 \%$ & $1 \%$ & $1 \%$ & $1 \%$ & $1 \%$ & $1 \%$ & $1 \%$ & $d n$ \\
\hline & & $1 \%$ & $1 \%$ & $1 \%$ & $1 \%$ & $1 \%$ & $1 \%$ & $1 \%$ & $1 \%$ & $f-F$ \\
\hline & & \multicolumn{2}{|c|}{ BFE } & \multicolumn{2}{|c|}{ BF } & \multicolumn{2}{|c|}{ BE } & \multicolumn{2}{|c|}{ FE } & \\
\hline & & $*$ & $*$ & $1 \%$ & $2 \%$ & $*$ & $*$ & $*$ & $*$ & $s f$ \\
\hline & & $1 \%$ & $3 \%$ & $1 \%$ & $2 \%$ & $1 \%$ & $3 \%$ & $1 \%$ & $3 \%$ & $d n$ \\
\hline & & $1 \%$ & $1 \%$ & $1 \%$ & $1 \%$ & $1 \%$ & $1 \%$ & $1 \%$ & $1 \%$ & $f-F$ \\
\hline & & \multicolumn{2}{|c|}{ BGE } & \multicolumn{2}{|c|}{ BG } & \multicolumn{2}{|c|}{ BE } & \multicolumn{2}{|c|}{ GE } & \\
\hline & & * & $*$ & $1 \%$ & $9 \%$ & * & $*$ & $*$ & * & $s f$ \\
\hline & & $1 \%$ & $3 \%$ & $1 \%$ & $1 \%$ & $1 \%$ & $3 \%$ & $1 \%$ & $3 \%$ & $d n$ \\
\hline & & $1 \%$ & $1 \%$ & $1 \%$ & $1 \%$ & $1 \%$ & $1 \%$ & $1 \%$ & $1 \%$ & $f-F$ \\
\hline & & \multicolumn{2}{|c|}{ GHD } & \multicolumn{2}{|c|}{ GH } & \multicolumn{2}{|c|}{ GD } & \multicolumn{2}{|c|}{ HD } & \\
\hline & & $1 \%$ & $9 \%$ & $1 \%$ & $9 \%$ & $1 \%$ & $9 \%$ & $1 \%$ & $1 \%$ & $s f$ \\
\hline & & $1 \%$ & $17 \%$ & $1 \%$ & $17 \%$ & $1 \%$ & $17 \%$ & $1 \%$ & $1 \%$ & $d n$ \\
\hline & & $1 \%$ & $1 \%$ & $1 \%$ & $1 \%$ & $1 \%$ & $1 \%$ & $1 \%$ & $1 \%$ & $f-F$ \\
\hline
\end{tabular}

Esta situação difere um pouco do caso 1, pois aqui a filtragem com wavelet-denoise proveu a capacidade de localização para as combinações BCE, BGE e BFE. A explicação é que neste caso o ruído, mesmo pequeno, provocou a dúvida na determinação se o ponto de máximo da correlação cruzada ente $\mathrm{A}$ e $\mathrm{E}$ estava à direita ou à esquerda do zero, falha esta eliminada com a eliminação do ruído pela wavelet-denoise. 
Neste caso, a filtragem com Filtro de Fourier também proveu a capacidade de localização e com igual ou melhor grau de acerto comparado a wavelet-denoise.

\subsubsection{Caso 5}

A TAB. 9.7 apresenta uma situação em que os erros ocorrem apenas nas combinações dependentes do sensor $G$, todas as outras acertam a resposta esperada. Este exemplo recai no caso 2 para a relação de atraso entre os sensores $\mathrm{A}$ e $\mathrm{G}$, onde as componentes de ruído presentes na medida do sensor $\mathrm{G}$ induzem um desvio no atraso desejado. Aqui, igualmente ao caso 2, a filtragem com wavelet produziu resultados satisfatórios para as combinações BGE e GHD.

Realizando a filtragem com Filtro de Fourier e refazendo-se a busca para BGE e GHD, observam-se resultados com igual ou melhor grau de acerto comparado a wavelet-denoise.

TABELA 9.7 - Resultados encontrados para a fonte em $+1,0 \mathrm{~m}$ e $0^{\circ}$ com freqüência de $3 \mathrm{KHz}$.

\begin{tabular}{|c|c|c|c|c|c|c|c|c|c|c|}
\hline $\begin{array}{c}\text { Posição da } \\
\text { fonte }\end{array}$ & arquivo & $\begin{array}{c}\Delta \\
\text { tempo }\end{array}$ & $\begin{array}{c}\Delta \\
\text { RMS }\end{array}$ & $\begin{array}{c}\Delta \\
\text { tempc }\end{array}$ & $\begin{array}{c}\Delta \\
\text { RMS }\end{array}$ & $\begin{array}{c}\Delta \\
\text { tempc }\end{array}$ & $\begin{array}{c}\Delta \\
\text { RMS }\end{array}$ & $\begin{array}{c}\Delta \\
\text { tempo }\end{array}$ & $\begin{array}{c}\Delta \\
\text { RMS }\end{array}$ & \\
\hline \multirow{12}{*}{$+1 \mathrm{~m} \mathrm{e} 0^{\circ}$} & \multirow{12}{*}{ Z3K_P100.txt } & \multicolumn{2}{|c|}{ BCE } & \multicolumn{2}{|c|}{ BC } & \multicolumn{2}{|c|}{$\overline{B E}$} & \multicolumn{2}{|c|}{ CE } & \\
\hline & & $1 \%$ & $1 \%$ & $1 \%$ & $1 \%$ & $1 \%$ & $1 \%$ & $1 \%$ & $1 \%$ & $s f$ \\
\hline & & \multicolumn{2}{|c|}{ BCD } & \multicolumn{2}{|c|}{ BC } & \multicolumn{2}{|c|}{ BD } & \multicolumn{2}{|c|}{ CD } & \\
\hline & & $1 \%$ & $1 \%$ & $1 \%$ & $1 \%$ & $1 \%$ & $1 \%$ & $1 \%$ & $1 \%$ & $s f$ \\
\hline & & \multicolumn{2}{|c|}{ BFE } & \multicolumn{2}{|c|}{ BF } & \multicolumn{2}{|c|}{$B E$} & \multicolumn{2}{|c|}{ FE } & \\
\hline & & $1 \%$ & $1 \%$ & $1 \%$ & $1 \%$ & $1 \%$ & $1 \%$ & $1 \%$ & $1 \%$ & $s f$ \\
\hline & & \multicolumn{2}{|c|}{ BGE } & \multicolumn{2}{|c|}{ BG } & \multicolumn{2}{|c|}{$\mathrm{BE}$} & \multicolumn{2}{|c|}{ GE } & \\
\hline & & $*$ & $*$ & $*$ & $*$ & $1 \%$ & $1 \%$ & $*$ & $*$ & $s f$ \\
\hline & & $1 \%$ & $3 \%$ & $1 \%$ & $2 \%$ & $1 \%$ & $3 \%$ & $1 \%$ & $3 \%$ & $d n$ \\
\hline & & \multicolumn{2}{|c|}{ GHD } & \multicolumn{2}{|c|}{ GH } & \multicolumn{2}{|c|}{ GD } & \multicolumn{2}{|c|}{ HD } & \\
\hline & & $*$ & $*$ & $*$ & $*$ & $*$ & * & $1 \%$ & $1 \%$ & $s f$ \\
\hline & & $1 \%$ & $2 \%$ & $1 \%$ & $2 \%$ & $1 \%$ & $2 \%$ & $1 \%$ & $1 \%$ & $d n$ \\
\hline
\end{tabular}

\subsubsection{Caso 6}

Como observado na FIG. 7.12 do capítulo 7 , na linha de $30^{\circ}$ sobre todas as posições de $0 \mathrm{~m}$ até o limite do tubo, existe uma singularidade no mapa, ou de outro modo uma região onde os níveis são próximos de zero, uma região de nós para a excitação de $1 \mathrm{KHz}$ aplicada sobre a linha de $0^{\circ}$. 
Considerando a excitação na linha de $30^{\circ}$, implica que pela disposição adotada, os sensores A, B, C, D, E e H estarão deslocados da linha de excitação de $\pm 30^{\circ}, F I G$. 9.3. Ou seja, estarão na região dos nós. Já o sensor $G$ que foi posicionado na linha de $90^{\circ}$, está distante de $60^{\circ}$ da linha de excitação, pertencendo assim à região de picos e vales conforme pode ser visto na FIG. 7.12. O sensor $F$, o qual foi posicionado na linha de $-45^{\circ}$, está distante da linha de excitação de $75^{\circ}$, ficando também na região de picos e vales. A FIG. 9.7 apresenta os sinais capturados pelos sensores nesta situação. Pode ser observado que as curvas dos sensores $G$ e $F$ são as únicas que se sobressaem com amplitudes bem superiores. Os outros sensores por apresentarem níveis bem menores ficam mais sujeitos às interferências de ruídos externos e eletrônicos.

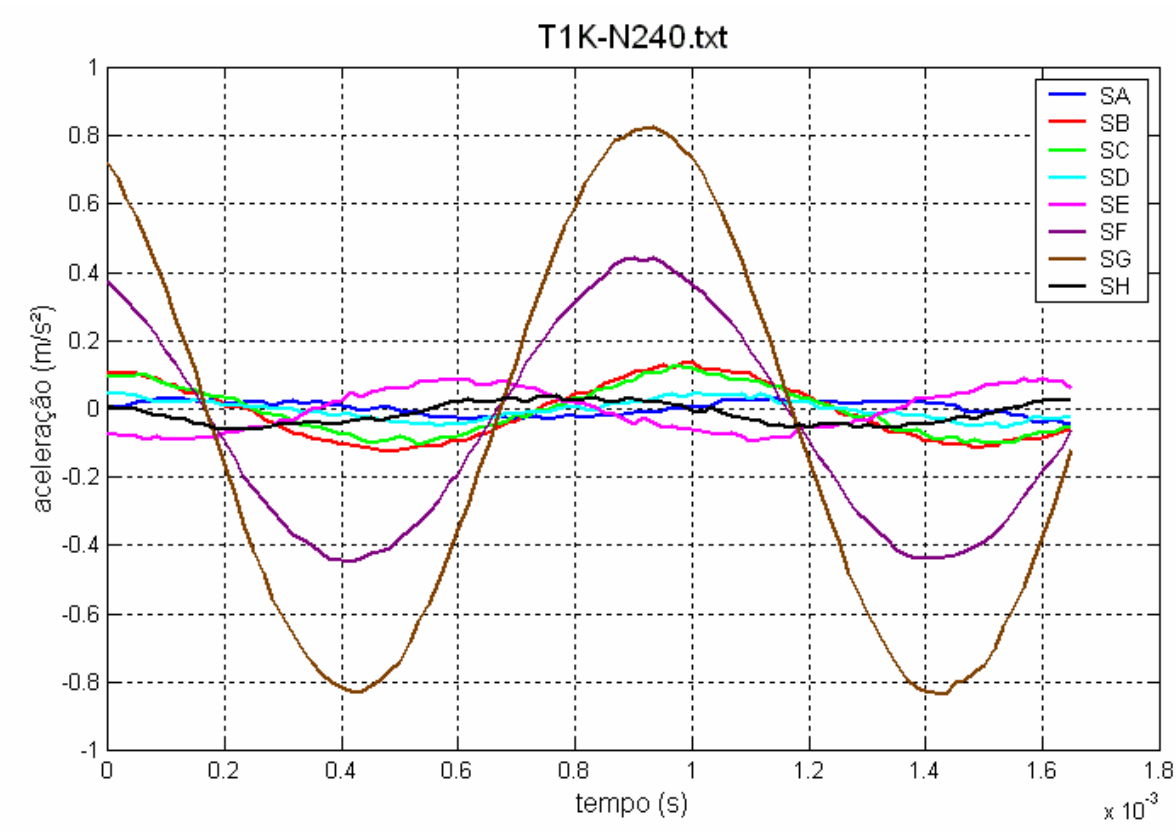

FIGURA 9.7 - Visualização dos sinais medidos para a excitação em $-2,4 \mathrm{~m}$ e $30^{\circ}$ com freqüência de $1 \mathrm{KHz}$.

Em alguns casos o nível de ruído pode interferir no instante de gatilhamento da placa de aquisição de dados, que é sincronizada pelo sensor $A, 0$ qual serve de referência para o processo de localização. Nesta situação a possibilidade de não localização da excitação mesmo após um processo de filtragem é aumentada. Possibilidades de soluções deste problema são a escolha de sensores com maior sensibilidade em volt/g ou um aumento no ganho dos amplificadores. Contudo de nada adianta se o ruído aumentar junto. Portanto 
alguns cuidados devem ser tomados no processo de aquisição para melhorar a qualidade do sinal, como por exemplo, aterramento dos instrumentos, cabos blindados, conectores limpos e firmes e instrumentos com boa relação sinal ruído.

Como exemplo é tomado o caso no qual a fonte foi posicionada em $-2,4 \mathrm{~m}$ sobre a linha de $30^{\circ}$, FIG. 9.7. Nesta situação, a filtragem tornou possível a localização da fonte pois não houve prejuízo na sincronização do sinal adquirido. Contudo nem sempre a situação é favorável, como pode ser observado para os sinais adquiridos quando a fonte foi posicionada em $+2,4 \mathrm{~m}$ sobre a linha de $30^{\circ}$, FIG. 9.8. Nesta situação o sinal do sensor $A$ é tão pequeno que o sincronismo foi perdido, e mesmo após a filtragem a informação do sinal de $1 \mathrm{KHz}$ não pode ser recuperada. Isto implica na não capacidade de localização da posição da fonte. A FIG. 9.8 apresenta os sinais capturados pelos sensores nesta situação, onde pode ser observado que o sinal SA na cor azul escuro praticamente não se levanta do zero.

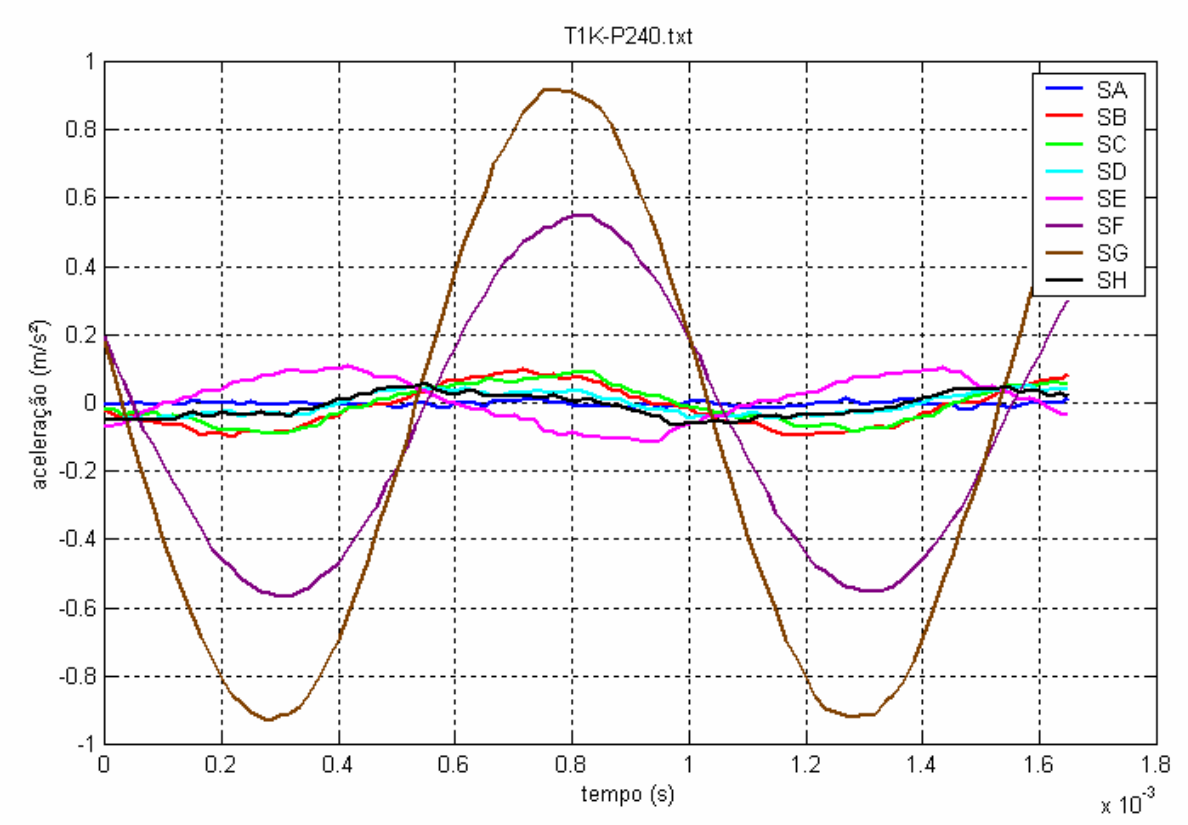

FIGURA 9.8 - Visualização dos sinais medidos para a excitação em $+2,4 \mathrm{~m}$ e $30^{\circ}$ com freqüência de $1 \mathrm{KHz}$.

\subsubsection{Caso 7}

Na TAB. 9.8 a linha sf apresenta o resultado para o sinal sem filtragem, a linha dn1 apresenta o resultado para o sinal filtrado através de wavelet-denoise com detecção automática dos limiares de corte dos níveis de decomposição do sinal, a linha dn2 apresenta o mesmo sinal com uma nova filtragem do sinal 
original através de wavelet-denoise com escolha manual dos limiares de corte e a linha $\boldsymbol{f}-\boldsymbol{F}$ a filtragem com filtro de Fourier.

TABELA 9.8 - Resultados encontrados para a fonte em $-2,5 \mathrm{~m}$ e $30^{\circ} \mathrm{com}$ freqüência de $2 \mathrm{KHz}$.

\begin{tabular}{|c|c|c|c|c|c|c|c|c|c|c|}
\hline $\begin{array}{l}\text { Posição da } \\
\text { fonte }\end{array}$ & arquivo & $\begin{array}{c}\Delta \\
\text { tempo }\end{array}$ & $\begin{array}{c}\Delta \\
\text { RMS }\end{array}$ & $\begin{array}{c}\Delta \\
\text { tempo }\end{array}$ & $\begin{array}{c}\Delta \\
\text { RMS }\end{array}$ & $\begin{array}{c}\Delta \\
\text { tempo }\end{array}$ & $\begin{array}{c}\Delta \\
\text { RMS }\end{array}$ & $\begin{array}{c}\Delta \\
\text { tempo }\end{array}$ & $\begin{array}{c}\Delta \\
\text { RMS }\end{array}$ & \\
\hline \multirow{23}{*}{$-2,5 \mathrm{~m} \mathrm{e} 30^{\circ}$} & \multirow{23}{*}{ T2K_N250.txt } & \multicolumn{2}{|c|}{ BCE } & \multicolumn{2}{|c|}{ BC } & \multicolumn{2}{|c|}{ BE } & \multicolumn{2}{|c|}{ CE } & \\
\hline & & $*$ & $*$ & $1 \%$ & $1 \%$ & $*$ & $*$ & $*$ & $*$ & $s f$ \\
\hline & & $1 \%$ & $5 \%$ & $1 \%$ & $5 \%$ & $1 \%$ & $4 \%$ & $1 \%$ & $5 \%$ & $d n 1$ \\
\hline & & $1 \%$ & $1 \%$ & $1 \%$ & $1 \%$ & $1 \%$ & $1 \%$ & $1 \%$ & $1 \%$ & $f-F$ \\
\hline & & \multicolumn{2}{|c|}{ BCD } & \multicolumn{2}{|c|}{$B C$} & \multicolumn{2}{|c|}{ BD } & \multicolumn{2}{|c|}{ CD } & \\
\hline & & $*$ & $*$ & $1 \%$ & $1 \%$ & $*$ & $*$ & $*$ & $*$ & $s f$ \\
\hline & & $*$ & $*$ & $1 \%$ & $2 \%$ & $*$ & $*$ & $*$ & $*$ & $d n 1$ \\
\hline & & $1 \%$ & $5 \%$ & $1 \%$ & $5 \%$ & $1 \%$ & $5 \%$ & $1 \%$ & $5 \%$ & $d n 2$ \\
\hline & & $1 \%$ & $1 \%$ & $1 \%$ & $1 \%$ & $1 \%$ & $1 \%$ & $1 \%$ & $1 \%$ & $f-F$ \\
\hline & & \multicolumn{2}{|c|}{ BFE } & \multicolumn{2}{|c|}{ BF } & \multicolumn{2}{|c|}{$B E$} & \multicolumn{2}{|c|}{ FE } & \\
\hline & & $*$ & $*$ & $1 \%$ & $1 \%$ & $*$ & $*$ & $*$ & $*$ & $s f$ \\
\hline & & $*$ & $*$ & $*$ & $*$ & $1 \%$ & $4 \%$ & $*$ & $*$ & $d n 1$ \\
\hline & & $1 \%$ & $7 \%$ & $1 \%$ & $2 \%$ & $1 \%$ & $7 \%$ & $1 \%$ & $7 \%$ & $d n 2$ \\
\hline & & $1 \%$ & $1 \%$ & $1 \%$ & $1 \%$ & $1 \%$ & $1 \%$ & $1 \%$ & $1 \%$ & $f-F$ \\
\hline & & \multicolumn{2}{|c|}{ BGE } & \multicolumn{2}{|c|}{ BG } & \multicolumn{2}{|c|}{ BE } & \multicolumn{2}{|c|}{ GE } & \\
\hline & & $*$ & $*$ & $1 \%$ & $1 \%$ & $*$ & $*$ & $*$ & * & $s f$ \\
\hline & & $1 \%$ & $6 \%$ & $1 \%$ & $2 \%$ & $1 \%$ & $6 \%$ & $1 \%$ & $6 \%$ & $d n 1$ \\
\hline & & $1 \%$ & $1 \%$ & $1 \%$ & $1 \%$ & $1 \%$ & $1 \%$ & $1 \%$ & $1 \%$ & $f-F$ \\
\hline & & \multicolumn{2}{|c|}{ GHD } & \multicolumn{2}{|c|}{ GH } & \multicolumn{2}{|c|}{ GD } & \multicolumn{2}{|c|}{ HD } & \\
\hline & & $*$ & $*$ & $1 \%$ & $1 \%$ & * & $*$ & $*$ & $*$ & $s f$ \\
\hline & & $*$ & $*$ & $1 \%$ & $2 \%$ & $*$ & $*$ & $*$ & * & $d n 1$ \\
\hline & & $1 \%$ & $6 \%$ & $1 \%$ & $6 \%$ & $1 \%$ & $4 \%$ & $1 \%$ & $6 \%$ & $d n 2$ \\
\hline & & $1 \%$ & $1 \%$ & $1 \%$ & $1 \%$ & $1 \%$ & $1 \%$ & $1 \%$ & $1 \%$ & $f-F$ \\
\hline
\end{tabular}

Em primeira análise observa-se que, para os sinais sem filtragem, em todas as combinações dos sensores não são obtidas respostas satisfatórias. Após uma primeira filtragem utilizando detecção automática dos limiares de corte, três combinações de sensores não geraram resposta satisfatória, são elas: BCD, BFE e GHD. Uma análise mostrou que os sinais dos sensores $D$ e $F$ possuem defasagem muito próximas de $180^{\circ}$ em relação ao sensor A de referência. Tal condição recai nos casos 1 e 4 já estudados, na situação da filtragem não ter surtido o efeito esperado. Uma segunda forma de filtragem do sinal medido foi realizada utilizando-se o ajuste manual e cuidadoso dos limiares de corte, após isto a resposta desejada foi obtida, linhas dn2 da TAB. 9.8. É interessante ressaltar que o sinal do sensor $E$, mesmo sendo o mais ruidoso, não é o crítico no processo de detecção, mostrando que uma das maiores dificuldades ocorre 
quando se tem a correlação cruzada simétrica causada por uma defasagem próxima de $180^{\circ}$ entre os sensores.

Aqui novamente, observam-se resultados com igual ou melhor grau de acerto para o filtro de Fourier comparado ao filtro com wavelet-denoise.

\subsubsection{Caso 8}

Aqui é apresentada uma situação onde duas respostas são encontradas para os duetos $\mathrm{BC}$ e $\mathrm{BF}$, contudo a resposta correta é identificada com base nas respostas dos outros duetos e dos trios de sensores.

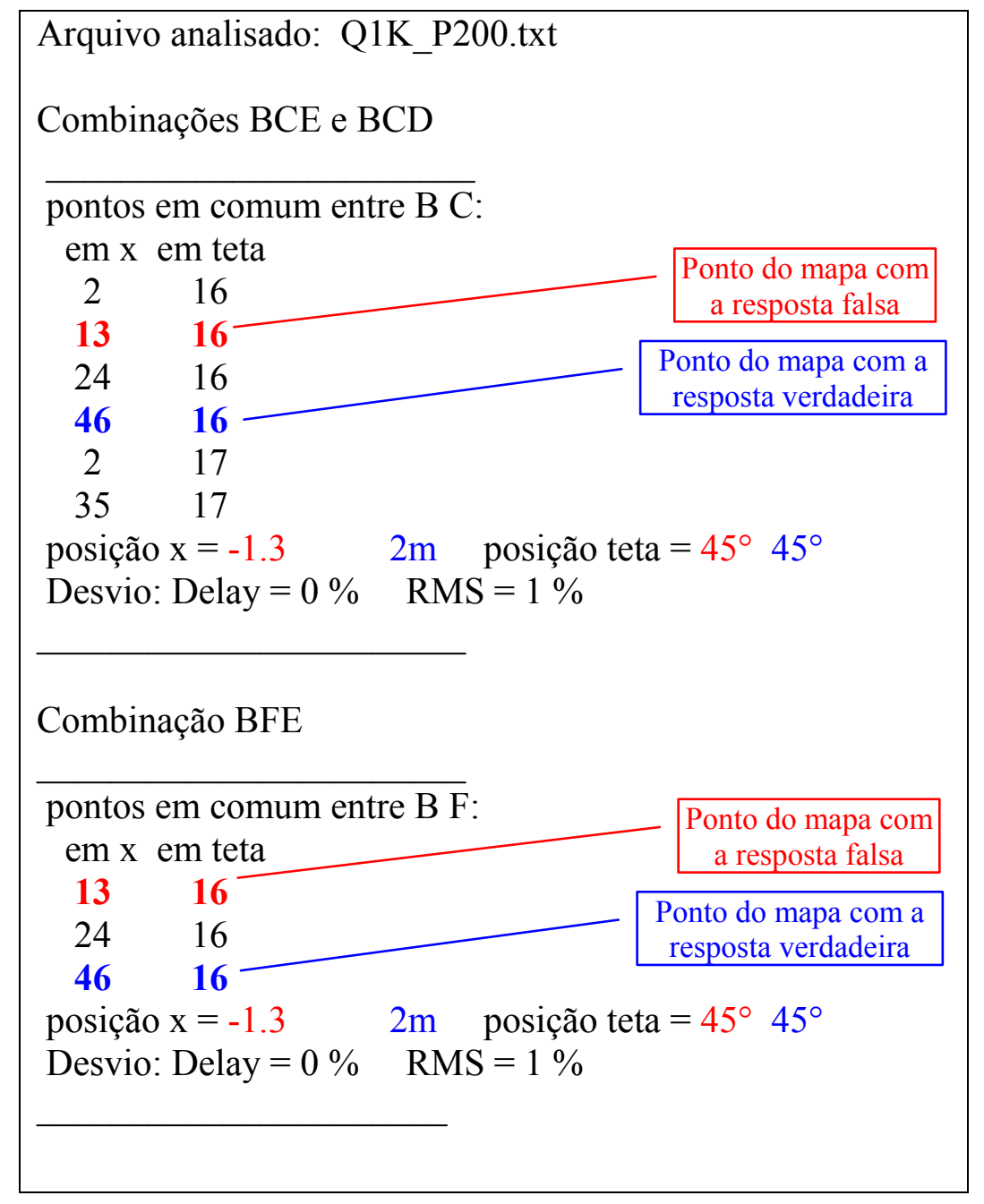

FIGURA 9.9 - Recortes das telas de resposta do programa de localização, sendo a excitação em $+2,0 \mathrm{~m}$ e $45^{\circ}$ com freqüência de $1 \mathrm{KHz}$.

A FIG. 9.9 contém recortes das telas de respostas do programa de localização para a fonte de excitação em $+2,0 \mathrm{~m}$ e $45^{\circ}$ com freqüência de $1 \mathrm{KHz}$. Observa-se que vários pontos satisfazem a condição da defasagem do sinal em 
relação à referência sendo que dois deles satisfazem também a condição de equivalência do RMS. Um deles é o ponto que realmente indica a localização da fonte (em azul) e o outro é um ponto que indica uma localização falsa (em vermelho). Tal fato não pode ser encarado como um erro e sim como uma condição plausível de ocorrer, pois para uma certa condição pode existir mais que uma solução que a satisfaça.

O método mostrou-se capaz de acertar, com boa precisão, a posição da fonte para vários pontos de excitação sobre o tubo, mesmo nos casos onde a presença de ruído gerou dificuldades no processo de localização. Nestes casos uma filtragem com Wavelet-denoise ou com filtro de Fourier melhoraram a relação entre o sinal e o ruído, reduzindo ou eliminando o erro da localização. Contudo, a filtragem com filtro de Fourier em alguns casos mostrou apresentar resultados melhores que a filtragem com Wavelet-denoise, pelo fato de estarmos processando um sinal estacionário e não um sinal transiente.

Quanto à geometria dos sensores, não foram notadas diferenças na capacidade de localização, a menos da condição que o sensor fique sobre um ponto de nó. Neste caso uma distribuição assimétrica dos sensores em relação ao sensor A de referência, pode garantir que um ou mais sensores fiquem fora da região de nó, melhorando a possibilidade de acerto da localização da fonte. 


\section{CONCLUSÕES}

A geometria fechada da casca cilíndrica e o fato das ondas geradas afastarem-se radialmente do ponto de excitação, leva a superposição de efeitos e a geração de estacionariedade na superfície com características específicas. A propagação da onda na superfície da casca cilíndrica fina descreve caminhos helicoidais ao redor da superfície, partindo do local da excitação em todas as direções. A onda resultante em um certo ponto é uma somatória de ondas chegando por caminhos de comprimentos diferentes ao redor da casca cilíndrica em ambas as direções, horária e anti-horária.

A onda estacionária formada na superfície da casca cilíndrica em decorrência de uma excitação harmônica, possui uma velocidade efetiva de valor diferente das velocidades longitudinal, transversal e de Rayleigh. Esta velocidade efetiva é equivalente à velocidade de uma onda resultante se propagando na direção axial. Tal efeito é o resultado das sobreposições de várias ondas chegando por caminhos diferentes, e por conseqüência com fases distintas, em um dado ponto da superfície do tubo. Para a direção circunferencial, a velocidade efetiva apresenta um valor menor que o observado para a direção axial. Esta diminuição da velocidade cresce com o aumento do ângulo em relação à direção axial, de maneira que o traço de fase constante, sobre a superfície cilíndrica planificada, forma uma elipse cujo eixo maior é na direção axial.

O modelo teórico analítico desenvolvido mostrou-se consistente do ponto de vista da resposta em freqüência e da caracterização das propagações das ondas na superfície cilíndrica, tanto no tempo como no espaço, quando esta é excitada por uma fonte pontual e harmônica. Através do modelo é possível determinar o comportamento da casca cilíndrica com base nas propriedades físicas do material que a compõe e da sua geometria, tanto qualitativamente quanto quantitativamente, conforme demonstraram os ensaios no tubo de testes. Esta é a originalidade e a contribuição cientifica deste estudo.

Pelo modelo, a condição de casca fina mostrou-se válida para relações h/a menores que 0,05 . A variação do comprimento de onda diminui com a diminuição da relação $h / a$, ou seja, a casca torna-se cada vez mais fina e o efeito 
da espessura torna-se menos significativo. A variação do raio a além de influenciar na relação $h / a$ também afeta o perímetro da casca cilíndrica, afetando os comprimentos dos caminhos das propagações das ondas, afetando desta maneira as sobreposições entre as ondas de forma mais acentuada. Quanto à influência dos parâmetros físicos do material, é interessante mencionar que, independente destes valores, se as velocidades $c_{p}$ entre materiais diferentes forem próximas, o comportamento do comprimento de onda e da velocidade efetiva apresentam semelhanças, ou seja, magnitudes também próximas.

Outra questão importante é a fixação dos sensores, a qual foi significativa para o sucesso dos experimentos e de sua repetibilidade. $O$ uso de cera de abelha mostrou resultados superiores no processo de fixação dos acelerômetros, quanto a repetibilidade dos ensaios e gerou menor interferência na resposta do sistema quando comparada com blocos magnéticos ou blocos de fixação. Quando comparada com fita dupla face, a cera mostrou melhor qualidade de fixação mecânica e melhor envolvimento do sensor com a superfície cilíndrica. Somado a isto, está a facilidade da colocação e remoção do sensor entre as medidas quando a fixação é com cera de abelha.

Os ensaios também mostraram que para uma onda periódica propagante captada por dois sensores espaçados entre si de uma certa distância, em função da velocidade de propagação e da freqüência da onda, pode-se ter um atraso de fase, entre as chegadas da onda propagante nestes pontos, superior a um período. Isto ocorre quando a distância entre os dois pontos na superfície é superior a um comprimento de onda. Tal condição implica na não capacidade de determinar com certeza o atraso real em função da periodicidade do atraso, quando não se conhece a distância da fonte com os sensores.

Para proceder à localização da fonte pontual sobre a superfície, adotou-se o processo de solução inversa, ou seja, conhecidos os sinais dos sensores, determina-se através do modelo teórico onde a fonte que gerou estes sinais pode estar. Para as condições consideradas neste estudo, a metodologia proposta mostrou-se capaz de localizar uma fonte de excitação pontual sobre a superfície do tubo, com boa margem de acerto. Nas situações em que ruídos geraram dificuldades de localização, a filtragem com wavelet-denoise ajudou neste processo na grande maioria dos casos, contudo em algumas situações específicas não mostrou melhoras nas respostas. Já a filtragem com o filtro de 
Fourier do tipo passa banda apresentou resultados satisfatórios em todos os casos. Isto mostra que a filtragem com Fourier é uma ferramenta interessante para eliminação de freqüências indesejadas no sinal medido, propiciando uma melhoria da capacidade de análise do sinal.

Conforme já relatado, do ponto de vista da geometria dos sensores, não foram notadas diferenças na capacidade de localização desde que os sensores fiquem fora de um ponto de nó. Neste caso uma distribuição assimétrica dos sensores em relação ao sensor de referência, pode garantir uma melhor possibilidade de acerto da localização da fonte. Quanto à quantidade de sensores, observou-se que quatro sensores são suficientes, ou seja, um sensor de referência posicionado em uma extremidade do tubo e três outros posicionados na outra extremidade são adequados para a localização da fonte de excitação.

Como sugestões de futuros desenvolvimentos ou continuidade deste estudo são apresentadas a seguir algumas propostas:

- Refazer o modelamento teórico incluindo carregamentos e acoplamentos com fluídos externos e internos ao tubo. Em função destes acoplamentos avaliar o efeito da atenuação com a distância.

- Refazer o modelamento teórico considerando outras condições de contornos, tais como, tubo finito, com flanges, apoios, singularidades e reflexões. Considerar para este novo modelamento o uso de métodos numéricos.

- Aplicar o modelamento teórico para fontes de excitação oriundas de vazamentos reais tais como furos e trincas sob diferentes pressões de gases ou líquidos. Avaliar o modelo contra experimentos controlados em tubulação real.

- Nas condições do modelo atual, avançar os estudos para freqüências de excitação harmônica bem superiores, além da faixa audível até centenas de $\mathrm{KHz}$. Avaliar outros sensores como emissão acústica, filmes e cristais piezelétricos contra a resposta do modelo teórico. 
- Para as novas condições do modelamento teórico aplicar a metodologia de localização proposta, com o objetivo de testar a sua validade e limitações.

- Para a metodologia de localização proposta, continuar o estudo da capacidade de localização para novas geometrias de disposições de sensores sobre a superfície do tubo em conjunto com o estudo e aplicação de técnicas de beamforming.

- Estender os estudos para a condição de tubo não infinito, considerando as reflexões como sendo distribuições de fontes pontuais de excitações, posicionadas nas extremidades do tubo ou nos pontos de origem das reflexões, as quais podem ser tratadas pelo método de sobreposição de ondas.

- Melhoria do programa de localização quanto à forma de realização da análise e da apresentação dos resultados:

- Nesta versão a decisão quanto à adequação da resposta deve ser humana, em versões futuras poderá ser avaliada a possibilidade desta função fazer parte do programa.

- Estudo de ferramentas de otimização de busca e de inteligência artificial, com o objetivo de encontrar não o primeiro ponto e sim um ponto ótimo com maior probabilidade de acerto da localização.

- Implementar metodologia Fuzzy para busca do ponto de localização da excitação.

- Criação de interfaces amigáveis e interativas para entrada dos dados e obtenção dos resultados.

- Estudo de outras aplicações do filtro de Fourier em processos de análise e tratamento de sinais, considerando a inclusão de janelas de apodização no processo de filtragem. $O$ estudo pode avaliar os efeitos destas janelas sobre diferentes tipos de sinais reais e sintéticos. 
APÊNDICES 


\section{APÊNDICE A - Número de onda axial $k_{n s}$ em função do modo $n$ e da freqüência $\Omega$}

Tubo de aço: $\quad$ Módulo de elasticidade: $E=19,210^{10} \mathrm{~N} / \mathrm{m}^{2}$; Poisson: $v=0,3$

Densidade do sólido: $\rho=7800 \mathrm{Kg} / \mathrm{m}^{3}$;

Espessura da casca: $h=5.10^{-3} \mathrm{~m}$; Raio da casca: $a=0,1 \mathrm{~m}$

Relação $h / a=0,05$

$K_{n s}$ dado em $1 / \mathrm{m}$

TABELA A.1 - $K_{n s}$ para $n=0$

\begin{tabular}{|c|c|c|c|c|c|c|c|c|}
\hline$\Omega$ & S1 & S2 & S3 & S4 & S5 & S6 & S7 & S8 \\
\hline 0.1 & $59,77+59,77 i$ & $59,77-59,77 i$ & $-59,77-59,77 i$ & $-59,77+59,77 i$ & 1,69 & $-1,69$ & 1,05 & $-1,05$ \\
\hline 0.2 & $59,26+59,26 i$ & $59,26-59,26 i$ & $-59,26-59,26 i$ & $-59,26+59,26 i$ & 3,38 & $-3,38$ & 2,10 & $-2,10$ \\
\hline 0.3 & $58,39+58,39 i$ & $58,39-58,39 i$ & $-58,39-58,39 i$ & $-58,39+58,39 i$ & 5,07 & $-5,07$ & 3,16 & $-3,16$ \\
\hline 0.4 & $57,10+57,11 i$ & $57,10-57,11 i$ & $-57,10-57,11 i$ & $-57,10+57,11 i$ & 6,76 & $-6,76$ & 4,23 & $-4,23$ \\
\hline 0.5 & $55,30+55,32 i$ & $55,30-55,32 i$ & $-55,30-55,32 i$ & $-55,30+55,32 i$ & 8,45 & $-8,45$ & 5,33 & $-5,33$ \\
\hline 0.6 & $52,83+52,86 i$ & $52,83-52,86 i$ & $-52,83-52,86 i$ & $-52,83+52,86 i$ & 10,14 & $-10,14$ & 6,47 & $-6,47$ \\
\hline 0.7 & $49,37+49,43 i$ & $49,37-49,43 i$ & $-49,37-49,43 i$ & $-49,37+49,43 i$ & 11,83 & $-11,83$ & 7,71 & $-7,71$ \\
\hline 0.8 & $44,17+44,29 i$ & $44,17-44,29 i$ & $-44,17-44,29 i$ & $-44,17+44,29 i$ & 13,52 & $-13,52$ & 9,24 & $-9,24$ \\
\hline 0.9 & $34,26+34,79 i$ & $34,26-34,79 i$ & $-34,26-34,79 i$ & $-59,93+59,93 i$ & 15,21 & $-15,21$ & 12,39 & $-12,39$ \\
\hline 1.0 & 48,06 & $-47,01 i$ & $-48,06$ & $47,01 \mathrm{i}$ & 16,90 & $-16,90$ & 0 & 0 \\
\hline 1.1 & 64,37 & $-64,09 i$ & $-64,37$ & $64,09 i$ & 18,59 & $-18,59$ & 9,20 & $-9,20$ \\
\hline 1.2 & 74,13 & $-73,96 i$ & $-74,13$ & $73,96 i$ & 20,28 & $-20,28$ & 10,93 & $-10,93$ \\
\hline 1.3 & 81,61 & $-81,49 i$ & $-81,61$ & $81,49 i$ & 21,97 & $-21,97$ & 12,23 & $-12,23$ \\
\hline 1.4 & 87,89 & $-87,80 \mathrm{i}$ & $-87,89$ & $87,80 \mathrm{i}$ & 23,66 & $-23,66$ & 13,39 & $-13,39$ \\
\hline 1.5 & 93,41 & $-93,33 i$ & $-93,41$ & $93,33 i$ & 25,35 & $-25,35$ & 14,49 & $-14,49$ \\
\hline 1.6 & 98,39 & $-98,32 i$ & $-98,39$ & $98,32 \mathrm{i}$ & 27,04 & $-27,04$ & 15,56 & $-15,56$ \\
\hline 1.7 & 102,97 & $-102,91 i$ & $-102,97$ & $102,91 \mathrm{i}$ & 28,74 & $-28,74$ & 16,61 & $-16,61$ \\
\hline 1.8 & 107,24 & $-107,19 i$ & $-107,24$ & $107,19 i$ & 30,43 & $-30,43$ & 17,65 & $-17,65$ \\
\hline 1.9 & 111,27 & $-111,21 i$ & $-111,27$ & $111,21 \mathrm{i}$ & 32,12 & $-32,12$ & 18,68 & $-18,68$ \\
\hline 2.0 & 115,08 & $-115,03 i$ & $-115,08$ & $115,03 i$ & 33,81 & $-33,81$ & 19,71 & $-19,71$ \\
\hline
\end{tabular}


TABELA A.2 - $K_{n s}$ para $n=1$

\begin{tabular}{|c|c|c|c|c|c|c|c|c|}
\hline$\Omega$ & S1 & S2 & S3 & S4 & S5 & S6 & S7 & S8 \\
\hline 0.1 & $56,46+58,22 i$ & $56,46-58,22 i$ & $-56,46-58,22 i$ & $-56,46+58,22 i$ & 4,23 & $-4,23$ & $-3,44 i$ & $3,44 i$ \\
\hline 0.2 & $55,96+57,76 i$ & $55,96-57,76 i$ & $-55,96-57,76 i$ & $-55,96+57,76 i$ & 6,58 & $-6,58$ & $-4,29 i$ & $4,29 i$ \\
\hline 0.3 & $55,08+56,97 i$ & $55,08-56,97 i$ & $-55,08-56,97 i$ & $-55,08+56,97 i$ & 8,80 & $-8,80$ & $-4,48 i$ & $4,48 \mathrm{i}$ \\
\hline 0.4 & $53,78+55,81 i$ & $53,78-55,81 i$ & $-53,78-55,81 i$ & $-53,78+55,81 i$ & 11,10 & $-11,10$ & $-4,15 i$ & $4,15 i$ \\
\hline 0.5 & $51,96+54,21 i$ & $51,96-54,21 i$ & $-51,96-54,21 i$ & $-51,96+54,21 i$ & 13,60 & $-13,60$ & $-3,19 i$ & $3,19 i$ \\
\hline 0.6 & $49,43+52,07 i$ & $49,43-52,07 i$ & $-49,43-52,07 i$ & $-49,43+52,07 i$ & 16,52 & $-16,52$ & 1,06 & $-1,06$ \\
\hline 0.7 & $45,83+49,19 i$ & $45,83-49,19 i$ & $-45,83-49,19 i$ & $-45,83+49,19 i$ & 20,26 & $-20,26$ & 4,12 & $-4,12$ \\
\hline 0.8 & $40,30+45,35 i$ & $40,30-45,35 i$ & $-40,30-45,35 i$ & $-40,30+45,35 i$ & 25,96 & $-25,96$ & 6,16 & $-6,16$ \\
\hline 0.9 & $30,51+41,07 i$ & $30,51-41,07 i$ & $-30,51-41,07 i$ & $-30,51+41,07 i$ & 36,87 & $-36,87$ & 8,08 & $-8,08$ \\
\hline 1.0 & $14,12+40,09 i$ & $14,12-40,09 i$ & $-14,12+40,09 i$ & $-14,12-40,09 i$ & 51,95 & $-51,95$ & 10,06 & $-10,06$ \\
\hline 1.1 & $23,10 \mathrm{i}$ & $-23,10 \mathrm{i}$ & $59,56 i$ & $-59,56 i$ & 63,24 & $-63,24$ & 12,21 & $-12,21$ \\
\hline 1.2 & $14,97 i$ & $-14,97 i$ & $70,43 i$ & $-70,43 i$ & 71,61 & $-71,61$ & 14,54 & $-14,54$ \\
\hline 1.3 & $9,45 i$ & $-9,45 i$ & $78,07 i$ & $-78,07 i$ & 78,41 & $-78,41$ & 16,97 & $-16,97$ \\
\hline 1.4 & $3,03 i$ & $-3,03 i$ & $84,31 \mathrm{i}$ & $-84,31 \mathrm{i}$ & 84,25 & $-84,25$ & 19,36 & $-19,36$ \\
\hline 1.5 & 6,97 & $-6,97$ & $89,71 \mathrm{i}$ & $-89,71 i$ & 89,44 & $-89,44$ & 21,63 & $-21,63$ \\
\hline 1.6 & 9,84 & $-9,84$ & $94,55 i$ & $-94,55 i$ & 94,15 & $-94,15$ & 23,79 & $-23,79$ \\
\hline 1.7 & 11,87 & $-11,87$ & $98,99 i$ & $-98,99 i$ & 98,51 & $-98,51$ & 25,85 & $-25,85$ \\
\hline 1.8 & 13,55 & $-13,55$ & $103,11 \mathrm{i}$ & $-103,11 i$ & 102,58 & $-102,58$ & 27,84 & $-27,84$ \\
\hline 1.9 & 15,03 & $-15,03$ & $106,99 i$ & $-106,99 i$ & 106,43 & $-106,43$ & 29,78 & $-29,78$ \\
\hline 2.0 & 16,40 & $-16,40$ & $110,66 i$ & $-110,66 i$ & 110,07 & $-110,07$ & 31,67 & $-31,67$ \\
\hline
\end{tabular}




\section{APÊNDICE B - Instrumentos utilizados nos experimentos}

- Osciloscópio TEKTRONIX TDS 3034 Four Channel Color Digital Oscilloscope:

○ Freqüência: $300 \mathrm{MHz}$;

- Amostragem máxima: 2,5 G Amostras/s;

- Acessórios: TDS3 FFT, TDS3 TRG, advanced Trigger.

- Nexux Conditioning Amplifiers - 2692:

- Fabricante: Brüel\&Kjær;

- Entrada de carga:

- Ganho do amplificador: 0,01 mV/pC até $10 \mathrm{~V} / \mathrm{pC}$;

- Faixa de freqüência para aceleração: $0,1 \mathrm{~Hz}$ até $100 \mathrm{kHz}$ (com cabo < 10m);

- Filtro passa baixa: ajustável até $100 \mathrm{kHz}$, inclinação da atenuação de $40 \mathrm{~dB} /$ década;

- Filtro passa alta: 0,$1 ; 1,0$ ou $20 \mathrm{~Hz}$.

- Saída analógica:

- Conector: BNC;

- Saída aterrada ou flutuante;

- Impedância de saída: 50//500 pF;

- Máxima saída (tensão diferencial): $10 \mathrm{~V}$ pico (20V pico a pico);

- Máximo DC offset: $\pm 25 \mathrm{mV}$, típico $<2 \mathrm{mV}$.

- Acelerômetros (usados nos experimentos do Capítulo 8):

- Fabricante: Endevco;

- Modelo: PE - 7701A-100

TABELA B.1 - Características dos acelerômetros

\begin{tabular}{c|c|c}
\hline Número de série & Sensibilidade & Ressonância \\
\hline 13926 & $9,709 \mathrm{pC} / \mathrm{m} / \mathrm{s}^{2}$ & $21531 \mathrm{~Hz}$ \\
\hline 13932 & $10,07 \mathrm{pC} / \mathrm{m} / \mathrm{s}^{2}$ & $21537 \mathrm{~Hz}$ \\
\hline
\end{tabular}

- Martelo Instrumentado (usado nos experimentos do Capítulo 8):

- Modelo:Impact Hammers - Types 8206;

- Fabricante: Brüel\&Kjær. 
- Acelerômetros:

- Fabricante: Endevco;

TABELA B.2 - Características dos acelerômetros

\begin{tabular}{c|c|c|c}
\hline Sensor & Número de série & Sensibilidade & Modelo \\
\hline $\mathrm{A}$ & 12576 & $461,1 \mathrm{mV} / \mathrm{g}$ & ISOTRON accelerometer 7254A-500 \\
\hline $\mathrm{B}$ & 12558 & $480,2 \mathrm{mV} / \mathrm{g}$ & ISOTRON accelerometer 7254A-500 \\
\hline $\mathrm{C}$ & 12527 & $490 \mathrm{mV} / \mathrm{g}$ & ISOTRON accelerometer 7254A-500 \\
\hline $\mathrm{D}$ & 12017 & $478,9 \mathrm{mV} / \mathrm{g}$ & ISOTRON accelerometer 7254A-500 \\
\hline $\mathrm{E}$ & 12222 & $104,3 \mathrm{mV} / \mathrm{g}$ & IEPE accelerometer 7254A-100 \\
\hline $\mathrm{F}$ & 12209 & $104,6 \mathrm{mV} / \mathrm{g}$ & IEPE accelerometer 7254A-100 \\
\hline $\mathrm{G}$ & 12227 & $107,1 \mathrm{mV} / \mathrm{g}$ & IEPE accelerometer 7254A-100 \\
\hline $\mathrm{H}$ & 12232 & $107,7 \mathrm{mV} / \mathrm{g}$ & IEPE accelerometer 7254A-100 \\
\hline
\end{tabular}

- Amplificador:

- Fabricante: Endevco;

- Modelo: $\quad$ ISOTRON Signal Conditioner - 2793;

- 16 canais com alimentação de corrente constante;

- Freqüência de corte inferior: $2 \mathrm{~Hz}$ máximo, $-3 \mathrm{~dB}$ em $0,3 \mathrm{~Hz}$;

- Freqüência de corte superior: $20 \mathrm{KHz}$ mínimo, $-3 \mathrm{~dB}$ em $40 \mathrm{KHz}$;

- Distorção Harmônica menor que 1\%;

- Ganho: 1 ou 10 (usado em ganho 10);

- Excitação do transdutor: $4 \mathrm{~mA}$ ou $10 \mathrm{~mA} \pm 10 \%$ ajustável internamente via jumper (ajustado para $4 \mathrm{~mA}$ );

- Impedância de entrada > $20 \mathrm{~K} \Omega$;

- Impedância de saída $<10 \Omega$.

- Gerador de sinais:

- Fabricante: Hewlett Packard;

- Modelo: $\quad 33120$ A Function/Arbitrary Waveform Generator;

- Freqüência: $100 \mu \mathrm{Hz}$ até $15 \mathrm{MHz}$;

- Distorção harmônica de $\mathrm{DC}$ até $20 \mathrm{KHz}$ : $-70 \mathrm{~dB}$;

- Formas de ondas: senoidal, quadrada e triangular;

- Tensão de saída: $\quad 50 \mathrm{mVpp}$ até $10 \mathrm{Vpp}$ com carga $50 \Omega$;

- Resolução em amplitude: 12 bits;

- Impedância de saída: $50 \Omega$. 
- Placa de aquisição:

- Fabricante: National Instruments;

- Modelo: DAQ Card - AI - 16E - 4;

- Barramento de conexão: PCMCIA;

- Canais de entrada: 16 aterrados ou 8 diferenciais;

- Canais de saída: 2 com 12 bit de resolução;

- Freqüência de amostragem máxima: $500 \mathrm{~K}$ Amostras/s;

○ Resolução: 12 bits.

- Bloco conector:

- Fabricante: National Instruments;

o Modelo: SCB-68. 


\section{APÊNDICE C - Dispositivos utilizados nos experimentos}

A seguir são apresentados os dispositivos e acessórios criados para atender as necessidades dos experimentos:

- Braço articulado:

- Finalidade: suporte de sensor ou excitador;

- Demissões: altura $1 \mathrm{~m}$, comprimento da base $50 \mathrm{~cm}$, comprimento do braço articulado $48 \mathrm{~cm}$;

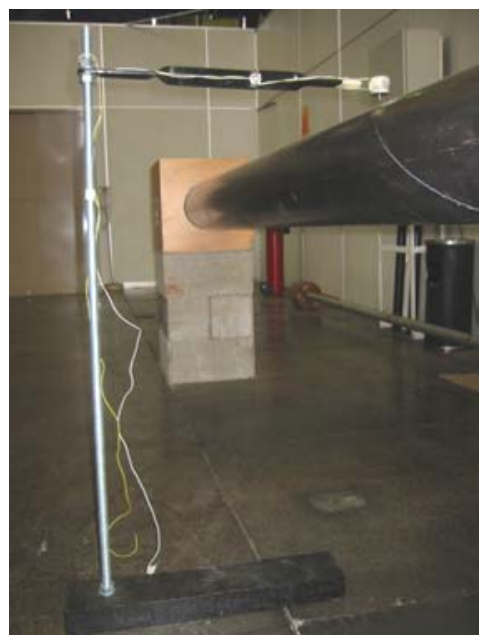

FIGURA C.1 - Foto do braço articulado.

- Excitador pontual:

- Composto de uma pastilha piezelétrica circular acoplada, através de resina epóxi, a um pino com ponta.

- Princípio de funcionamento, quando o cristal é percorrido por uma corrente elétrica alternada este se expande e se contrai, deformando a chapa metálica de suporte do cristal piezelétrico, a qual movimenta a ponta metálica perpendicularmente.
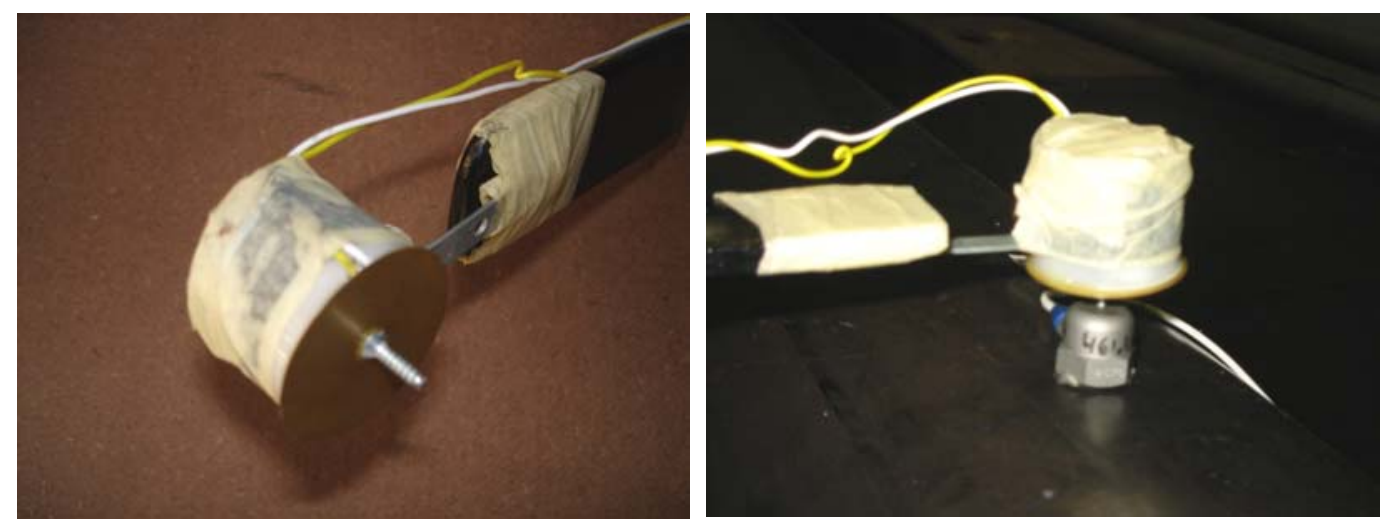

FIGURA C.2 - Fotos do excitador. 
- Desacoplador de nível DC:

No processo de aquisição a presença do nível DC no sinal é um problema, pois a sua presença afeta o "ângulo inicial" do sinal, ou de outra forma, interfere no instante de sincronismo da placa de aquisição e por conseqüência nos atrasos entre os sinais, perdendo-se assim a referência do instante zero.

Para resolver este problema foi inserido entre a saída do amplificador e a entrada do bloco de conexão um circuito de desacoplamento DC, conforme mostrado no esquema elétrico abaixo. $O$ capacitor funciona como um filtro passa alta, rejeitando assim a componente DC. Como a placa de aquisição foi configurada para o modo desbalanceado, o circuito deve ser simétrico em relação às duas entradas de sinal na placa. $O$ circuito é composto de oito blocos de desacoplamento idênticos.

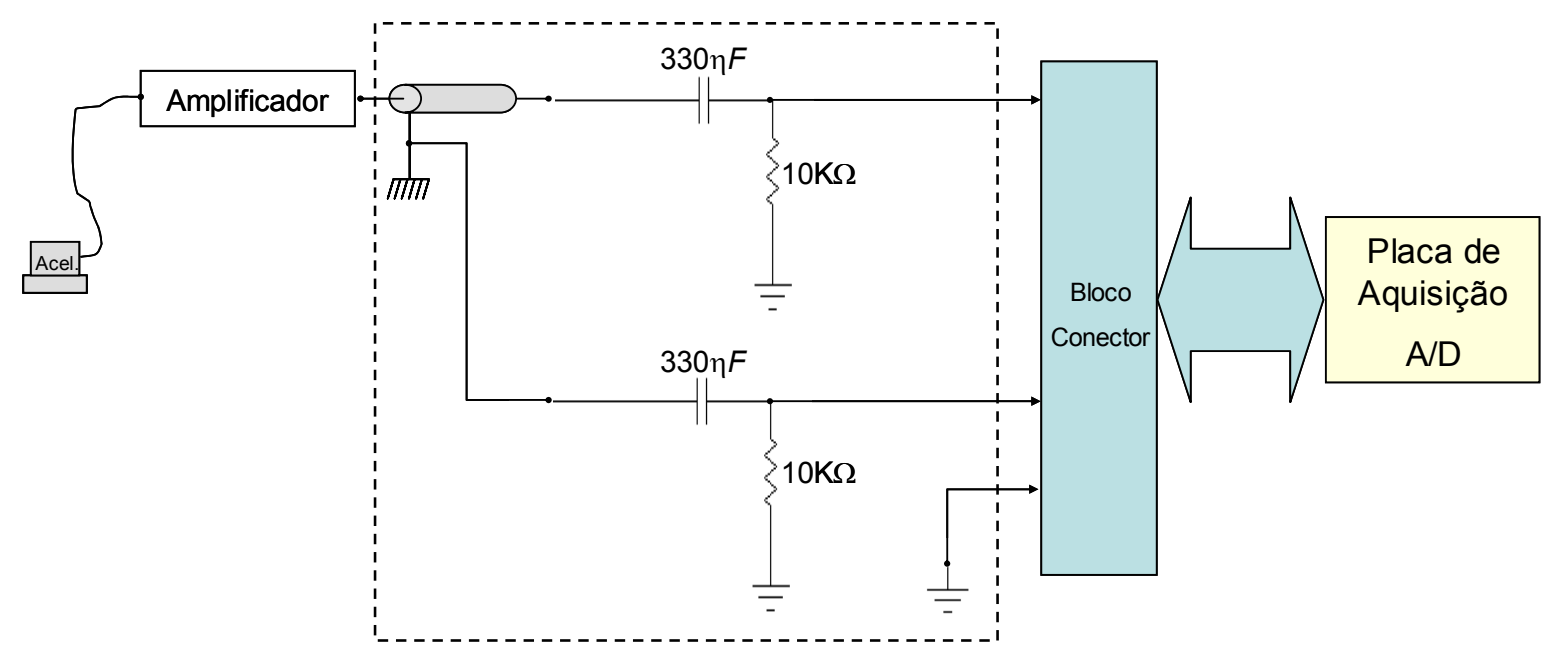

FIGURA C.3 - Esquema elétrico do desacoplador de nível DC. 


\section{APÊNDICE D - Análise da fixação do acelerômetro com cera de abelha}

O objetivo deste apêndice é tratar questões relativas à adesão dos acelerômetros na superfície a ser medida.

Os acelerômetros podem ser fixos com vários tipos de adesivos, tais como: cianoacrilato; fita de dupla face; cera e cola-quente, bem como através de imãs ou aparafusados na superfície. Para a escolha da fixação, a largura de banda de trabalho e a temperatura do ponto de medida devem ser consideradas. Quando o acelerômetro é montado com adesivo, a quantidade de adesivo usada pode executar um papel crítico para se obter uma boa resposta em freqüência. Um filme esbelto ou quantidades mínimas de adesivo promovem mais alta transmissibilidade e conseqüentemente uma resposta de freqüência mais larga. Não há dúvida que a fixação com parafuso é a que mais intimamente agrega o acelerômetro à superfície a ser medida, contudo é aplicável em situações mais definitivas de fixação ou que seja possível a criação de rosca na superfície.

Segundo Mathews (Technical paper 312 - Guide to adhesively mounting accelerometers da Endevco Corporation), na maioria das vezes, podem ser usados cianoacrilato, fita dupla face ou cera, as quais resultam em uma espessura uniforme que proverá bons resultados. Por outro lado, cola quente requer mais atenção em sua aplicação. Isto é devido ao tempo limitado para aplicação antes de cola endurecer. O cianoacrilato tem a desvantagem de exigir um solvente para desmontar o sensor da superfície, tornando-o não adequado em experimentos que exigem a realocação do sensor repetidas vezes.

Para a realização deste trabalho, a fixação que melhor se adequou foi a realizada com cera de abelha. Primeiro pela excelente fixação, garantindo uma área de contato uniforme do acelerômetro com a superfície do tubo. Segundo, pela facilidade de colocação e remoção do sensor entre as medidas e excelente repetibilidade da fixação.

A fixação com base magnética mostrou-se ineficiente, pois além de inserir uma massa extra ao acelerômetro, apresentou-se como um sistema com resposta em freqüência própria, e o que é pior diferente entre as bases de mesmo modelo, conforme mostra a FIG. D.1. Outro fato é que as bases são projetadas para trabalhar em superfícies planas e a curvatura do tubo dificulta 0 seu assentamento. 
A FIG. D.1, apresenta uma amostra dos resultados obtidos para 2 acelerômetros fixo com bases magnéticas e posteriormente com cera sobre a superfície do tubo de testes terminado por caixa de areia. O procedimento foi aplicar um impacto na superfície do tubo e verificar como os acelerômetros registravam isto. Os dois acelerômetros foram combinados com as duas bases, de forma a verificar que a alteração do comportamento acompanhava a base magnética e não o acelerômetro, como pode ser visto nos quatro primeiros gráficos da FIG. D.1. É notadamente visível que as bases mesmo sendo do mesmo modelo apresentam respostas em freqüência distintas.

Nos dois últimos gráficos são apresentados os resultados obtidos para a fixação com cera de abelha, onde se observa uma resposta semelhante para os dois sensores quanto à banda de trabalho em freqüência.
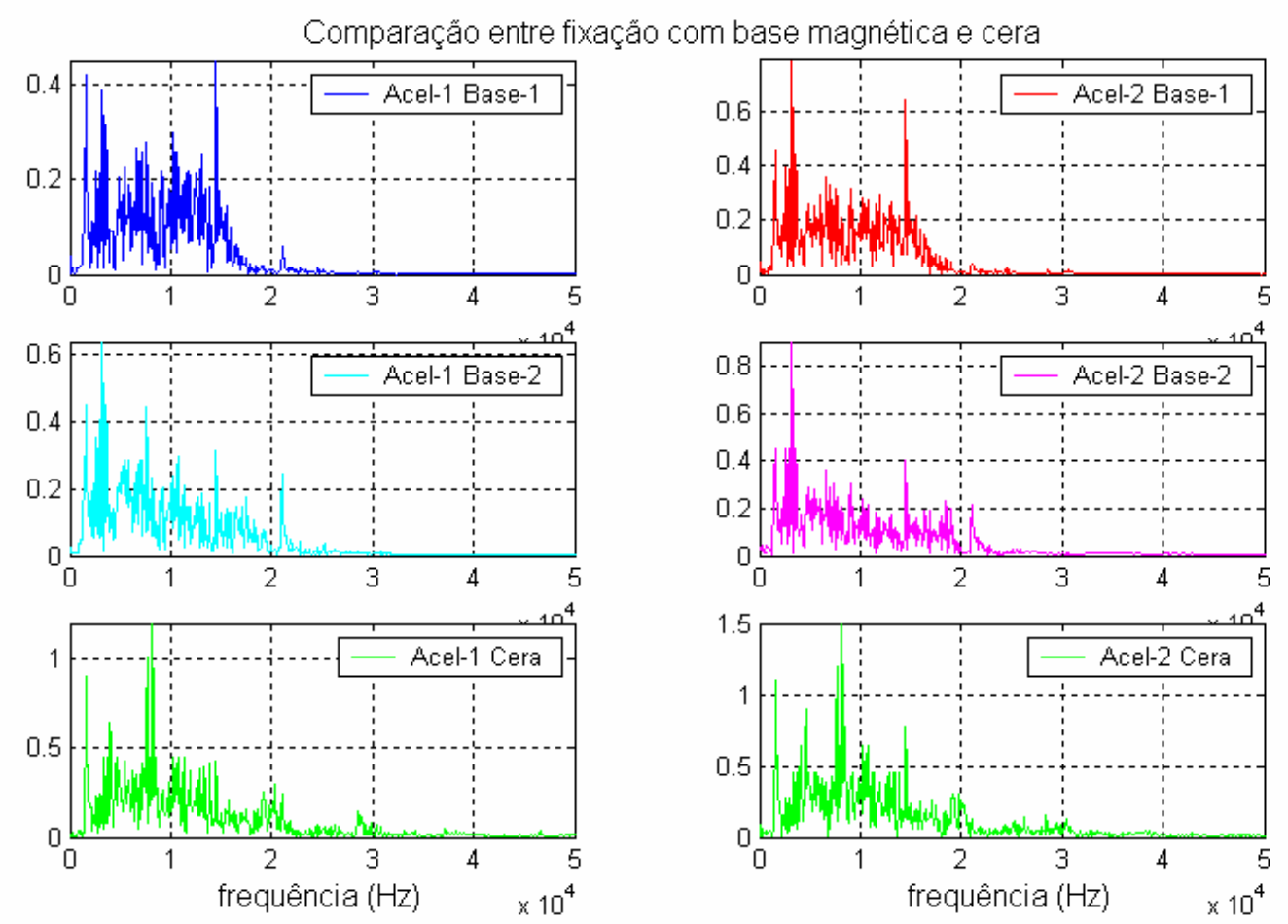

FIGURA D.1 - Espectros das respostas em freqüência para fixação com base magnética e com cera de abelha.

A seguir são apresentadas fotos do processo de fixação com cera de abelha. Na primeira foto vê-se o acelerômetro preparado para a fixação, com duas pequenas bolotas de cera de abelha, pouco maior que uma cabeça de fósforo. Nas duas últimas vê-se o acelerômetro após a sua remoção da superfície, onde se observa que o filme de cera formado é muito esbelto. $\mathrm{Na}$ foto superior 
direita, pode-se ver que o acelerômetro fica intimamente ligado à superfície do tubo pela cera.
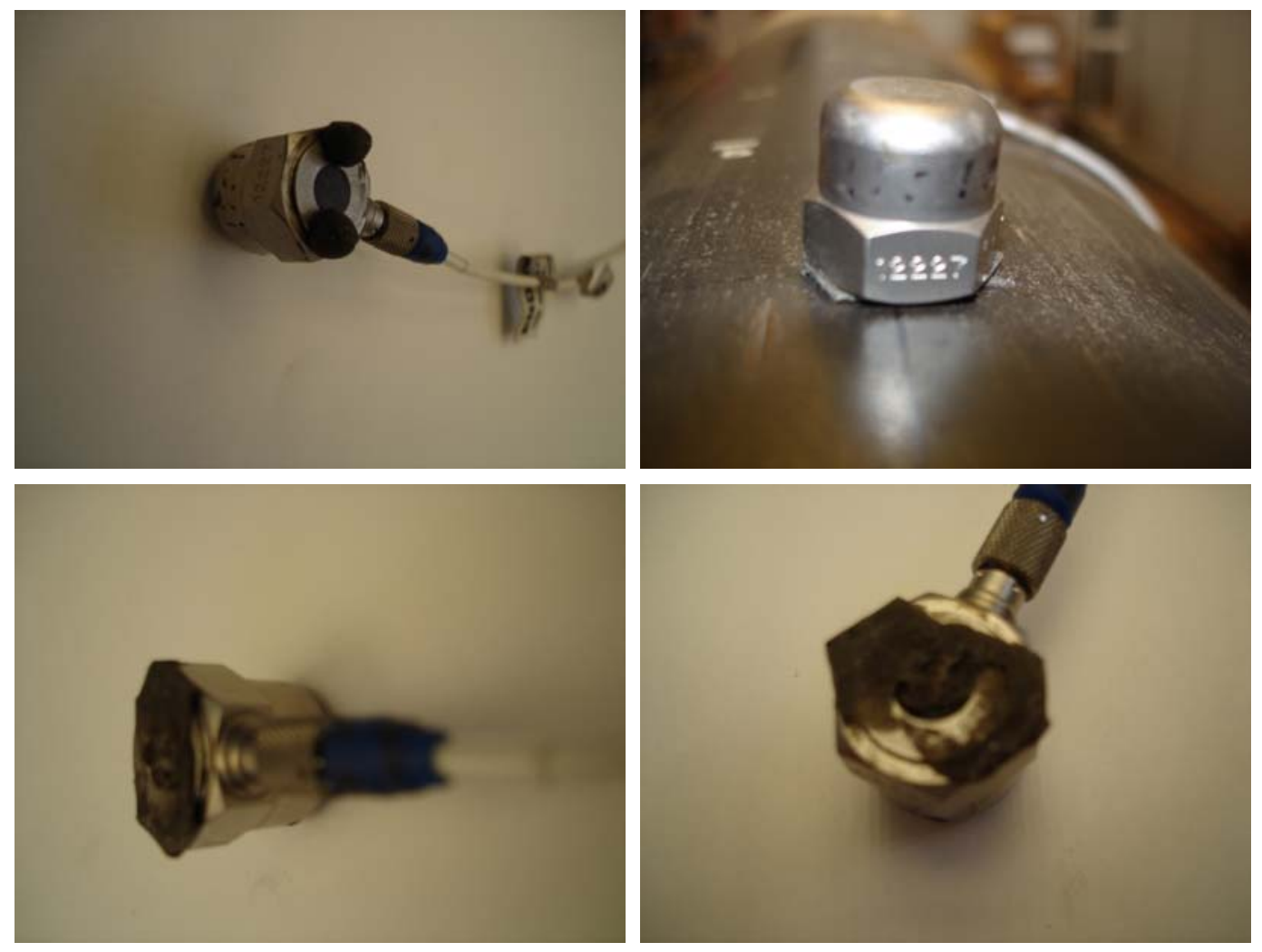

FIGURA D.2 - Fotos do acelerômetro com cera de abelha.

Outro fato é que a cera de abelha é reaproveitável, podendo ser usada inúmeras vezes em uma seqüência de ensaios sem perder suas características, desde que a superfície de adesão esteja isenta de poeira e gordura. 


\section{APÊNDICE E - Fluxogramas do processo de localização}

A seguir são apresentados o fluxograma de geração dos mapas teóricos e o fluxograma do programa de localização.

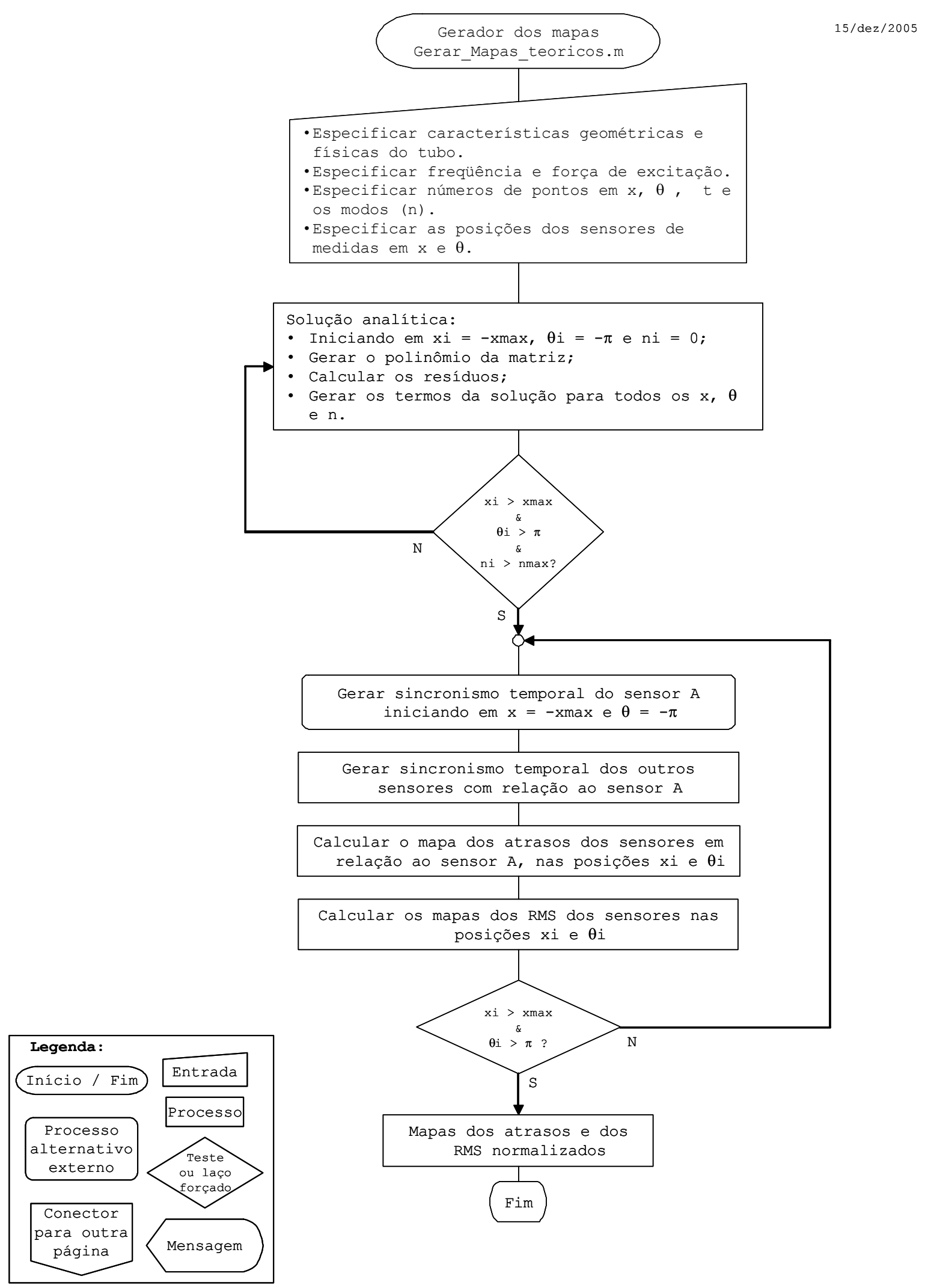




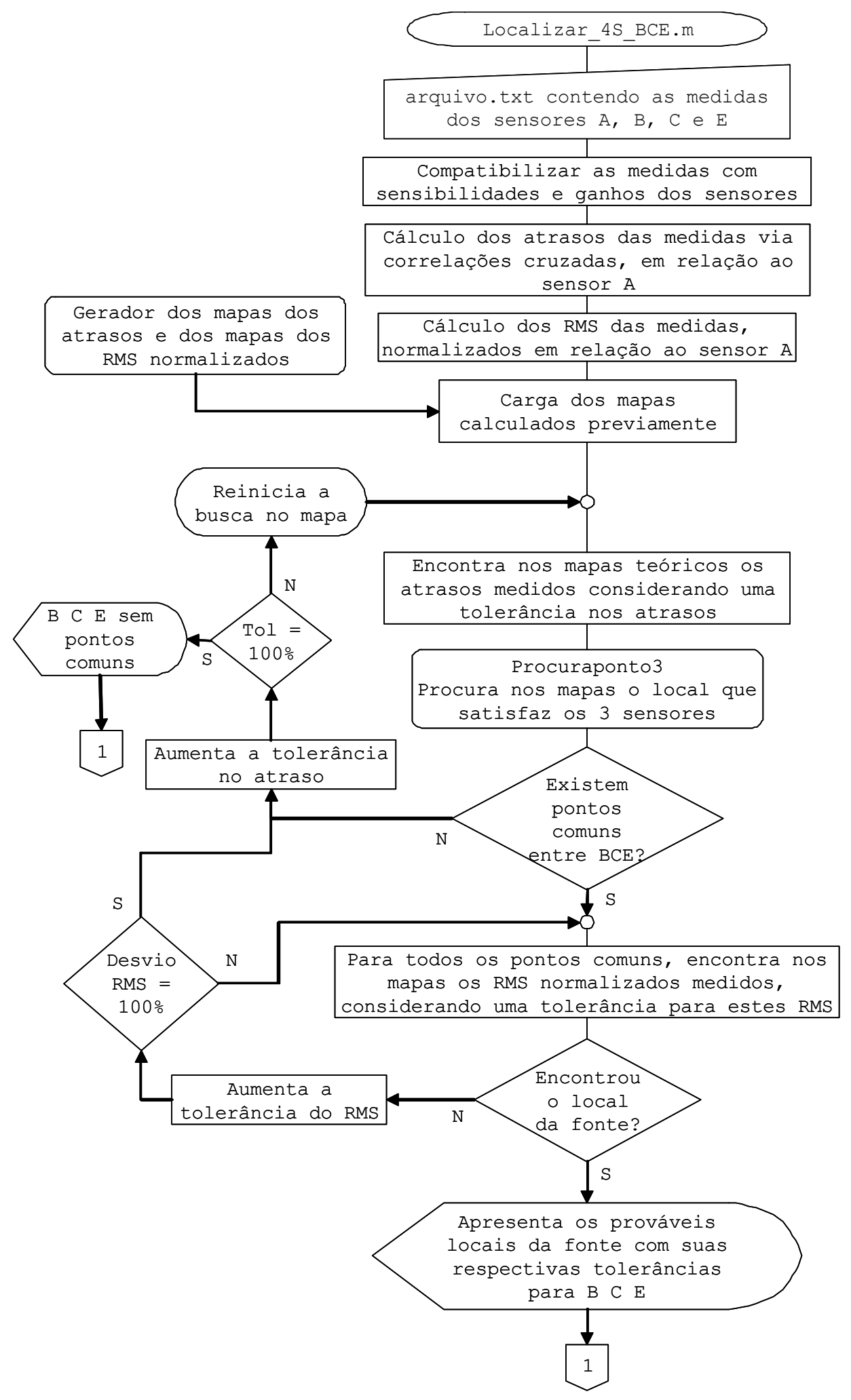

$20 /$ dez/2005 


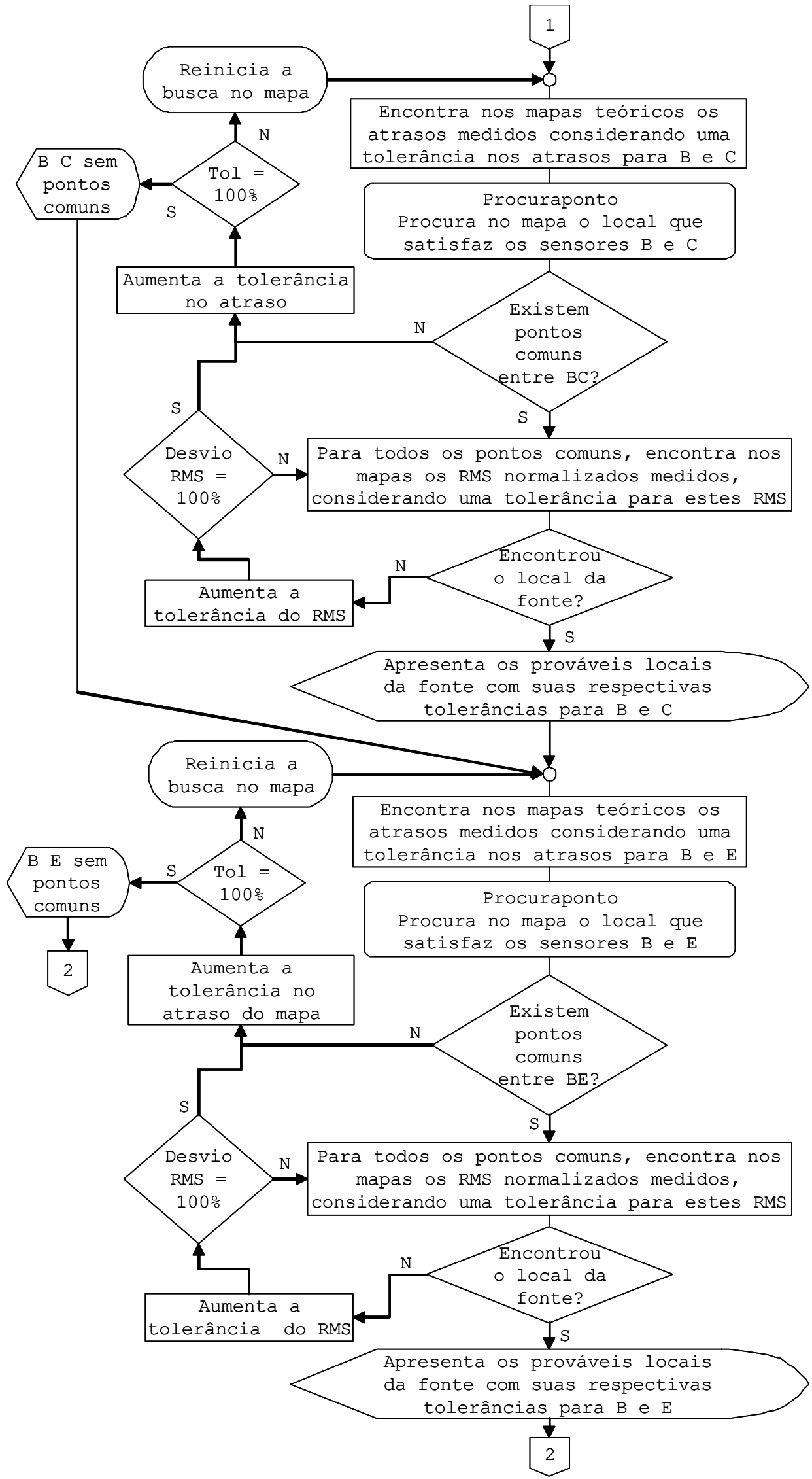




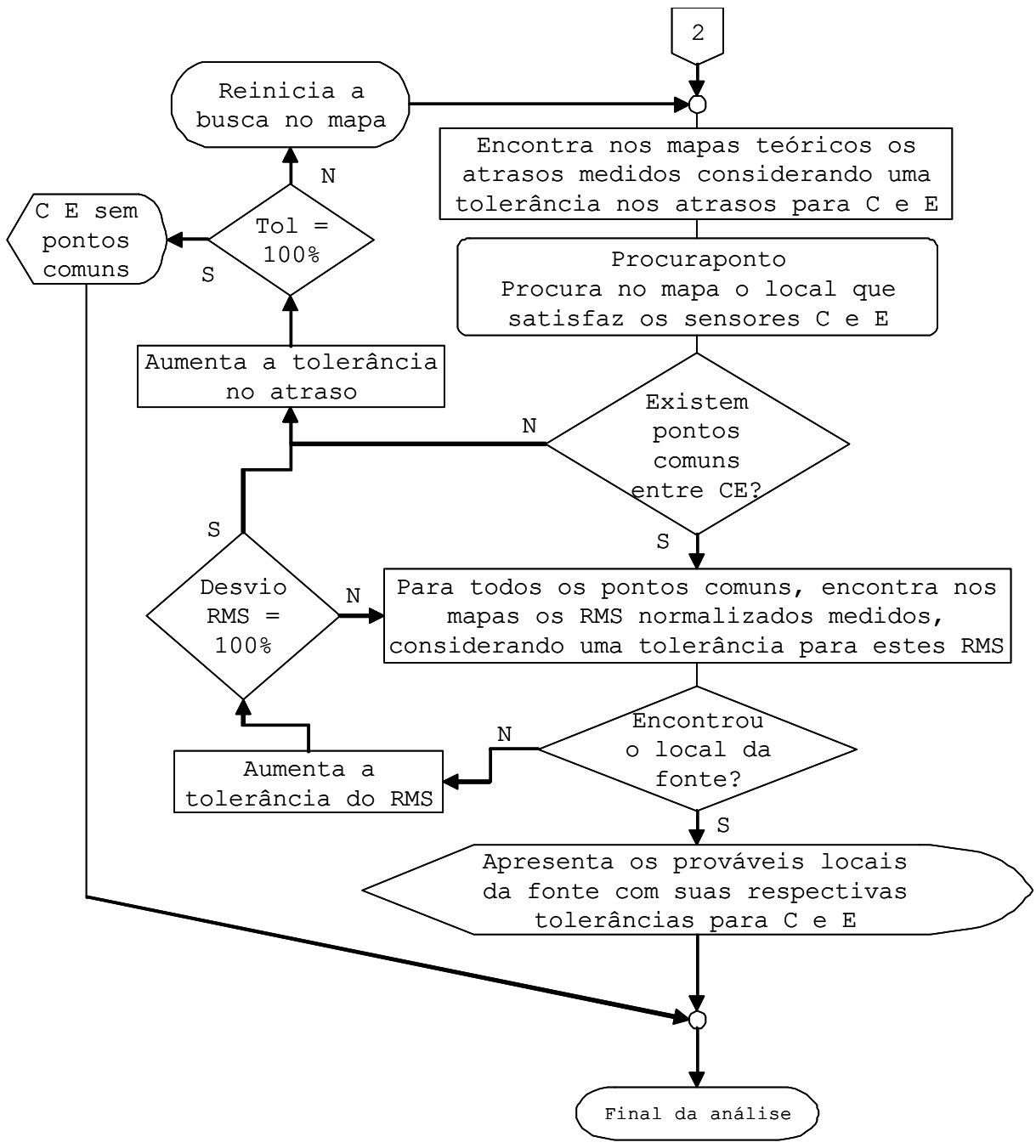




\section{REFERÊNCIAS BIBLIOGRÁFICAS}

1. AHLFORS, L. V. Complex analysis, an introduction to the theory of analytic functions of one complex variable. 2.ed. Tokyo: McGraw-Hill KogaKusha Ltd, 1966.

2. ALONSO, M.; FINN, E. J. Física um curso universitário, campos e ondas. Vol.2. São Paulo, S. P.: Edgard Blucher, 1972.

3. AMABILI, M. Free vibration of partially filled, horizontal cylindrical shells. Journal of Sound and Vibration, v. 191, n. 5, p. 757-780, 1996.

4. BATDORF, S. B. A simplified method of elastic-stability analysis for thin cylindrical shells: I - Donnell's equation. NACA - National Advisory

Committee for Aeronautics, Technical Note, n. 1341, June 1947.

Disponível em: <http://naca.central.cranfield.ac.uk/>. Acesso em: Abril de 2004.

5. BLAKE, W. K. Mechanics of flow-induced sound and vibration. Vol. 1. London.: Academic Press, Inc., 1986.

6. BLEVINS, R. D. Formulas for natural frequency and mode shape. 10.ed. Malabar, FL.: Krieger Publishing Company, 1995.

7. BOARATTI, M. F. G.; TING D. K. S.; PADOVESE, L. R. A proposal for a methodology for remote and on-line monitoring of leaks in tubes using piezoelectric sensors array and higher-order spectral analysis. In: 3rd SEMINAR ON PIPELINE, Nov. 21 - 22, 2001, Rio de Janeiro, RJ. Papers... RJ: Instituto Brasileiro de Petróleo e Gás, 2001. CD-ROM.

8. BOARATTI, M. F. G.; TING D. K. S. Measurement of stress waves propagation velocities in solid media using wavelet transforms. In: INTERNATIONAL NUCLEAR ATLANTIC CONFERENCE, XIV ENFIR, Aug. 28 - Sept. 2, 2005, Santos, SP. Papers, RJ: Associação Brasileira de Energia Nuclear - ABEN, 2005. CD-ROM.

9. BOARATTI, M. F. G.; TING D. K. S. Modelling leaks in primary piping of nuclear power plants. In: INTERNATIONAL NUCLEAR ATLANTIC CONFERENCE, XIV ENFIR, Aug. 28 - Sept. 2, 2005, Santos, SP. Papers... RJ: Associação Brasileira de Energia Nuclear - ABEN, 2005. CD-ROM.

10. BOARATTI, M. F. G.; TING D. K. S. Monitoring leaks in primary piping of nuclear power plants. In: International Mediterranean Modeling Multiconference, IMAACA 2005, Oct. 20 - 22, 2005, Marseilles, France. Proceedings... CD-ROM.

11. BOARATTI, M. F. G.; TING D. K. S. Analytic model of the cylindrical shell motion equations. In: 18th International Congress of Mechanical Engineering, COBEM 2005, Nov. 16 - 11, 2005, Ouro Preto, Minas Gerais, Brazil.

Proceedings... RJ: ABCM - Associação Brasileira de Engenharia e Ciências Mecânicas. CD-ROM. 
12. CERQUEIRA E. O.; POPPI, R. J.; KUBOTA, L.T. Utilização de filtro de transformada de Fourier para a minimização de ruídos em sinais analíticos. Química Nova, v. 23, n. 5, p. 690-698, 2000.

13. CHURCHILL, R. V. Variáveis Complexas e suas Aplicações. São Paulo, S.P.: McGraw-Hill, 1975.

14. CIZELJ, L.; HAUER , I.; ROUSSEL, G.; CUVELLIEZ, C. Probabilistic assessment of excessive leakage through steam generator tubes degraded by secondary side corrosion. Elsevier, Nuclear Engineering and Design, n. 185, p. 347-359, 1998.

15. DONNELL, L. H. Stability of thin-walled tubes under torsion. NACA National Advisory Committee for Aeronautics, Report 479, 1935. Disponível em: <http://naca.central.cranfield.ac.uk/>. Acesso em: Abril de 2004.

16. FENG, L. Acoustic properties of fluid-filled elastic pipes. Journal of Sound and Vibration, v. 176, n. 3, p. 399-413, 1994.

17. FENG, L. Experimental studies of the acoustic properties of a finite elastic pipe filled with water/air. Journal of Sound and Vibration, v. 189, n. 4, p. 511-524, 1996.

18. FOX. R. W.; MCDONALD, A. T. Introdução à mecânica dos fluídos. 2.ed. Rio de Janeiro, R. J.: Guanabara Dois, 1981.

19. FUKUSHIMA, K.; MAESHIMA ,R.; KINOSHITA , A.; SHIRAISHI ,H.; KOSHIJIMA, I. Gas pipeline leak detection system using the online simulation method. Elsevier, Computers and Chemical Engineering, n. 24, p. 453-456, 2000.

20. FULLER, R. C. The effects of wall discontinuities on the propagation of flexural waves in cylindrical shell. Journal of Sound and Vibration, v. 75, n. 2, p. 207-228, 1981.

21. FULLER, C. R.; FAHY, F. J. Characteristics of wave propagation and energy distributions in cylindrical elastic shells filled with fluid. Journal of Sound and Vibration, v. 81, n. 4, p. 501-518, 1982.

22. FULLER, R. C. The Input mobility of an infinite circular cylindrical elastic shell filled with fluid. Journal of Sound and Vibration, v. 87, n. 3, p. 409-427, 1983.

23. HAUSER JR, A. A. Variáveis complexas com aplicações à física, Rio de Janeiro, R.J.: LTC, 1972. p. 229-232.

24. HESSEL, G.; SCHMITT, W.; VORST, K. V. D.; WEISS, F. P. A neural network approach for acoustic leak monitoring in the VVER-440 pressure vessel head. Elsevier, Progress in Nuclear Energy, v. 34, n. 3, p. 173-183, 1999.

25. HINDERS, M. Guided wave helical ultrasound tomography of pipes and tubes. Applied Science Department. The College of William \& Mary in Virginia, Mar. 2003. Disponível em: $<$ http://as.wm.edu/Faculty/Hinders/HUT-W\&M.pdf>. Acesso em: Out. 2005. 
26. HSIUNG, J. T.; HIMMELBLAU, D. M. Detection of leaks in a liquid-liquid heat exchanger using passive acoustic noise. Elsevier, Computers and Chemical Engineering, V. 20, n. 9, p. 1101-1111, 1996.

27. HUNAIDI, O.; CHU, W. T. Acoustical characteristics of leak signals in plastic water distribution pipes. Elsevier, Applied Acoustics. n. 58, p. 235-254, 1999.

28. JUNGER, M.C.; FEIT, D. Sound, structures, and their interaction. 2.ed. USA: The MIT Press, 1986.

29. KINO, G. S. Acoustic Waves: Devices, Imaging, and Analog Signal Processing. Englewood Cliffs, N.J.: Prentice-Hall, 1987.

30. KINSLER, L. E.; FREY, A. R.; COPPENS, A. B.; SANDERS, J. V. Fundamentals of acoustics. 3.ed. USA: John Wiley \& Sons, 1982.

31. KOLSKY, H. Stress waves in solids. New York, N. Y.: Dover Publications, Inc., 1963.

32. KRAUS, H. Thin Elastic Shells. New York, N. Y.: John Wiley \& Sons, 1967.

33. KUNZE, U. Experience With The Acoustic Leakage Monitoring System ALUES In 17 VVER Plants. Elsevier, Progress in Nuclear Energy, v. 34, n. 3, p. 213-220, 1999.

34. LOPES, L. A. N.; TING, D. K. S. Ensaios de Eddy-Current na avaliação do estado operacional de tubos de geradores de vapor de centrais nucleares. In: NATIONAL CONFERENCE OF MECHANICAL ENGINEERING, CONEM 2000, Aug. 7-11, 2000, Natal, Brazil.

35. LOTH, J. L.; MORRIS, G. L.; PALMER, G. J. Acoustic detecting and locating gas pipe line infringement. Final contract report, National Energy Technology Laboratory, Strategic Center for Natural Gas (SCNG), 2004. Disponível em: <http://www.netl.doe.gov/technologies/oil-gas/publications/td/ FG123104 1.pdf>. Acesso em: fev de 2006.

36. LOVE, A. E. H. A treatise on the mathematical theory of elasticity. 4.ed. New York, N. Y.: Dover Publications, 1927.

37. MATHEWS, J. Guide to adhesively mounting accelerometers. Technical Paper 312. Endevco Corporation. Disponível em:

$<$ http://www.endevco.com/resources/techpapers.php>. Acesso em: fev de 2006.

38. MEDEIROS, L. A. J. Introdução às Funções Complexas, São Paulo, S.P.: McGraw-Hill do Brasil Ltda, 1972. p.193-194.

39. MING, R.; PAN, J.; NORTON, M. P. The measurement of structural mobilities of a circular cylindrical shell. Journal of Acoustic Society of America, v. 107, n. 3, Mar. 2000.

40. MISITI, M.; MISITI, Y.; OPPENHEIM, G.; POGGI, J. Wavelet Toolbox User's Guide. Version 2. USA: The Math Works, Inc., 2002. 
41. RODRIGUEZ, P.; RAJ, B. Development of In-service Inspection Techniques for Nuclear Power Plants in India. Elsevier, Int. J. Pres. Ves. \& Piping, n. 73, p. 59-68, 1997.

42. SIEMENS, FLÜS, for rapid detection and localization of steam and water leaks. Siemens Power Generation. Germany. Catálogo técnico. Oct., 1993

43. SMITH, P. W. Phase Velocities and Displacement Characteristics of Free Waves in a Thin Cylindrical Shell. The Journal of the Acoustical Society of America, v. 27, n. 6, p.1065-1072, Nov, 1955.

44. SONNTAG, R. E.; BORGNAKKE, C.; WYLEN, G. J. V. Fundamentos da termodinâmica. 5.ed. São Paulo, S. P.: Edgard Blucher, 1998.

45. SOUZA, A. L.; CRUZ S. L.; PEREIRA, J. F. R. Leak detection in pipelines through spectral analysis of pressure signals. Brazilian Journal of Chemical Engineering, v.17, n. 4-7, São Paulo, Dec. 2000. Disponível em: < http://www.scielo.br/cgi-bin/wxis.exe/iah/ >. Acesso em: fev de 2006.

46. SRINIVASAN, G.S.; SINGH, O. P.; PRABHAKAR, R. Leak Noise Detection and Characterisation Using Statistical Features. Elsevier, Annals of Nuclear Energy, n. 27, p. 329-343, 2000

47. TIMOSHENKO, S. P.; GOODIER, J. N. Teoria da Elasticidade. 3.ed. Rio de Janeiro, R.J.: Guanabara Dois, 1980.

48. TIMOSHENKO, S. P.; KRIEGER, S. W. Theory of Plates and Shells. 2.ed. 1959, 26th printing, Singapore: McGraw-Hill, 1985.

49. TIPLER, P. A. Física para cientistas e engenheiros: Mecânica, Oscilações e Ondas, Termodinâmica. Vol.1. 4.ed. Rio de Janeiro, R. J.: LTC, 2000.

50. VENNARD, J. K.; STREET, R. L. Elementos de mecânica dos fluídos. 5.ed. Rio de Janeiro, R. J.: Guanabara Dois, 1978.

51. XU, M. B.; ZHANG, X. M. Vibration power flow in a fluid-filled cylindrical shell. Journal of Sound and Vibration, v. 218, n. 4, p. 587-598, 1998.

52. XU, M. B.; ZHANG, X. M.; ZHANG. W. H. The effect of wall joint on the vibration power flow propagation in a fluid-filled shell. Journal of Sound and Vibration, v. 224, n. 3, p. 395-410, 1999.

53. XU, M. B.; ZHANG, W. H. Vibrational power flow input and transmission in a circular cylindrical shell filled with fluid. Journal of Sound and Vibration, v. 234. n. 3, p. 387-403, 2000. 